\title{
Homogeneous precipitation of nickel hydroxide powders
}

by

\section{Bora Maviş}

A dissertation submitted to the graduate faculty in partial fulfillment of the requirements for the degree of DOCTOR OF PHILOSOPHY

\author{
Major: Materials Science and Engineering \\ Program of Study Committee: \\ Mufit Akinc, Major Professor \\ Scott Chumbley \\ Matthew J. Kramer \\ James H. Espenson \\ Surya K. Mallapragada
}

Iowa State University

Ames, Iowa

2003

Copyright (C) Bora Maviş, 2003. All rights reserved. 


\section{Graduate College \\ Iowa State University}

This is to certify that the doctoral dissertation of

\section{Bora Maviş}

has met the dissertation requirements of Iowa State University

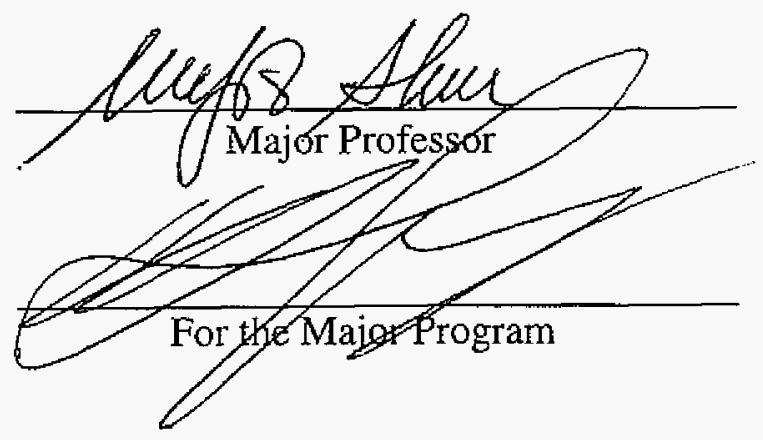


to my wife and parents 


\section{TABLE OF CONTENTS}

GENERAL INTRODUCTION

Dissertation Organization

References

KINETICS OF UREA DECOMPOSITION IN THE PRESENCE OF TRANSITION

METAL IONS: $\mathrm{Ni}^{2+}$

Abstract

Introduction

Experimental Section

Results

Discussion

Conclusions

Acknowledgement

References

INTERCALATING SPECIES IN THE HOMOGENEOUS PRECIPITATION OF NICKEL HYDROXIDES

Abstract

Introduction 
$\begin{array}{ll}\text { Results } & 46\end{array}$

$\begin{array}{ll}\text { Discussion } & 62\end{array}$

$\begin{array}{ll}\text { Conclusions } & 73\end{array}$

$\begin{array}{ll}\text { Acknowledgements } & 74\end{array}$

$\begin{array}{ll}\text { References } & 74\end{array}$

THREE-COMPONENT LAYER DOUBLE HYDROXIDES BY UREA

PRECIPITATION: STRUCTURAL STABILITY AND ELECTROCHEMISTRY 81

$\begin{array}{ll}\text { Abstract } & 81\end{array}$

Introduction $\quad 81$

$\begin{array}{ll}\text { Experimental Method } & 83\end{array}$

Results $\quad 85$

$\begin{array}{ll}\text { Discussion } & 96\end{array}$

$\begin{array}{ll}\text { Conclusions } & 98\end{array}$

$\begin{array}{ll}\text { Acknowledgements } & 99\end{array}$

$\begin{array}{ll}\text { References } & 99\end{array}$

$\begin{array}{ll}\text { GENERAL CONCLUSIONS } & 104\end{array}$

$\begin{array}{ll}\text { References } & 106\end{array}$

$\begin{array}{ll}\text { ACKNOWLEDGEMENTS } & 107\end{array}$

APPENDIX A. DETAILS OF UREA DECOMPOSITION IN THE PRESENCE OF 108 TRANSITION METAL IONS 


\section{$15-T 2111$}

1

\section{GENERAL INTRODUCTION}

Nickel hydroxide electrode has been one of the centerpieces in secondary battery research, with its common or intended uses in a range of applications like portable electronics, satellites, space applications and electric cars. As a common electrode for a number of battery systems, such as $\mathrm{Ni} / \mathrm{Cd}, \mathrm{Ni} / \mathrm{MH}, \mathrm{Ni} / \mathrm{Zn}$ and $\mathrm{Ni} / \mathrm{H}_{2}$, research towards its chemistry had been multifaceted. ${ }^{1}$ Intimacy of electrochemical characteristics with its structure and the complex redox behavior poses intriguing challenges to materials chemists. One of many ways of producing this active electrode material was reported to be precipitation from aqueous solutions of $\mathrm{Ni}^{2+}$ by urea decomposition. ${ }^{2-9}$

Urea decomposition has been employed for precipitating precursors of various mixed metal oxides. ${ }^{10-14}$ At temperatures above $60^{\circ} \mathrm{C}$ decomposition is fast enough to increase $\mathrm{pH}$ slowly and homogeneously throughout the solution to appreciable levels at which precipitation of some metal (hydr)oxides or carbonates becomes possible without creating high levels of supersaturation. Decomposition reaction could simply be written as depicted in equation (1), where $k_{1}$ is the first order rate constant. This one-step decomposition has been assumed valid for most systems examined. ${ }^{7,13}$

$$
\mathrm{OC}\left(\mathrm{NH}_{2}\right)_{2}+\mathrm{H}_{2} \mathrm{O} \stackrel{\mathrm{k}_{1}}{\longrightarrow}-\mathrm{CO}_{2}+2 \mathrm{NH}_{3}
$$

Urea precipitation method, as applied in aqueous solutions containing $\mathrm{Ni}^{2+}$ ions, has been reported to yield $\mathrm{Ni}(\mathrm{OH})_{2}$ with the $\alpha$ structure. ${ }^{5,7,8}$ There are two polymorphs of nickel hydroxides, namely $\beta$ and $\alpha$. Both structures are formed by the stacking of "brucite" type layers formed by the hydroxyl ions that are in hexagonal closed packed arrangement. Every other plane accommodates the nickel ions in octahedral interstices. ${ }^{15}$ While in $\beta$-phase layers are perfectly stacked along the c-axis with an interlamellar distance of $4.6 \AA$, they are misoriented with respect to each other in the $\alpha$-phase (a.k.a. turbostratic). Interlamellar distance in the $\alpha$-phase can be 7 to $8 \AA$ depending on the processing route. Schematic representation of $\alpha$ and $\beta$ phase of $\mathrm{Ni}(\mathrm{OH})_{2}$ structures is shown in Figure 1. Presence of 


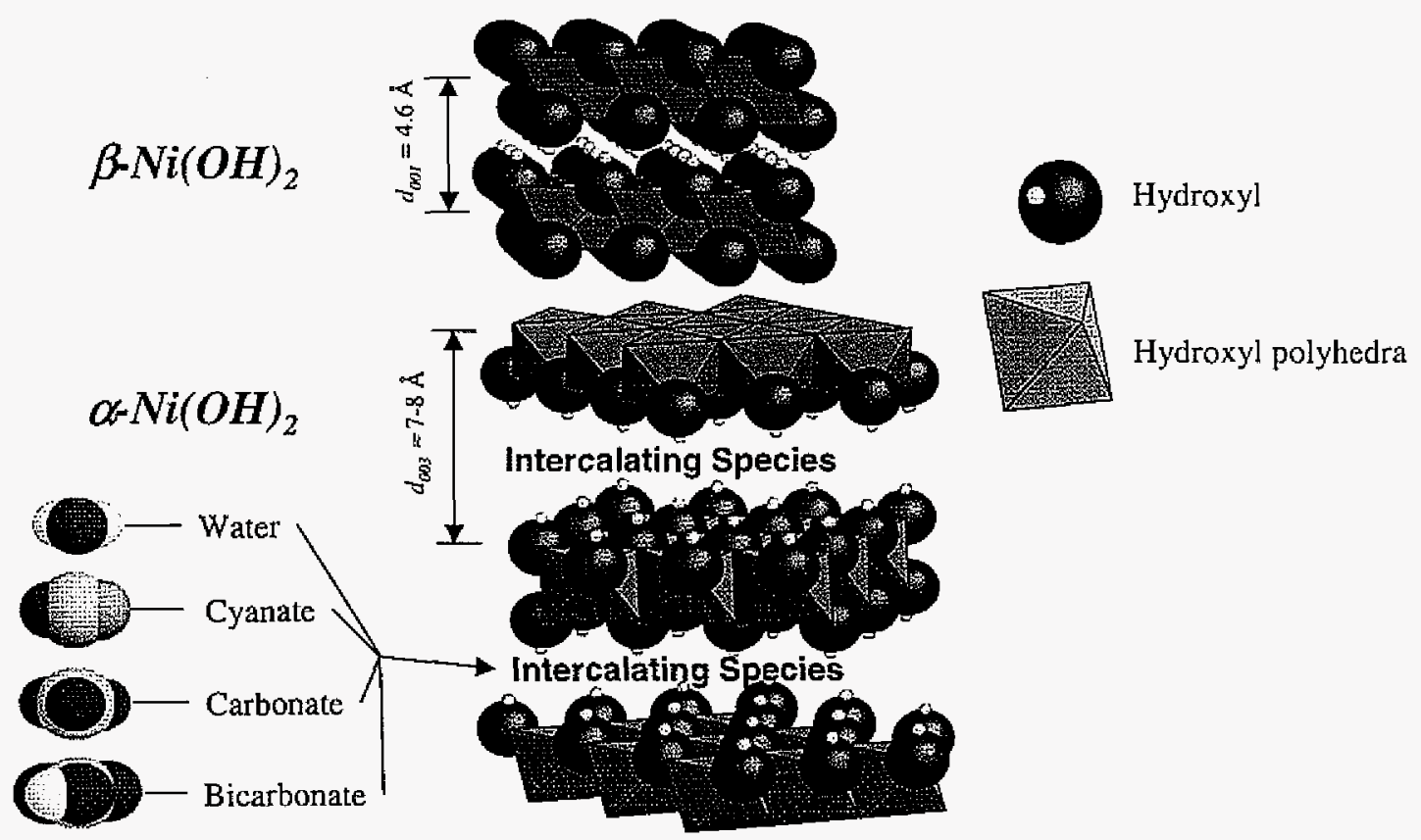

Figure 1. Schematic representation of $\alpha$ and $\beta$ polymorphs of $\mathrm{Ni}(\mathrm{OH})_{2}$.

water molecules and anionic species in the Van der Waals gap between the layers of $\alpha$-phase is well documented. ${ }^{16}$ Intercalating species in $\alpha$-phase produced from urea were identified as water, cyanate and carbonaceous species. ${ }^{8}$

Maruthiprasad et al. named the urea precipitated powder as trihydroxyisocyanate upon the observation of a peak around $2200 \mathrm{~cm}^{-1}$. $^{2}$ Avena et al. claimed that it is a "poorly crystallized" $\beta$-phase and seemed to ignore the respective region in the IR spectra. ${ }^{4}$ It was Dixit and coworkers who realized that the precipitate is $\alpha$-phase. ${ }^{5}$ Although Dixit et al. had observed a similar peak around $2200 \mathrm{~cm}^{-1}$, they were cautious in accepting the assignment made by Maruthiprasad et al. and only suggested that it is due to intercalated and adsorbed species. It was Soler-Illia et al. who both assigned the $2200 \mathrm{~cm}^{-1}$ absorption to intercalated cyanate in $\alpha$-phase. ${ }^{8}$

Observation of cyanate among intercalates is captivating because cyanate is the intermediate product of the two-step urea decomposition. This calls upon the possible limitations of the generally accepted representation given in equation (1). Although existence of intermediate $\mathrm{CNO}^{-}$in urea decomposition has been known for sometime, its significance in the precipitation reactions has not been acknowledged before. ${ }^{17}$ Soler-Illia et al. envisioned 
the same reaction in two steps and offered an approximate numerical solution to system of reactions depicted in equations (2) and (3). ${ }^{18}$ Depending on the magnitudes of the rate constants and $\mathrm{pH}$ of the solution for a given precipitation reaction, one can predict that the cyanate intermediate can accumulate to critical levels.

$$
\begin{aligned}
& \mathrm{OC}\left(\mathrm{NH}_{2}\right)_{2} \underset{\mathrm{k}_{-1}}{\stackrel{\mathrm{k}_{1}}{\rightleftharpoons} \mathrm{OCN}-}+\mathrm{NH}_{4}^{*} \\
& \mathrm{OCN}+\mathrm{H}^{+}+2 \mathrm{H}_{2} \mathrm{O} \stackrel{\mathrm{K}_{2}}{\longrightarrow} \mathrm{HCO}_{3}{ }^{-}+\mathrm{NH}_{4}{ }^{+} \\
& k_{2}=\left(k_{2}^{0}+k_{2}^{a}\left[H^{+}\right]\right)
\end{aligned}
$$

Although the possibility of formation of Ni-cyanate complexes was put forward ${ }^{8}$, numerical solutions were not extended to include metal ions. ${ }^{13,18}$ For a more accurate depiction of urea hydrolysis in the presence of metal ions; incorporation of metal ion hydrolysis, complexation and precipitation reactions into the numerical solution is considered necessary.

An important aspect of layered structures like $\alpha$-phase is the intercalate chemistry. SolerIllia et al. identified the presence of cyanate in the $\alpha$ structure, but its possible bonding modes with the layers did not receive much attention in their discussion. Presence of the other intercalates, bicarbonate and/or carbonate, was also mentioned. ${ }^{8}$ Further elaboration on the reported scarcity of literature on Ni-cyanate complexes ${ }^{19}$ and the peculiar role of cyanate in the precipitation nickel hydroxides is necessary for understanding of the urea precipitation and intercalate chemistry of the layered structures.

Upon charging, $\beta$ - and $\alpha$-phases transform into $\beta-\mathrm{NiOOH}\left(\beta^{\prime}\right)$ and $\gamma-\mathrm{NiOOH}$, respectively. Besides the added advantage of reduced mechanical strains (i.e. similar lattice constants), $\alpha / \gamma$ couple has been observed to deliver a higher capacity compared to the $\beta / \beta$, couple. Figure 2 shows the phase transformation/redox cycle for nickel hydroxide system. ${ }^{20}$

Although $\alpha$-phase delivers a higher specific mass capacity compared to $\beta$-phase, challenge had been the stability of $\alpha$-phase against transformation to the $\beta$-phase in the strong alkaline electrolyte. ${ }^{21}$ Urea precipitated $\alpha-\mathrm{Ni}(\mathrm{OH})_{2}$ was not an exception and transformed to $\beta$-phase after about a week of exposure to $6 \mathrm{M} \mathrm{KOH}^{6,9}$ 


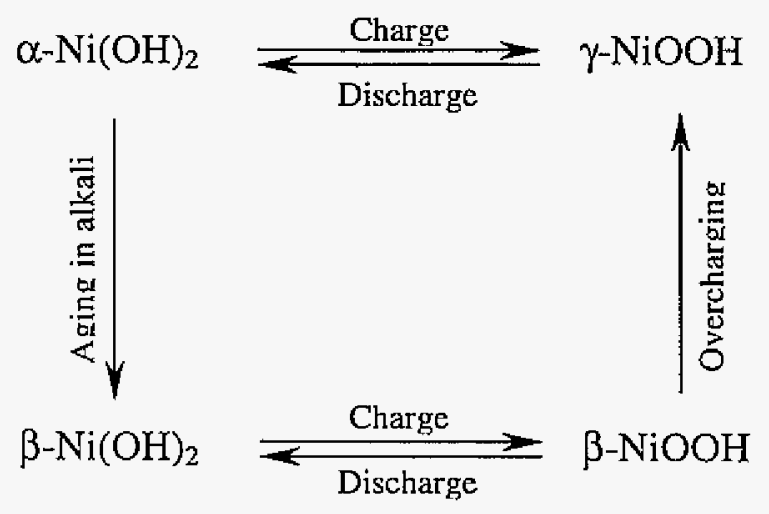

Figure 2. Charge/discharge and phase transformation cycle for nickel hydroxide system.

Layer Double Hydroxides (LDHs) are intercalation compounds that are represented by the formula $\left[\mathrm{M}^{2+}{ }_{1-x} \mathrm{M}^{3+}{ }_{\mathrm{x}}(\mathrm{OH})_{2}\right]^{\mathrm{x}+}\left[\mathrm{A}^{\mathrm{n}-}{ }_{\mathrm{x} / \mathrm{n}}\right]^{\mathrm{x}-} \cdot \mathrm{mH}_{2} \mathrm{O}$. Structurally they are akin to $\alpha$-phase. However, direct substitution of the divalent cation $\left(\mathrm{M}^{2+}\right.$ can be $\mathrm{Mg}^{2+} \mathrm{Mn}^{2+} \mathrm{Fe}^{2+} \mathrm{Co}^{2+} \mathrm{Ni}^{2+}$ $\mathrm{Cu}^{2+} \mathrm{Zn}^{2+}$ or $\left.\mathrm{Ca}^{2+} \ldots\right)$ with a trivalent cation $\left(\mathrm{M}^{3+}\right.$ can be $\left.\mathrm{Al}^{3+} \mathrm{Cr}^{3+} \mathrm{Mn}^{3+} \mathrm{Fe}^{3+} \mathrm{Co}^{3+} \mathrm{Ni}^{3+} \ldots\right)$ creates a permanent positively charged layer, which necessitates the intercalation of anions between the layers as charge balancing species. This results in a stronger columbic attraction between the layers and subsequent alignment of them. ${ }^{22-24}$ Use of a trivalent cation like $\mathrm{Al}^{3+}$ to produce a $\mathrm{Ni} / \mathrm{Al} \mathrm{LDH}$ had been demonstrated. Such powders were proved to be highly stable in the electrolyte. ${ }^{25,26}$ Costantino et al. were the first to use urea precipitation to producing Ni/Al LDHs. Nevertheless since their main focus was to prepare intercalation compounds with alkoxides, neither electrochemical properties nor the intercalate chemistry was investigated. ${ }^{27}$

Nickel hydroxide is a p-type semiconductor and shows poor electrical conductivity. It has been reported on various occasions that addition of cobalt physically or in the atomic scale improves the charge efficiency and the utilization of active material. During charging, cobalt is irreversibly oxidized to $\mathrm{Co}^{3+}$ but the resulting product has appreciable conductivity. ${ }^{15,28}$ Besides increasing the overall conductivity of the active material, when added in the atomic scale as a substitution element, cobalt is also claimed to stabilize the $\alpha$ structure upon electrochemical or chemical cycling with a similar mechanism that was discussed for LDHs. That is, $\mathrm{Co}^{3+}$ generates extra positive charge that is compensated by intercalation anions 
between the layers. In other words, intercalating anions may be considered as anchoring pillars of hydroxide layers. ${ }^{29,30} \mathrm{It}$ is proven that urea precipitation method can be used to produce cobalt doped $\alpha-\mathrm{Ni}(\mathrm{OH})_{2}$ 's that can be electrochemically cycled to give relatively stable $\alpha$-phases. ${ }^{9}$

A three-component $\mathrm{LDH}(\mathrm{TC}-\mathrm{LDH})$ formed by $\mathrm{Ni}^{2+}, \mathrm{Co}^{2+}$ and $\mathrm{Al}^{3+}$ could present a viable alternative to the structures formed either by $\mathrm{Al}^{3+}$ or $\mathrm{Co}^{2+}$. The product would not only be stable for a prolonged time due to presence of $\mathrm{Al}^{3+}$, but also benefit from the added conductivity in the basal plane with the addition of $\mathrm{Co}^{3+.}$. One point that bears comment is the fact that addition of the trivalent cation or the "sacrificial" divalent cation reduces the number of redox-active cation (i.e. $\mathrm{Ni}^{2+} / \mathrm{Ni}^{3+}$ ) per unit mass of the sample. Therefore there might be an optimum level to maximize the overall capacity. The author is aware of only one concurrent study where synthesis of Ni/Al/Co LDH was reported. ${ }^{21}$ Powders were prepared by heterogeneous precipitation and determined to be $\alpha$-phase. Precipitation of a TC-LDH with urea decomposition has not been attempted.

Although much of the effort went to the stabilization of the structure, electrochemical characterization of the stabilized phases had been limited. ${ }^{31}$ Nevertheless, a number of reports on the electrochemical properties of the Ni/Al based LDHs have recently appeared paralleling our work. ${ }^{20,32-35}$ Reported capacities were between 238 and $319 \mathrm{mAhr} / \mathrm{g}$ at different C-rates. In addition, a TC-LDH with Ni/Al/Zn resulted in a capacity of $425 \mathrm{mAhr} / \mathrm{g}$ at $\mathrm{C}$-rate, while an interstratified structure ( $\alpha$ and $\beta$ phase mixture) produced by doping of $\mathrm{Co}, \mathrm{Zn}$, and $\mathrm{Mn}$ to different extends delivered a capacity of $375 \mathrm{mAhr} / \mathrm{g}$. Interplay between synthesis, structure and electrochemical properties, along with the technological significance of Nickel hydroxide as a common positive electrode for secondary battery systems justifies a careful look at this material and its TC-LDH derivatives. Primary objective of this research was to better understand the mechanism of precipitation of nickel hydroxide and LDHs by urea decomposition, determine the structure and electrochemical properties of resulting materials and establish the relationship between the chemistry, structure and properties. 


\section{Dissertation Organization}

This dissertation is arranged in accordance to the alternate dissertation format described in the Graduate College Thesis Manual, and consists of three separate manuscripts prepared for publication. First paper which had been submitted to the Journal of American Ceramic Society is in the review process (Manuscript Number: JACS-10043) and titled "Kinetics of Urea Decomposition in the Presence of Transition Metal Ions: $\mathrm{Ni}^{2+"}$. It discusses the reaction kinetics model developed for the urea precipitation of nickel hydroxide. Second chapter, "Intercalating Species in the Precipitation of Nickel Hydroxides", reports the possible bonding modes of intercalates observed in $\alpha-\mathrm{Ni}(\mathrm{OH})_{2}$ and the $\mathrm{Ni} / \mathrm{Al}-\mathrm{LDH}$ produced by urea precipitation and will be submitted to the Materials Chemistry and Physics. Third chapter, "Three-Component Layer Double Hydroxides by Urea Precipitation: Structural Stability and Electrochemistry" will be submitted to the Joumal of Power Sources and discusses the various aspects of $\mathrm{Ni} / \mathrm{Al} / \mathrm{Co}-\mathrm{LDH}$ sroduced by urea precipitation.

Note that although all three manuscripts are largely the work of this author, Dr. Mufit Akinc (major professor) has made significant contributions throughout the study and appears as co-author on these papers. In addition, a couple of related articles were also published in conference proceedings during the course of dissertation work and given in the Appendices.

\section{References}

'P. M. Gomadam, J. W. Weidner, R. A. Dougal and R. E. White, "Mathematical Modeling of Lithium-Ion and Nickel Battery Systems," Joumal of Power Sources, 110 [2] 267-84 (2002).

${ }^{2}$ B. S. Maruthiprasad, M. N. Sastri, S. Rajagopal, K. Seshan, K. R. Krishnamurthy and T. S. R. P. Rao, "A Novel Nickel Trihydroxy Isocyanate - Preparation and Characterization," Proc. - Indian Acad. Sci., Chem. Sci, 100 [6] 459-62 (1988).

${ }^{3}$ R. M. Torresi, M. V. Vazquez, A. Gorenstein and S. 1. C. d. Torresi, "Infrared Characterization of Electrochromic Nickel Hydroxide Prepared by Homogeneous Chemical Precipitation," Thin Solid Films, 229 [2] 180-6 (1993).

${ }^{4}$ M. J. Avena, M. V. Vazquez, R. E. Carbonio, C. P. De Pauli and V. A. Macagno, "A Simple and Novel Method for Preparing $\mathrm{Ni}(\mathrm{OH})_{2}$. Part I: Structural Studies and Voltammetric Response," J. Appl. Electrochem., 24 [3] 256-60 (1994). 
${ }^{5}$ M. Dixit, G. N. Subbanna and P. V. Kamath, "Homogeneous Precipitation from Solution by Urea Hydrolysis: A Novel Chemical Route to the $\alpha$-Hydroxides of Nickel and Cobalt," $J$. Mater. Chem., 6 [8] 1429-32 (1996).

${ }^{6} \mathrm{~A}$. Widjaja, "Synthesis and Characterization of Nickel Hydroxide Powders for Battery Applications," M.Sc. Thesis. Iowa State University, Ames, 1997.

${ }^{7} \mathrm{M}$. Akinc, N. Jongen, J. Lemaitre and H. Hofmann, "Synthesis of Nickel Hydroxide Powders by Urea Decomposition," Journal of the European Ceramic Society, 18 [11] 155964 (1998).

${ }^{8}$ G. J. d. A. A. Soler-Illia, M. Jobbagy, A. E. Regazzoni and M. A. Blesa, "Synthesis of Nickel Hydroxide by Homogeneous Alkalinization. Precipitation Mechanism," Chem. Mater., 11 [11] 3140-46 (1999).

${ }^{9}$ I. Yazdi, "Synthesis and Electrochemical Studies of Cobalt Substituted Nickel Hydroxide for Battery Applications," M.Sc. Thesis. Iowa State University, Ames, 1999.

${ }^{10}$ A. Janekovic and E. Matijevic, "Preparation of Monodispersed Colloidal Cadmium Compounds," Journal of Colloid and Interface Science, 103 [2] 436-47 (1985).

${ }^{11} \mathrm{D}$. Sordelet and M. Akinc, "Preparation of Spherical, Monosized Yttrium Oxide Precursor Particles," J. Colloid Interface Sci., 122 [1] 47-59 (1988).

${ }^{12}$ D. J. Sordelet, M. Akinc, M. L. Panchula, Y. Han and M. H. Han, "Synthesis of Yttrium Aluminum Garnet Precursor Powders by Homogeneous Precipitation," J. Eur. Ceram. Soc., 14 [2] 123-30 (1994).

${ }^{13}$ G. J. d. A. A. Soler-Illia, M. Jobbagy, R. J. Candal, A. E. Regazzoni and M. A. Blesa, "Synthesis of Metal Oxide Particles from Aqueous Media: The Homogeneous Alkalinization Method," J. Dispersion Sci. Technol., 19 [2 \& 3] 207-28 (1998).

${ }^{14}$ E. Matijevic and R. S. Sapieszko, "Formation of Monodispersed Metal (Basic) Carbonates in the Presence of Urea," Surfactant Science Series, 92 [Fine Particles] 386-95 (2000).

${ }^{15} \mathrm{C}$.-C. Yang, "Synthesis and Characterization of Active Materials of $\mathrm{Ni}(\mathrm{OH})_{2}$ Powders," International Journal of Hydrogen Energy, 27 [10] 1071-81 (2002). 
${ }^{16}$ X. Wang, H. Luo, P. V. Parkhutik, A.-C. Millan and E. Matveeva, "Studies of the Performance of Nanostructural Multiphase Nickel Hydroxide," Journal of Power Sources, 115 [1] 153-60 (2003).

${ }^{17}$ W. H. R. Shaw and J. J. Bordeaux, "The Decomposition of Urea in Aqueous Media," $J$. Am. Chem. Soc., 77, 4729-33 (1955).

${ }^{18}$ G. J. d. A. A. Soler-Illia, "A Study of $\mathrm{Cu}-\mathrm{Ni}$ and $\mathrm{Cu}-\mathrm{Zn}$ Mixed Oxide Precursors Synthesis by Homogeneous Alkalinization Methods," Ph.D. Thesis. Universidad de Buenos Aires, Buenos Aires, 1998.

${ }^{19} \mathrm{~K}$. Nakamoto, Infrared and Raman Spectra of Inorganic and Coordination Compounds, Part B: Applications in Coordination, Organometallic, and Bioinorganic Chemistry, Fifth Edition. Wiley-Interscience, New York, 1997.

${ }^{20} \mathrm{C}$. Y. Wang, S. Zhong, K. Konstantinov, G. Walter and H. K. Liu, "Structural Study of Al-Substituted Nickel Hydroxide," Solid State Ionics, 148 [3,4] 503-08 (2002).

${ }^{21}$ C. Y. Wang, S. Zhong, D. H. Bradhurst, H. K. Liu and S. X. Dou, "Ni/Al/CoSubstituted $\alpha-\mathrm{Ni}(\mathrm{OH})_{2}$ as Electrode Materials in the Nickel Metal Hydride Cell," Journal of Alloys and Compounds, 330-332, 802-05 (2002).

${ }^{22}$ J. Wang, A. G. Kalinichev, R. J. Kirkpatrick and X. Hou, "Molecular Modeling of the Structure and Energetics of Hydrotalcite Hydration," Chemistry of Materials, 13 [1] 145-50 (2001).

${ }^{23} \mathrm{~V}$. R. L. Constantino and T. J. Pinnavaia, "Basic Properties of $\mathrm{Mg}^{2+}{ }_{1-\mathrm{xAl}}{ }^{3+} \mathrm{x}$ Layered Double Hydroxides Intercalated by Carbonate, Hydroxide, Chloride, and Sulfate Anions," Inorganic Chemistry, 1995, 34 (1995).

${ }^{24} \mathrm{X}$. Hou and R. J. Kirkpatrick, "Solid-State 77Se NMR and XRD Study of the Structure and Dynamics of Seleno-Oxyanions in Hydrotalcite-like Compounds," Chem. Mater., 12 [7] 1890-97 (2000).

${ }^{25}$ K. T. Ehlsissen, A. Delahaye-Vidal, P. Genin, M. Figlarz and P. Willmann, "Preparation and Characterization of Turbostratic Nickel/Aluminum Layered Double Hydroxides for Nickel Hydroxide Electrode Applications," J. Mater. Chem., 3 [8] 883-8 (1993). 
${ }^{26}$ P. V. Kamath, M. Dixit, L. Indira, A. K. Shukla, V. G. Kumar and N. Munichandraiah, "Stabilized $\alpha-\mathrm{Ni}(\mathrm{OH})_{2}$ as Electrode Material for Alkaline Secondary Cells," J. Electrochem. Soc., 141 [11] 2956-9 (1994).

${ }^{27}$ U. Costantino, F. Marmottini, M. Nocchetti and R. Vivani, "New Synthetic Routes to Hydrotalcite-Like Compounds. Characterization and Properties of the Obtained Materials," Eur. J. Inorg. Chem., [10], 1439-46 (1998).

${ }^{28}$ A. B. Yuan and N. X. Xu, "Electrochemical Studies of the Nickel Electrode with Cobalt Modification," Journal of Applied Electrochemistry, 31 [2] 245-50 (2001).

${ }^{29}$ C. Faure, C. DeImas, M. Fouassier and P. Willmann, "Preparation and Characterization of Cobalt-Substituted $\alpha$-Nickel Hydroxides Stable in Potassium Hydroxide Medium. Part I. $\alpha^{\prime}$-Hydroxide with an Ordered Packing," J. Power Sources, 35 [3] 249-61 (1991).

${ }^{30}$ C. Faure, C. Delmas and P. Willmann, "Preparation and Characterization of CobaltSubstituted $\alpha$-Nickel Hydroxide Stable in Potassium Hydroxide Medium. Part II. $\alpha$ Hydroxide with a Turbostratic Structure," J. Power Sources, 35 [3] 263-77 (1991).

${ }^{31}$ H. Chen, J. M. Wang, T. Pan, H. M. Xiao, J. Q. Zhang and C. N. Cao, "Effects of Coprecipitated Zinc on the Structure and Electrochemical Performance of Ni/Al-Layered Double Hydroxide," International Journal of Hydrogen Energy, 27 [5] 489-96 (2002).

${ }^{32}$ B. Liu, X. Y. Wang, H. T. Yuan, Y. S. Zhang, D. Y. Song and Z. X. Zhou, "Physical and Electrochemical Characteristics of Aluminum-Substituted Nickel Hydroxide," Journal of Applied Electrochemistry, 29 [7] 855-60 (1999).

${ }^{33}$ R. Roto and G. Villemure, "Electrochemical Impedance Spectroscopy of Electrodes Modified with Thin Films of Ni-Al-Cl Layered Double Hydroxides," Journal of Electroanalytical Chemistry, 527 [1-2] 123-30 (2002).

${ }^{34}$ Z. Hengbin, L. Hansan, C. Xuejing, L. Shujia and S. Chiachung, "Preparation and Properties of the Aluminum-Substituted $\alpha-\mathrm{Ni}(\mathrm{OH})_{2}, "$ Materials Chemistry and Physics, 79 [1] 37-42 (2003).

${ }^{35}$ T. Pan, J. M. Wang, Y. L. Zhao, H. Chen, H. M. Xiao and J. Q. Zhang, "Al-Stabilized $\alpha$-Nickel Hydroxide Prepared by Electrochemical Impregnation," Materials Chemistry and Physics, 78 [3] 711-18 (2003). 


\title{
KINETICS OF UREA DECOMPOSITION IN THE PRESENCE OF TRANSITION METAL IONS: $\mathrm{Ni}^{2+}$
}

A paper submitted to the Journal of American Ceramic Society

Bora Mavis and Mufit Akinc

\begin{abstract}
Literature on kinetics of urea decomposition reaction was reviewed for 333-373 $\mathrm{K}$ range. Possible reactions in the $\mathrm{pH}$ range of 5 to 9 were identified. Kinetic simulations indicated significant accumulation of the cyanate intermediate in the $\mathrm{pH}$, time-temperature range that was studied. Effects of $\mathrm{Ni}^{2+}$ hydrolysis and complexation with the urea decomposition products were incorporated into the simulations. The kinetic simulation of the rate of $\mathrm{Ni}^{2+}$ removal from the solutions was compared against the experimental data. Experimental results indicated an agglomerative growth mechanism for the precipitation process. Chemical analyses showed that the composition of the precipitate varies with digestion time in agreement with the predictions of the kinetic simulation.

\section{Introduction}

Urea $\left(\mathrm{OC}\left(\mathrm{NH}_{2}\right)_{2}\right)$ decomposition in aqueous solutions has been widely used to prepare various metal-oxide precursor powders. ${ }^{1-7}$ Powders prepared with $\mathrm{Ni}^{2+}$ as cation, resulted in $\alpha-\mathrm{Ni}(\mathrm{OH})_{2}$ structure at digestion temperatures between 60 and $100^{\circ} \mathrm{C}$. Also reported is that layers are intercalated with $\mathrm{OCN}^{-}$(cyanate), which is an intermediate species in the two-step

decomposition reaction of urea. ${ }^{8-12}$ Besides cyanate, carbonate and water were also detected ${ }^{12}$ and ascribed as other important species in the formation of $\alpha$-phase in favor of $\beta$-phase, an isomorph of brucite. Although proven to be applicable to many systems, observation of the $\mathrm{OCN}^{\prime \prime}$ intermediate in precipitation of $\mathrm{Ni}^{2 \cdot+}$, raises some doubts regarding validity of the simplified urea decomposition reaction expressed as:
\end{abstract}




$$
\mathrm{OC}\left(\mathrm{NH}_{2}\right)_{2}+\mathrm{H}_{2} \mathrm{O} \stackrel{\mathrm{k}_{1}}{\longrightarrow} \mathrm{CO}_{2}+2 \mathrm{NH}_{3}
$$

where $\mathrm{k}_{1}$ is a rate constant for forward reaction.

Soler-Illia and co-workers ${ }^{7,12}$ considered the distribution of various species during the decomposition of urea. They observed that the concentration of cyanate intermediate could indeed reach significant levels under mild $\mathrm{pH}$ conditions, before it decreases to a lower steady state level. Following reactions were considered:

$$
\begin{aligned}
\mathrm{OC}\left(\mathrm{NH}_{2}\right)_{2} & \frac{\mathrm{k}_{1}}{\mathrm{k}_{-1}} \mathrm{OCN}^{-}+\mathrm{NH}_{4}{ }^{+} \\
\mathrm{OCN}^{-}+\mathrm{H}^{+}+2 \mathrm{H}_{2} \mathrm{O} & \stackrel{\mathrm{k}_{2}}{\longrightarrow} \mathrm{HCO}_{3}{ }^{+}+\mathrm{NH}_{4}{ }^{+} \\
\mathrm{k}_{2} & =\left(\mathrm{k}_{2}{ }^{\circ}+\mathrm{k}_{2}{ }^{a}\left[\mathrm{H}^{+}\right]\right)
\end{aligned}
$$

Inclusion of urea formation reaction and rate dependent representation of both uncatalyzed and acid catalyzed cyanate hydrolysis reactions had been considered and elaborated by Warner. ${ }^{13}$ However, his study was limited to variation of concentrations of urea, ammonia and cyanate with time. Soler-Illia provided approximate numerical solutions to the reaction constants as a function of temperature using the values reported by Warner. ${ }^{14}$ Numerical solution necessitated the hydrogen ion concentration as an input, and the method with which this constraint circumvented was not provided explicitly. Numerical solutions were not extended to include metal ions. Instead, by superimposing the "trajectories described by the systems during the course of experiments" on the phase diagram of $\mathrm{M}^{2+}$ $\mathrm{H}_{2} \mathrm{O}-\mathrm{CO}_{2}$ systems, a qualitative tool for the predicting the phases that are most likely to form was obtained. ${ }^{15}$ However, trajectories did not take into account the consumption of base or carbonate due to complexation or precipitation. ${ }^{7}$ Also neglected were the effects of intermediates' accumulation, complexation reactions (i.e. $\mathrm{NH}_{3}$ ) and of nucleation kinetics on the formation of solid particles.

Needless to say an accurate model should consider evolution of all species simultaneously. In this communication we demonstrate incorporation of metal ion hydrolysis, 
complexation and precipitation reactions into the numerical solution of urea hydrolysis reactions while integrating the pertinent acid/base equilibria. Numerical predictions are then compared to the experimental results.

Six independent reactions related to urea decomposition and hydrolysis are given in Scheme 1 with associated rate constants. A detailed account of selection rules developed for choosing most appropriate reactions is beyond the scope of this article. Interested reader is referred to the references cited herein for more details. A robust model that is applicable to a variety of metal ion systems requires a priori knowledge of $\mathrm{pH}$ dependence of the reactions under consideration. This is especially so for the second step of decomposition (i.e. cyanate hydrolysis step). Five distinct reactions could be identified. Unfortunately not all reaction constants were reported in the temperature regime of interest for this study $\left(90^{\circ} \mathrm{C}\right)$. Carbonic acid, ammonium ion and cyanic acid dissociations comprise the equilibria related to decomposition products and summarized in Scheme 2.

Reactions involving $\mathrm{Ni}^{2+}$ ion and water, cyanate, ammonia and carbonate ions with respect to hydrolysis, precipitation, and complexation are given in Scheme 3.

Scheme 1. Stepwise decomposition reactions of urea and hydrolysis of cyanate in aqueous solutions at $\mathrm{T}<100^{\circ} \mathrm{C}$.

$$
\begin{aligned}
& \mathrm{OC}\left(\mathrm{NH}_{2}\right)_{2} \underset{\mathrm{k}_{-1}}{\stackrel{\mathrm{k}_{1}}{\rightleftharpoons}} \mathrm{NCO}^{-}+\mathrm{NH}_{4}{ }^{+} \\
& \mathrm{HNCO}+\mathrm{H}_{2} \mathrm{O}+\mathrm{H}^{+} \stackrel{\mathrm{k}_{2}}{\longrightarrow} \mathrm{NH}_{4}{ }^{+}+\mathrm{CO}_{2}^{\mathrm{a}} \\
& \mathrm{HNCO}+\mathrm{H}_{2} \mathrm{O} \stackrel{\mathrm{k}_{3}}{\longrightarrow} \mathrm{NH}_{3}+\mathrm{CO}_{2}^{\mathrm{a}} \\
& \mathrm{NCO}+2 \mathrm{H}_{2} \mathrm{O} \stackrel{\mathrm{K}_{4}}{\longrightarrow} \mathrm{NH}_{3}+\mathrm{HCO}_{3}^{-} \\
& \mathrm{NCO}^{-}+2 \mathrm{H}_{2} \mathrm{O}+\mathrm{HCO}_{3}^{-} \stackrel{\mathrm{K}_{5}}{\longrightarrow} \mathrm{NH}_{3}+2 \mathrm{HCO}_{3}^{-} \\
& \mathrm{NCO}^{-}+2 \mathrm{H}_{2} \mathrm{O}+\mathrm{NH}_{3} \stackrel{\mathrm{k}_{6}}{\longrightarrow} 2 \mathrm{NH}_{3}+\mathrm{HCO}_{3}^{-}(6)^{\mathrm{b}}
\end{aligned}
$$

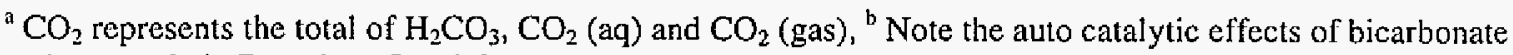
and ammonia in Reactions 5 and 6. 
Scheme 2. Acid/base equilibria associated with the urea decomposition products in urea hydrolysis. Note that hereafter, equilibrium reaction will be represented by an equal sign.

$$
\begin{aligned}
& \mathrm{H}_{2} \mathrm{O}=\mathrm{H}^{+}+\mathrm{OH}^{-} \\
& \mathrm{NH}_{4}^{+}=\mathrm{NH}_{3}+\mathrm{H}^{+} \\
& \mathrm{CO}_{2}+\mathrm{H}_{2} \mathrm{O}=\mathrm{HCO}_{3}+\mathrm{H}^{+} \\
& \mathrm{HCO}_{3}^{-}=\mathrm{CO}_{3}=+\mathrm{H}^{+} \\
& \mathrm{HNCO}=\mathrm{NCO}^{-}+\mathrm{H}^{+}
\end{aligned}
$$

Specific interaction between $\mathrm{Ni}^{2+}$ and cyanate ions was reported by Foster and Goodgame, ${ }^{16}$ however data for complex formation constants was given for $25{ }^{\circ} \mathrm{C}$. Since no heat of formation data could be found, extrapolation to elevated temperatures was not possible. Therefore, room temperature data was used owing to the aforementioned importance of cyanate intermediate. Similarly, temperature dependent values for the $\mathrm{NiCO}_{3}$ (aq) and $\mathrm{NiHCO}_{3}{ }^{+}$(aq) species were not available, hence the room temperature data was used. On the other hand, formation of transition metal-amine complexes was extensively studied by Stupko et al. ${ }^{17}$ at elevated temperatures allowing incorporation of appropriate reaction constants to the simulations.

It should be noted that the supersaturation and nucleation are not incorporated into the model but their contribution to model predictions will be discussed. Although "nucleation" was incorporated in some systems, ${ }^{18}$ its value is questionable for this investigation in light of the uncertainties in the reaction constants employed. Nonetheless, the agglomerative growth of primary crystallites will be elaborated in comparing the model predictions to the experimental data. 
Scheme 3. Reactions between $\mathrm{Ni}^{2+}$ ions and water, cyanate, ammonia and carbonate. Also included are the precipitation reactions for $\mathrm{NiCO}_{3}(\mathrm{~s})$ and $\mathrm{Ni}(\mathrm{OH})_{2}(\mathrm{~s})$.

$$
\begin{aligned}
& \mathrm{Ni}^{++}+\mathrm{H}_{2} \mathrm{O}=\mathrm{Ni}(\mathrm{OH})^{+}+\mathrm{H}^{+} \\
& \mathrm{Ni}^{++}+2 \mathrm{H}_{2} \mathrm{O}=\mathrm{Ni}(\mathrm{OH})_{2}(\mathrm{aq})+2 \mathrm{H}^{+} \\
& \mathrm{Ni}^{++}+3 \mathrm{H}_{2} \mathrm{O}=\mathrm{Ni}(\mathrm{OH})_{3}^{-}+3 \mathrm{H}^{+} \\
& 2 \mathrm{Ni}^{++}+\mathrm{H}_{2} \mathrm{O}=\mathrm{Ni}_{2}(\mathrm{OH})^{3+}+\mathrm{H}^{+} \\
& 4 \mathrm{Ni}^{++}+4 \mathrm{H}_{2} \mathrm{O}=\mathrm{Ni}_{4}(\mathrm{OH})_{4}^{4+}+4 \mathrm{H}^{+} \\
& \mathrm{Ni}^{2+}+2 \mathrm{H}_{2} \mathrm{O}=\mathrm{Ni}(\mathrm{OH})_{2}(\mathrm{~s})+2 \mathrm{H}^{+} \\
& \mathrm{NiNCO}^{+}=\mathrm{Ni}^{2+}+\mathrm{NCO}^{-} \\
& \mathrm{Ni}(\mathrm{NCO})_{2}=\mathrm{NiNCO}^{+}+\mathrm{NCO}^{-} \\
& \mathrm{Ni}(\mathrm{NCO})_{3}{ }^{-}=\mathrm{Ni}(\mathrm{NCO})_{2}+\mathrm{NCO}^{-} \\
& \mathrm{Ni}(\mathrm{NCO})_{4}{ }^{2-}=\mathrm{Ni}(\mathrm{NCO})_{3}{ }^{-}+\mathrm{NCO}^{-} \\
& \mathrm{NiNH}_{3}{ }^{2+}=\mathrm{Ni}^{2+}+\mathrm{NH}_{3} \\
& \mathrm{Ni}\left(\mathrm{NH}_{3}\right)_{2}{ }^{2+}=\mathrm{NiNH}_{3}{ }^{2+}+\mathrm{NH}_{3} \\
& \mathrm{Ni}\left(\mathrm{NH}_{3}\right)_{3}{ }^{2+}=\mathrm{Ni}\left(\mathrm{NH}_{3}\right)_{2}{ }^{2+}+\mathrm{NH}_{3} \\
& \mathrm{Ni}\left(\mathrm{NH}_{3}\right)_{4}{ }^{2+}=\mathrm{Ni}\left(\mathrm{NH}_{3}\right)_{3}{ }^{2+}+\mathrm{NH}_{3} \\
& \mathrm{NiCO}_{3}(\mathrm{aq})=\mathrm{Ni}^{2+}+\mathrm{CO}_{3}= \\
& \mathrm{NiHCO}_{3}{ }^{+}=\mathrm{Ni2+}+\mathrm{HCO}_{3}{ }^{-} \\
& \mathrm{NiCO}_{3}(\mathrm{~s})=\mathrm{Ni}^{2+}+\mathrm{CO}_{3}=
\end{aligned}
$$




\section{Experimental Section}

\section{Computational Modeling}

As mentioned in previous sections, a large number of reactions need to be considered for determining the concentrations of various species as a function of time. Concentrations of species were estimated using a program called KINSIM developed by Barshop et al. ${ }^{19}$ Input for the program is kinetic rate data at the temperature of interest. Wherever available, most reliable kinetic rate data was used at or near $90^{\circ} \mathrm{C}$. When data was not available at $90^{\circ} \mathrm{C}$, the values were estimated from Arrhenius parameters or by extrapolating from slopes and intercepts of typical Arrhenius plots. When the reactions were fast enough or kinetic data were not available, equilibrium constants were used. Kinetic data was available for reactions involving urea decomposition.

In most cases, the equilibrium data was available for room temperature but not at the temperature of interest. To estimate the equilibrium constant at $90{ }^{\circ} \mathrm{C}$, the isocoulombic method described by Lindsay ${ }^{20}$ was adopted. A flow-chart of the method as applied to Reaction 11 is presented in Figure 1. Polar water molecules interact much more strongly with ions than with neutral species, results of which lead to changes in heat capacity and molar volume. In a process that involves no change in number of ionic charges in solution, the contribution of ion-solvent interactions to heat capacity and volume is considered to be negligible. This reveals itself as minimal change in standard enthalpy of the reaction with respect to temperature, which enables one to use Van't Hoff's equation in a wider temperature range without introducing a significant error. In aqueous medium, any hydrolysis reaction could be written in isocoulombic form by use of water dissociation reaction (Reaction 7). Since water dissociation constant is known accurately at elevated temperatures, the equilibrium constant for metal hydrolysis reaction at $90{ }^{\circ} \mathrm{C}$ could be determined using isocoulombic method.

Next, the equilibrium constants were extrapolated to zero ionic strength by Specific Interaction Theory (SIT) software released by IUPAC ${ }^{21}$ provided that the cation/anion SIT parameters were available for the medium mentioned in the original reference. Equilibrium reactions were converted to kinetic rate constants by assuming a fast reverse reaction (10 ${ }^{10}$ $\mathrm{M}^{-1} \cdot \mathrm{s}^{-1}$ ), and finding the forward reaction rate: 


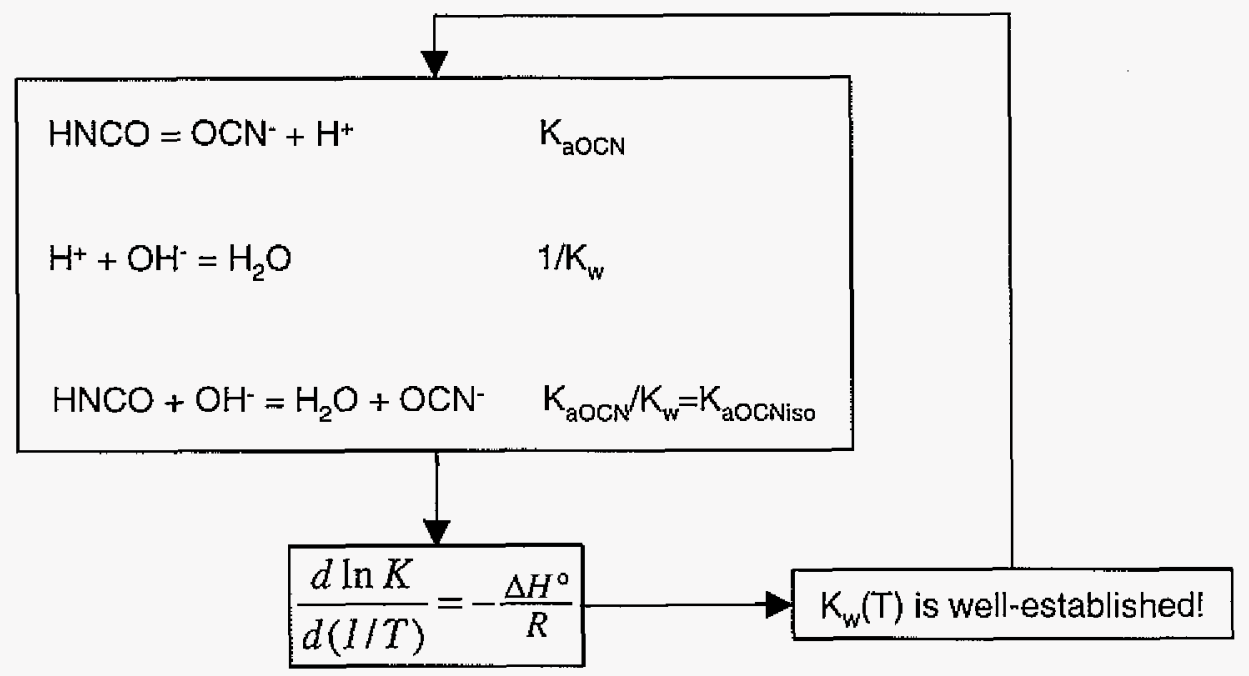

Figure 1. Summary of the isocoulombic method as applied to Reaction 11.

$\mathrm{k}_{\text {forward }}=\mathrm{k}_{\text {reverse }} \times \mathrm{K}_{\text {equilibrium }}$

In order to keep the kinetic simulation solution stable, the reaction direction should be chosen such that the forward reaction must be slower than the reverse reaction.

Initial concentrations of hydrolysis products of metal ions and acid dissociation products of dissolved carbon dioxide were assumed zero (although they have finite values imposed by the initial $\mathrm{pH}$, their magnitude is considered negligible). Initial metal ion concentration was changed for each simulation run while keeping initial $\mathrm{pH}$ and initial concentration of urea constant at 5 and $2 \mathrm{M}$, respectively.

A kinetic analysis outlined as above would only be complete when the constants used are corrected for the instantaneous ionic strength of the solution. On one hand, the ionic strength decreases with precipitation on the other; it increases with urea hydrolysis as more ions are produced. Effect of such a dynamic change in the ionic strength and ionic species is difficult to incorporate in kinetic simulations and will not be attempted in this work. Considering the uncertainties in other parameters, variation in the ionic strength with time seems to be inconsequential. Figure 2 gives flow-chart of the method described above. 


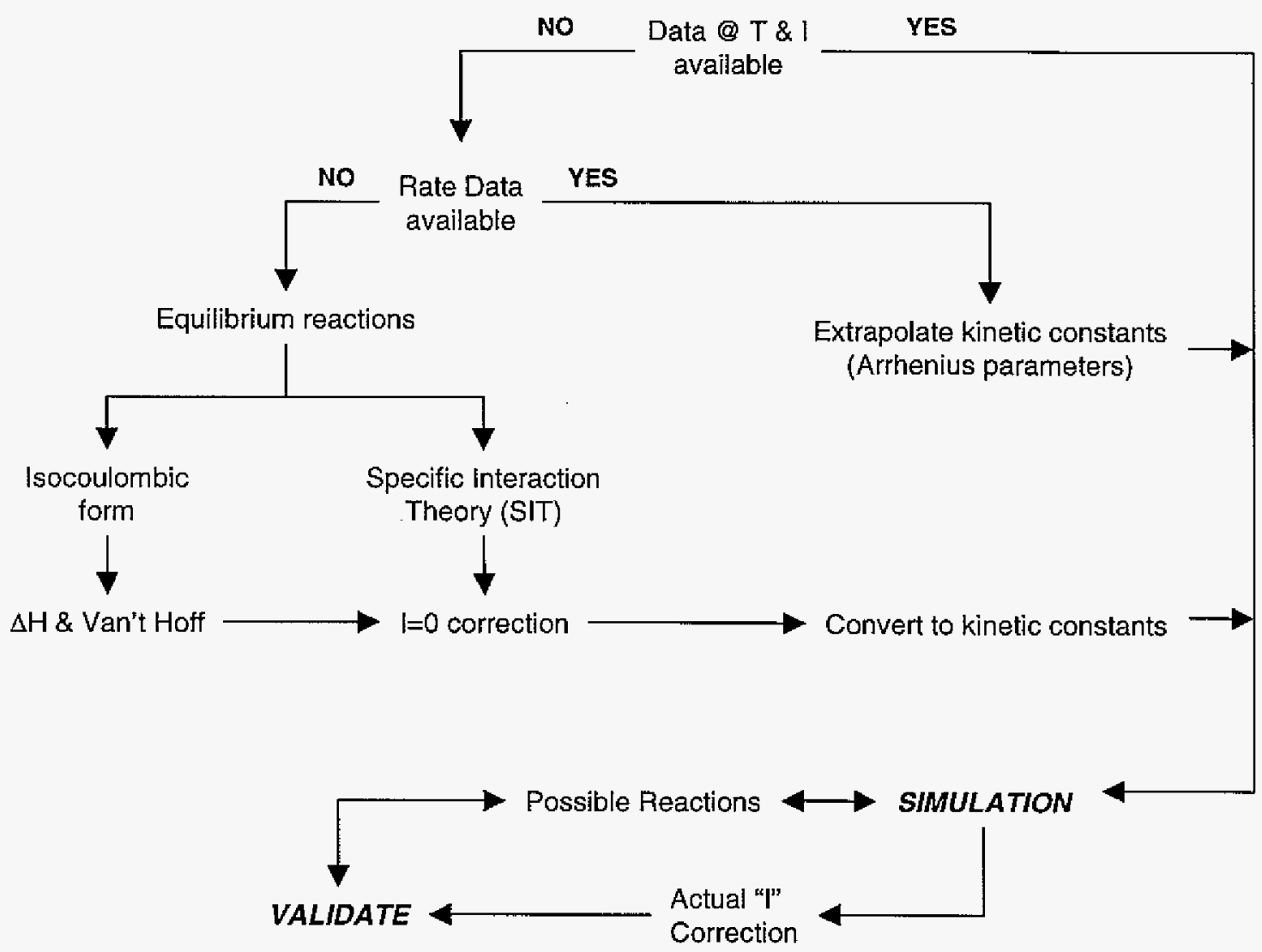

Figure 2. Flow-chart of the computational method used in this work. Due to the dynamic nature of the solution, reaction constants were not corrected for ionic strength values in the first iteration but validated later.

Table 1 summarizes the constants used for Reactions 1-28. Constants that were reported in molal units $(\mathrm{mol} / \mathrm{kg}$ ), were converted to molar units ( $\mathrm{mol} / \mathrm{L}$ ) using temperature dependent values of density of water. ${ }^{22}$

\section{Powder Synthesis}

Precipitation of nickel hydroxide by urea decomposition was carried out in $250 \mathrm{~mL}$ Pyrex Brand media bottles. Pressure was kept near ambient by attaching a balloon to the reaction bottle. $5.9428 \mathrm{~g}$ of reagent grade $\mathrm{NiCl}_{2} \cdot 6 \mathrm{H}_{2} \mathrm{O}$ (Fisher Scientific) was dissolved in $190 \mathrm{~mL}$ deionized water $(18 \mathrm{M} \Omega-\mathrm{cm})$ and preheated in a thermostatic water bath that was maintained at $90 \pm 1{ }^{\circ} \mathrm{C} .30 .0300 \mathrm{~g}$ of reagent grade urea (Fisher Scientific) was dissolved in $60 \mathrm{~mL}$ 
Table 1. Arrhenius Parameters for the Rate Constants (Reactions 1-6) and Equilibrium Constants (Reactions 7-28).

\begin{tabular}{|c|c|c|c|c|c|}
\hline Reaction & Rate Constant & $\mathrm{E}_{\mathrm{n}}, \mathrm{kJ} / \mathrm{mol}$ & $\ln \mathbf{A}, \mathbf{h \mathbf { r } ^ { - 1 }}$ & $\log K$ & Ref.', Commenits \\
\hline 1 & $k_{1}$ & 136.2 & 42.0 & & 23 \\
\hline 1 & $k_{. i}$ & 98.0 & $37.9^{\mathrm{a}}$ & & 24 \\
\hline 2 & $k_{2}$ & 62.3 & $31.1^{\mathrm{a}}$ & & 2526 \\
\hline 3 & $k_{3}$ & 30.3 & 15.4 & & 27 \\
\hline 4 & $k_{\phi}$ & 100.5 & 30.7 & & 25,26 \\
\hline 5 & $k_{5}$ & 67.8 & $24.4^{\mathrm{a}}$ & & 28 \\
\hline 6 & $k_{6}$ & 74.7 & $27.8^{\mathrm{b}}$ & & 27 \\
\hline 7 & & & & -11.99 & 29 \\
\hline 8 & & & & -7.81 & 30 \\
\hline 9 & & & & -6.35 & 31 \\
\hline 10 & & & & -10.13 & 32 \\
\hline 11 & & & & -3.00 & ${ }^{33}:$ ISO $^{d, t}$ \\
\hline 12 & & & & -8.23 & ISO \\
\hline 13 & & & & -15.40 & ISO \\
\hline 14 & & & & -29.86 & $25^{\circ} \mathrm{C}^{f}$ \\
\hline 15 & & & & -8.83 & ISO; SIT $^{\mathrm{B}}$ \\
\hline 16 & & & & -22.34 & ISO; SIT \\
\hline $17^{\mathrm{h}}$ & & & & -10.20 & ISO \\
\hline 18 & & & & -1.97 & $25^{\circ} \mathrm{C} ; \mathrm{I}=$ variable ${ }^{\mathrm{i}}$ \\
\hline 19 & & & & -1.56 & $25^{\circ} \mathrm{C} ; \mathrm{I}=$ variable \\
\hline 20 & & & & -1.37 & $25^{\circ} \mathrm{C} ; \mathrm{I}=$ variable \\
\hline 21 & & & & -1.30 & $25^{\circ} \mathrm{C} ; \mathrm{I}=$ variable \\
\hline 22 & & & & -1.79 & ${ }^{17}: I=3$ \\
\hline 23 & & & & -1.57 & ${ }^{17}: I=3$ \\
\hline 24 & & & & -1.07 & ${ }^{17}: I=3$ \\
\hline 25 & & & & -0.56 & ${ }^{17}: I=3$ \\
\hline 26 & & & & -3.57 & $25^{\circ} \mathrm{C} ; \mathrm{I}=0.7$ \\
\hline 27 & & & & -1.59 & $25^{\circ} \mathrm{C} ; \mathrm{I}=0.7$ \\
\hline 28 & & & & $-7.59^{\mathrm{j}}$ & ${ }^{34}$ : ISO \\
\hline
\end{tabular}

${ }^{\mathrm{a}}$ In units of $\mathrm{L} \mathrm{mol}{ }^{-\mathrm{b}} \mathrm{hr}^{-1},{ }^{\mathrm{b}}$ In units of $\mathrm{kg} \mathrm{mol}^{-1} \mathrm{hr}^{-1},{ }^{\mathrm{c}}$ Reference is given if it is not, ${ }^{35 \mathrm{~d}}$ Isocoulombic method is used, ${ }^{c} \Delta \mathrm{H}$ values are taken from NBS tables ${ }^{36}$ whenever Isocoulombic method is used, ${ }^{i}$ Temperature is given if it is not $90^{\circ} \mathrm{C},{ }^{8}$ SIT is used for zero ionic strength correction, ${ }^{h}$ Various data was found as will be discussed in "Results" section. Given value was calculated for a $\mathrm{pK}_{\mathrm{sp}}$ value of 14.70 (negative logarithm of solubility product of solid phase: $\mathrm{M}_{\mathrm{a}} \mathrm{L}_{\mathrm{b}}=\mathrm{aM}+\mathrm{bL}$, where $\mathrm{K}_{\mathrm{sp}}=[\mathrm{M}]^{\mathrm{a}} \times[\mathrm{L}]^{\mathrm{b}}$ ), ${ }^{\mathrm{i}}$ Ionic strength is given if it is not zero, ${ }^{\mathrm{j}}$ Data for $\mathrm{NiCO}_{3} \cdot 6 \mathrm{H}_{2} \mathrm{O}$ (hellyerite); in units of $\mathrm{L} \mathrm{mol}^{-1} \mathrm{~atm}$.

deionized water and added to the preheated $\mathrm{Ni}^{2+}$ solution. Concentrations of $\mathrm{Ni}^{2+}$ and urea correspond to 0.1 and $2.0 \mathrm{M}$ respectively. The solution temperature drops to about $70^{\circ} \mathrm{C}$ 
momentarily upon addition of urea solution but recovers the set temperature of $90{ }^{\circ} \mathrm{C}$ in 10 minutes. Chronometer was started after the initial 10 minutes. During digestion, the solution was stirred continuously and the sample aliquots were withdrawn from the middle of the solution. Precipitates were separated from the mother liquor by an in-line filter. These precipitates were washed three times and subsequently filtered by either $0.2 \mu \mathrm{m}$ (cellulose acetate) or $0.45 \mu \mathrm{m}$ (mixed cellulose ester) membranes after each washing cycle. Powders were saved for further analysis after drying at $70{ }^{\circ} \mathrm{C}$ for at least 12 hours. Solution $\mathrm{pH}$ was monitored (within \pm 0.02 units) continuously in an identical bottle. During the first hour, the data was logged every 10 seconds. For the second and subsequent hours, the pH measurements were made less frequently.

\section{Characterization}

Concentration of free $\mathrm{Ni}^{2+}$ ion was measured by a Shimadzu UV-2401PC UV/VIS spectrophotometer unit equipped with a water-jacketed sample and reference cell holder. A flow-through sample cell with a nominal volume of $0.45 \mathrm{~mL}$ was used. Calibration curves at 25 and $90{ }^{\circ} \mathrm{C}$ were used to deduce the molar absorption coefficient of $\mathrm{Ni}^{2+}$ at those temperatures. Linear curves were obtained from the absorption peak maxima centered at $395.5 \mathrm{~nm}$ for the uncomplexed aqueous $\mathrm{Ni}^{2+}$ (standard solutions were prepared by diluting $0.24 \mathrm{M} \mathrm{NiCl}_{2} \cdot 6 \mathrm{H}_{2} \mathrm{O}$ solution). Molar absorption coefficients were determined to be 5.15 and $5.48 \mathrm{~L} \mathrm{~mole} \mathrm{~cm}^{-1}$ at 25 and $90^{\circ} \mathrm{C}$, respectively. Peak maximum between 300 and $500 \mathrm{~nm}$ was used to determine the $\mathrm{Ni}^{+2}$ concentration in complexed solutions.

Carbon, Nitrogen and Hydrogen contents of the precipitated powders were determined using a Perkin Elmer Series II CHNS/O 2400 analyzer. Each analysis represents average of three measurements. Nickel content was measured by atomic absorption spectrometer (AAS) of the acid $\left(\mathrm{HNO}_{3}\right)$ digested powders. Balance was assigned to oxygen content.

Structural characterization was made by powder X-ray diffraction (Scintag X1-365) unit with $\mathrm{Cu}-\mathrm{K} \alpha$ radiation. In crystallite size determinations, instrumental broadening of the peaks was accounted for by correcting the FWHM (full width at half maximum) values with that of the crystalline silicon reference. ${ }^{37}$ 


\section{Results}

\section{Urea Decomposition}

To be able to visualize the distribution of species in a $2 \mathrm{M}$ urea solution at $90{ }^{\circ} \mathrm{C}$, a simulation was carried out with the first 11 reactions (i.e. with no metal ions). Initial $\mathrm{pH}$ was set to 5 , which is a typical value for solutions containing $0.1 \mathrm{M} \mathrm{Ni}^{2+}$ ions. Figure 3 shows the concentrations of decomposition products for up to five hours. The figure also indicates that the cyanate ion ( $\mathrm{OCN}^{\top}$ ) concentration can reach to about $0.017 \mathrm{M}$ before it decreases linearly as it further hydrolyzes to carbon dioxide and ammonia. Although this result is qualitatively similar to what Soler-Illia et al. ${ }^{7,14}$ presented previously, a closer examination reveals that the cyanate ion concentration in our simulation reaches almost twice the concentration that was reported by them. Also there is a significant discrepancy between the $\mathrm{pH}$ values reported. Soler-lllia ${ }^{14}$ used a $\mathrm{pK}_{\mathrm{a}}$ of 9.2 for Reaction 8 and reported this as identical to the upper limit for $\mathrm{pH}$. According to our literature survey, this value should be 7.81 at $90^{\circ} \mathrm{C}$, which is significantly lower than the value at $25{ }^{\circ} \mathrm{C}(9.7) .{ }^{30}$ Indeed, 7.81 represents an upper limit for the $\mathrm{pH}$ in the system depicted in Figure 3. Concentrations of $\mathrm{NH}_{4}{ }^{+}$and $\mathrm{NH}_{3}$ should become equal at the point where $\mathrm{pH}$ equals $\mathrm{pK}_{\mathrm{a}}$, which is reached after 20 hours (not shown). After this cross-over $\left[\mathrm{NH}_{3}\right]$ becomes larger than $\left[\mathrm{NH}_{4}{ }^{+}\right]$and the $\mathrm{pH}$ increase is minimal $(7.82$ at $36^{\text {th }}$ hour).

One might consider that the reverse reaction in Reaction 1 could have significant ramifications on the results of the simulations. Werner et al. ${ }^{23}$ argued that the first step of decomposition of urea produces neutral molecules (i.e. $\mathrm{HNCO}$ and $\mathrm{NH}_{3}$ ). In contrast, Warner et al. and Svirbely et al. published a series of papers in which they found evidence for the "ionic mechanism - collision between $\mathrm{OCN}^{-}$and $\mathrm{NH}_{4}{ }^{+}$" by investigating the effect of ionic strength of the solution on reaction constants. ${ }^{24,38,39}$ However, Shaw et al. ${ }^{23}$ and Frost et al. ${ }^{40}$ claimed that "both mechanisms were equally supported by the kinetic evidence". On the other hand, by comparing the pre-exponential term for this reaction with reactions with similar charge type, Hughes ${ }^{41}$ argued against Frost and Pearson and favored the ionic mechanism. Ionic mechanism found further support by the work of Wen et al. ${ }^{42}$ In light of the above discussion, the ionic mechanism was adopted (Reaction 1) for the simulations used 


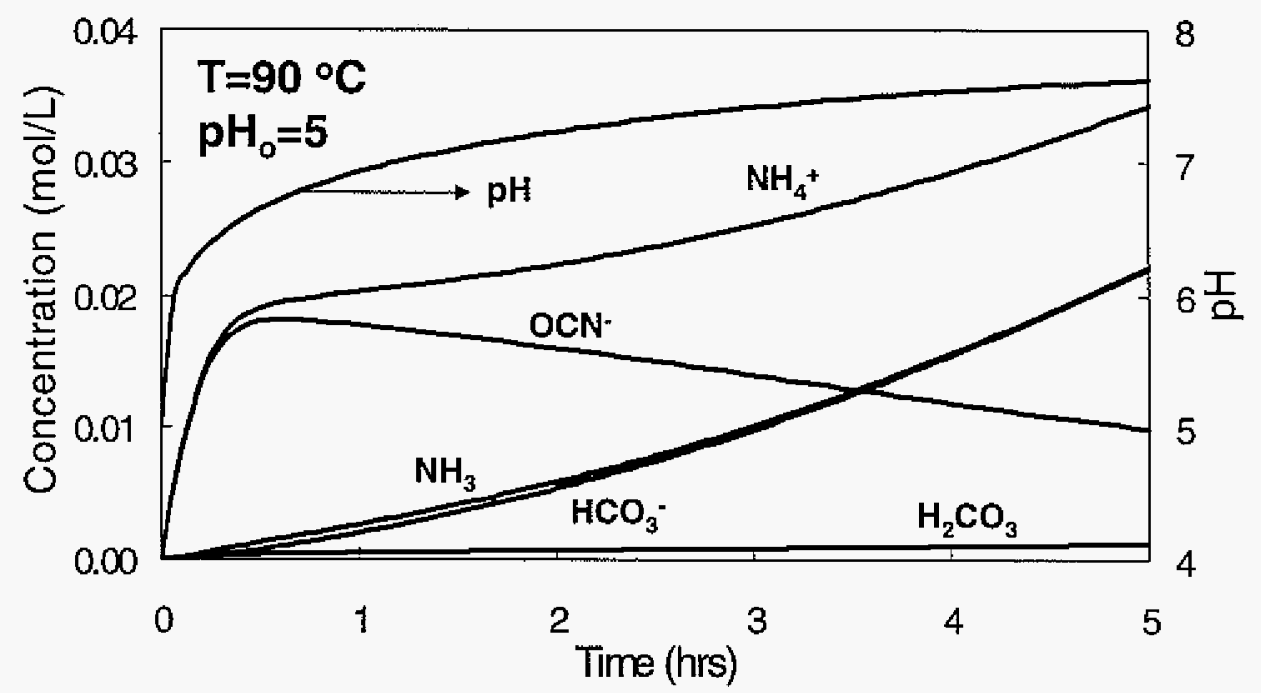

Figure 3. Simulation of distribution of species (only the significant ones are plotted) during the decomposition of $2 \mathrm{M}$ urea at $90{ }^{\circ} \mathrm{C}$ with an initial $\mathrm{pH}$ of 5 (typical value in the presence of $\mathrm{Ni}^{2+}$ ions). Important to note are the accumulation of $\mathrm{OCN}^{-}$and the upper limit of $\mathrm{pH}$ (less than 8). $\mathrm{NH}_{3}$ represents sum of $\mathrm{NH}_{3}$ (gas) and $\mathrm{NH}_{3}$ (aq); and $\mathrm{H}_{2} \mathrm{CO}_{3}$ represents sum of $\mathrm{H}_{2} \mathrm{CO}_{3}(\mathrm{aq}), \mathrm{CO}_{2}(\mathrm{aq})$ and $\mathrm{CO}_{2}$ (gas).

in this study. However, fast equilibrium imposed for $\mathrm{HNCO} / \mathrm{OCN}^{-}$and $\mathrm{NH}_{3} / \mathrm{NH}_{4}{ }^{+}$couples should account for any accumulation due to the kinetically controlled reactions and the distinction between the two mechanisms should be minimal.

Initial value of $\mathrm{pH}$ sets the trends and magnitude of each species in urea decomposition reactions as depicted in Figure 3. While Reactions 2 and have negligible effects ( $\mathrm{pK}_{\mathrm{a}}$ for $\mathrm{HNCO}$ is 3 ) on the concentration of species formed, Reactions 4-6 will have profound effect at higher $\mathrm{pH}$. The fact that concentrations of $\mathrm{NH}_{3}$ and $\mathrm{HCO}_{3}{ }^{-}$are almost identical, supports this claim. Relatively fast increase in the $\mathrm{pH}$ in metal-ion-free solutions leads to the same result even if a lower initial $\mathrm{pH}$ (i.e. $\mathrm{pH}_{0}$ ) was chosen. However, in the presence of metal ions where the hydrolysis and precipitation reactions may regulate the $\mathrm{pH}$ of the solution at a certain level, the system might be dominated by various reactions and as will be discussed later, the acid/base couples and gas phase solubilities can result in a much different distribution of species. 


\section{Precipitation of $\mathrm{Ni}^{2+}$}

Precipitation of $\mathrm{Ni}^{2+}$ by urea decomposition was followed by determining the free nickel concentration in the solution. First, a calibration curve was constructed for free $\mathrm{Ni}^{+2}$ using $\mathrm{NiCl}_{2} \cdot 6 \mathrm{H}_{2} \mathrm{O}$ solutions. To assess the role of urea and its decomposition products on the $\mathrm{Ni}^{2+4}$ absorption spectra, urea and $\mathrm{OCN}^{-}$were added to solutions. Figure 4 demonstrates the increase in absorption coefficient in the presence of $0.04 \mathrm{M} \mathrm{OCN}$ (approximately the maximum level of free $\mathrm{OCN}^{-}$and related complexes). The presence of $\mathrm{OCN}^{*}$ results in $15 \%$ error in measured $\mathrm{Ni}^{2+}$ ion concentration. A similar error was observed when urea was present in $\mathrm{Ni}^{2+}$ solution. Measured $\mathrm{Ni}^{2+}$ ion concentration in $2 \mathrm{M}$ urea solution was about $4 \%$ higher than the actual concentration. Furthermore, since urea concentration decreases slightly during the whole process (to about $1.9 \mathrm{M}$ even after 36 hours of digestion at $90^{\circ} \mathrm{C}$ ), this error is considered constant for the entire digestion period. The errors introduced by $\mathrm{OCN}^{-}$and urea were corrected in $\left[\mathrm{Ni}^{2+}\right]$ determinations.

UV/VIS spectra of the solutions withdrawn during the digestion of $0.1 \mathrm{M} \mathrm{Ni}^{2+}$ with $2 \mathrm{M}$ urea are given in Figure 5. A gradual blue shift of the characteristic $\mathrm{Ni}^{2+}$ peaks was noted with digestion time. Furthermore, the doublet around $600-800 \mathrm{~nm}$ progressively transformed into a single peak at a lower wavelength. This is due to the fact that $\mathrm{Ni}^{2+}$ ions interact with the ammonia, a product of urea decomposition to form various $\mathrm{Ni}\left(\mathrm{NH}_{3}\right)_{n}{ }^{2+}(\mathrm{n}=1$ to 4 for temperatures above $\approx 80{ }^{\circ} \mathrm{C}^{17}$ ) complexes. No effort was made to determine the molar absorption coefficient (MAC) of these complexes and it is expected that MAC of complexed $\mathrm{Ni}^{2+}$ is significantly different from that of the uncomplexed ion.

\section{Kinetic Simulations}

Review of literature indicates that different preparation methods can lead to a significant variation on the observed solubility products of nickel hydroxide. "Active" powders has been shown to have $\mathrm{pK}_{\mathrm{sp}}$ values as low as 14.7 , while $\mathrm{pK}_{\mathrm{sp}}$ for "aged" powders was as high as 17.95 at $25^{\circ} \mathrm{C}$ and at zero ionic strength. ${ }^{35}$ Figure 6 shows the concentrations of free $\mathrm{Ni}^{+2}$ (A) and $\mathrm{NiOCN}^{+}$(B), (at several $\mathrm{pK}_{\text {sp }}$ values) as a function of digestion time. Looking at the spread of the "prediction envelope" for the concentration of free $\mathrm{Ni}^{2+}$ ion in the solution, it appears that the uncertainty in the solubility product constant is the largest error contributor 
to the whole simulation process. As discussed earlier, the correction for the error introduced by $\mathrm{OCN}^{-}$on the $\mathrm{Ni}^{2+}$ determination by UV/VIS was necessary.

Results of the two experiments with initial $\mathrm{Ni}^{2+}$ ion concentrations of 0.1 and $0.075 \mathrm{M}$ simulated with the $\mathrm{pK}_{\mathrm{sp}}$ value of 15.5 are given in Figure 7. Apart from the slight discrepancy in the initial stages of the process, the agreement between experimental result and model predictions is excellent. Divergence at longer digestion times is attributed to formation of $\mathrm{Ni}\left(\mathrm{NH}_{3}\right)_{\mathrm{n}}{ }^{2+}$ complexes as discussed earlier.

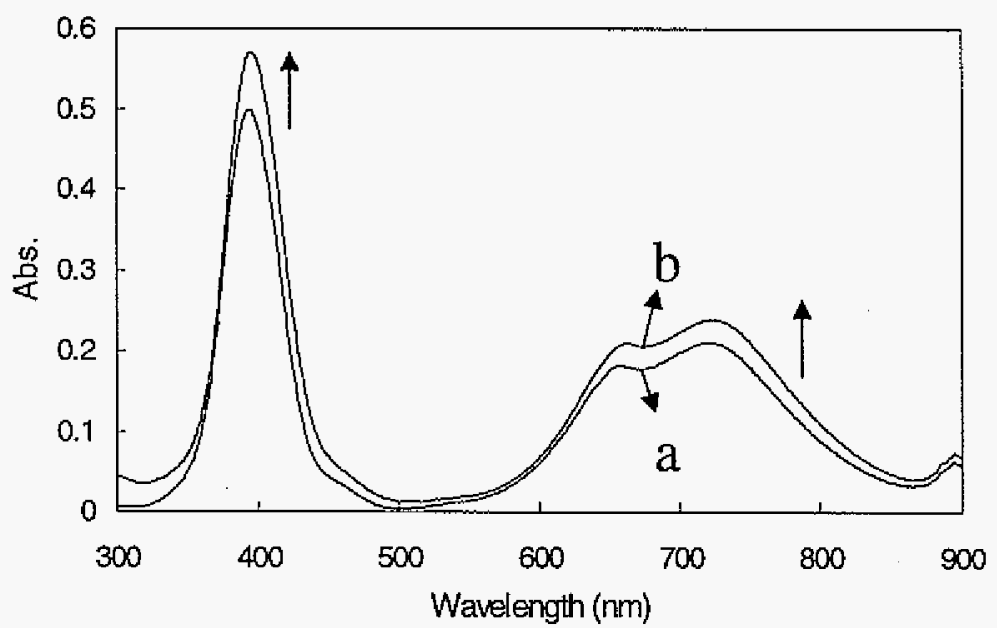

Figure 4. Effect of $\mathrm{OCN}^{-}$on the UV/VIS spectrum of $\mathrm{Ni}^{2+}$ : (a) $0.1 \mathrm{M} \mathrm{Ni}^{2+}$; (b) $0.1 \mathrm{M} \mathrm{Ni}^{2+}$ and $0.04 \mathrm{M} \mathrm{OCN}^{-}$. A positive deviation as much as $15 \%$ is observed in the presence of $0.04 \mathrm{M}$ $\mathrm{OCN}^{-}$.

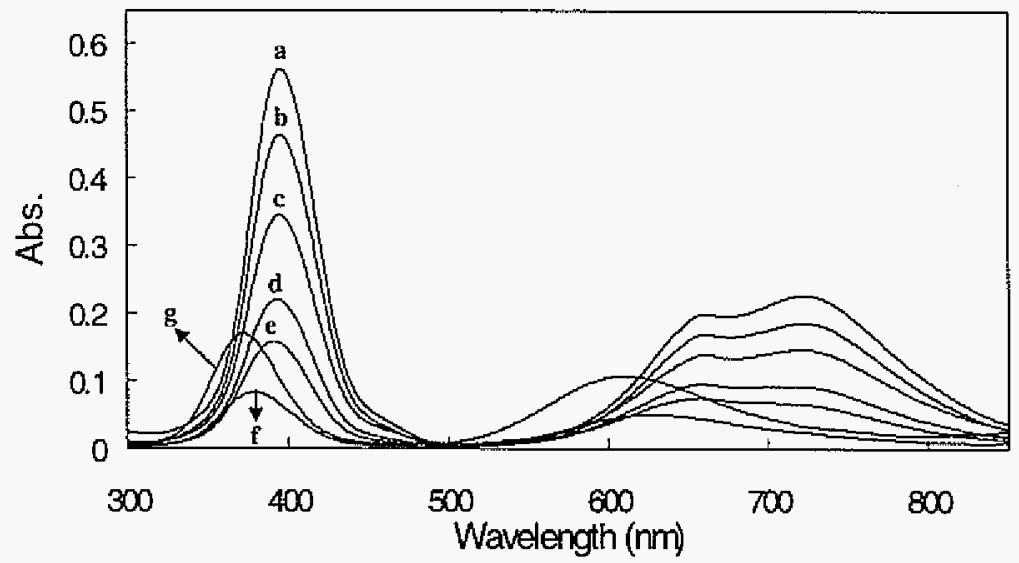

Figure 5. UV/VIS spectra of $\mathrm{Ni}^{2+}$ ions that remain in the solution after; a) $10 \mathrm{~min}$; b) $40 \mathrm{~min}$; c) $80 \mathrm{~min}$; d) $2.5 \mathrm{hr}$; e) $3.5 \mathrm{hr} ; \mathrm{f}) 12 \mathrm{hr} ; \mathrm{g}) 36 \mathrm{hr}$ of digestion $\left(\left[\mathrm{Ni}^{2+}\right]_{0}=0.1 \mathrm{M}\right.$; [Urea]=2M; 90 $\left.{ }^{\circ} \mathrm{C}\right)$. A blue shift in the absorption peaks and the appearance of a single peak instead of the high wavelength doublet indicates the formation of Nickel-Amine complexes. 

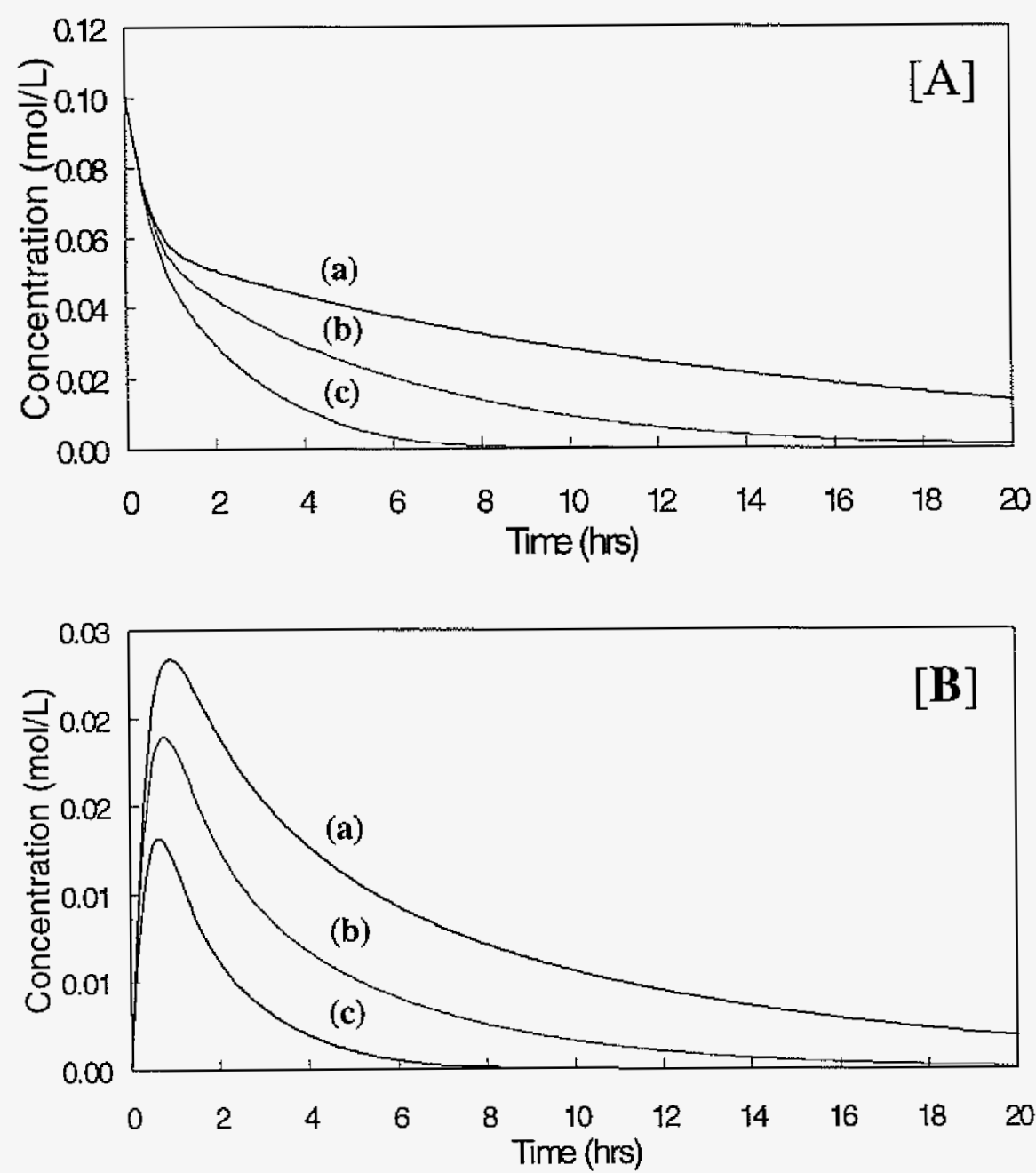

Figure 6. Predicted changes in concentrations of [A] free $\mathrm{Ni}^{2+}$ ion and [B] $\mathrm{NiNCO}^{+}$complex with increasing digestion time $\left(90^{\circ} \mathrm{C} ;\left[\mathrm{Ni}^{2 \div}\right]_{0}=0.1 \mathrm{M} ; \mathrm{pH}_{0}=5 ; \mathrm{I}=0\right)$. Plots present the predictions with different $\mathrm{pK}_{\mathrm{sp}}$ entries: ${ }^{35}$ (a) 14.7 ; (b) 15.5 ; (c) 16.36 (corrected for zero ionic strength by SIT). These $25^{\circ} \mathrm{C}$ data were extrapolated to $90^{\circ} \mathrm{C}$ by the isocoulombic method prior to their use in simulations as follows: (a) 13.8 ; (b) 14.6 ; (c) 15.47 .

Variation of observed $\mathrm{pH}$ with digestion time along with the same predicted by the model at several $\mathrm{pK}_{\mathrm{sp}}$ values are shown in Figure 8. Temperature of the $\mathrm{Ni}^{+2}$ solution drops from 90 to about $70^{\circ} \mathrm{C}$ upon the addition of urea solution. This shows itself in the experimental data as an increase in the initial $\mathrm{pH}$ up to about 5.5 due to lower dissociation constant of water at lower temperatures. As the temperature rises, $\mathrm{pH}$ starts to drop, coupled with urea decomposition resulting in increasing $\mathrm{pH}$. Thus $\mathrm{pH}$ vs. time goes through a minimum in the 

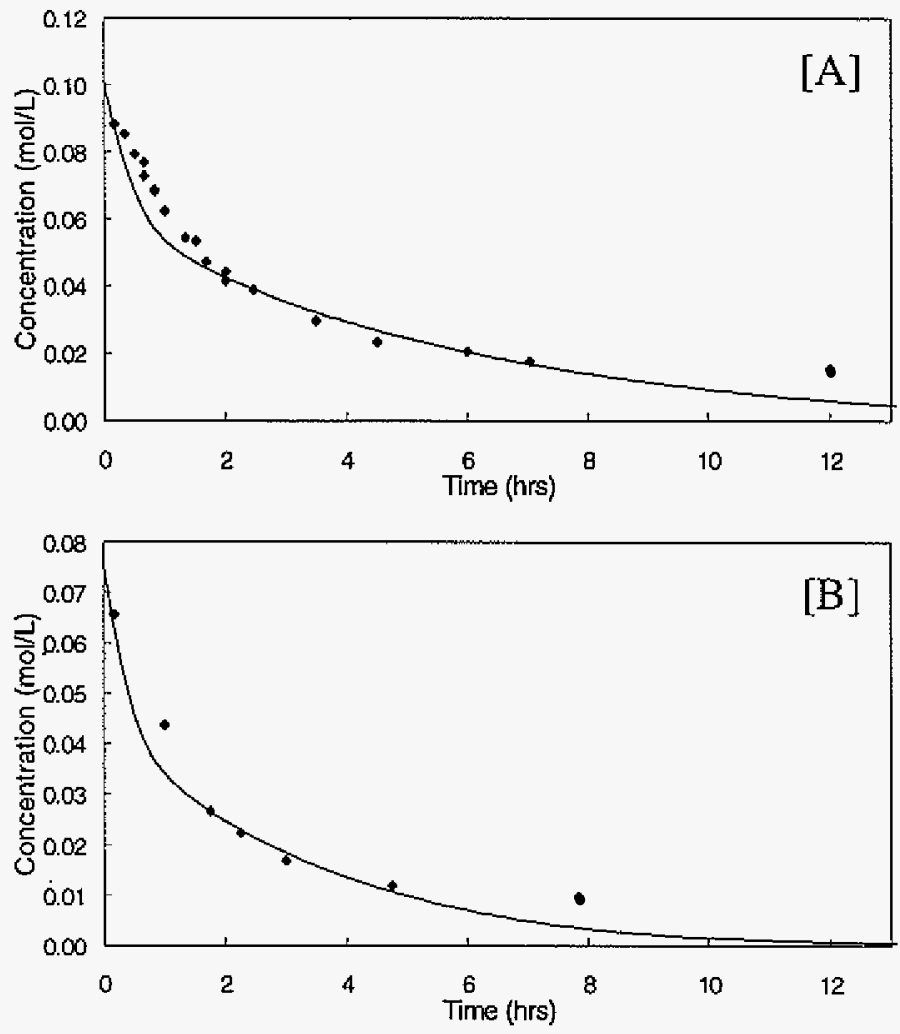

Figure 7. Comparison of simulated $\left(-\right.$ ) and experimental $(\bullet)$ free $\mathrm{Ni}^{2+}$ ion concentrations in solutions with $\left[\mathrm{Ni}^{2+}\right]_{0} ;[\mathrm{A}] 0.1 \mathrm{M}$ and [B] $0.075 \mathrm{M}$. Random experimental errors were smaller than the data labels.

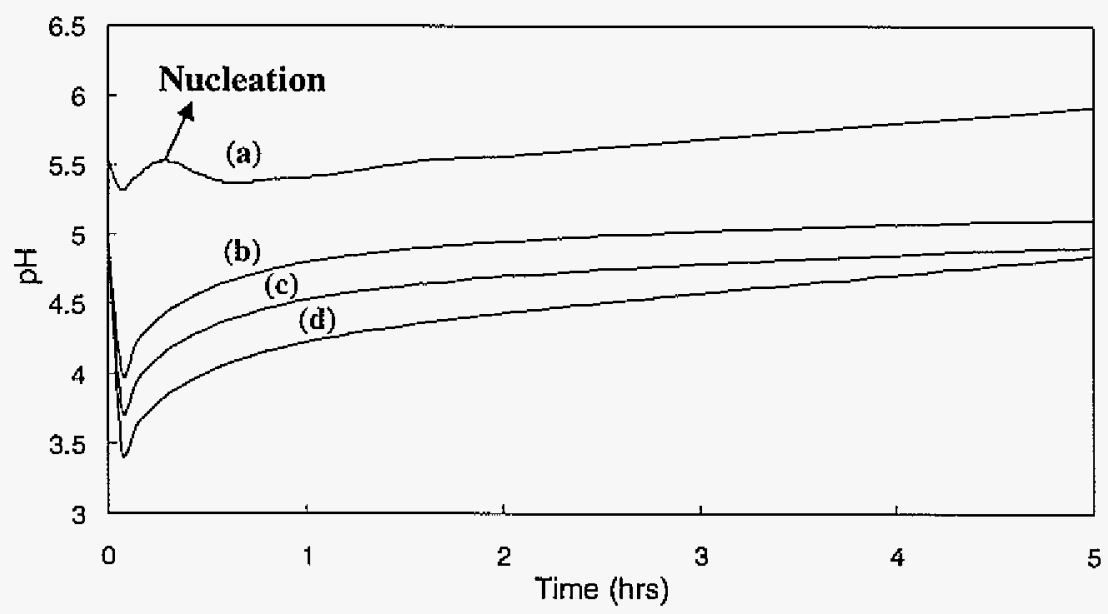

Figure 8. Change in $\mathrm{pH}$ with respect to digestion time with $\left[\mathrm{Ni}^{2+}\right]_{\mathrm{o}}=0.1 \mathrm{M}$; (a) Experimental and (b), (c) and (d) are predictions with $\mathrm{pK}_{\mathrm{sp}}$ of 14.7, 15.5 and 16.36, respectively. Peak observed in the experimental data (a) marks the nucleation event that was not included in the simulations. Note that the initial 10 minutes, during which the temperature equilibration takes place is included in the plot. 
first ten minutes of the digestion. The increase in $\mathrm{pH}$ continues until the critical supersaturation is reached $(\approx 16-18$ minutes). The burst of nuclei causes a noticeable drop in $\mathrm{pH}$, followed by a steady-state increase with continued urea decomposition during the growth stage. On the other hand, the initial drop observed in the predicted plots (simulation) is due to lack of nucleation barrier for precipitation which assumes instantaneous precipitation with concomitant decrease in $\mathrm{pH}$ until $\mathrm{OH}^{-}$consumption is compensated by urea decomposition. Predicted trends in $\mathrm{pH}$ after the nucleation event is in agreement with experimental data within an order of magnitude (Note that the discrepancy is on the order of $10^{-4} \mathrm{M}$ ).

\section{Crystallite Size}

XRD patterns taken from the precipitates sampled at different digestion times are given in Figure 9. Patterns exhibit "turbostratic" $\alpha-\mathrm{Ni}(\mathrm{OH})_{2}$ similar to ones reported by others. ${ }^{12,43-}$ ${ }^{45}$ Interlayer spacing along $c$-axis that was calculated from the positions of [003] peak gave similar values for different samples, $7.24 \pm 0.01 \AA$.

Crystallite sizes were calculated using the Scherrer formula, ${ }^{37,46}$

$t_{h k l}=\frac{0.9 \lambda}{\Delta B_{h k l}(\theta) \cdot \cos \theta}$

where $t_{l k k l}$ is the crystallite size along [hkl] direction, $\Delta B_{h k l}$ is the FWHM of the [hkl] peak corrected for instrument broadening, $\lambda$ is the wavelength of the radiation $(1.5406 \AA$ for $\mathrm{Cu}$ $\mathrm{K} \alpha$ ) and 0.9 is the "structure factor" for [00l] planes. Standard deviation in calculations was $0.2 \mathrm{~nm}$. Along the c-axis (as calculated from the [003] peak), the crystallite size increased slightly in the first day and stabilized after that $(5.6,6.1,7.9$ and $7.6 \mathrm{~nm}$ for $50 \mathrm{mins}, 2 \mathrm{hrs}, 24$ hrs and 36 hrs samples, respectively). Crystallite size parallel to the basal the plane was calculated from [110]. Owing to the asymmetric nature of the peak, calculation was only approximate and crystallite size was found to vary from $15.5 \mathrm{~nm}$ to about $16.1 \mathrm{~nm}$ at $50 \mathrm{~min}$ and 36 hour respectively (structure factor of 1.84 was used for [hk0] reflections ${ }^{12}$ ). Asymmetric character of the [012] peak lends additional support for the "turbostratic" nature of the stacked layers. 


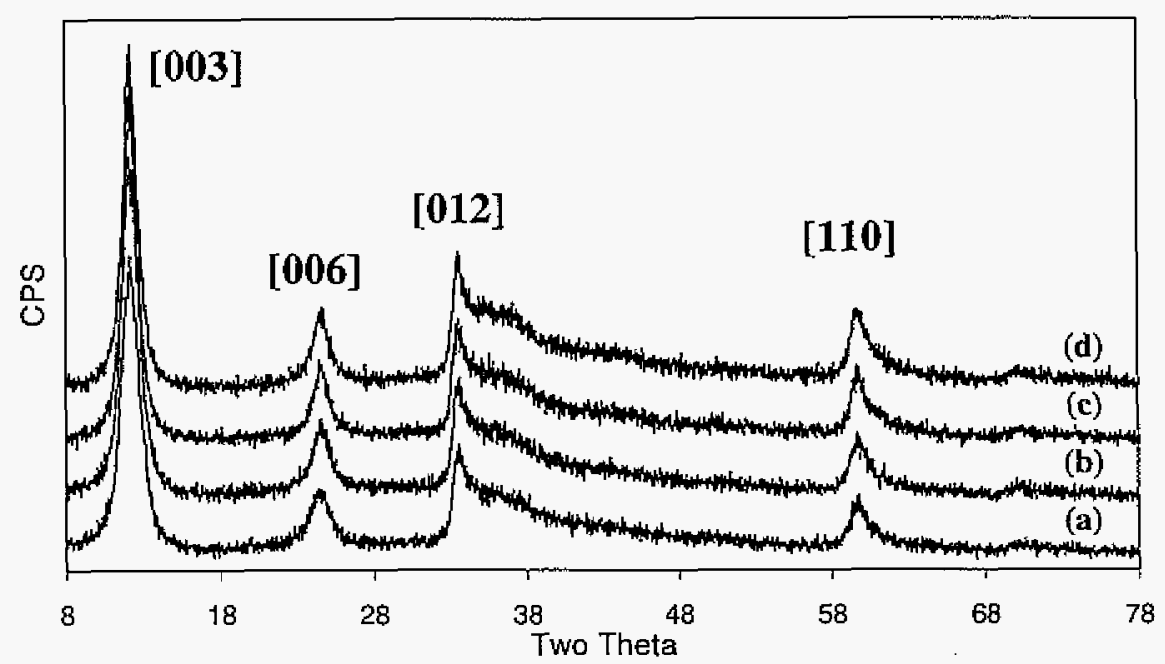

Figure 9. XRD patterns of precipitates sampled at different digestion times: (a) 50 mins, (b) $2 \mathrm{hrs}$, (c) $24 \mathrm{hrs}$ and (d) $36 \mathrm{hrs}$.

\section{Chemical Analysis}

FTIR studies in our group and others ${ }^{8-10,12}$ indicated the presence of cyanate, carbonate or bicarbonate, and the anion of the starting $\mathrm{Ni}^{2+}$ salt along with water in the precipitate. Figure 3 indicates that bicarbonate dominates carbonate or carbonic acid throughout the process for the $\mathrm{pH}$ range observed in this study. Hence a formula, $\mathrm{Ni}_{\mathrm{a}}(\mathrm{OH})_{\mathrm{x}}(\mathrm{OCN})_{\mathrm{z}}\left(\mathrm{HCO}_{3}\right)_{\mathrm{y}} \mathrm{Cl}_{\mathrm{k}} \cdot \mathrm{rH}_{2} \mathrm{O}$, appears to be a reasonable representation of the chemical composition of the precipitate. Variations in the composition of the precipitated powders will be reflected in the coefficients of the species (i.e., $\mathrm{x}, \mathrm{y}, \mathrm{z}, \mathrm{k}$, and $\mathrm{r}$ ) in the above formula. Indeed, when the coefficients were plotted against digestion time, it was seen that variations in the composition is significant, especially for the cyanate ion (z). Table 2 summarizes the variation of the coefficients at several digestion times. Variation of the weight percent of Nitrogen in the precipitate as a function of time is plotted in Figure 10. Note that the general trend in $\mathrm{OCN}^{*}$ content in the precipitate mirrors that in solution as predicted by the kinetic simulation (See Figure $6 \mathrm{~B}$ ). Although the percent error in $\mathrm{N}$ and $\mathrm{C}$ analyses was never above 2.7, it ranged between 0.7 and 6.8 for $\mathrm{H}$ analyses. As a result, percent error in $\mathrm{O}$ estimates was up to about 9 in some samples. Hence the relative error in the value of " $r$ " can be as high as $38 \%$. Therefore fluctuations in the reported hydration numbers ( $\mathrm{r}$ ) are not as serious as it might seem. 
Table 2. Calculated chemical formula numbers for precipitates $\left(\left[\mathrm{Ni}^{2+}\right]_{0}=0.1 \mathrm{M}\right)$.

\begin{tabular}{ccccccc}
\hline Digestion Time (hrs) & $\mathrm{a}$ & $\mathrm{x}$ & $\mathrm{z}$ & $\mathrm{y}$ & $\mathrm{k}$ & $\mathrm{r}$ \\
\hline 0.7 & 1 & 1.23 & 0.51 & 0.18 & 0.08 & 0.10 \\
1.5 & 1 & 1.35 & 0.53 & 0.05 & 0.06 & 1.24 \\
2 & 1 & 1.45 & 0.47 & 0.05 & 0.02 & 0.59 \\
7 & 1 & 1.47 & 0.42 & 0.09 & 0.02 & 0.57 \\
22.5 & 1 & 1.47 & 0.37 & 0.15 & 0.01 & 1.12 \\
29 & 1 & 1.51 & 0.34 & 0.15 & 0.00 & 0.85
\end{tabular}

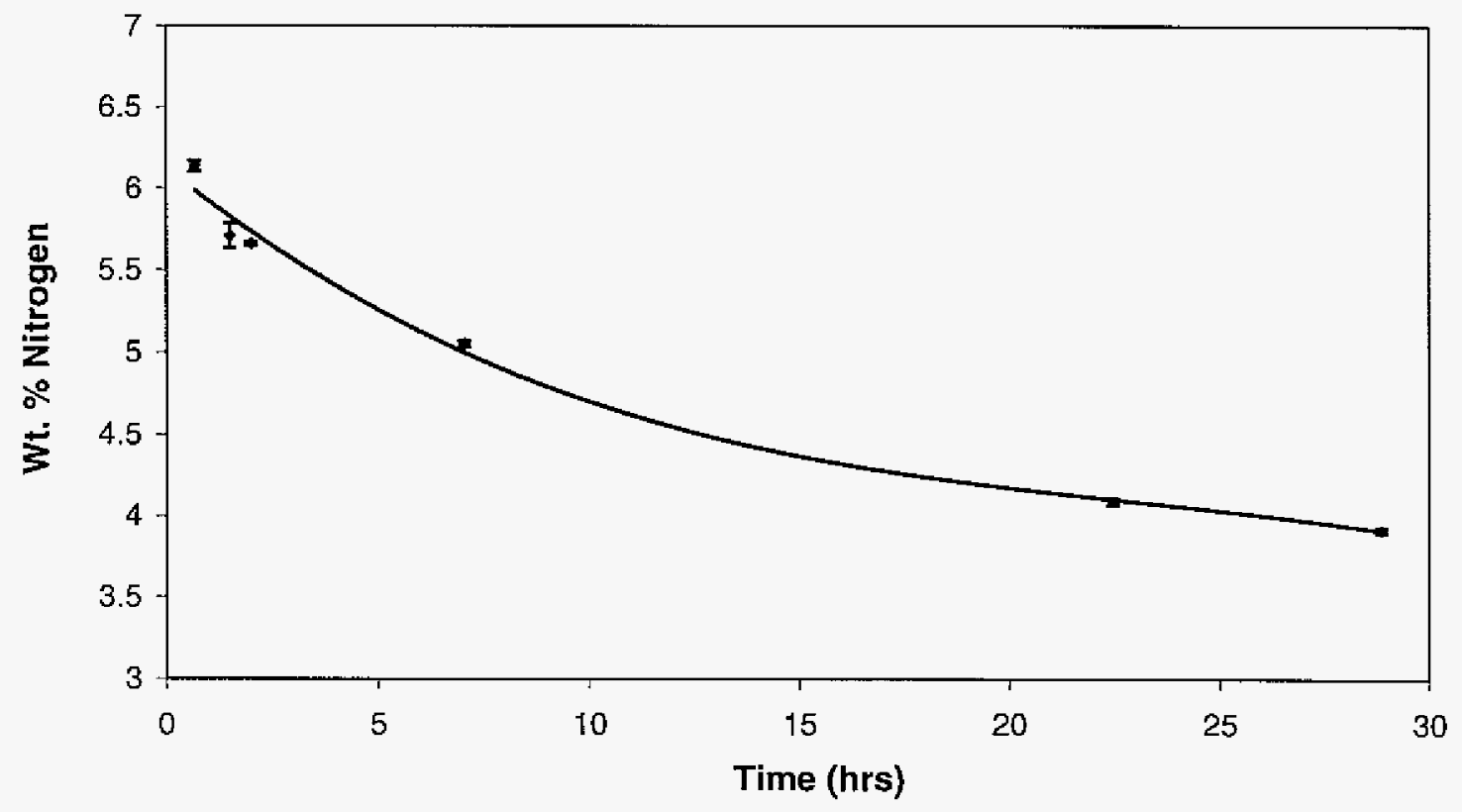

Figure 10. Change in the weight percent of Nitrogen with digestion time. Note that all Nitrogen can be attributed to cyanate present in the sample.

\section{Discussion}

One of the requirements of a robust model for predicting the rate of removal of metal ions and formation of hydrolysis products and complexes is the availability of $\mathrm{pH}$ dependent rate constants. In the $\mathrm{pH}$ ranges which metal oxide precursor powders are generally produced, Reaction 1 shows little or no dependency on $\left[\mathrm{H}^{+}\right]$, whereas it is not the case for the second step of urea decomposition. Representation of this step with five separate reactions reduces the sensitivity of the model predictions to $\mathrm{pH}$ changes that might occur during precipitation. 
The model developed in this study can be employed with any first row transition metal ion as long as appropriate hydrolysis and complexation data are available. Although the accuracy of the rate constants may be questionable due in part to extrapolating with simple Arrhenius parameters and uncertainty in the effect of ionic strength on the measured constants, it is believed that Reactions 1-11, related to hydrolysis of urea, was quite reliable and hence the incorporation of metal ions into the process is justified.

Reactions involving metal ions were represented as equilibrium reactions. A degree of supersaturation $\left(\Omega=\mathrm{Q} / \mathrm{K}_{\mathrm{sp}}\right.$, where $\mathrm{Q}$ is the ion product at the onset of precipitation and $\mathrm{K}_{\mathrm{sp}}$ is the equilibrium ion product) is needed before the primary crystallites nucleate. A value of $\Omega=10^{0.56}$ was reported by Soler-Illia et al. ${ }^{[2}$ for a similar system (where $\left[\mathrm{Ni}^{2+}\right]_{0}$ changes from 1.5 to $5.4 \times 10^{-3} \mathrm{M}$; $\mathrm{pH}$ measurements were made at $25^{\circ} \mathrm{C}$ and a $25^{\circ} \mathrm{C}_{\mathrm{pK}}$ value of 15.2 was used). The supersaturation value we calculated for a representative system at $90{ }^{\circ} \mathrm{C}$ was $10^{0.36}$. This supersaturation value was obtained at $90{ }^{\circ} \mathrm{C}$ with $\mathrm{pK}_{\mathrm{w}}^{\prime}=12$ and nucleation at a $\mathrm{pH} \approx 5.53$ and $16-18 \mathrm{~min}$ digestion time. Again, the solubility product value, $\mathrm{pK}_{\mathrm{sp}}$ of 15.2 was extrapolated to $90^{\circ} \mathrm{C}$ as 14.3 . The difference between the supersaturation value reported by Soler-Illia and ours is well within the error in $\mathrm{pH}$ measurements at low ionic strengths (an error of $0.1 \mathrm{pH}$ units would yield the same result). Both the observed discrepancy between the predictions and experimental results in the initial stages and the observed peak in the $\mathrm{pH}$ vs. time plots indicate that $\Omega$ values as low as about 2.3 should be observable. Although the model would have been more accurate if it had accounted for nucleation event; the predictions were found to be quite adequate for post-nucleation stage owing to the wellbehaved nature of the urea system.

Accuracy of the model predictions could be improved provided high temperature formation constants or heats of formation of $\mathrm{Ni}(\mathrm{NCO})_{\mathrm{n}}$ (Reactions 18-21) or $\mathrm{NiCO}_{3}(\mathrm{aq})$ and $\mathrm{NiHCO}_{3}{ }^{*}$ (Reactions 26-27) are available. Simulations were carried out at a constant ionic strength for the whole digestion time. In reality, the ionic strength increases with urea hydrolysis generating more ions in the solution whereas precipitation and complexation cause reduction in the ionic strength. Simultaneous iterative ionic strength calculations could improve the accuracy slightly. However, not only the ionic strength varies (especially during 


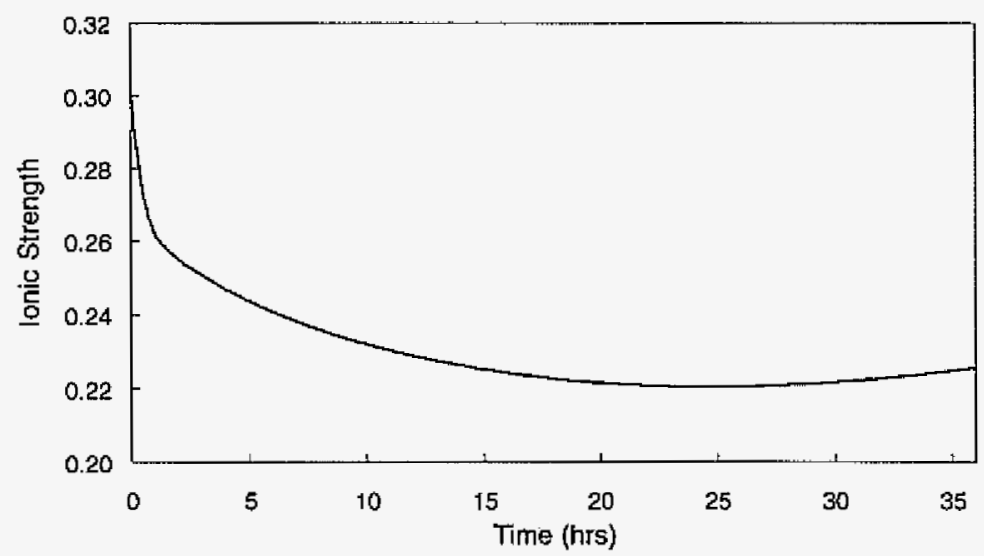

Figure 11. Change in ionic strength with respect to digestion time. Initially there is only $0.1 \mathrm{M} \mathrm{NiCl}{ }_{2} \cdot \mathrm{H}_{2} \mathrm{O}$ and $2 \mathrm{M}$ Urea in the solution, however as soon as the precipitation starts $\mathrm{Ni}^{2+}$ ions are depleted and ionic strength drops significantly. On the other hand, after some point this decrease is slowed down by the urea decomposition products, mainly $\mathrm{NH}_{4}{ }^{+}$. Arithmetic average of ionic strength is 0.23 .

the nucleation period as presented in Figure 11) but also the major contributors to the ionic strength changes (from $\mathrm{Ni}^{2+}$ and $\mathrm{Cl}^{-}$to $\mathrm{NH}_{4}{ }^{+}$and $\mathrm{Cl}^{-}$). Furthermore, the validity of the corrections depends on the availability of SIT parameters of the ions, which was not the case for the system under consideration. Therefore even an iterative procedure would not have improved the accuracy of the results.

Largest contribution to the error in simulations was from the values used for the solubility product of $\mathrm{Ni}(\mathrm{OH})_{2}$ (Reaction 17). This was partly due to the fact that it can sometimes be difficult to distinguish between $\alpha$ and $\beta$ phases of $\mathrm{Ni}(\mathrm{OH})_{2}$ and this information is not clearly extractable from the experimental details. Running the simulations with different solubility product values demonstrated that an inaccuracy in this data can explain, for the most part, the discrepancy between the predictions and experimental data. Therefore, any additional refinement to the other reaction constants (i.e. ionic strength corrections) was not considered necessary.

When $\mathrm{pH}$ vs. time plots with different $\mathrm{pK}_{\mathrm{sp}}$ data were examined, it appears that the experimental data shows a better agreement with the simulations employing lower $\mathrm{pK}_{\mathrm{sp}}$ in the initial stage and higher $\mathrm{pK}_{\mathrm{sp}}$ for long digestion times (slopes in this case are identical). However it is believed that the significant fraction of the error is due to an inaccurate measurement of $\mathrm{pH}$ at elevated temperatures and low ionic strengths. Errors as much as 1-2 
$\mathrm{pH}$ units are not unlikely. In addition, unavoidable clogging of the fritted glass junction, which is inherent to most common $\mathrm{pH}$ probes, by the precipitates; results in non-reproducible junction potentials. ${ }^{47}$ This itself explains the difference between the $\mathrm{pH}$ measurements and predictions.

Crystallite size reported by Soler-Illia and co-workers indicates that the crystallite size along the c-axis grows from $6 \mathrm{~nm}$ to about $15 \mathrm{~nm}$ in 200 minutes, ${ }^{12}$ whereas it seems to show much less growth even in 36 hours (5.6 to less than $8 \mathrm{~nm}$ ) in this study. Although subtle differences between experimental procedures might have had some effect on this discrepancy (i.e. $\left[\mathrm{Ni}^{2+}\right]_{0},[\mathrm{Urea}]_{0}$, and the digestion procedure), there appears to be a more fundamental reason for the discrepancy. The peak broadening observed in XRD patterns may not only be due to crystalline domain size, which had been the basic assumption in both calculations, but also to strains and stacking faults in the crystal as well. ${ }^{37}$ The term "turbostratic" invokes possible broadening effects due to straining (i.e. misalignment of layers with respect to each other). There has been efforts to explain the observed patterns of a similar compound, $\alpha-$ $\mathrm{Co}(\mathrm{OH})_{2}$, by performing pattern simulations with stacking faults. ${ }^{48}$ Therefore, crystallite size calculations in these systems should be considered qualitative in nature, and it suffices to state that the crystallites are small enough to be called "nano-sized". On the other hand, crystallite size calculations explain the growth mechanism of the precipitated particles. Although the particles grow up to several microns, ${ }^{11,49,50}$ the fact that primary crystallites remain nano-sized, imply an agglomerative growth mechanism. This mechanism is in line with the recent reports ${ }^{18}$ and offers an alternative to LaMer's "burst-nucleation/diffusional growth" mechanism for the precipitation of monodispersed colloids, which may be valid only for particles with well-developed habits.

FTIR experiments carried out by our group (to be published) and others ${ }^{8-10,12}$ clearly point out that nitrogen found in elemental analyses of the precipitates is in the form of cyanate. Chemical analyses on powders sampled at different digestion times indicated a systematic compositional variation. That is, the crystallites forming in the initial couple of hours have significantly different composition (i.e. different distribution of intercalated species) compared to the ones form later. Since the solutions were stirred constantly during the entire digestion, the variation in composition can not be attributed to inhomogeneity in 
solution composition. Based on the agglomerative growth mechanism offered above, one can assume that the crystallites, which agglomerate to form the larger particles, exhibit different interlayer chemistries.

Possibility of formation of $\mathrm{NiCO}_{3}$ (Reaction 28) has not been discussed yet. Simulations predict that its concentration could reach significant levels depending on the experimental conditions. In the simulations, an implicit assumption was made that any aqueous $\mathrm{NH}_{3}$ or $\mathrm{CO}_{2}$ forming remains in the solution, which is a reasonable assumption if the volume above the solutions is kept constant (sealed bottles). The equilibrium partial pressure dictated by the Henry's constant at a given temperature is reached quickly in a constant volume and the concentration of the dissolved gas would not be depleted significantly. However, if the set-up allows the evolution of gas above the solution and keeps the total pressure at approximately ambient (as was the case when a balloon was attached to the reaction bottle), the equilibrium partial pressure is dictated by the solubility of the gas in the solution under the given experimental conditions. For more accurate description of the system used in this work, the following reactions need to be incorporated into the simulations:

$$
\begin{aligned}
& \mathrm{CO}_{2} \text { (gas) }=\mathrm{CO}_{2}(\mathrm{aq}) \\
& \mathrm{NH}_{3} \text { (gas) }=\mathrm{NH}_{3}(\mathrm{aq})
\end{aligned}
$$

While effect of this modification on predicted concentrations of free $\mathrm{Ni}^{2+}$ and many other species was minimal, predictions on carbonate related species (Reactions 26-28) deserve some consideration. Figure 12[A] gives the changes in partial pressures of $\mathrm{CO}_{2}$ (gas) and $\mathrm{NH}_{3}$ (gas) in atmospheres, whereas changes in concentrations of $\mathrm{NiCO}_{3}$ (s) and $\mathrm{NiHCO}_{3}(\mathrm{aq})$ with and without the gas phase solubility is presented in Figure 12[B]. It is evident from the figures that if the reaction bottles are sealed concentrations of carbonate related species could reach significant values, possibly leading to formation of solid $\mathrm{NiCO}_{3}$ (s) phase. On the other hand, if the gas is allowed to expand freely into the gas phase, formation of $\mathrm{NiCO}_{3}(\mathrm{~s}$ ) is not likely (a two-to-three orders of magnitude difference was predicted).

One point that bears comment is the "bi-dimensional condensation model" for the nucleation mechanism offered by Soler-Illia and co-workers. ${ }^{12}$ Their basic premise relies on 

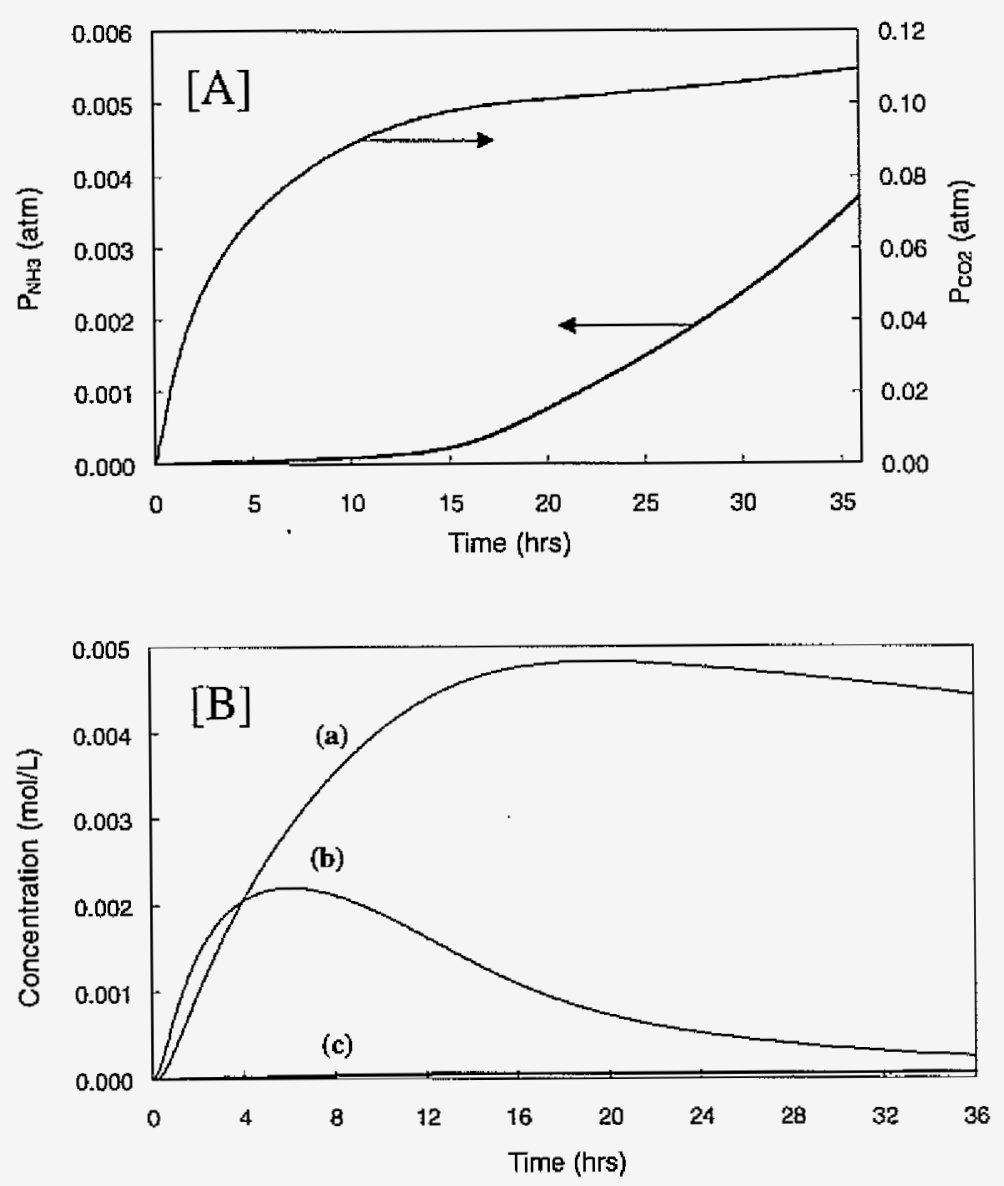

Figure 12. [A] Predicted partial pressures (in atm.) of $\mathrm{CO}_{2}$ (gas) and $\mathrm{NH}_{3}$ (gas) upon inclusion of Reactions 29 and 30 in the simulations. Henry's constant used for Reactions 29 and 30 were $10^{-2.02}$ and $10^{0.73} \mathrm{~mol} \mathrm{~L}^{-1}$ atm $^{-1}$ at $90^{\circ} \mathrm{C}$, respectively. ${ }^{51}$ [B] Predicted concentrations of (a) $\mathrm{NiCO}_{3}$ (s) and (b) $\mathrm{NiHCO}_{3}$ (aq) without Reactions 29 and 30 and (c) $\mathrm{NiCO}_{3}$ (s) with the Reactions 29 and 30 . Note that second solid phase formation is almost negligible when Reactions 29 and 30 were incorporated. Other carbonate related species' concentrations are insignificant.

the Ostwald step rule, which was stated as "the coordinative environment of the aqueous species that promote nucleation should closely resemble those of the ions in the solid state". They proposed that the nucleation of $\alpha-\mathrm{Ni}(\mathrm{OH})_{2}$ is driven by the edge-on condensation of tetrameric $\left(\mathrm{Ni}_{4}(\mathrm{OH})_{4}{ }^{4+}\right)$ units, yet their report indicates that the concentration of the very same species should be "negligible" in the solution. In addition, while a constant supersaturation value under different conditions was taken as an indication of participation of only $\mathrm{OH}^{-}$ions in nucleation, no proof for the argument on the intercalation of $\mathrm{NiNCO}^{+}$is 
given. Thus, the role of cyanate containing species does not go beyond a probable "poisoning" effect to the growth of crystallites, which is far from certain. Although the experimental support for the mechanisms offered were not sufficient, their work should be considered a good interpretation of limited knowledge on this system which the present work is built on and a more detailed and quantitative description of nickel hydroxide precipitation by urea decomposition was realized. More refined description of the system will be achieved with the availability of more accurate reaction constants.

\section{Conclusions}

A robust predictive model for urea precipitation method for transition metal ion, $\mathrm{Ni}^{2+}$ was developed and tested at $90^{\circ} \mathrm{C}$. Predictions on $\mathrm{Ni}^{2+}$ precipitation rate and $\mathrm{pH}$ were confirmed with the experimental work. Considering the sources of errors in experimental data and the uncertainty in the reaction constants, the agreement between experimental data and model predictions was remarkable. The growth mechanism was determined to be the aggregation of nano-sized primary crystallites to form micron-size particles. Primary crystallites forming at different stages of the process exhibit demonstrable compositional differences that cause variations through the cross-section of the particles. The compositional variation across the particle cross section is also implied by the predicted changes in the concentrations of simple and complex ions in the solution. The comprehensive set of hydrolysis reactions allows for investigation of other systems provided that accurate reaction constants and other initial experimental data are available.

\section{Acknowledgement}

This manuscript has been authored by Iowa State University of Science and Technology under Contract No. W-7405-ENG-82 with the U.S. Department of Energy. The United States Government retains and the publisher, by accepting the article for publication, acknowledges that the United States Government retains a nonexclusive, paid-up, irrevocable, world-wide license to publish or reproduce the published form of this manuscript, or allow others to do so, for United States Government purposes. Authors thank Dr. Soler-Illia for providing a hard copy of his PhD thesis, and Drs. Jim Espenson, Andy Thom and Matt Kramer for 
valuable discussions. B. M. furthermore acknowledges the financial support from Catron Fellowship.

\section{References}

${ }^{1}$ D. Sordelet and M. Akinc, "Preparation of Spherical, Monosized Yttrium Oxide Precursor Particles," J. Colloid Interface Sci., 122 [1] 47-59 (1988).

${ }^{2}$ B. Aiken, W. P. Hsu and E. Matijevic, "Preparation and Properties of Monodispersed Colloidal Particles of Lanthanide Compounds: III. Yttrium(III) and Mixed Yttrium(III)/Cerium(III) Systems," Journal of the American Ceramic Society, 71 [10] 845-53 (1988).

${ }^{3}$ B. Aiken, W. P. Hsu and E. Matijevic, "Preparation and Properties of Uniform Mixed and Coated Colloidal Particles. Part V. Zirconium Compounds," Journal of Materials Science, 25 [3] 1886-94 (1990).

${ }^{4}$ D. J. Sordelet, M. Akinc, M. L. Panchula, Y. Han and M. H. Han, "Synthesis of Yttrium Aluminum Garnet Precursor Powders by Homogeneous Precipitation," J. Eur. Ceram. Soc., 14 [2] 123-30 (1994).

${ }^{5}$ M. L. Panchula and M. Akinc, "Morphology of Lanthanum Carbonate Particles Prepared by Homogeneous Precipitation," Joumal of the European Ceramic Society, 16 [8] 833-41 (1996).

${ }^{6}$ G. J. d. A. A. Soler-IHlia, R. J. Candal, A. E. Regazzoni and M. A. Blesa, "Synthesis of Mixed Copper-Zinc Basic Carbonates and Zn-Doped Tenorite by Homogeneous Alkalinization," Chem. Mater., 9 [1] 184-91 (1997).

${ }^{7}$ G. J. d. A. A. Soler-Illia, M. Jobbagy, R. J. Candal, A. E. Regazzoni and M. A. Blesa, "Synthesis of Metal Oxide Particles from Aqueous Media: The Homogeneous Alkalinization Method," J. Dispersion Sci. Technol., 19 [2 \& 3] 207-28 (1998).

${ }^{8}$ B. S. Maruthiprasad, M. N. Sastri, S. Rajagopal, K. Seshan, K. R. Krishnamurthy and T. S. R. P. Rao, "A Novel Nickel Trihydroxy Isocyanate - Preparation and Characterization," Proc. - Indian Acad. Sci., Chem. Sci., 100 [6] 459-62 (1988).

${ }^{9}$ M. J. Avena, M. V. Vazquez, R. E. Carbonio, C. P. De Pauli and V. A. Macagno, "A Simple and Novel Method for Preparing $\mathrm{Ni}(\mathrm{OH})_{2}$. Part I: StructuraI Studies and Voltammetric Response," J. Appl. Electrochem., 24 [3] 256-60 (1994). 
${ }^{10}$ M. Dixit, G. N. Subbanna and P. V. Kamath, "Homogeneous Precipitation from Solution by Urea Hydrolysis: A Novel Chemical Route to the $\alpha$-Hydroxides of Nickel and Cobalt," J. Mater. Chem., 6 [8] 1429-32 (1996).

${ }^{11}$ M. Akinc, N. Jongen, J. Lemaitre and H. Hofmann, "Synthesis of Nickel Hydroxide Powders by Urea Decomposition," Journal of the European Ceramic Society, 18 [11] 155964 (1998).

${ }^{12}$ G. J. d. A. A. Soler-Illia, M. Jobbagy, A. E. Regazzoni and M. A. Blesa, "Synthesis of Nickel Hydroxide by Homogeneous Alkalinization. Precipitation Mechanism," Chem. Mater., 11 [11] 3140-46 (1999).

${ }^{13}$ R. C. Warner, "Kinetics of the Hydrolysis of Urea and of Arginine," J. Biol. Chem., 142, 705-23 (1942).

${ }^{14}$ G. J. d. A. A. Soler-Illia, "A Study of $\mathrm{Cu}-\mathrm{Ni}$ and $\mathrm{Cu}-\mathrm{Zn}$ Mixed Oxide Precursors Synthesis by Homogeneous Alkalinization Methods," PhD Thesis. Universidad de Buenos Aires, Buenos Aires, 1998.

${ }^{15}$ R. J. Candal, A. E. Regazzoni and M. A. Blesa, "Precipitation of Copper(II) Hydrous Oxides and Copper(II) Basic Salts," J. Mater. Chem., 2 [6] 657-61 (1992).

${ }^{16}$ D. Forster and D. M. L. Goodgame, "Vibrational Spectra of Pseudohalide Complexes. I. Tetrahedral Isocyanate Complexes," J. Chem. Soc., [Jan.], 262-7 (1965).

${ }^{17}$ T. V. Stupko, V. E. Mironov and G. L. Pashkov, "Temperature Effect on Equilibrium Formations of Metal Ion Complexes with Ammonia in Aqueous Ammonium Sulfate Solutions," Zhurnal Prikladnoi Khimii (Sankt-Peterburg), 71 [7] 1087-90 (1998).

${ }^{18}$ V. Privman, D. V. Goia, J. Park and E. Matijevic, "Mechanism of Formation of Monodispersed Colloids by Aggregation of Nanosize Precursors," Journal of Colloid and Interface Science, 213 [1] 36-45 (1999).

${ }^{19}$ B. A. Barshop, R. F. Wrenn and C. Frieden, "Analysis of Numerical Methods for Computer Simulation of Kinetic Processes: Development of KINSIM - a Flexible, Portable System," Analytical Biochemistry, 130, 134-45 (1983).

${ }^{20}$ W. T. Lindsay, Jr., "Estimation of Concentration Quotients for Ionic Equilibriums in High Temperature Water: The Model Substance Approach," Proc. - Int. Water Conf., Eng. Soc. West. Pa., 41, 284-94 (1980). 
${ }^{2 \mathrm{~L}}$ L. D. Pettit, "Ionic Strength Corrections Using Specific Interaction Theory, v. 1.2" OIUPAC, 2002.

${ }^{22}$ G. S. Kell, "Density, Thermal Expansivity, and Compressibility of Liquid Water from $0^{\circ}$ to $150^{\circ}$. Correlations and Tables for Atmospheric Pressure and Saturation Reviewed and Expressed on 1968 Temperature Scale," J. Chem. Eng. Data, 20 [1] 97-105 (1975).

${ }^{23}$ W. H. R. Shaw and J. J. Bordeaux, "The Decomposition of Urea in Aqueous Media," J. Am. Chem. Soc. , 77, 4729-33 (1955).

${ }^{24}$ W. J. Svirbely and J. C. Warner, "The Critical Increment of Ionic Reactions. Influence of Dielectric Constant and Ionic Strength," J. Am. Chem. Soc., 57, 1883-6 (1935).

${ }^{25}$ M. B. Jensen, "Kinetics of the Decomposition of Cyanic Acid," Acta Chem. Scand., 12 1657-70 (1958).

${ }^{26}$ M. W. Lister, "Cyanic Acid and Cyanates," Can. J. Chem., 33, 426-40 (1955).

${ }^{27}$ A. J. Belsky and T. B. Brill, "Spectroscopy of Hydrothermal Reactions. 14. Kinetics of the pH-Sensitive Aminoguanidine-Semicarbazide-Cyanate Reaction Network," J. Phys. Chem. A, 103 [39] 7826-33 (1999).

${ }^{28} \mathrm{M}$. B. Jensen, "Kinetics of the Decomposition of Cyanic Acid. M. Carbonate Catalysis," Acta Chem. Scand., 13, 659-64 (1959).

${ }^{29}$ W. L. Marshall and E. U. Franck, "Ion Product of Water Substance, 0-1000 ${ }^{\circ} \mathrm{C}$, 110,000 Bars, New International Formulation and Its Background," J. Phys. Chem. Ref. Data, 10 [2] 295-304 (1981).

${ }^{30}$ R. E. Mesmer, W. L. Marshall, D. A. Palmer, J. M. Simonson and H. F. Holmes, "Thermodynamics of Aqueous Association and Ionization Reactions at High Temperatures and Pressures," J. Solution Chem., 17 [8] 699-718 (1988).

${ }^{31}$ S. Nam Park, C. Shik Kim, M. Hwa Kim, I.-J. Lee and K. Kim, "Spectrophotometric Measurement of the First Dissociation Constants of Carbonic Acid at Elevated Temperatures," J. Chem. Soc., Faraday Trans., 94 [10] 1421-25 (1998).

${ }^{32}$ S. Park, H. Kim, K. Kim, J. Lee and D.-s. Lho, "Spectroscopic Measurement of the Acid Dissociation Constant of 2-Naphthol and the Second Dissociation Constant of Carbonic Acid at Elevated Temperatures," Phys. Chem. Chem. Phys., 1 [8] 1893-98 (1999). 
${ }^{33}$ D. D. Perrin, Chemical Data Series, No. 29: Ionization Constants of Inorganic Acids and Bases in Aqueous Solution, 2nd Edition. Pergamon Press, New York, 1982.

${ }^{34} \mathrm{H}$. Wallner, W. Preis and H. Gamsjager, "Solid-Solute Phase Equilibria in Aqueous Solutions XV [1]. Thermodynamic Analysis of the Solubility of Nickel Carbonates," Thermochimica Acta, 382 [1-2] 289-96 (2002).

${ }^{35}$ L. D. Pettit and K. J. Powell, "Stability Constants Database - ScQuery, v. 5.15" IUPAC, 2001.

${ }^{36}$ D. D. Wagman, W. H. Evans, V. B. Parker, R. H. Schumm, I. Halow, S. M. Bailey, K. L. Churney and R. L. Nuttall, Joumal of Physical and Chemical Reference Data, Vol. 11, Suppl. No. 2: The NBS Tables of Chemical Thermodynamic Properties. Selected Values for Inorganic and CI and C2 Organic Substances in SI Units. American Chemical Society and the American Institute of Physics for the National Bureau of Standards, New York, 1982.

${ }^{37}$ F. Boulc'h, M.-C. Schouler, P. Donnadieu, J.-M. Chaix and E. Djurado, "Domain Size Distribution of Y-TZP Nanoparticles Using XRD and HRTEM," Image Analysis \& Stereology, 20 [3] 157-61 (2001).

${ }^{38}$ J. C. Warner and E. L. Warrick, "Kinetic Medium and Salt Effects in Reactions between Ions of Unlike Sign. Reaction between Ammonium Ion and Cyanate Ion," J. Am. Chem. Soc., 57, 1491-5 (1935).

${ }^{39}$ W. J. Svirbely and S. Peterson, "The Rate of Conversion of Ammonium Cyanate to Urea in Nonaqueous Solvents. Vi," J. Am. Chem. Soc., 65, 166-70 (1943).

${ }^{40}$ A. A. Frost and R. G. Pearson, Kinetics and Mechanism - a Study of Homogeneous Chemical Reactions, 2nd Edition. John Wiley \& Sons, Inc., New York, 1961.

${ }^{41}$ E. A. M. Hughes, The Chemical Statics and Kinetics of Solutions. Academic Press Inc., London, 1971.

${ }^{42}$ N. Wen and M. H. Brooker, "Rate Constants for Cyanate Hydrolysis to Urea: A Raman Study," Can. J. Chem., 72 [4] 1099-106 (1994).

${ }^{43}$ A. Delahaye-Vidal and M. Figlarz, "Textural and Structural Studies on Nickel Hydroxide Electrodes. II. Turbostratic Nickel(II) Hydroxide Submitted to Electrochemical Redox Cycling," J. Appl: Electrochem., 17 [3] 589-99 (1987). 
${ }^{44}$ F. Portemer, A. Delahaye-Vidal and M. Figlarz, "Characterization of Active Material Deposited at the Nickel Hydroxide Electrode by Electrochemical Impregnation," $J$. Electrochem. Soc., 139 [3] 671-8 (1992).

${ }^{45}$ J. J. Braconnier, C. Delmas, C. Fouassier, M. Figlarz, B. Beaudouin and P. Hagenmuller, "A Novel Nickel(II) Hydroxide Obtained by Soft Chemistry," Rev. Chim. Miner, 21 [4] 496-508 (1984).

${ }^{46} \mathrm{~B}$. D. Cullity, Elements of X-Ray Diffraction, 2nd Edition. Addison-Wesley Publishing Company, Inc, Reading, 1978.

${ }^{47}$ D. A. Skoog, D. M. West and F. J. Holler, Fundamentals of Analytical Chemistry, 7th Edition. Harcourt Inc, Orlando, 1997.

${ }^{48}$ M. Rajamathi, P. V. Kamath and R. Seshadri, "Chemical Synthesis of $\alpha$-Cobalt Hydroxide," Materials Research Bulletin, 35 [2] 271-78 (2000).

${ }^{49} \mathrm{~A}$. Widjaja, "Synthesis and Characterization of Nickel Hydroxide Powders for Battery Applications," M.Sc. Thesis. Iowa State University, Ames, 1997.

${ }^{50}$ I. Yazdi, "Synthesis and Electrochemical Studies of Cobalt Substituted Nickel Hydroxide for Battery Applications," M.Sc. Thesis. Iowa State University, Ames, 1999.

${ }^{51}$ K. P. Yoo, S. Y. Lee and W. H. Lee, "Ionization and Henry's Law Constants for Volatile, Weak Electrolyte Water Pollutants," Korean Journal of Chemical Engineering, 3 [1] 67-72 (1986). 


\title{
INTERCALATING SPECIES IN THE HOMOGENEOUS PRECIPITATION OF NICKEL HYDROXIDES
}

\author{
A paper to be submitted to Materials Chemistry and Physics
}

Bora Mavis and Mufit Akinc

\begin{abstract}
$\alpha-\mathrm{Ni}(\mathrm{OH})_{2}$ and $\mathrm{Ni}-\mathrm{Al}$ layer double hydroxides (LDHs) precipitated by urea were investigated with FTIR and XPS. The role of cyanate (CNO), an intermediate in urea decomposition, in nucleation and growth of precipitates is demonstrated. In the early stages, cyanate ion in $\alpha-\mathrm{Ni}(\mathrm{OH})_{2}$ 's is found mainly to be $\mathrm{N}$-bonded to $\mathrm{Ni}^{2+}$ ions in the layers, whereas later in the growth stages, it is bonded through oxygen. In LDHs cyanate remains $\mathrm{N}$ bonded. Precipitation with substituted ureas, revealed the link between spectral features and structures observed in XRD patterns. With slower decomposition rates and low levels of supersaturation an extensively hydrated structure was observed. Effects of experimental parameters, like mixing level, pressure and digestion time were discussed.
\end{abstract}

\section{Introduction}

Hydroxide precursors of $\mathrm{NiO}$ can be used in rechargeable batteries and are prepared from aqueous solutions. $\mathrm{Ni}(\mathrm{OH})_{2}$ is the common positive electrode for nickel based alkaline secondary batteries. 'It has two polymorphic forms, $\beta$ and $\alpha$. Beta phase exhibits closely packed brucite type layers in which $\mathrm{Ni}^{2+}$ is in the center of hydroxyl octahedra, whereas $\alpha$ phase exhibits larger layer separations afforded by the intercalation of water and anions. ${ }^{2}$ of the two phases, $\alpha$ has been the main point of interest. A higher specific capacity is anticipated in $\alpha$ because the intercalated species can actively participate in the electrode reaction or provides easy access to redox species. However, stability of $\alpha$ against transformation into $\beta$ in its strongly alkaline electrolyte (generally $6 \mathrm{M} \mathrm{KOH}$ ) during cycling or storage has been a long-lasting problem. ${ }^{1,3,4}$ 
Urea decomposition at temperatures above $60^{\circ} \mathrm{C}$ has been widely applied to produce various precursors for mixed metal oxides..$^{5-7}$ Homogeneous precipitation forced by urea decomposition in solutions containing $\mathrm{Ni}^{2+}$ ions has been observed to yield $\alpha-\mathrm{Ni}(\mathrm{OH})_{2}{ }^{8-17}$ Nevertheless the product suffers from the same phase instability in alkaline solutions. The intercalating species besides water were found to be either cyanate (intermediate decomposition product) or carbonaceous species. ${ }^{11,14,17-19}$

Layer double hydroxides (LDHs) are a class of intercalation compounds that could be

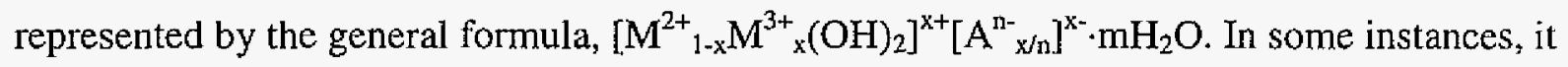
was reported that $\alpha$-phase could be stabilized, at least against ageing, by trivalent cations that substitute for some of the $\mathrm{Ni}^{2++}$ ions. Substitution of trivalent cations (such as $\mathrm{Al}^{3+}, \mathrm{Cr}^{3+}, \mathrm{Co}^{3+}$, $\mathrm{Mn}^{3+}$ and $\mathrm{Fe}^{3+}$ ), creates a positive charge in the sheets and insertion of hydrated anions between the layers is believed to compensate this extra charge. ${ }^{20-23}$ Stabilization of $\alpha$ $\mathrm{Ni}(\mathrm{OH})_{2}$ and related compounds with the trivalent cations should be investigated under this class of materials, i.e. LDHs. ${ }^{24}$ Costantino et al. had investigated the potential of urea hydrolysis for producing $\mathrm{LDHs}$ with $\mathrm{Mg}-\mathrm{Al}, \mathrm{Ni}-\mathrm{Al}$ and $\mathrm{Zn}-\mathrm{Al}$ systems and reported that the powders from $\mathrm{Mg}$-Al were crystallized well enough for a Rietveld refinement ${ }^{25}$. However, they assumed that all the intercalated species would be water and carbonate, and did not provide any spectroscopic evidence. Here we will elaborate on spectral features observed in $\alpha-\mathrm{Ni}(\mathrm{OH})_{2}$ and $\mathrm{LDH}$ produced by urea decomposition.

Soler-Illia et al. mentioned presence of cyanate ion in the precipitates. ${ }^{7}$ From their urea hydrolysis model, which did not include metal ions, they deduced that there is an accumulation of cyanate in the initial stages of hydrolysis. A more comprehensive model, which includes $\mathrm{Ni}^{2+}$ leading to precipitation, hydrolysis and complexation reactions, is necessary for complete description of precipitation process. Indeed, we have shown that Nicyanate complexes were the dominant species before nucleation. ${ }^{18,19}$

Cyanate in metal-cyanate complexes was generally reported to be $\mathrm{N}$-bonded to the metal. ${ }^{26-31}$ Foster et al. studied nickel isocyanate complexes and reported an intense peak at $2186 \mathrm{~cm}^{-1}$ with a shoulder at $2237 \mathrm{~cm}^{-1}$. 30 This combined with our observation of an intense peak at $2250 \mathrm{~cm}^{-1}$ with a low wavenumber shoulder for the $\alpha$-phase and an intense peak at $\approx 2186 \mathrm{~cm}^{-1}$ with a high wavenumber shoulder for the LDHs was intriguing. Carbacho et al. 
reported an interesting change in the position of this shoulder in the nickel thiocyanate complexes. $^{32}$ As the thiocyanate moves from nitrogen (M-NCS) to sulphur (M-SCN) and then to bridged coordinations, a shift of the intense side of the $\mathrm{C}-\mathrm{N}$ stretch to the higher wavenumbers was observed by $30-40,50-70$ and $70-120 \mathrm{~cm}^{-1}$, respectively. This observation was interesting as it leads to the assumption that cyanate ion should be oxygen bonded to $\mathrm{Ni}^{2+}$ in $\alpha-\mathrm{Ni}(\mathrm{OH})_{2}$ precipitates. Recently, Yang et al. studied the adsorption of cyanate on $\mathrm{Ni}(100)$ surfaces with ab-initio methods. ${ }^{33,34}$ They considered energetics of $\mathrm{N}$ - and $\mathrm{O}$-bonded geometries on 3 different surface sites. Using their assignments, we will demonstrate how the deconvolution of the $\mathrm{C}-\mathrm{N}$ absorption peak reveals information about cyanate bonding geometries in $\alpha-\mathrm{Ni}(\mathrm{OH})_{2}$ and LDHs.

Shaw et al. studied decomposition of methylated thioureas and methylurea. ${ }^{35,36}$ They related the measured differences in the rate constants to methyl substitutions. In general, the mechanism of thiourea decomposition followed similar paths to that of urea except that the intermediate was thiocyanate $\left(\mathrm{SCN}^{-}\right)$. When a methyl group replaced one or more hydrogen atoms, of the two possible pathways the one that includes the formation of isocyanic acid and methylamine was more frequently seen. As a general trend, the elimination reactions with thioureas that have "asymmetric" substitutions (monomethyl, trimethyl or 1,1 -dimethyl) proceeded faster than the ones with "symmetric" substitutions (1,3-dimethyl). In an effort to mimic the effect of enzyme urease by compounds that has similar dinuclear metal centers, Barrios and Lippard decomposed methyl-substituted ureas on their relatively simple dinuclear nickel center. ${ }^{37}$ They observed the elimination of methylamine in cases where the substrates having methyl substitutions on only one of the urea nitrogen atoms which was consistent with Shaw et al's interpretation. Current work also describes the use of alkylsubstituted ureas in probing the intercalating species and their bonding modes with the layer cations. 


\section{Experimental Method}

\section{Powder Synthesis}

\section{Homogeneous Precipitation}

All chemicals used in this study were reagent grade and used without further purification. Precipitation of nickel hydroxide by urea decomposition was carried out as described previously. ${ }^{18,19,38} 5.9428 \mathrm{~g} \mathrm{NiCl}_{2} \cdot 6 \mathrm{H}_{2} \mathrm{O}$ (Fisher Scientific) was dissolved in $190 \mathrm{~mL}$ deionized water and preheated at $90 \pm 1{ }^{\circ} \mathrm{C}, 30.0300 \mathrm{~g}$ urea (Fisher Scientific) was dissolved in $60 \mathrm{~mL}$ deionized water and added to the preheated $\mathrm{Ni}^{2+}$ solution. Concentrations of $\mathrm{Ni}^{2+}$ and urea in the resulting solution correspond to 0.1 and $2.0 \mathrm{M}$ respectively. Sample aliquots were withdrawn at various digestion times from the middle of the stirred solution. Precipitates were separated from the mother liquor by an in-line filter, washed three times and saved for further analysis after drying at $70{ }^{\circ} \mathrm{C}$. Solution $\mathrm{pH}$ was monitored (within \pm 0.02 units) continuously. A similar procedure was also followed for the Ni-Al layer double hydroxide synthesis employing $0.075 \mathrm{M} \mathrm{Ni}^{2+}$ and $0.025 \mathrm{M} \mathrm{Al}^{3+}$ (Al source: $\mathrm{AlCl}_{3} \cdot 6 \mathrm{H}_{2} \mathrm{O}$, Fisher Scientific) solution. These samples from the solutions that have only $\mathrm{Ni}^{2+}$ and the ones that have both $\mathrm{Ni}^{2+}$ and $\mathrm{Al}^{3+}$ will be named as $\alpha$-[time] and $\mathrm{LDH}$-[time], respectively. Here, [time] represents the length of digestion time before the sample was withdrawn from the solution.

In order to monitor the effects of deintercalation process during $\alpha-\beta$ transformation, $\alpha$ [2hrs] was aged in $6 \mathrm{M} \mathrm{KOH}$ for 1 week. Due to almost complete transformation to $\beta$ phase that occurred in this sample (retaining only some of the intercalating species), a $5 \% \mathrm{Co}^{2+}$

doped $\alpha$-[2hrs] sample from a concurrent work will be included in this study. ${ }^{38,39}$ This sample showed an intermediate amount transformation upon 1 week of ageing. Here it will be named as $5 \mathrm{Co}-\alpha[2 \mathrm{hrs}]$ and it was precipitated under conditions described above with initial $\mathrm{Ni}^{2+}$ and $\mathrm{Co}^{2++}$ concentrations of 0.095 and $0.005 \mathrm{M}$, respectively.

Precipitation experiments with alkyl-substituted ureas were conducted at $90^{\circ} \mathrm{C}$ in a water bath with rigorous shaking. Monomethyl urea (MMU, Aldrich Chemical Company), 1,1dimethyl urea (N,N-DMU, Alfa Aesar), 1,1'-dimethyl urea, (N,N'DMU, Sigma) and Tetramethyl urea (TMU, Aldrich Chemical Company) were employed as precipitating agent. 
Total volume in these experiments was adjusted to $100 \mathrm{~mL}$. Since solubilities of methylsubstituted ureas in water were lower than that of urea, their concentrations were adjusted to $0.9 \mathrm{M}$. Longer digestion times were employed to collect sufficient sample for analysis, i.e. 5 hrs, 4 hrs and 8 hrs for MMU, N,NDMU and N,N'DMU, respectively. TMU produced no precipitation even after 28 hours of digestion.

Effect of counter anion on the morphology was assessed by employing $\mathrm{Ni}\left(\mathrm{NO}_{3}\right)_{2} \cdot 6 \mathrm{H}_{2} \mathrm{O}$ (Fisher Scientific) and solutions were rigorously shaken to determine the role of stirring on particle morphology.

\section{Heterogeneous Precipitation}

For these experiments total metal ion concentrations in the solutions were again fixed at $0.1 \mathrm{M}$. Reagents were dispensed at a rate of $0.45 \mathrm{~mL} / \mathrm{min}$ at $25^{\circ} \mathrm{C}$. $\mathrm{NaOH}, \mathrm{NaOCN}$ and $\mathrm{Na}_{2} \mathrm{CO}_{3}$ were used as anion source. Separation, washing and drying of precipitate remained same as in homogeneous precipitation experiments.

\section{Characterization}

FTIR analyses were conducted in transmission mode with $\mathrm{KBr}$ pellets. Spectra from the $4000-400 \mathrm{~cm}^{-1}$ range were recorded in a Bomem - Hartmann and Braun - MB 102 unit with $4 \mathrm{~cm}^{-1}$ resolution. $\mathrm{KBr}$ pellets were prepared by mixing $0.70-0.75 \mathrm{wt} \%$ ground powder into $\mathrm{KBr}$ matrix and pressed to $80 \mathrm{MPa}$ with an evacuable die. Pure $\mathrm{KBr}$ was used as the reference. Quantitative comparison of spectra was not practical due to inability to match sample masses exactly. In more than one instance, we were able to deconvolute cyanate peak around $2200 \mathrm{~cm}^{-1}$ to assign specific coordination modes of those species. In such cases, ratio of integrated peak areas was used to estimate the relative populations of specific modes. Possible interaction between $\mathrm{K}^{+}$and the anionic species, especially the cyanate was taken into consideration. In order to judge whether various split bands were due to Fermi resonance (FR), attempts were also made to take Raman spectra of the samples. However samples burned when exposed to laser beam.

X-ray photoelectron spectra (XPS) were acquired using a Physical Electronics 5500 Multitechnique spectrometer with monochromatic $\mathrm{Al}$ and standard $\mathrm{Mg} / \mathrm{Al}$ sources. Analysis spot size could be varied from $1 \times 0.8 \mathrm{~mm}$ to $0.4 \times 0.4 \mathrm{~mm}$ with energy resolution of less than 
$0.50 \mathrm{eV}$ FWHM. Powders were sprinkled on double-sided adhesive tapes in a preparation chamber after they were dried at $70^{\circ} \mathrm{C}$ in a vacuum oven $(\approx 0.4 \mathrm{mmHg})$ for 12 hours. All chambers were monitored by RGA for vacuum quality control. The base pressure for the analyzer system was less than $3 \times 10^{-10}$ Torr. In order to compensate for charging effects, the photoelectron spectra were calibrated using the $\mathrm{C} 1 \mathrm{~s}$ binding energy of the adventitious carbon at $285.0 \mathrm{eV}^{40}$ For better assignment of certain peaks, besides literature references, XP spectra from $\mathrm{NaOCN}, \mathrm{AgOCN}, \beta-\mathrm{Ni}(\mathrm{OH})_{2}$ (Aldrich Chemical Company) and $\mathrm{Na}_{2} \mathrm{CO}_{3}$, $\mathrm{NaHCO}_{3}$ (Fisher Scientific) were also recorded.

Further analysis on FTIR and XPS data was carried out using PeakFit (Version 4.11, SYSTAT Software Inc.) software, which is capable of smoothing, background subtraction and peak deconvolution. For most cases a Gaussian-Lorentzian (Amplitude) summation function was sufficient to describe the peaks. A fit was accepted only when an $r^{2}$ value of at least 0.999 was reached. This procedure was generally preceded by a non-parametric digital filtering and a linear or cubic background subtraction.

Bulk Carbon, Nitrogen and Hydrogen contents of the precipitated powders were determined using a Perkin Elmer Series II CHNS/O 2400 analyzer. Each analysis represents average of three measurements. Once the assignments of peaks in FTIR and XPS were established, the XPS peak intensities of Nitrogen and Carbon containing species were used to qualitatively investigate the changes in surface concentrations these species with time. Qualitative comparison to bulk concentrations was possible by normalizing each data set with the highest concentration detected among them.

A powder X-ray diffraction (Scintag X1-365) unit with $\mathrm{Cu}-\mathrm{K} \alpha$ radiation was used for structural characterization. For crystallite size determinations, instrumental broadening of the peaks was accounted for by correcting the FWHM (full width at half maximum) values with that of the crystalline silicon reference. ${ }^{41}$ Turbostratic character of the layers relative to each other was judged by comparing the asymmetric peak between $30^{\circ}$ and $55^{\circ} 2 \theta$. Powder morphology was studied with SEM (Hitachi S-2460N VP-SEM). Specific surface area of powders was measured with 11-point BET method after outgasing the sample at $100{ }^{\circ} \mathrm{C}$ for 12 hours (Quantachrome Autosorb - 1). 


\section{Results}

\section{FTIR and XRD}

Particular significance of cyanate ion in precipitation of $\alpha-\mathrm{Ni}(\mathrm{OH})_{2}$ was recognized earlier. ${ }^{18,19,38}$ Figure 1 shows the FTIR spectra taken from $\alpha$-[2hrs] compared to that of $\beta$ $\mathrm{Ni}(\mathrm{OH})_{2}$ and $\mathrm{LDH}-[2 \mathrm{hrs}]$ and illustrates the significant differences among the three.

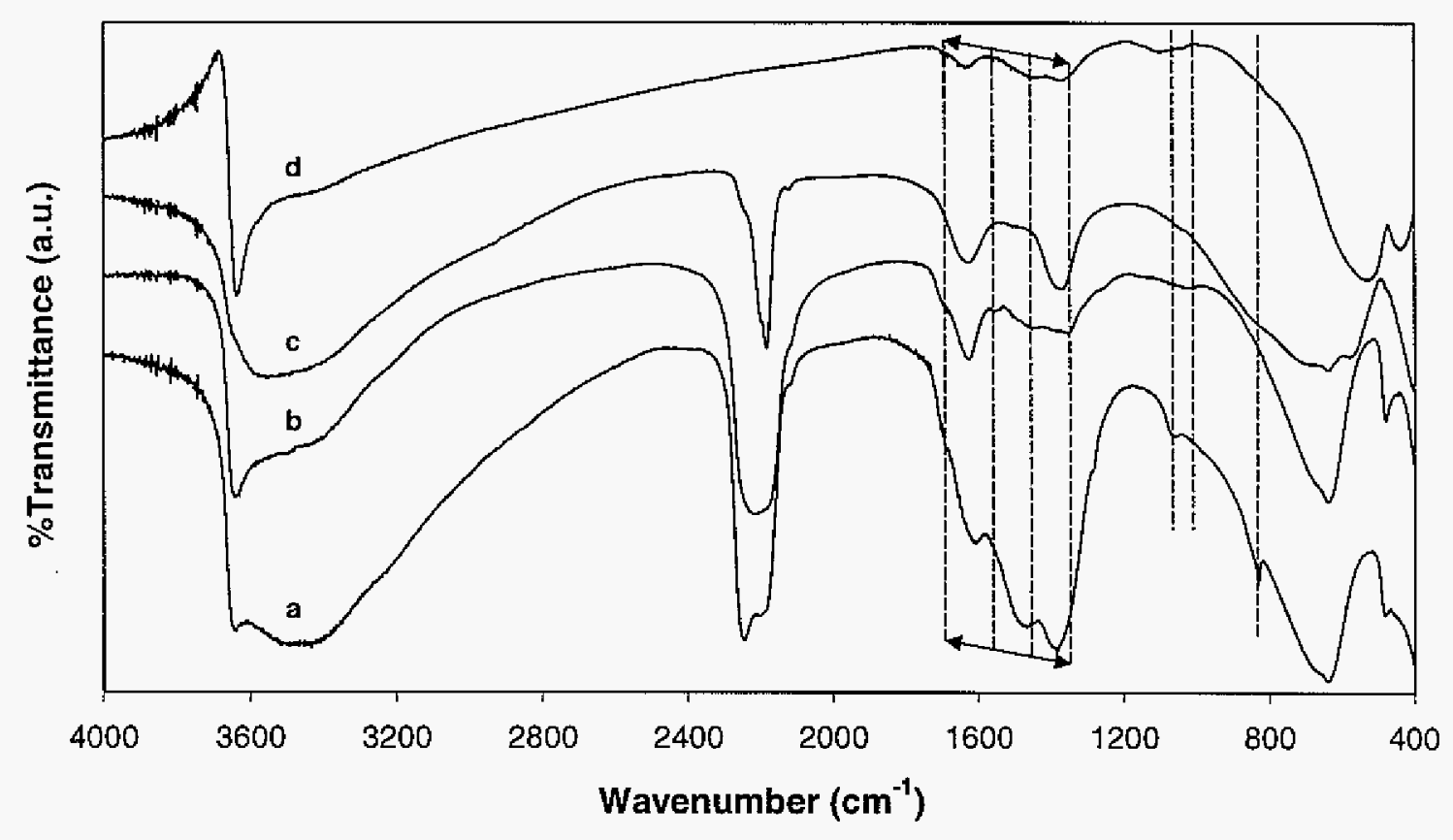

Figure 1. FTIR spectra of a. $\alpha$-[2hrs] (shaken), b. $\alpha$-[2hrs] (stirred), c. LDH-[2hrs] and d. $\beta$ $\mathrm{Ni}(\mathrm{OH})_{2}$ (Aldrich Chemical Company). Important ranges are either individually marked or taken into boundaries.

Sharp peak at $\approx 3640 \mathrm{~cm}^{-1}$, is a distinct feature of $\beta$ phase, which is attributed to hydroxyl stretching in a highly ordered brucite structure that does not permit hydrogen bonding across the layers. Absorption peaks at 530 and $440-470 \mathrm{~cm}^{-1}$ are due to in-plane $O H$ deformations and Ni-O lattice stretch, respectively. ${ }^{2,4,42}$ Under normal conditions $\beta$-phase spectrum should show no other distinct features, however for this sample we observe absorption in the 1600 and 1350-1450 $\mathrm{cm}^{-1}$ range due to water and carbonate related species. These are probably due to surface adsorption. Figure $2 \mathrm{~A}$ shows XRD pattern of $\beta-\mathrm{Ni}(\mathrm{OH})_{2}$. Although it shows no sign of "interstratification" ( $\alpha-\beta$ phase mixture), its presence can not be excluded. The 
relatively high electrochemical capacity measured for this sample supports presence of slight interstratification claim. ${ }^{38,39}$

Intercalated species, especially water, cause extensive hydrogen bonding which shows up as the broad band covering $3640-3300 \mathrm{~cm}^{-\mathrm{I}}$ region of the FTIR spectrum (e.g. OH stretching of intercalated and hydrogen bonded or adsorbed water, hydrogen bond formation between the layer hydroxyl and intercalating species, adsorption of intercalating species on hydroxyl terminated crystallite surfaces or hydroxyl group containing species like $\left.\mathrm{HCO}_{3}{ }^{-}\right)^{4,42,43}$ Both $\alpha$-[2hrs] (shaken) and LDH-[2hrs] show this typical feature, while $\alpha$-[2hrs] (stirred) shows a weak absorption around $3400 \mathrm{~cm}^{-1}$. Hydrogen bonding that hinders the in-plane $\mathrm{OH}$ deformations causes a shift to higher frequencies (530 to $580-700 \mathrm{~cm}^{-1}$ ), which is another well-established evidence for the existence of $\alpha$ structure. ${ }^{4,44}$ In $\alpha$-[2hrs] samples this displays itself as the broadening of an otherwise sharp peak around $630-640 \mathrm{~cm}^{-1}$, which is assigned to the Nitrogen bonded cyanate deformations $-\delta(\mathrm{NCO})$ and will be discussed later in this section. Another indication of intercalated water is the $\mathrm{H}-\mathrm{O}-\mathrm{H}$ bending mode observed between $1600-1650 \mathrm{~cm}^{-1}$. Upon coordination to metal ions or association to anions, this mode that is usually observed around $1600 \mathrm{~cm}^{-1}$ can be split, broaden or exhibit a shoulder on the high wavenumber side. ${ }^{31,45}$ This can be observed in all samples, which furthermore supports the fact that both $\alpha$ and LDH's produced in this study are highly hydrated.

The sharp peak situated around $2200 \mathrm{~cm}^{-1}$ has been assigned to $\mathrm{C}-\mathrm{N}$ stretch of $\mathrm{OCN}^{-}$ion by previous authors who studied precipitation of nickel hydroxide with urea. ${ }^{11,14,17}$ Although we do not dispute this assignment, different "splitting and shoulder" features observed in different samples raise questions about their origin and was not addressed in the cited work above. It is known that $v(\mathrm{CN})$ stretches are highly active in $\mathrm{IR}$ region and result in intense and sharp peaks. ${ }^{45}$ Although its intensity can not be used for quantifying cyanate content, it provides distinct signature for labeling of cyanate containing compounds. ${ }^{46}$ Probable trends in components of this peak will be discussed in detail in light of other results. The broad peak around $620-720 \mathrm{~cm}^{-1}$ was partially assigned to shifted in-plane $\mathrm{OH}$ deformations. Various metal-NCO complexes and free $\mathrm{OCN}^{-}$ion (in $\mathrm{KNCO}$ ) have been observed to have sharp peaks at $\approx 620$ and $630 \mathrm{~cm}^{-1}$, respectively. ${ }^{30,31,45}$ Throughout this study, when the $O \mathrm{ON}^{*}$ was missing (in $\alpha$-phases precipitated by heterogeneous precipitation or diminishing during 
transformation to $\beta$-phase (Figure 2B)), the sharp protrusion at $630-640 \mathrm{~cm}^{-1}$ disappeared. Therefore, assigning this region only to in-plane $\mathrm{OH}$ deformations and extensive hydrogen bonding will not be accurate. As will be discussed later, bicarbonate or carbonate species can also have a contribution to the high wavenumber end of this broad peak. It is also worth mentioning here that relatively weaker pseudo-symmetric stretching of $\mathrm{C}-\mathrm{O}$ bond of cyanate in metal cyanate complexes that was reported by Forster et al. and Tsintsadze et al. at 1330 and $1318 \mathrm{~cm}^{-1}$, respectively, was not observed in any spectra given in Figure $1{ }^{30,31}$ However, it can be observed from Figure $2 \mathrm{~B}$ that it was actually hidden under the carbonate related peak covering the $1300-1500 \mathrm{~cm}^{-1}$ region. This missing feature became apparent as a shoulder upon removal of the carbonaceous intercalation species or upon vacuum drying. A considerable shift (by $\approx 100 \mathrm{~cm}^{-1}$ with respect to the reference compounds' at $\approx 1200 \mathrm{~cm}^{-1}$ ) in this mode towards high wavenumbers is generally taken as an evidence of nitrogen bonding to the metal ion. ${ }^{31}$ Although the vacuum dried sample shows a peak at $1267 \mathrm{~cm}^{-1}$ even more distinctly, one should be cautious about attributing this one only to cyanate. It may also be assigned to bidentate carbonate, which shows a peak at $1265-1284 \mathrm{~cm}^{-1}$. Obviously, coordination modes of cyanate is far from being well understood and requires further study.

Carbonaceous species given in Figure 1 have slightly different signatures that are important for our discussion. In Figure 3, free carbonate ion $\left(\mathrm{D}_{3 \mathrm{~h}}\right)$ (a.k.a. tridentate) and the two of its possible coordinations, unidentate $\left(\mathrm{C}_{\mathrm{s}}\right)$ and bidentate $\left(\mathrm{C}_{2 \mathrm{v}}\right)$, are schematically shown. ${ }^{45}$

Tridentate or hydrogen bonded (either to the basal planes or intercalated water molecules) carbonate is generally seen in LDHs owing to its stronger interaction with the hydroxide layer. $^{47}$ It manifests itself as a single peak around $1380 \mathrm{~cm}^{-1}$ and as extensive hydrogen bonding at around $3500 \mathrm{~cm}^{-1}$. Unidentate and bidentate coordinations are generally characterized by the splitting of the degenerate vibrations $\left(\mathrm{v}_{\mathrm{C}=\mathrm{O}}\right)$. For a Co (III) carbonato complex, splitting for unidentate (at 1453 and $1373 \mathrm{~cm}^{-1}$ ) was smaller than in bidentate (at 1593 and $1265 \mathrm{~cm}^{-1}$ ). From the other modes the one at $\approx 678 \mathrm{~cm}^{-1}$ was observed for both coordinations at similar wavenumbers, while $1070 \mathrm{~cm}^{-1}$ and $1030 \mathrm{~cm}^{-1}$ were observed in 

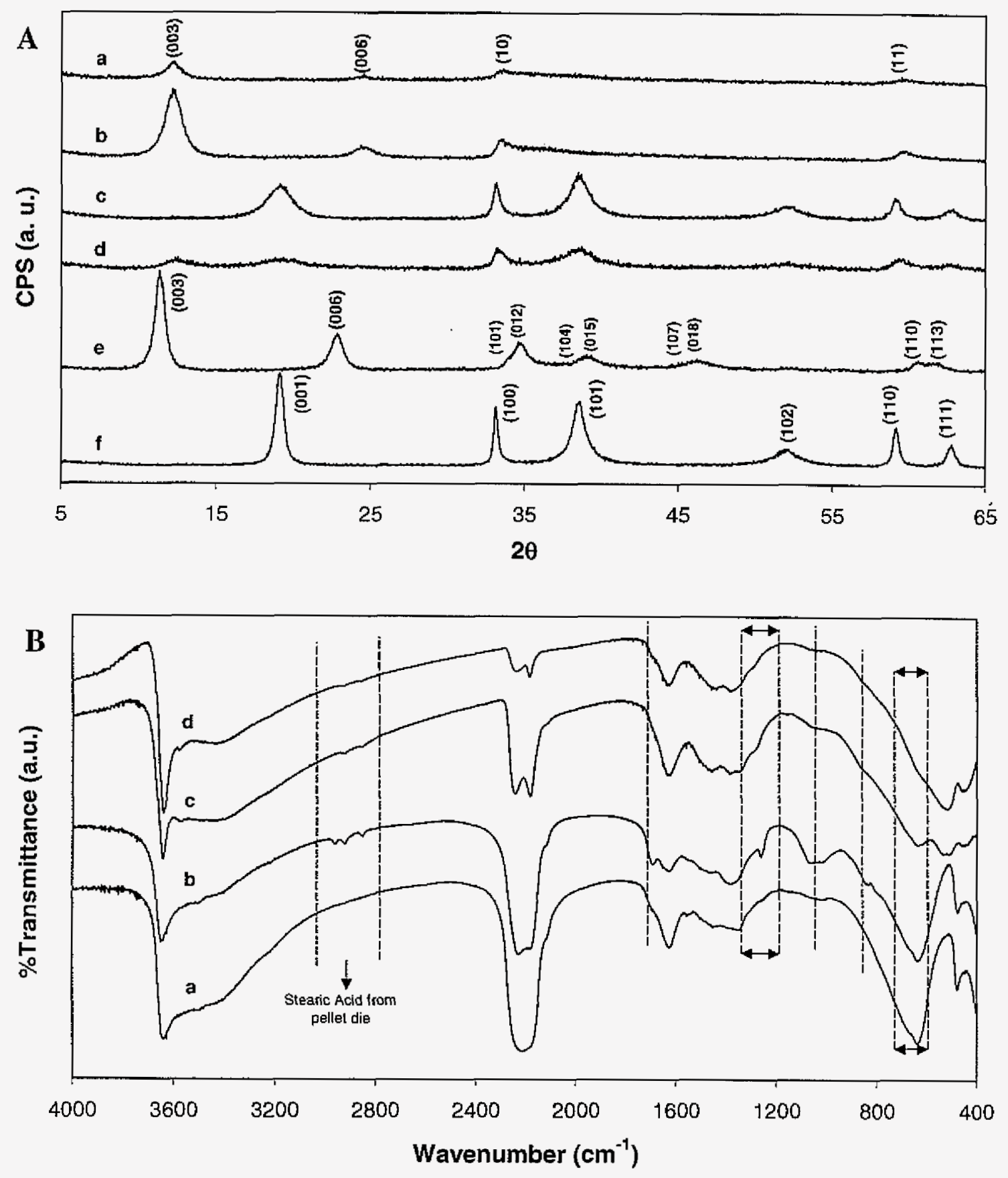

Figure 2. A. XRD Patterns from a. $\alpha$-[2hrs] (shaken), b. $\alpha$-[2hrs] (stirred), c. $\alpha-[2 h r s]$ (aged/mostly transformed to $\beta$ ), d. $5 \mathrm{Co}-\alpha-[2 \mathrm{hrs}]$ (aged/partially transformed to $\beta$ ), e. LDH[2hrs] and f. $\beta$-Ni $(\mathrm{OH})_{2}$. Each peak in representative patterns from $\alpha, \beta$ and LDH is marked with their indices. B. FTIR spectra of a. $\alpha$-[2hrs] (stirred), b. $\alpha$-[36hrs] (stirred/dried in a vacuum oven at $70^{\circ} \mathrm{C}$ for 12 hours), c. $5 \mathrm{Co}-\alpha$-[2hrs] (aged/partially transformed to $\beta$ ), d. $\alpha$ [2hrs] (aged/mostly transformed to $\beta$ ). 


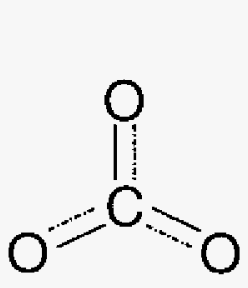

A

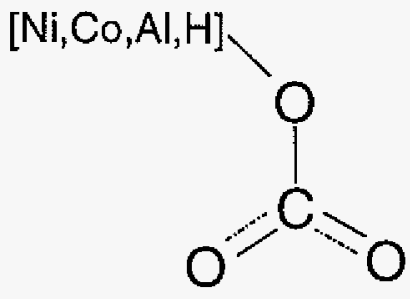

B

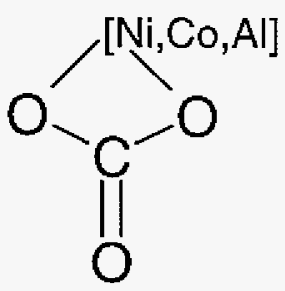

C

Figure 3. Schematic representations of carbonate coordinations. A. Free ion $\left(D_{3 \mathrm{~h}}\right), \mathbf{B}$. Unidentate $\left(C_{s}\right)$, C. Bidentate $\left(C_{2 v}\right){ }^{45}$

unidentate and bidentate, respectively. Out of plane bending $(\pi)$ for unidentate was at 850 $\mathrm{cm}^{-1}$ and for bidentate at $834 \mathrm{~cm}^{-1} \cdot{ }^{17,45}$ Looking at Figure 1, $\alpha$ [2hr] (shaken) exhibits these modes roughly between $1300-1600 \mathrm{~cm}^{-1}, 1040-1150 \mathrm{~cm}^{-1}, 820-870 \mathrm{~cm}^{-1}$ and as a broadening factor on the high wavenumber side of $640 \mathrm{~cm}^{-1}$ peak of cyanate. Although the carbonate concentration appears to be relatively low in the $\alpha-\left[2 \mathrm{hr}\right.$ ] (stirred) sample, the $1300-1600 \mathrm{~cm}^{-1}$ features remain similar with the added fact that absorption at $\approx 1580 \mathrm{~cm}^{-1}$ and a shoulder around $1680 \mathrm{~cm}^{-1}$ appear, signaling the possibility of bridging and bidentate coordinations. ${ }^{45}$ In addition, the maximum of $1040-1150 \mathrm{~cm}^{-1}$ peak shifts to lower wavenumbers and $820-870$ $\mathrm{cm}^{-1}$ is too week to be observable. However, this peak was seen in vacuum oven dried sample at $\approx 850$ and $\approx 820 \mathrm{~cm}^{-1}$ (Figure $2 \mathrm{~B}$ ). Interestingly, the $1040-1150 \mathrm{~cm}^{-1}$ absorption band shows two distinct protrusions around at 1070 and $1030 \mathrm{~cm}^{-1}$ for this sample. It is reasonable to assume that vacuum drying results in removal of surface species but not the intercalated ones leading to a cleaner spectrum showing the presence intercalated species more distinctly. The peak at $480-484 \mathrm{~cm}^{-1}$ could be assigned to Ni-O in the $\alpha$-[2hrs] samples. In the LDH-[2hrs] the metal-O bond stretches show up in the $520-600 \mathrm{~cm}^{-1}$ region. ${ }^{47}$ Variations in these peaks will not be elaborated further in this work.

XRD patterns of several samples are given in Figure 2A. All $\alpha-[2 \mathrm{hrs}]$ samples exhibit "turbostratic" $\alpha-\mathrm{Ni}(\mathrm{OH})_{2}$ similar to ones reported by others. ${ }^{3,17,48,49}$ Interlayer spacing along c-axis that was calculated from the positions of [003] peak were all similar and equal to $7.24 \pm 0.02 \AA$. LDH-[2hrs] sample exhibited the expected alignment of layers with respect to each other manifested by the appearance of (hkl) reflections. In a turbostratically disordered phase, random orientation of layers about the c-axis, eliminates the (hkl) reflections. Only 
$(00 \ell)$ and (hk0) reflections are observed. ${ }^{47}$ The interlayer separation calculated for the LDH[2hrs] was $7.80 \pm 0.02 \AA$. This result is in agreement with the literature values. ${ }^{50}$

\section{Precipitates from Alkyl-Substituted Ureas}

Alkyl-substituted ureas were claimed to decompose in warm aqueous solutions similar to urea with alkyl-isocyanate or alkyl-amine being the possible intermediates. ${ }^{35}$ In this study, we used methyl-substituted urea derivatives in order to study the intercalation of methyl isocyanate into the layers by following the distinct stretching peaks of $\mathrm{C}-\mathrm{H}$, and understand the coordination modes of $\mathrm{OCN}^{-}$groups. FTIR spectra and XRD patterns taken from powders precipitated by N,NDMU, MMU and N,N'DMU are given in Figure 4. FTIR showed no characteristic $\mathrm{C}-\mathrm{H}$ peaks.

In line with the analysis of Barrios et al. only ureas with asymmetric methyl substitutions resulted in precipitation levels similar to urea. ${ }^{37}$ Consistent with that, TMU did not yield any precipitation. FTIR spectrum and XRD pattern of N,NDMU showed the closest, N,N'DMU the least, and MMU between the two in resemblance to urea precipitation.

Examination of XRD and FTIR data revealed interesting observations. When there was no crystallization along the c-axis (with $N, N^{\prime} D M U$ ) the $O \mathrm{ON}^{-}$related peaks were vanished. It was also observed in the cyanate peak of MMU precipitates that low wavenumber shoulder was even more depressed. The corresponding structural change accompanied by an increase in interlayer separation, from $\approx 7.2$ to $\approx 8.8 \AA$. Carbonate (mostly unidentate) was observed in all cases even if the $\alpha$ structure wasn't observed. Increased hydrogen bonding in the series; $\mathrm{N}_{2} \mathrm{NDMU}, \mathrm{MMU}, \mathrm{N}, \mathrm{N}^{\prime} \mathrm{DMU}$ was notable. In the lower end of the spectrum, disappearance of $\mathrm{Ni}-\mathrm{O}\left(\approx 480 \mathrm{~cm}^{-1}\right)$ peak in N,N'DMU precipitates is expected due to lack of crystallization along the c-axis. The peak at $630-640 \mathrm{~cm}^{-1}$ was also vanished in $\mathrm{N}, \mathrm{N}^{\prime} \mathrm{DMU}$ precipitates. This supports the previous assignment of this absorption to cyanate deformations, $\delta(\mathrm{NCO})$.

Change of $\mathrm{pH}$ with time of precipitation of nickel hydroxide with urea and substituted ureas are shown in Figure 5. Since pH measurements at elevated temperatures are not reliable and errors up to one $\mathrm{pH}$ unit are common ${ }^{51}$, discussion will be limited to the spread of fluctuations during the nucleation events. As expected, upon sedimentation of Iarge 

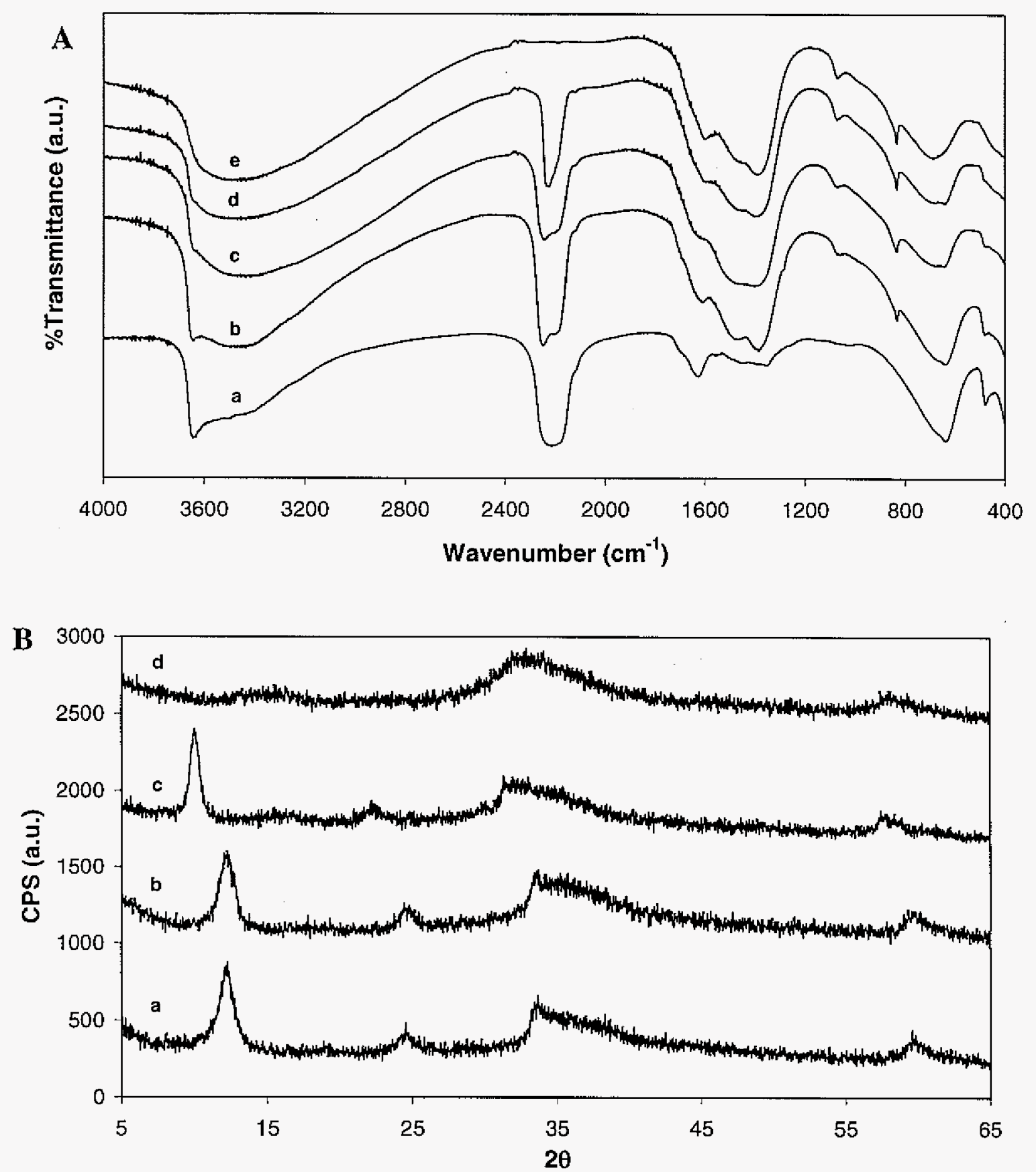

Figure 4. A. FTIR spectra from a. $\alpha$-[2hrs] (stirred), b. $\alpha$-[2hrs] (shaken), c. N,NDMU, d. MMU and e. N,N'DMU precipitated powders, B. XRD patterns of a. $\alpha-[2 \mathrm{hrs}]$ (shaken), b. N,NDMU, c. MMU and d. N,N'DMU precipitated powders. 

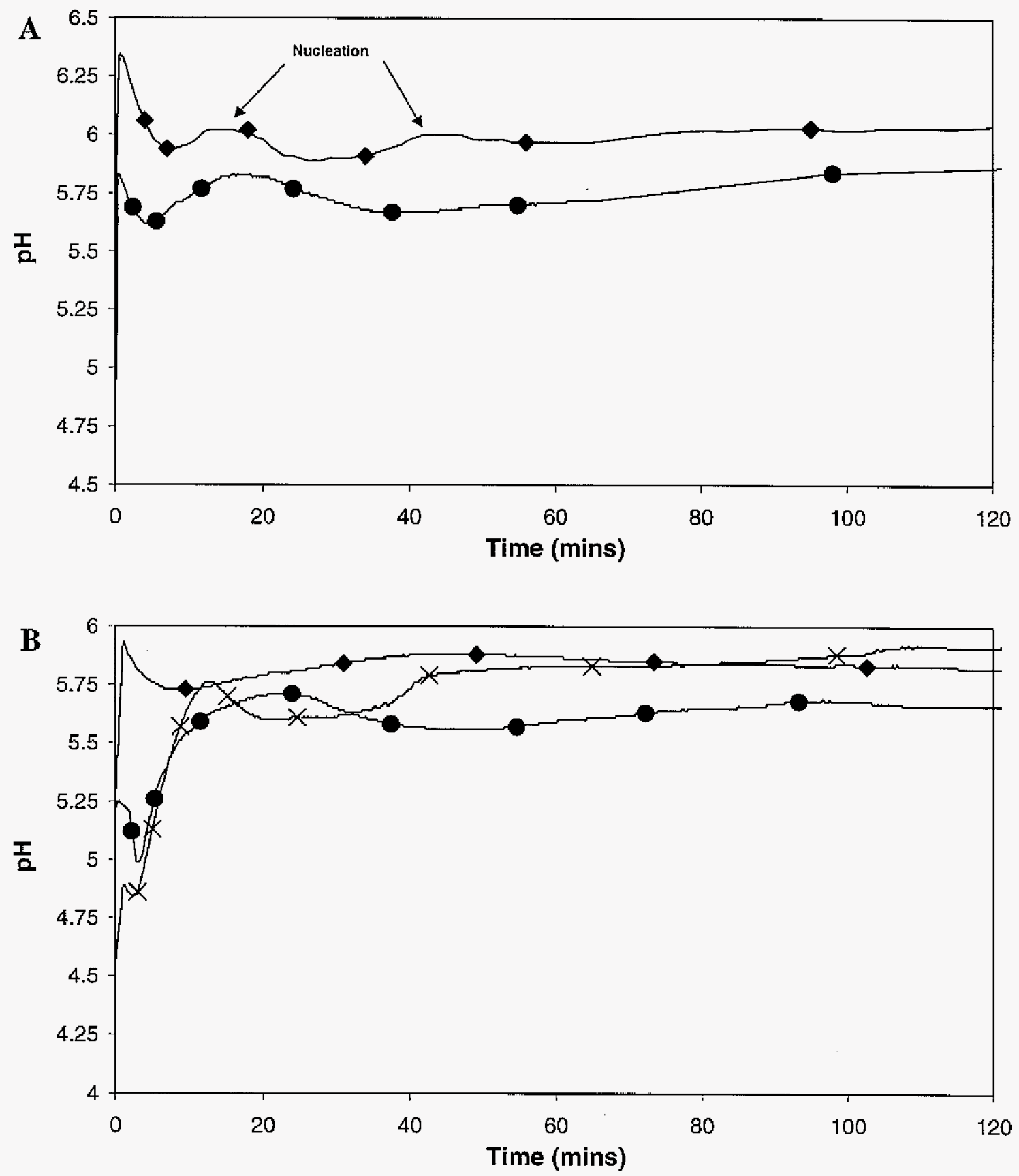

Figure 5. $\mathrm{pH}$ versus time plots of; A. $\alpha$-[2hrs] (shaken - $\bullet$ - and stirred - -) and B. N,NDMU $\times-$, MMU - - , N,N'DMU - -. Note that initial fluctuations are due to momentary cooling of the $\mathrm{Ni}^{2+}$ solution by the addition of substituted urea solution. 
particles the solution that was shaken shows second nucleation event, while the stirred sample shows only one. The relatively narrow nucleation peak observed for N,NDMU broadens for MMU and N,N'DMU consistent with the slower decomposition rates for the substituted ureas. It was claimed that precipitation at low $\mathrm{pH}$ conditions results in hydroxyldeficient amorphous precipitates, ${ }^{2}$ which agrees with our observations. Both hydroxyl deficiency and the lack of periodic order (amorphous) favor formation of "increasingly" hydrated precipitates as a manifestation of slow decomposition rates.

\section{Heterogeneous Precipitation}

Table 1 summarizes the concentrations of the reactants used in heterogeneous precipitation experiments. Figure 6 presents the FTIR spectra and XRD patterns obtained for four of the samples. In the presence of cyanate ions, the structure of the product was $\alpha$ with turbostratic character. Existence of $\mathrm{Al}^{3+}$ in the cyanate containing solutions triggered the $\mathrm{LDH}$ formation. LDH structure was also observed in precipitations using carbonate/hydroxide, but crystallization along c-axis is observed only in the presence of $\mathrm{Al}^{+3}$ ions. The resulting powder is structurally similar (also with similar IR signatures) to powder from N-N'DMU. Observation of $\alpha$ using cyanate/hydroxide in the absence of $\mathrm{Al}^{3+}$ might suggest that some of $\mathrm{Ni}^{2+}$ oxidizes to $\mathrm{Ni}^{3+}$ by donating electrons to cyanate, while this

Table 1. Concentrations of cations and anions used in the heterogeneous precipitation experiments."

\begin{tabular}{ccccccc}
\hline Sample & {$\left[\mathrm{Ni}^{2+}\right]$} & {$\left[\mathrm{Al}^{3+} / \mathrm{Ni}^{2+}\right]$} & {$\left[{\left.\mathrm{OH} / \mathrm{CO}_{3}{ }^{2}\right]}[\mathrm{OH} / \mathrm{OCN}]\right.$} & $\begin{array}{c}d_{003} \\
\pm 0.02(\AA)\end{array}$ & $\begin{array}{c}\text { Crystallite size }^{\mathrm{b}} \\
\pm 0.2(\mathrm{~nm})\end{array}$ \\
\hline 1 & 0.1 & - & - & $0.05 / 0.1$ & 7.13 & 3.8 \\
2 & - & $0.025 / 0.075$ & - & $0.05 / 0.1$ & 7.48 & 4.9 \\
3 & - & $0.025 / 0.075$ & $0.05 / 0.1$ & - & 7.69 & 4.4 \\
4 & 0.1 & - & $0.05 / 0.1$ & - & - & - \\
$\alpha-[2 \mathrm{hrs}]$ & 0.1 & - & - & - & 7.24 & 6.1 \\
LDH-[2hrs] & - & $0.025 / 0.075$ & - & - & 7.80 & 10.7
\end{tabular}

"Arions were dispensed from a $50 \mathrm{~mL}$ aqueous solution into the $210 \mathrm{~mL}$ cation solution. Numbers represent the molar concentrations reached at the end of deliverance of all anions, ${ }^{b}$ Crystallite size along caxis. 

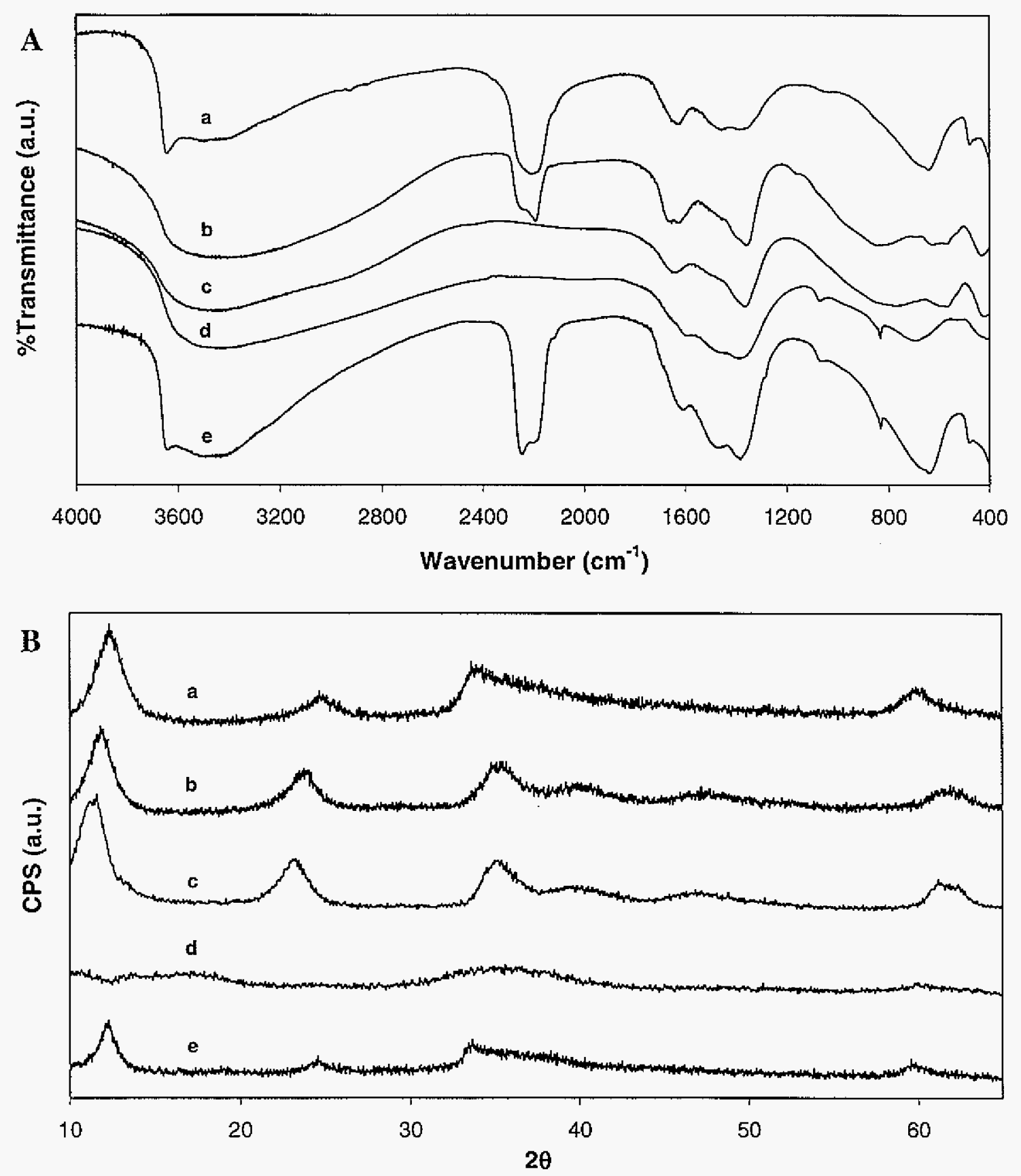

Figure 6. A. FTIR spectra of samples a. 1, b. 2, c. 3, d. 4 and e. $\alpha$-[2hrs] (shaken), B. XRD patterns of samples a. 1, b. 2, c. 3, d. 4 and e. $\alpha$-[2hrs] (shaken). 
mechanism does not apply for $\mathrm{Ni}^{2+}$-carbonate coupling. Observation of carbonate related peak even in the $\mathrm{NaOCN}$ precipitated sample may be easily explained if one considers the instability of $\mathrm{OCN}^{*}$ in aqueous solutions. Indeed, hydrolysis of cyanate is the second step of urea decomposition to carbonate, which explains their coexistence in the FTIR spectra of NaOCN precipitated powders. ${ }^{18}$ It is important to note that LDH obtained by urea precipitation yields higher interlayer separation and larger crystallite size than that obtained by heterogeneous precipitation.

\section{Spectral Analysis}

Representative deconvolutions of the cyanate peak $\left(\approx 2200 \mathrm{~cm}^{-1}\right)$ in $\alpha$-[2hrs] and LDH[2hrs] samples are given in Figure 7. While a total of 6 peaks were needed in order to fit the $\alpha-[2 h r s]$ peak, only 4 peaks were sufficient for defining the peak observed in LDH-[2hrs]. Although the spectra are generally not affected by the existence of carbon dioxide (with peaks 2330 to $2370 \mathrm{~cm}^{-1}$ ) in the chamber, it is not unlikely. Also when one of the peak's FWHM was significantly different from the others, an additional peak was introduced as long as such a peak is justified by sample's chemistry. Results imply that cyanate has more than one coordination mode.

Although quantitative interpretation of FTIR is not fully justified, changes in the relative intensities of certain peaks may shed light into the progress of precipitation reaction by tracking changes in the dominant coordination modes of intercalated species. Since the integrated area under a peak is related to its content in the sample, each peak represents relative fraction of certain coordination as long as molar extinction coefficient is independent of the coordination mode. This assumption is justifiable for $\mathrm{v}(\mathrm{CN})$ absorption as long as there is not a Fermi resonance (FR) effect. Careful analysis of the observed peak around $2200 \mathrm{~cm}^{-1}$ leads to a conclusion that peak splitting is not strongly correlated with carbonaceous species, hence FR effect is not causing this splitting. In Table 2 change in relative area under the deconvolved peaks (\% area) is given with respect to time for $\alpha$-[time] and LDH-[time]. Although relative changes observed in "relative intensities" were not as demonstrative as "\% area", results were still duplicates of each other. 

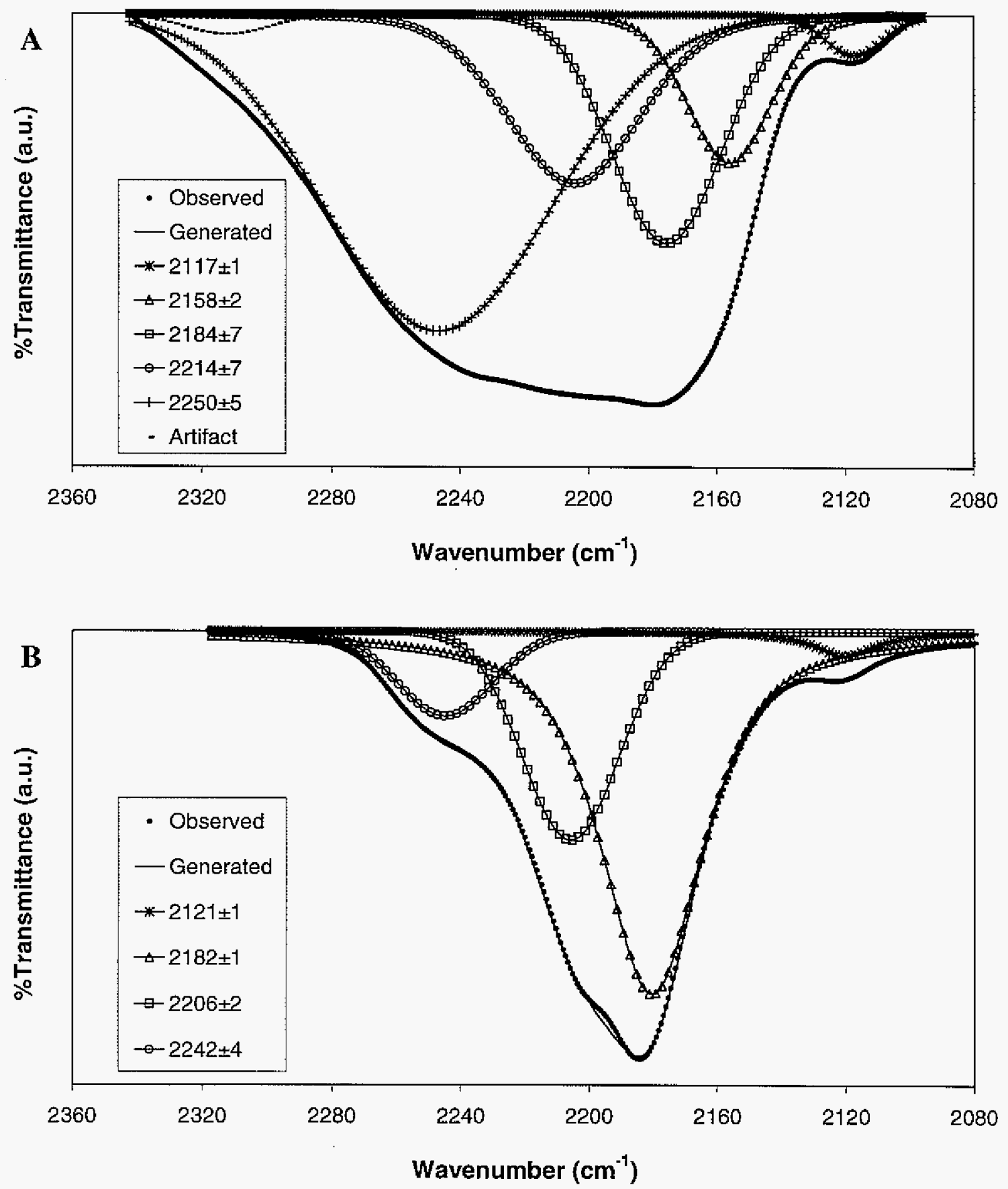

Figure 7. Representative deconvolution of the $\approx 2200 \mathrm{~cm}^{-1}$ region in A. $\alpha-[2 \mathrm{hrs}]$ and $\mathbf{B}$. LDH-[2hrs] samples. 
Table 2. Relative integrated area (\% area) under the deconvolved peaks from $\approx 2200 \mathrm{~cm}^{-1}$ region in $\alpha$-[time] and LDH-[time] samples.

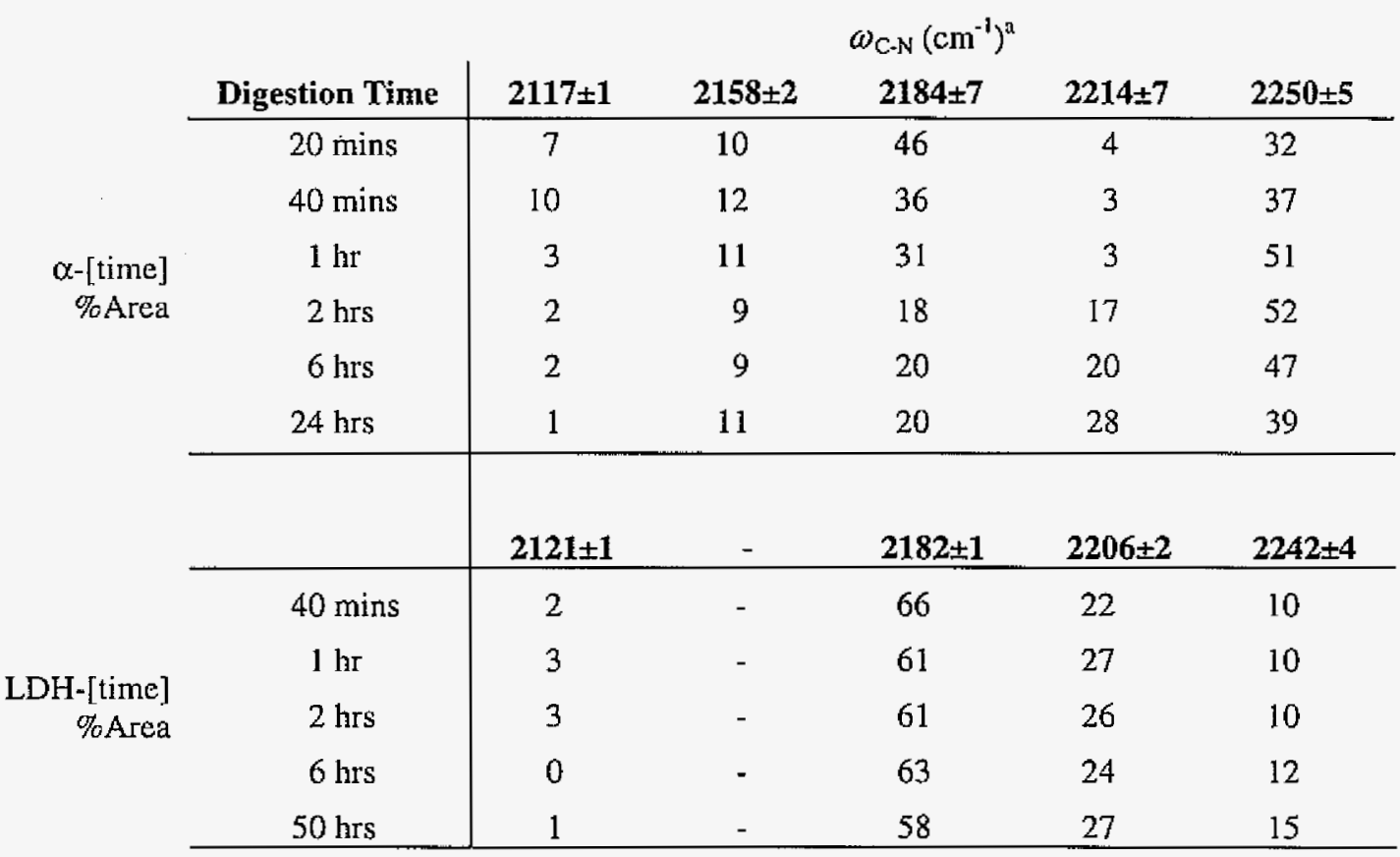

${ }^{\mathrm{a}}$ Peak positions are averages of positions observed with respect to time.

Analysis of the data indicates that while 2184, 2158 and $2117 \mathrm{~cm}^{-1}$ peak intensities decrease, 2214 and $2250 \mathrm{~cm}^{-1}$ peaks emerge and increase in intensity. Another interesting trend is that $2214 \mathrm{~cm}^{-1}$ seems to be compensated by $2250 \mathrm{~cm}^{-1}$ until a break point, which is followed by a decrease $2250 \mathrm{~cm}^{-1}$. Interestingly, the $2182 \mathrm{~cm}^{-1}$ peak dominates throughout the entire digestion in LDHs. Using the analogy drawn between nickel thiocyanate and nickel cyanate complexes $^{32}$, one can conclude that the cyanate that is dominantly nitrogen bonded (i.e. isocyanate: $-\mathrm{NCO}$ ) in the initial stages, changes to an oxygen bonded (i.e. cyanate: OCN) or to bridging coordination (bonded through $\mathrm{N}$ and $\mathrm{O}$ simultaneously).

Surface chemical analysis of the precipitates at various digestion times gives an accurate representation of instantaneous composition of the growing particle and may be related to bulk chemical analysis of the samples reported previously ${ }^{18}$. In addition, the chemical environment of the element can be deduced by examination of its chemical shifts. For this investigation, the peak shifts associated with $\mathrm{C} 1 s$ and $\mathrm{N} 1 s$ binding energies are of interest. 

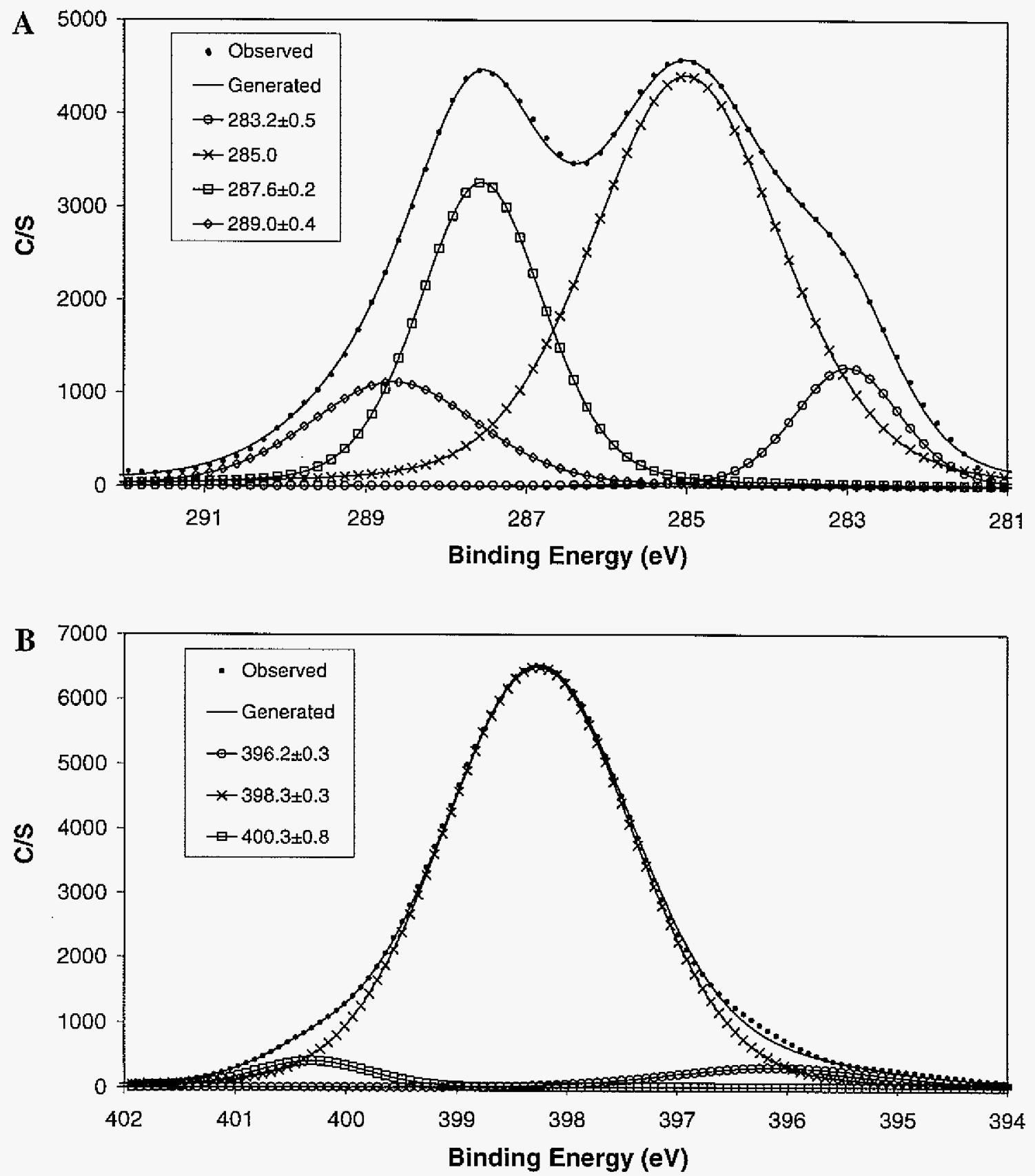

Figure 8. Typical peak fitting for the A. C1s and B. N1s spectra of the $\alpha-[2 h r s]$. 
Results of typical deconvolutions are given in Figure 8. Shirley background subtraction that is generally applied in XP spectral analysis was not available in PeakFit software. Therefore there is a minor error source in chemical shift calculations.

Results of XP spectra deconvolutions are presented in Table 3. All reference spectra show good agreement with literature data. ${ }^{52-54}$. Since the error associated with the data collection and spectral analyses is hard to predict, the origins of the assignments will not be discussed in detail. However, $\mathrm{C}-\mathrm{N}$ peak positions observed in $\mathrm{C} 1 s$ spectra needs attention. Note that there is almost a difference of $1 \mathrm{eV}$ in the binding energies observed for this peak in $\alpha$-[time] and LDH-[time] samples. Such a difference could be an indication of a considerable change in the electronic charge residing on carbon atom. This observation is in agreement with the observed differences noted in FTIR spectra of $\alpha$-[time] and LDH-[time] samples.

Bulk chemical analysis reported previously showed a decrease in Nitrogen content with digestion time. ${ }^{18,19}$ This was in agreement with kinetic simulations that predicted a decrease in the concentration of nickel-cyanate complexes implying that interlayer chemistry of the crystallites changes with digestion time. Since the growth mechanism is by agglomeration of the primary crystallites, crystallites formed at the later stages of precipitation are expected to have a different composition. Figure 9 compares the variation of Nitrogen concentration as a function of time by bulk (wet chemical) and surface (XPS) analyses. Because of the nature of the two analytical techniques, only trends in the change in Nitrogen content with time should be considered. ${ }^{51}$ As expected, Nitrogen (i.e. cyanate) diminishes at a much faster rate along the cross section of a particle. All XPS data was normalized against a maximum peak. Intensity from C1s (cyanate) at $287.6 \mathrm{eV}$ was in good agreement with that of $\mathrm{N} 1 s$ spectrum.

\section{Particle Morphology}

Figure 10 shows various particle morphologies obtained under slightly different experimental conditions. Previously, we reported ${ }^{8,18,19}$ that the growth mechanism for the $\alpha$ particles is the agglomeration of sheet-like primary crystallites. However, it was shown that degree to which particles agglomerate might change under different experimental conditions 
Table 3. Peak positions and assignments in $\mathrm{C} 1 s$ and N1s spectra of reference materials, $\alpha$ [time] and LDH-[2hrs].

\begin{tabular}{|c|c|c|c|c|c|c|c|c|}
\hline \multirow[b]{2}{*}{ Sample } & \multicolumn{5}{|l|}{ C1s } & \multicolumn{3}{|l|}{ N1s } \\
\hline & $\mathrm{M}-\mathrm{C}^{\mathrm{a}}$ & $\mathbf{C}-\mathbf{H}^{\mathbf{b}}$ & $\begin{array}{c}\mathrm{C}-\mathrm{O} \text { and } \\
\mathrm{C}=\mathrm{O}^{\mathrm{C}}\end{array}$ & $\mathrm{C}-\mathrm{N}^{\mathrm{d}}$ & $\mathrm{O}=\mathrm{C}-\mathrm{O}^{\mathrm{e}}$ & $\mathbf{M}-\mathbf{N}^{\mathfrak{R}}$ & $\mathrm{N}-\mathrm{C}^{\mathrm{B}}$ & Complex ${ }^{\mathrm{h}}$ \\
\hline $\mathrm{NaOCN}$ & - & 285.0 & . & 288.0 & $290.1^{i}$ & 396.7 & 398.5 & 400.4 \\
\hline AgOCN & - & 285.0 & - & 288.0 & - & - & 398.9 & - \\
\hline $\mathrm{Na}_{2} \mathrm{CO}_{3}$ & 282.3 & 285.0 & 287.3 & - & 289.4 & - & - & - \\
\hline $\mathrm{NaHCO}_{3}$ & 283.1 & 285.0 & 287.3 & - & 289.5 & - & - & - \\
\hline$\beta$-Aldrich & 282.8 & 285.0 & - & - & $288.7^{\mathrm{j}}$ & - & - & - \\
\hline$\alpha-[30$ mins $]$ & 282.8 & 285.0 & - & 287.8 & 289.6 & 396.7 & 398.5 & 400.5 \\
\hline$\alpha-[40 \mathrm{mins}]$ & 283.8 & 285.0 & - & 287.5 & 289.2 & 396.1 & 398.1 & 399.9 \\
\hline$\alpha-[1 \mathrm{hr}]$ & 282.9 & 285.0 & - & 287.5 & 288.8 & 396.6 & 398.1 & 399.7 \\
\hline$\alpha-[2 \mathrm{hrs}]$ & 283.0 & 285.0 & - & 287.6 & 288.7 & 396.1 & 398.3 & 400.3 \\
\hline$\alpha-[4.5 \mathrm{hrs}]$ & 283.8 & 285.0 & - & 287.4 & 288.6 & 396.3 & 398.0 & 399.2 \\
\hline$\alpha-[11 \mathrm{hrs}]$ & 282.6 & 285.0 & - & 287.5 & 289.3 & 395.9 & 398.7 & 401.2 \\
\hline$\alpha-[16 \mathrm{hrs}]$ & - & 285.0 & - & 287.9 & 289.0 & 395.9 & 398.8 & 401.3 \\
\hline LDH-[2hrs] & 284.0 & 285.0 & 286.2 & 288.7 & 289.2 & 396.9 & 398.8 & 401.5 \\
\hline
\end{tabular}

"Carbidic carbon (nickel carbon direct association), ${ }^{55.56 \mathrm{~b}}$ Adventitious carbon (organic contamination); used for referencing, ${ }^{400} \mathrm{C}-\mathrm{O}$ and $\mathrm{C}=\mathrm{O}$ in carbonate, ${ }^{57 d} \mathrm{C}-\mathrm{N}$ in cyanate, ${ }^{52,54} \mathrm{e} \mathrm{O}=\mathrm{C}-\mathrm{O}$ in carbonate, ${ }^{57} \mathrm{i}$ Nitride, ${ }^{58 \mathrm{~g}} \mathrm{~N}-\mathrm{C}$ in cyanate or $\mathrm{M}-\mathrm{N}-\mathrm{C}$ cyanate complex, ${ }^{52,54 \mathrm{~h}} \mathrm{M}-\mathrm{N}-\mathrm{C}$ in cyanate complex ${ }^{52,54,59}$ i Note that $\mathrm{NaOCN}$ can decompose to $\mathrm{Na}_{2} \mathrm{CO}_{3}$ during storage, ${ }^{j} \beta$-Aldrich shows the existence of carbonate in XP spectra too.

(e.g. mixing level, counter anion used, pressure above the solution) resulting a significant variation in surface area measured. Among the variables, choice of counter ion (i.e. nitrate vs. chloride) did not yield any visible change in the morphology. However, mixing level and pressure above the solution induced significant change in the morphology. Sealing the bottles (prevents free evolution of $\mathrm{CO}_{2}$ and $\mathrm{NH}_{3}$ ) seems to increase the surface area and roughness of the powders. Furthermore stirring results in higher level of agglomeration. An intermediate surface area was obtained from the powders produced in the shaken and sealed bottles. These samples also exhibit a wide variety of particle morphologies (i.e. closely packed sheet-like crystallites to loosely packed ones). 


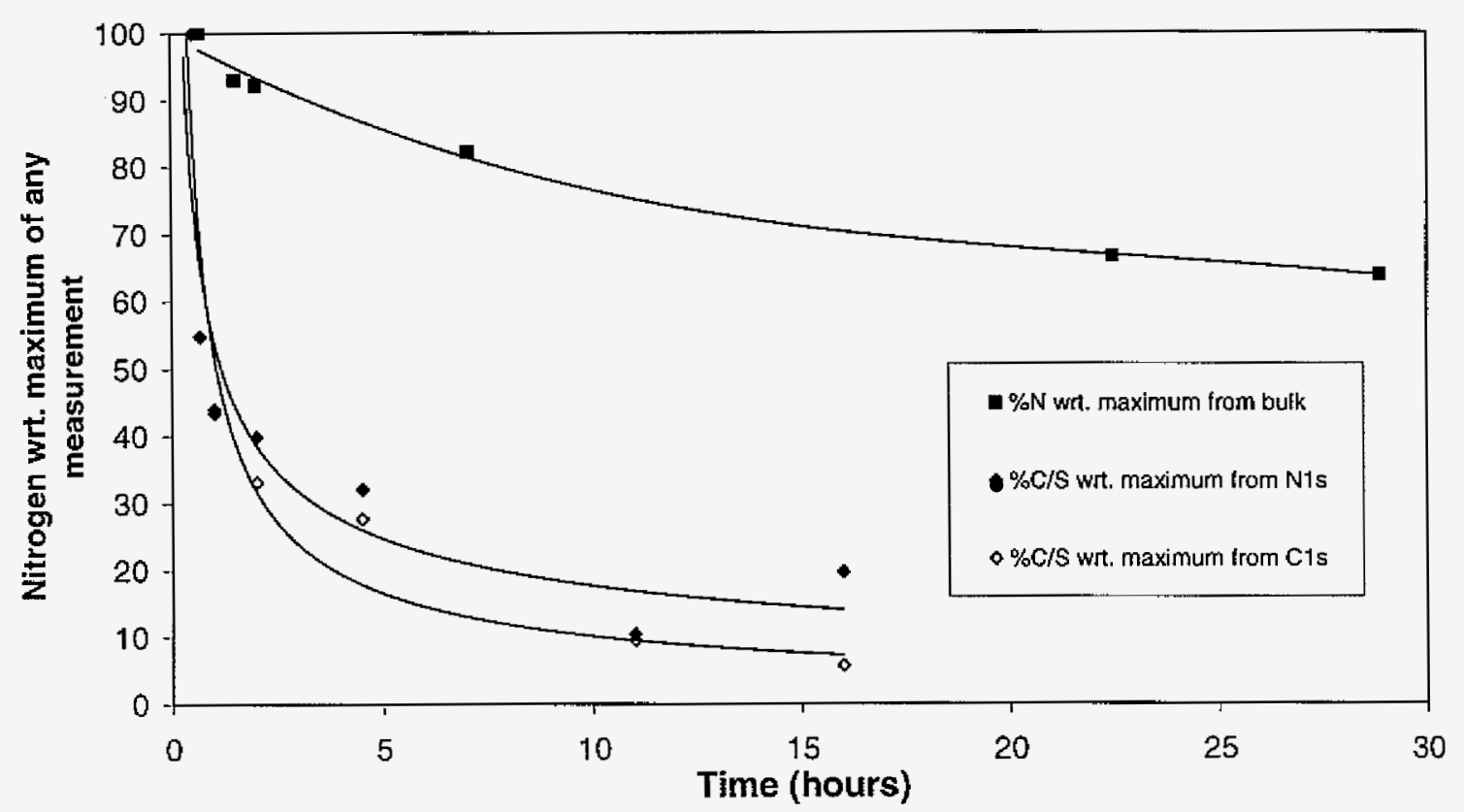

Figure 9. Qualitative comparison of elemental Nitrogen analysis from bulk with analyses from $\mathrm{N} 1 s$ and $\mathrm{C} 1 s$ XP spectra. Note that every data point within one set is normalized with the maximum among that set. Solid lines represent the trend in data.

\section{Discussion}

FTIR peak centered at around $2200 \mathrm{~cm}^{-1}$ showed most significant changes with experimental conditions leading to a better understanding of the precipitation process. Results indicate that this peak shows a distinct split character. Literature is rather limited on the nature of the splitting of this peak. In most cases it was not mentioned or noticed. For instance, Tsintsadze et al. studied the coordination compounds of metals cyanates (nickel included) with urotropine. They reported a peak around $2230 \mathrm{~cm}^{-1}$ but never mentioned a shoulder. ${ }^{31}$ In one instance, a shoulder at $2237 \mathrm{~cm}^{-1}$ for a sharp peak at $2186 \mathrm{~cm}^{-1}$ was noted. ${ }^{30}$ As demonstrated above, in an ionic crystal lattice like $\alpha-\mathrm{Ni}(\mathrm{OH})_{2}$ or $\mathrm{Ni}-\mathrm{Al} \mathrm{LDH}$, one can observe up to four peaks in the same region besides $2186 \mathrm{~cm}^{-1}$. In a previous study ${ }^{18}$ we showed accumulation of cyanate ion and subsequent formation of nickel-cyanate complexes during the first two hours of digestion. Its role in triggering the crystallization along the caxis was illustrated here. From the peak-shape profiles, it was shown that the coordination of cyanate might be changing from nitrogen-bonded (as in tetrahedral isocyanate complexes ${ }^{30}$ ) to oxygen-bonded, bridging or hydrogen bonded free anion. ${ }^{54}$ 

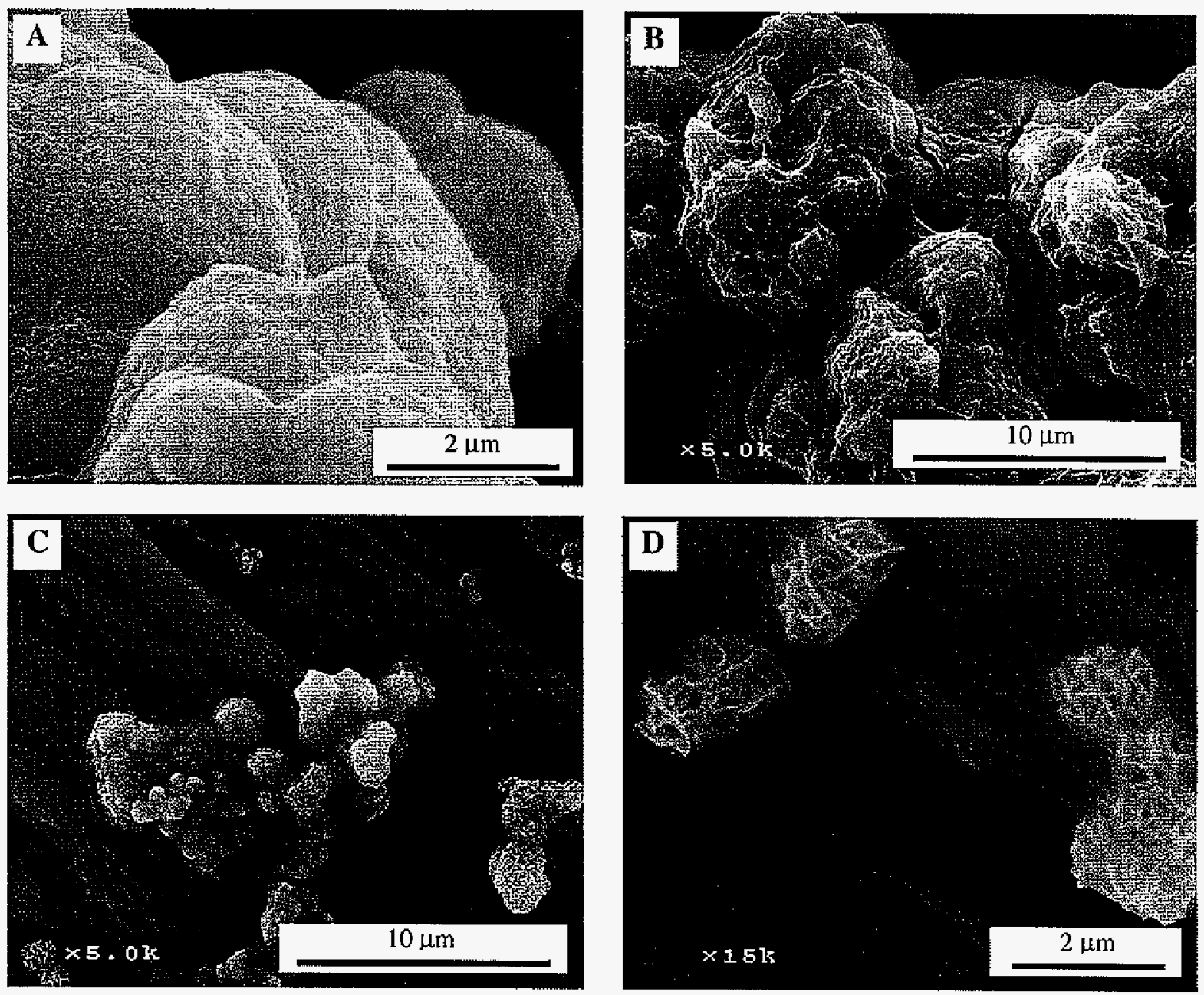

Figure 10. SEM micrographs showing the agglomeration level of samples from; A. Stirred/Ambient $\left(95 \pm 2 \mathrm{~m}^{2} / \mathrm{gr}\right)(\mathrm{x} 15.0 \mathrm{k})$, B. Stirred/Sealed $\left(140 \pm 1 \mathrm{~m}^{2} / \mathrm{gr}\right)$ and C. Shaken/Sealed $\left(113 \pm 1 \mathrm{~m}^{2} / \mathrm{gr}\right)$ reaction bottles. D. A close-up on a certain type of agglomerate observed in powders from shaken/sealed bottles.

In a related work Carbacho et al. studied complexes of $\mathrm{Ni}^{2+}$ with thiocyanate to distinguish between $\mathrm{N}$ - versus $\mathrm{S}$ - coordination of the thiocyanate. ${ }^{32}$ They reported a shift of the intense side of this stretch to higher wavenumbers by $30-40 \mathrm{~cm}^{-1}$ for M-NCS; $50-70 \mathrm{~cm}^{-1}$ for M-SCN and $70-120 \mathrm{~cm}^{-1}$ for strong-bridged coordinations compared to free ion. A very intense peak was reported along with a shoulder in almost all coordination modes. In addition, these shoulders changed their positions from high wavenumbers to low wavenumbers as the coordination mode changed from nitrogen-bonded to sulphur-bonded. Despite the inherent differences in the chemistries, an analogy can be drawn between 
thiocyanate and cyanate complexes of $\mathrm{Ni}^{2+}$. The competition between electronic and steric requirements was offered as a reason for appearance of three types of bonding modes. It was claimed that since the steric requirements for an angular M-SCN linkage would be greater than for a linear M-NCS bonding, the latter would be preferred with bulky ligands. On the other hand, the additional stability provided by the interaction of $d$-electrons of the metal with the empty antibonding orbitals localized on sulphur ( $\pi$ bonding) could help the electronic factors to take on. Although this effect is frequently reported for thiocyanates, the case is not always the same for cyanates. ${ }^{45,54}$. D'Agnano et al. noted that all cyanate complexes of first-row transition metals had been claimed to be $\mathrm{N}$-bonded, despite the fact that first principles calculations had pointed out equal densities existing on nitrogen and oxygen. Although majority of the literature suggests coordination through nitrogen, ${ }^{30,31,45,52,60}$ existence of bridging coordinations was also reported. ${ }^{54,61}$ In addition, spectral analysis in this study suggests that there can be up to 5 different peaks in the region, origins of which could not be completely explained by the available literature. If one adopts the analogy between thiocyanate and cyanate, a plausible explanation could be developed for the changes observed in FTIR by taking steric and/or electronic contributions into the consideration. Initially (i.e. nucleation stages) where peaks that are generally claimed to represent bonding through nitrogen dominate, steric factors must be preventing the coordination through oxygen. With increasing digestion however, the additional peaks, positions of which favors either oxygen or bridging coordinations, starts to emerge indicating that the electronic factors might become significant.

Splitting (i.e. increased number of vibrational modes) in an FTIR spectrum can be a manifestation of separate phenomena; a more complicated symmetry of anion in the solid state (loss of symmetry), ${ }^{30}$ electronegativity, oxidation number and coordination number of the metal. ${ }^{62}$ It is probable that a combination of these factors resulted in the peak splitting observed in this study. In his review, Ben-Efraim ${ }^{63}$ noted that both organic molecules of isocyanate and cyanate, are characterized by strong bands at $2290-2240$ and $2280-2240 \mathrm{~cm}^{-1}$, respectively, independent of the alkyl constituent they are associated with. Isocyanate absorption was usually a singlet with signs of broadening from FR effect, whereas cyanate was slightly asymmetric or split into a doublet due to the same effect. It can be inferred from 
this work that the effect is due to the resonance between $\mathrm{C}-\mathrm{N}$ stretching and the first overtone of $\mathrm{C}-\mathrm{O}-\mathrm{C}$ asymmetric vibration in the associated alkyl constituents. Therefore, it is reasonable to assume that a similar vibration in carbonate may be responsible for the splitting behavior. Although the very nature of the two $\mathrm{C}-\mathrm{O}-\mathrm{C}$ vibrations are different and less pronounced in carbonate, it may still be considered as a potential cause for the splitting observed. Nevertheless, the fact that there are always at least 4 peaks under this band leads to the conclusion that even if such an effect is possible, it can't rule out the coexistence of more than one bonding mode.

In their recent work Yang et al. had studied the chemisorption of cyanate on Ni(100) using ab initio many electron embedding theory. ${ }^{33,34}$ Results of their calculations for different geometries are given in Table 4. Figure 11 gives the adsorption sites indicated in Table 4. All isocyanate- $\mathrm{N}$ species were found to be more stable than cyanate-O by about $15 \mathrm{kcal} / \mathrm{mol}$ in respective sites. They compare their result and find good agreement with the few experimental data, which was discussed above. Nonetheless, the remarkable agreement between our results and their calculations bears importance in supporting our hypothesis.

We had noted that the $\approx 2200 \mathrm{~cm}^{-1}$ region of the $\alpha$-[time] spectra can be represented by 5 modes. Comparing these modes with frequencies calculated for both bonding configurations at different sites, following assignments could be made:

1. $2250 \pm 5 \mathrm{~cm}^{-1}$ : Cyanate-O at "atop"

2. $2214 \pm 7 \mathrm{~cm}^{-1}$ : Cyanate-O at "4-fold"

3. $2184 \pm 7 \mathrm{~cm}^{-1}$ : Isocyanate-N at "atop"

4. $2158 \pm 2 \mathrm{~cm}^{-1}$ : Isocyanate- $\mathrm{N}$ at "bridge" or "4-fold"

5. $2117 \pm 1 \mathrm{~cm}^{-1}$ : Observation of "\%Area vs. time" plots for $\alpha$-[time] reveals that trend in population of these species follows the one of $2158 \mathrm{~cm}^{-1}$ species. Although due to their low population compared to other species we tend to neglect this peak in our discussions, a brief explanation for its appearance is justified. 


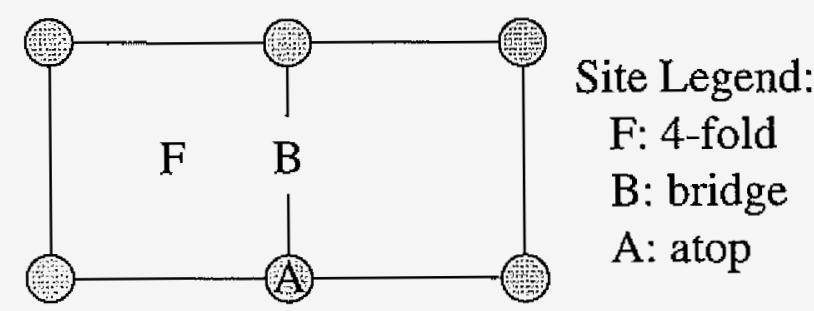

Figure 11. Notation used for different adsorption sites. Reproduced from Ref., ${ }^{33}$.

A similar analysis for $\mathrm{LDH}-[$ time] is given below:

1. $2242 \pm 4 \mathrm{~cm}^{-1}$ : Cyanate-O at "atop"

2. $2206 \pm 2 \mathrm{~cm}^{-1}$ : Cyanate-O at "4-fold"

3. $2182 \pm 1 \mathrm{~cm}^{-1}$ : Isocyanate-N at "atop"

4. $2121 \pm 1 \mathrm{~cm}^{-1}$ : similar with $2117 \mathrm{~cm}^{-1}$ given for $\alpha$-[time]

Considering the differences in environment assumed for calculations and the layered structure where the cyanate ions reside, assignments are acceptable and possibly some intermediate geometries exist. If the assignments were assumed correct; our initial hypothesis that the cyanate coordination mode changes from $\mathrm{N}$-bonded to $\mathrm{O}$-bonded with digestion time would be confirmed. This is because with time, we were observing the domination of 2214 and $2250 \mathrm{~cm}^{-1}$ over the 2184,2158 and $2117 \mathrm{~cm}^{-1}$; groups of peaks that are assigned to $\mathrm{O}$ bonded and N-bonded species, respectively. It can also be inferred that LDH-[time] shows the domination of $\mathrm{N}$-bonded species throughout the entire digestion. This appears to be the primary factor for the difference in the relative stabilities of the two phases against transformation to $\beta$-phase. ${ }^{38,39}$

One can discuss whether the $\mathrm{Ni}(100)$ can be assumed similar to a "defective" brucite-type layer, which is generally assumed ${ }^{1,64}$ and had been confirmed in our previous study ${ }^{18}$ for $\alpha$ $\mathrm{Ni}(\mathrm{OH})_{2}$. Figure 12 depicts three of many possibilities of these defect sites. Looking at the available positions, it is not surprising to see that the dominant modes are generally at "atop" sites, which in fact corresponds to a "grafted" interlayer species, for both cyanate- $\mathrm{O}$ and isocyanate-N. Only for cyanate-O it can be claimed that "bridge" sites have a considerable dominance at certain stages. Broken edges of crystallites represented in Figure 12C 
Table 4. Cyanate- $\mathrm{O}$ and Isocyanate- $\mathrm{N}$ adsorption on $\mathrm{Ni}(100){ }^{a}$

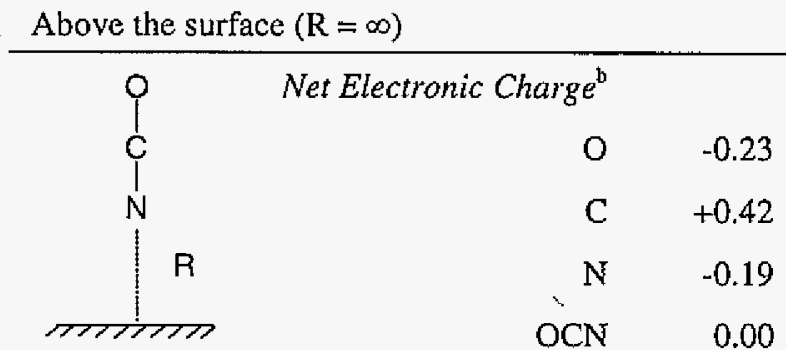

Cyanate- $O$ on the surface

\begin{tabular}{|c|c|c|c|c|}
\hline & Sites ${ }^{\mathrm{e}}$ & 4-fold & bridge & atop \\
\hline & $E_{\text {ads }}(\mathrm{kcal} / \mathrm{mol})^{\mathrm{d}}$ & 87 & 84 & 77 \\
\hline & $\omega_{\mathrm{C}-\mathrm{N}}\left(\mathrm{cm}^{-1}\right)$ & 2212 & 2228 & 2246 \\
\hline & $\omega_{\mathrm{C}-0}\left(\mathrm{~cm}^{-1}\right)$ & 1136 & 1166 & 1191 \\
\hline $\mathrm{N}$ & Net Electronic Charge & & & \\
\hline & $\mathrm{O}$ & -0.76 & -0.74 & -0.68 \\
\hline & $\mathrm{C}$ & +0.22 & +0.24 & +0.26 \\
\hline $\mathrm{R}$ & $\mathrm{N}$ & -0.29 & -0.30 & -0.37 \\
\hline menter & $\mathrm{OCN}$ & -0.83 & -0.80 & -0.79 \\
\hline \multicolumn{5}{|c|}{ Isocyanate- $\mathrm{N}$ on the surface } \\
\hline & Sites & 4-fold & bridge & atop \\
\hline & $E_{\text {ads }}(\mathrm{kcal} / \mathrm{mol})$ & 103 & 99 & 90 \\
\hline & $\omega_{\mathrm{C}-\mathrm{N}}\left(\mathrm{cm}^{-1}\right)$ & 2151 & 2163 & 2182 \\
\hline & $\omega_{\mathrm{C}-\mathrm{O}}\left(\mathrm{cm}^{-1}\right)$ & 1360 & 1380 & 1385 \\
\hline
\end{tabular}

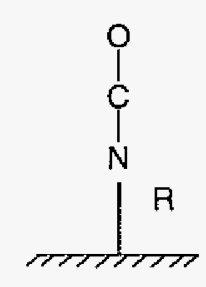

Net Electronic Charge

$\begin{array}{rrrr}\mathrm{O} & -0.35 & -0.37 & -0.42 \\ \mathrm{C} & +0.59 & +0.56 & +0.54 \\ \mathrm{~N} & -0.99 & -0.92 & -0.78 \\ \mathrm{OCN} & -0.75 & -0.73 & -0.66\end{array}$

a Reproduced from Ref. ${ }^{33},{ }^{\mathrm{b}}$ Calculated net electronic charge in units lel, ${ }^{\mathrm{C}}$ Figure 13 shows the adsorption sites, ${ }^{\mathrm{d}} E_{\text {ads }}$ is relative to $\mathrm{OCN}$ at infinite separation. Positive values are exothermic. 
serves to show how other modes can possibly appear. Within this context, finding a defect site that would permit a similar coordination as 4-fold site appears to be relatively difficult. Probability of 4-fold coordination should be higher for a cyanate-O as oxygen of cyanate is similar to hydroxyl of the substrate. While the assignment of the 4 -fold oxygen to $2214 \mathrm{~cm}^{-1}$ peak is well within the range, it is not possible to decide whether $2158 \mathrm{~cm}^{-1}$ peak is due to isocyanate- $\mathrm{N}$ at 4 -fold or bridge. The fact that overall charge associated with cyanate-O is higher than that for the isocyanate- $\mathrm{N}$, favors cyanate- $\mathrm{O}$ association as it will make up for most of the charge deficiency in defect- $\alpha$ phase.
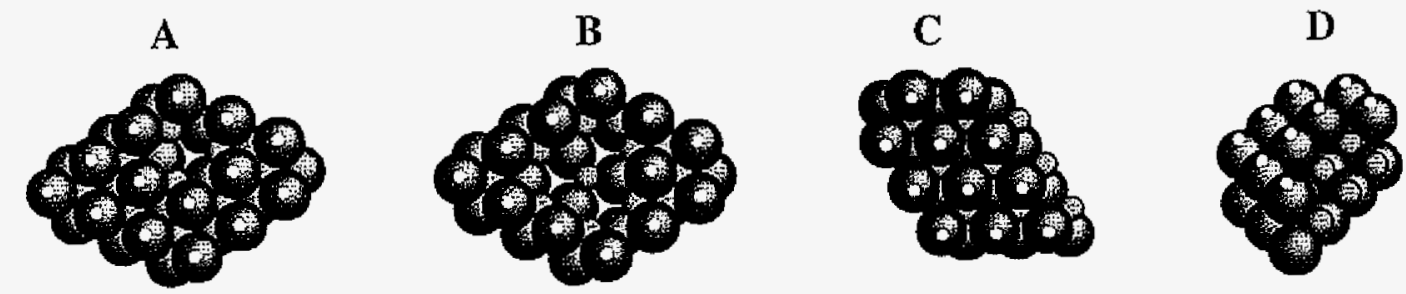

Figure 12. Defect possibilities in $\alpha$ structures: Missing A. one B. three hydroxyl ions from the layer, $\mathbf{C}$. Broken crystallite side, which might permit an uninterrupted exposure of nickel ions, D. Broken crystallite side with additional defects in the adjacent layer hydroxyl positions.

Energetics of an OCN tilted away from the surface normal and side-on geometry was also tackled by Yang and Whitten. ${ }^{33}$ Three of the geometries studied are shown in Figure 13. The adsorption energy reported for side-on geometry was comparable to that of all cyanate-O species, while significantly smaller than for the isocyanate- $N$ species. The stretching frequencies calculated were 2057 and $1510 \mathrm{~cm}^{-1}$ for $\mathrm{C}-\mathrm{N}$ and $\mathrm{C}-\mathrm{O}$ respectively. The 2117 and $2121 \mathrm{~cm}^{-1}$ peaks that consistently appear in our spectra can be explained with this information. Cyano complexes $\left(\left[\mathrm{M}(\mathrm{CN})_{4}\right]^{2-}\right)$ or fulminato complexes $\left(\left[\mathrm{M}(\mathrm{CNO})_{4}\right]^{2-}\right)$ were reported to have absorptions between $\approx 2110$ and $2190 \mathrm{~cm}^{-1}$, and are assigned to $\mathrm{C}-\mathrm{N}$ stretches. ${ }^{45}$ Hence it is very probable that the modes observed at 2117 and $2121 \mathrm{~cm}^{-1}$ for $\alpha$ and LDH samples are from a side-on association that is closely related to what is depicted in Figure 13.

Although tilting $\mathrm{C}-\mathrm{O}$ or the $\mathrm{O}-\mathrm{C}-\mathrm{N}$ axis away from the surface was reported to be destabilizing the system, the adsorption energies measured from given plots did not drop 
below $=82 \mathrm{kcal} / \mathrm{mol}$ (average of cyanate-O adsorption energies on 3 different sites is 82.7 $\mathrm{kcal} / \mathrm{mol}$ ), for a tilt angle of $\approx 30^{\circ}$ and $\approx 60^{\circ}$ for CO and OCN tilts, respectively. This is a strong indication that the scatter in our data can be explained by different modes that are energetically equivalent. Existence of XPS peak in our samples, which could be assigned to carbidic carbon (direct $\mathrm{Ni}-\mathrm{C}$ bond), lends additional support for the existence of a side-on geometry.

A

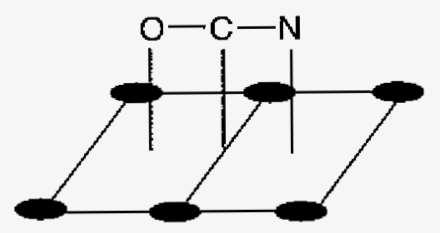

B

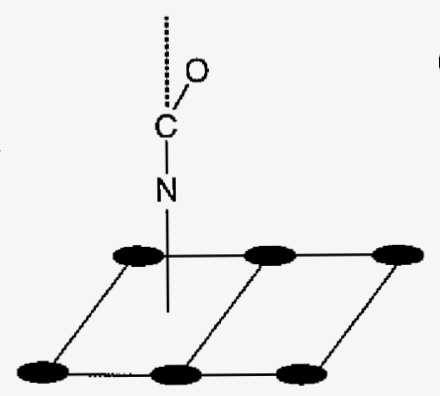

C

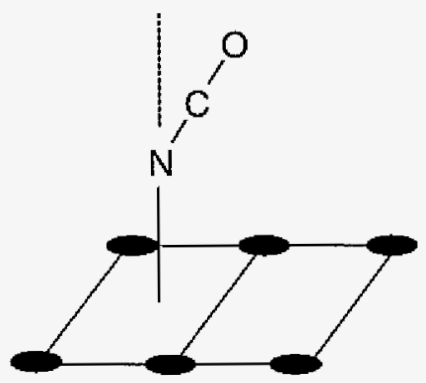

Figure 13. A. Equilibrium geometry for the side-on bonded OCN. The carbon atom is adsorbed above the bridge site. $E_{\text {ads }}$ relative to $O C N$ at infinite separation is $84 \mathrm{kcal} / \mathrm{mol}$. Note this geometry brings carbon to the proximity of nickel. End-on $\mathrm{N}$-bonded $\mathrm{OCN}$ at fourfold site with tilt between B. the O-C bond and the surface normal and $\mathrm{C}$. the $\mathrm{O}-\mathrm{C}-\mathrm{N}$ axis and the surface normal. Reproduced from Ref. ${ }^{33}$.

Dipole moment calculations indicate that both $\mathrm{O}-$ bonded and $\mathrm{N}$-bonded cyanate bonding to the surface is largely ionic. From population analysis, about 0.8 electrons were calculated to be transferred to cyanate- $\mathrm{O}$ and 0.7 electrons to the isocyanate- $\mathrm{N}$ from surface to the adsorbed species (see Table 4). A very striking observation is that the carbon atom was much more positive (more than twice) in the $\mathrm{N}$-bonded configuration than in the $\mathrm{O}$-bonded structure. This was very important as a distinguishing criterion in the XP spectra. Although the FTIR spectra was full of features that were indicative of different modes of bonding, XP spectra was not that informative except the $\mathrm{C} 1 s$, which was still showing only the main differences, like cyanate versus carbonate or carbidic carbon. However, in the case of LDH sample, in which the predominant population was $\mathrm{N}$-bonded cyanate, an increase of about 1 $\mathrm{eV}$ was seen in the cyanate carbon binding energy compared to that of $\alpha$ which was dominantly O-bonded cyanate after the initial digestion periods. The fact that carbon in $\mathrm{N}$ bonded cyanate has twice the positive charge compared to O-bonded cyanate suggests that a 
$\mathrm{N}$-isocyanate carbon would attract its core shell electron stronger than an $\mathrm{O}$-cyanate carbon. This evidently causes a higher binding energy in the LDH sample as observed in XP spectra.

\section{Hydration Level}

Table 5 is the summary of deconvolution results obtained from different mixing levels, precipitations with substituted urea and $\alpha$ samples aged in $6 \mathrm{M} \mathrm{KOH}$ for various times. We had noted an increasing level of "hydration" in the substituted urea series (here samples $\mathbf{a}, \mathbf{b}$, c, $\mathbf{d}$ represents the series in which increase in hydration level observed in FTIR spectra). It is apparent that with increasing levels of hydration cyanate-O at atop site looses intensity and cyanate-O bridge and isocyanate- $\mathrm{N}$ atop coordinations dominate.

During the precipitation with urea and substituted ureas, it was noted that decomposition rate slows in the series (Urea, $N, N D M U, M M U, N, N$ 'DMU), resulting in a shortage of anions that are needed both for stacking of layers and the lateral growth of crystallites. In such a situation cyanate would need to be in its most ionic coordination (i.e. cyanate-O) and at the same time coordinate to as many metal ions as possible (i.e. bridging sites or other modes of coordination discussed above). The structure looses almost all cyanate-O at atop sites in samples precipitated with MMU. It was demonstrated that the layer separation in these samples is slightly higher than the others. A mental exercise would clearly demonstrate the ramifications of this. In general, the interlayer space left for the species is calculated by the difference between the $d_{003}$ and $4.6 \AA^{65}$ (the approximate separation needed for the layers at the top and bottom of a gallery, i.e. unit cell parameter of $\beta$-phase, which is formed by closely packed layers). One-half of this distance should approximately be equal to the radius of the molecule that can be accommodated between the layers. While such values for $\alpha$ -

[2hrs] and NN-DMU were similar ( $\approx 1.3 \AA$ ), it was about $2.1 \AA$ and $1.6 \AA$ for MMU and $\mathrm{LDH}-\left[2 \mathrm{hrs}\right.$ ], respectively. Reported thermochemical radii for $\mathrm{HCO}_{3}{ }^{-}, \mathrm{NCO}, \mathrm{CO}_{3}{ }^{{ }^{\prime}}$ and water are $2.07,1.93,1.89^{66}$ and $1.41 \AA^{65}$, respectively. Although one should exercise caution with thermochemical radii data for planar $\left(\mathrm{CO}_{3}{ }^{\circ}\right)$ and linear $\left(\mathrm{OCN}^{-}\right)$molecules, it can still provide useful interpretation for the observations. The gallery space reported for $\alpha$ samples is significantly smaller than the radius of any of the anions and is close to that of water. This helps in explaining the grafted modes of intercalation for cyanate. On the other hand, it also 
supports the claim that bicarbonate would adsorb on the crystallite surfaces. The hindrance of crystallization along the $c$-axis in the presence of bicarbonate is a good indication that indeed carbonaceous species can "poison" the crystallite growth as claimed by Soler-Illia et al. ${ }^{17}$. In the LDH structures carbonates resides in the galleries as a planar molecule with its symmetry axis parallel to the c-axis. ${ }^{67}$ Therefore, the difference between the gallery spacing $(1.6 \AA)$ and the carbonate radii ( $1.89 \AA$ ) may be accommodated by the lateral orientation of carbonate and higher columbic forces between the layers. MMU has the largest space for intercalating molecules. It is very likely that while cyanate remains intact with the layers in grafted mode, additional layers of water or bicarbonate intercalates into the galleries causing the extensive hydrogen bonding.

Effect of ageing is clearly demonstrated in the samples " $e$ " and "ff," as shown in Table 5. Upon aging, bridging cyanate- $\mathrm{O}$ and atop isocyanate- $\mathrm{N}$ become the dominant coordinations

Table 5. Deconvolution results from; a. $\alpha$-[2hrs] (stirred) b. $\alpha$-[2hrs] (shaken), alkylsubstituted ureas; c. NN-DMU, d. MMU, e. 5Co- $\alpha$-[2hrs] (aged/partially transformed to $\beta$ ) and f. $\alpha$-[2hrs] (aged/mostly transformed to $\beta$ ).

\begin{tabular}{|c|c|c|c|c|c|c|c|}
\hline $\begin{array}{c}\text { Calculated }^{\mathrm{a}} \\
\left(\mathrm{cm}^{-1}\right)\end{array}$ & Sample & $\mathbf{a}$ & b & c & d & e & $\mathbf{f}$ \\
\hline \multirow{2}{*}{2246} & $\omega_{\mathrm{C}-\mathrm{N}}\left(\mathrm{cm}^{-1}\right)^{\mathrm{b}}$ & 2247 & 2258 & 2259 & 2239 & 2249 & 2248 \\
\hline & $\%$ Area ${ }^{\circ}$ & 52 & 32 & 21 & 9 & 17 & 15 \\
\hline \multirow{2}{*}{2228} & $\omega_{\mathrm{C}-\mathrm{N}}\left(\mathrm{cm}^{-1}\right)$ & - & 2221 & 2226 & 2225 & 2224 & 2225 \\
\hline & \%Area & - & 30 & 38 & 43 & 35 & 34 \\
\hline \multirow{2}{*}{2212} & $\omega_{\mathrm{C}-\mathrm{N}}\left(\mathrm{cm}^{-1}\right)$ & 2204 & - & - & - & - & - \\
\hline & \%Area & 17 & - & - & - & - & - \\
\hline \multirow{2}{*}{2182} & $\omega_{\mathrm{C}-\mathrm{N}}\left(\mathrm{cm}^{-1}\right)$ & 2176 & 2180 & 2179 & 2191 & 2180 & 2182 \\
\hline & \%Area & 18 & 33 & 35 & 44 & 38 & 49 \\
\hline \multirow{2}{*}{2163} & $\omega_{C-N}\left(\mathrm{~cm}^{-1}\right)$ & - & - & - & - & - & . \\
\hline & \%Area & - & - & - & - & - & - \\
\hline \multirow{2}{*}{$215 I$} & $\omega_{\mathrm{C}-\mathrm{N}}\left(\mathrm{cm}^{-1}\right)$ & 2156 & - & - & - & 2148 & - \\
\hline & \%Area & 9 & - & - & - & 2 & - \\
\hline \multirow{2}{*}{ Additional } & $\omega_{\mathrm{C}-\mathrm{N}}\left(\mathrm{cm}^{-1}\right)$ & 2117 & 2117 & 2115 & 2119 & 2124 & . \\
\hline & \%Area & 2 & 3 & 4 & 1 & 5 & - \\
\hline
\end{tabular}

${ }^{a}$ Calculated positions are given in Table $3,{ }^{b}$ Observed position of $\mathrm{C}-\mathrm{N}$ stretch of cyanate, ${ }^{\mathrm{c}}$ Balance $(=2 \%)$ is the area under the "artifact" peaks due to $\mathrm{CO}_{2}$ in the measurement system. 
in favor of cyanate-O. In addition, at still longer aging times, atop isocyanate-N will dominate them all. This observation is in agreement with the energetics calculated for these sites. Isocyanate- $\mathrm{N}$ is more stable than cyanate- $\mathrm{O}$ and is more likely to remain intercalated.

The cyanate peak reported by Soler-Illia et al. has a low wavenumber shoulder, implying that the precipitate is highly hydrated and can be easily observed in the broadened 3300-3600 $\mathrm{cm}^{-1}$ region. ${ }^{17}$ The SEM micrographs also show the agglomeration of plate-like crystallites. This morphology may also be attributed to the low metal ion concentrations.

\section{Carbonate}

Experimental evidence presented earlier indicates that unidentate and bidentate coordinations are present in $\alpha$-[2hrs] samples. However, the unidentate coordination dominates the bidentate population for "shaken" samples. Therefore, since unidentate coordination could also mean coordination to hydrogen (gallery or surface) as well as one of the metal ions via grafting, it is not surprising that this spectrum has more hydrogen bonding character in the $3300-3600 \mathrm{~cm}^{-1}$ region compared to the stirred sample. This inference is supported by the corresponding changes in the low wavenumber region.

Question remains whether the prominent difference in "hydration" level of two samples could be related to cyanate peak shape around $2200 \mathrm{~cm}^{-1}$. In a recent paper, kinetic simulation predictions led us to conclude that more carbonaceous species may remain in the solution in a sealed experiment (shaken) compared to an ambient pressure experiment (stirred). This explanation can justify the presence of relatively high fraction of unidentate carbonate in sealed experiments. Kinetic simulations also predicted that bicarbonate ion is the dominant carbonaceous species in the $\mathrm{pH}$-temperature range investigated. Therefore, intuitively one can favor unidentate carbonate intercalation by hydrogen bonding or grafting and/or adsorption over bidentate coordination. The conditions under which anion concentrations remain low (low $\mathrm{pH}$ and low supersaturation was observed and predicted ${ }^{18,19}$ ), charge neutrality requirement may force carbonate into bidentate or bridging (not shown in Figure 3) coordination ${ }^{45}$ in the stirred samples. One support for such coordinations comes from XRD results discussed in the previous section. Since small interlayer separation will not favor bicarbonate intercalation, a viable alternative is the grafting of the carbonate in bidentate coordination. 
All attempts toward unequivocal deconvolution of low wavenumber region (620-720, 1200-1350 and $1300-1600 \mathrm{~cm}^{-1}$ ) of the FTIR spectra failed due to the overlap of different modes of carbonate, cyanate and water. Also, 820-870 and 1010-1150 $\mathrm{cm}^{-1}$ absorptions could not be used in distinguishing the unidentate and bidentate coordinations of carbonaceous species because of the elevated backgrounds.

In our previous communication, the results of urea decomposition simulations indicated that there is a crossover point between the third and fourth hour, where the cyanate and bicarbonate concentrations become same and beyond which bicarbonate is the dominant species.

In light of foregoing discussions the following nucleation mechanism may be offered. In the initial stages of urea decomposition, the lack of sufficient bicarbonate leads to formation of Nickel hydroxide clusters along with Nickel cyanate species as the building blocks of the layered structure (isocyanate- $\mathrm{N}$ ). With time, coordination of cyanate changes to include cyanate- $O$ as well as bicarbonate participates in the $\alpha$ while cyanate coordination remains practically unaltered in LDHs. It is hard to predict what might be happening during the growth of the particles with the available data. However, cyanate seems to recess and loose its overall function in the growth process. Probably a combination of experimental parameters like, pressure, mixing level, initial metal ion concentration, solubility of the precipitate and formation of complexes results in a dynamic system that is governed with the charge balance criterion in the ionic lattice.

Intermediate cyanate coordinations observed in three-component $\mathrm{LDH}$ 's precipitated with $\mathrm{Ni}^{2+} \mathrm{Co}^{2+}$ and $\mathrm{Al}^{3+}$ will be discussed in an upcoming publication. ${ }^{38,39}$

\section{Conclusions}

Analysis of FTIR data combined with XPS results showed that cyanate and carbonaceous species exhibit different bond geometries in $\alpha-\mathrm{Ni}(\mathrm{OH})_{2}$ and $\mathrm{Ni} / \mathrm{Al} \mathrm{LDH}$ 's. Assignments for the peaks observed under the cyanate absorption at $\approx 2200 \mathrm{~cm}^{-1}$ showed that with increasing digestion time, cyanate changed from $\mathrm{N}$-bonded to $\mathrm{O}$-bonded end-on geometries in $\alpha$-phase precipitation, whereas stayed predominantly as N-bonded in Ni/Al LDH's. XPS results indicated a higher positive charge on carbon of cyanate in $\mathrm{N}$-bonded species, which 
compliments FTIR results. Methyl-substituted ureas, ageing in concentrated KOH solutions and heterogeneous precipitation reactions were employed to clarify the intercalation phenomena for this system. Key experimental parameters in molecular (i.e. interlayer chemistry) and micro (i.e. particle morphology) level processing were identified to better understand the $\mathrm{Ni}(\mathrm{OH})_{2}$ precipitation by urea. All results point out that cyanate ion, the intermediate of urea decomposition plays a critical role in determining the composition, structure and morphology of the particles synthesized. Compositional variation across the particle is verified.

\section{Acknowledgements}

This manuscript has been authored by Iowa State University of Science and Technology under Contract No. W-7405-ENG-82 with the U.S. Department of Energy. The United States Government retains and the publisher, by accepting the article for publication, acknowledges that the United States Government retains a non-exclusive, paid-up, irrevocable, world-wide license to publish or reproduce the published form of this manuscript, or allow others to do so, for United States Government purposes. Authors thank Drs. Andy Thom and Matt Kramer for valuable discussions and James W. Anderegg for collecting and interpreting XPS data. B. M. furthermore acknowledges the financial support from Catron Fellowship.

\section{References}

${ }^{1} \mathrm{C}$. Faure, C. Delmas and M. Fouassier, "Characterization of a Turbostratic $\alpha$-Nickel Hydroxide Quantitatively Obtained from an Nickel Sulfate Solution," J. Power Sources, 35 [3] 279-90 (1991).

${ }^{2}$ M. Rajamathi, P. V. Kamath and R. Seshadri, "Polymorphism in Nickel Hydroxide: Role of Interstratification," J. Mater. Chem., 10 [2] 503-06 (2000).

${ }^{3}$ J. J. Braconnier, C. Delmas, C. Fouassier, M. Figlarz, B. Beaudouin and P. Hagenmuller, "A Novel Nickel(II) Hydroxide Obtained by Soft Chemistry," Rev. Chim. Miner., 21 [4] 496508 (1984).

${ }^{4}$ P. V. Kamath and G. N. Subbanna, "Electroless Nickel Hydroxide: Synthesis and Characterization," J. Appl. Electrochem., 22 [5] 478-82 (1992). 
${ }^{5}$ D. Sordelet and M. Akinc, "Preparation of Spherical, Monosized Yttrium Oxide Precursor Particles," J. Colloid Interface Sci., 122 [1] 47-59 (1988).

${ }^{6}$ D. J. Sordelet, M. Akinc, M. L. Panchula, Y. Han and M. H. Han, "Synthesis of Yttrium Aluminum Garnet Precursor Powders by Homogeneous Precipitation," J. Eur. Ceram. Soc., 14 [2] 123-30 (1994).

${ }^{7}$ G. J. d. A. A. Soler-Illia, M. Jobbagy, R. J. Candal, A. E. Regazzoni and M. A. Blesa, "Synthesis of Metal Oxide Particles from Aqueous Media: The Homogeneous Alkalinization Method," J. Dispersion Sci. Technol., 19 [2 \& 3] 207-28 (1998).

${ }^{8}$ M. Akinc, N. Jongen, J. Lemaitre and H. Hofmann, "Synthesis of Nickel Hydroxide Powders by Urea Decomposition," Journal of the European Ceramic Society, 18 [11] 155964 (1998).

${ }^{9}$ A. Widjaja, "Synthesis and Characterization of Nickel Hydroxide Powders for Battery Applications," M.Sc. Thesis. Iowa State University, Ames, 1997.

${ }^{10}$ I. Yazdi, "Synthesis and Electrochemical Studies of Cobalt Substituted Nickel Hydroxide for Battery Applications," M.Sc. Thesis. Iowa State University, Ames, 1999.

${ }^{11}$ B. S. Maruthiprasad, M. N. Sastri, S. Rajagopal, K. Seshan, K. R. Krishnamurthy and T. S. R. P. Rao, "A Novel Nickel Trihydroxy Isocyanate - Preparation and Characterization," Proc. - Indian Acad. Sci., Chem. Sci., 100 [6] 459-62 (1988).

${ }^{12}$ M. J. Avena, M. V. Vazquez, R. E. Carbonio, C. P. De Pauli and V. A. Macagno, "A Simple and Novel Method for Preparing $\mathrm{Ni}(\mathrm{OH})_{2}$. Part I: Structural Studies and Voltammetric Response," J. Appl. Electrochem., 24 [3] 256-60 (1994).

${ }^{13}$ R. M. Torresi, M. V. Vazquez, A. Gorenstein and S. I. C. d. Torresi, "Infrared Characterization of Electrochromic Nickel Hydroxide Prepared by Homogeneous Chemical Precipitation," Thin Solid Films, 229 [2] 180-6 (1993).

${ }^{14}$ M. Dixit, G. N. Subbanna and P. V. Kamath, "Homogeneous Precipitation from Solution by Urea Hydrolysis: A Novel Chemical Route to the $\alpha$-Hydroxides of Nickel and Cobalt," J. Mater. Chem., 6 [8] 1429-32 (1996).

${ }^{15}$ M. Jobbagy, G. J. d. A. A. Soler-Illia, A. E. Regazzoni and M. A. Blesa, "Synthesis of Copper(II)-Containing Nickel(II) Hydroxide Particles as Precursors of Copper(II)Substituted Nickel(II) Oxides," Chem. Mater., 10 [6] 1632-37 (1998). 
${ }^{16}$ G. J. d. A. A. Soler-Illia, "A Study of Cu-Ni and Cu-Zn Mixed Oxide Precursors Synthesis by Homogeneous Alkalinization Methods," Ph.D. Thesis. Universidad de Buenos Aires, Buenos Aires, 1998.

${ }^{17}$ G. J. d. A. A. Soler-Illia, M. Jobbagy, A. E. Regazzoni and M. A. Blesa, "Synthesis of Nickel Hydroxide by Homogeneous Alkalinization. Precipitation Mechanism," Chem. Mater., 11 [11] 3140-46 (1999).

${ }^{18} \mathrm{~B}$. Mavis and M. Akinc, "Kinetics of Urea Decomposition in the Presence of Transition Metal Ions: $\mathrm{Ni}^{2+}$," submitted to Journal of American Ceramic Society, (2003).

${ }^{19} \mathrm{~B}$. Mavis and M. Akinc, "Details of Urea Decomposition in the Presence of Transition Metal Ions," to be published in the American Ceramic Society (ACerS) Ceramic Engineering and Science Proceedings (CESP), 24 [3 \& 4] (2003).

${ }^{20} \mathrm{C}$. Faure, C. Delmas, M. Fouassier and P. Willmann, "Preparation and Characterization of Cobalt-Substituted $\alpha-$ Nickel Hydroxides Stable in Potassium Hydroxide Medium. Part I. $\alpha^{\prime}$-Hydroxide with an Ordered Packing," J. Power Sources, 35 [3] 249-61 (1991).

${ }^{21}$ L. Demourgues-Guerlou and C. Delmas, "Effect of Iron on the Electrochemical Properties of the Nickel Hydroxide Electrode," J. Electrochem. Soc., 141 [3] 713-17 (1994).

${ }^{22}$ K. T. EhIsissen, A. Delahaye-Vidal, P. Genin, M. Figlarz and P. Willmann, "Preparation and Characterization of Turbostratic Nickel/Aluminum Layered Double Hydroxides for Nickel Hydroxide Electrode Applications," J. Mater. Chem., 3 [8] 883-8 (1993).

${ }^{23}$ L. Indira, M. Dixit and P. V. Kamath, "Electrosynthesis of Layered Double Hydroxides of Nickel with Trivalent Cations," J. Power Sources, 52 [1] 93-7 (1994).

${ }^{24}$ M. Rajamathi, G. S. Thomas and P. V. Kamath, "The Many Ways of Making Anionic Clays," Proceedings - Indian Academy of Sciences, Chemical Sciences, 113 [5-6] 671-80 (2001).

${ }^{25}$ U. Costantino, F. Marmottini, M. Nocchetti and R. Vivani, "New Synthetic Routes to Hydrotalcite-Like Compounds. Characterization and Properties of the Obtained Materials," Eur. J. Inorg. Chem., [10], 1439-46 (1998). 
${ }^{26}$ R. C. Aggarwal and V. Chandrasekhar, "Synthesis and Structural Studies on Some Diamine Complexes of Cobalt(II) and Nickel(II) Cyanates and Azides," Indian Journal of Chemistry, Section A: Inorganic, Physical, Theoretical \& Analytical, 17A [4] 361-3 (1979).

${ }^{27}$ R. L. Dieck and T. Moeller, "Rare Earths. LXXXVI. Isocyanato Adducts of Lanthanide(III) Chlorides and Isothiocyanates," Journal of the Less-Common Metals, 33 [3] 355-60 (1973).

${ }^{28}$ M. Quastlerova-Hvastijova, J. Kohout and J. Gazo, "Cyanato Copper Complexes with Organic Ligands. VI. Preparation, Electronic, and Infrared Spectra of Cyanato Copper(II) Complexes with Aniline Derivative Ligands," Zeitschrift fuer Anorganische und Allgemeine Chemie, 396 [3] 341-52 (1973).

${ }^{29}$ A. Sabatini and I. Bertini, "Infrared Spectra between 100 and $2500 \mathrm{~cm}^{-1}$ of Some Complex Metal Cyanates, Thiocyanates, and Selenocyanates," Inorg. Chem., 4 [7] 959-61 (1965).

${ }^{30}$ D. Forster and D. M. L. Goodgame, "Vibrational Spectra of Pseudohalide Complexes. I. Tetrahedral Isocyanate Complexes," J. Chem. Soc., [Jan.], 262-7 (1965).

${ }^{31}$ G. V. Tsintsadze, A. M. Mamulashvili and L. P. Demchenko, "Products of the Reaction of Hexamethylenetetramine with Cyanates, Thiocyanates, and Selenocyanates of Some Metals," Zh. Neorg. Khim., 15 [1] 276-8 (1970).

${ }^{32}$ H. Carbacho, B. Ungerer and G. Contreras, "Pseudo-Octahedral and Polymeric Complexes of Nickel(II) with Thiocyanate," J. Inorg. Nucl. Chem., 32 [2] 579-84 (1970).

${ }^{33} \mathrm{H}$. Yang and J. L. Whitten, "Chemisorption of OCN on Ni(100) - an Ab Initio Study," Surface Science, 401 [3] 312-21 (1998).

${ }^{34} \mathrm{H}$. Yang and J. L. Whitten, "Reaction and Adsorption Energetics of $\mathrm{CN}+\mathrm{O} \rightarrow \mathrm{OCN}$ on Nickel," Theochem, 458 [1-2] 131-42 (1999).

${ }^{35}$ W. H. R. Shaw and B. Grushkin, "Kinetic Studies of Urea Derivatives. I. Methylurea," J. Am. Chem. Soc, 82, 1022-4 (1960).

${ }^{36}$ W. H. R. Shaw and D. G. Walker, "Kinetic Studies of Thiourea Derivatives. IV. The Methylated Thioureas. Conclusions," J. Am. Chem. Soc., 80, 5337-42 (1958).

${ }^{37}$ A. M. Barrios and S. J. Lippard, "Decomposition of Alkyl-Substituted Urea Molecules at a Hydroxide-Bridged Dinickel Center," Inorg. Chem., 40 [6] 1250-55 (2001). 
${ }^{38}$ B. Mavis and M. Akinc, "Homogeneous Precipitation of Layer Double Hydroxides," to be published in the Key Engineering Materials, [European Ceramic Society VIII ${ }^{\text {th }}$ Biannual Meeting Proceedings], (2003).

${ }^{39}$ B. Mavis and M. Akinc, "Three Component Layer Double Hydroxides by Urea Precipitation: Structural Stability and Electrochemistry," to be submitted to Journal of Power Sources, (2003).

${ }^{40} \mathrm{P}$. Swift, "Adventitious Carbon - the Panacea for Energy Referencing?," Surface and Interface Analysis, 4 [2] 47-51 (1982).

${ }^{41}$ F. Boulc'h, M.-C. Schouler, P. Donnadieu, J.-M. Chaix and E. Djurado, "Domain Size Distribution of Y-TZP Nanoparticles Using XRD and HRTEM," Image Analysis \& Stereology, 20 [3] 157-61 (2001).

${ }^{42}$ M. Rajamathi, G. N. Subbanna and P. V. Kamath, "On the Existence of a Nickel Hydroxide Phase which is neither $\alpha$ nor $\beta, "$ J. Mater. Chem., 7 [11] 2293-96 (1997).

${ }^{43}$ M. A. Aramendia, V. Borau, C. Jimenez, J. M. Marinas, F. J. Romero and J. R. Ruiz, "Synthesis, Characterization, and $1 \mathrm{H}$ and 71Ga MAS NMR Spectroscopy of a Novel Mg/Ga Double Layered Hydroxide," Journal of Solid State Chemistry, 131, 78-83 (1997).

${ }^{44}$ J.-H. Choy, Y.-M. Kwon, K.-S. Han, S.-W. Song and S. H. Chang, "Intra- and InterLayer Structures of Layered Hydroxy Double Salts, $\mathrm{Ni}_{1-\mathrm{x}} \mathrm{Zn}_{2 \mathrm{x}}(\mathrm{OH})_{2}\left(\mathrm{CH}_{3} \mathrm{CO}_{2}\right)_{2 \mathrm{x}} \cdot \mathrm{nH}_{2} \mathrm{O}$," Materials Letters, 34 [3-6] 356-63 (1998).

${ }^{45} \mathrm{~K}$. Nakamoto, Infrared and Raman Spectra of Inorganic and Coordination Compounds, Part B: Applications in Coordination, Organometallic, and Bioinorganic Chemistry, Fifth Edition. Wiley-Interscience, New York, 1997.

${ }^{46}$ D. W. Conrad and C. H. Patterson, Jr., "Compounds Labeled with Cyanate or Thiocyanate Metal Complexes for Detection by Infrared Spectroscopy and Analytical Applications," U.S. Pat. Appl, 940736, U.S., 1998.

${ }^{47}$ A. S. Prakash, P. V. Kamath and M. S. Hegde, "Synthesis and Characterization of the Layered Double Hydroxides of Mg with Cr," Materials Research Bulletin, 35 [13] 2189-97 (2000). 
${ }^{48}$ A. Delahaye-Vidal and M. Figlarz, "Textural and Structural Studies on Nickel Hydroxide Electrodes. II. Turbostratic Nickel(II) Hydroxide Submitted to Electrochemical Redox Cycling," J. Appl. Electrochem., 17 [3] 589-99 (1987).

${ }^{49}$ F. Portemer, A. Delahaye-Vidal and M. Figlarz, "Characterization of Active Material Deposited at the Nickel Hydroxide Electrode by Electrochemical Impregnation," $J$. Electrochem. Soc., 139 [3] 671-8 (1992).

${ }^{50}$ C. Y. Wang, S. Zhong, K. Konstantinov, G. Walter and H. K. Liu, "Structural Study of Al-Substituted Nickel Hydroxide," Solid State Ionics, 148 [3,4] 503-08 (2002).

${ }^{51}$ D. A. Skoog, D. M. West and F. J. Holler, Fundamentals of Analytical Chemistry, $7^{\text {th }}$ Edition. Harcourt Inc., Orlando, 1997.

${ }^{52}$ D. Atzei, D. De Filippo, A. Rossi and R. Caminiti, "X-Ray Photoelectron Spectra of Dinitrogen Chelating Ligands with Some Transition Metals," Spectrochimica Acta, Part A: Molecular and Biomolecular Spectroscopy, 49A [12] 1779-85 (1993).

${ }^{53}$ F. J. Owens and J. Sharma, "XPS Measurement and Molecular Orbital Calculation of Valence Band Electronic Structure of Sodium Cyanate," Chem. Phys. Lett., 74 [1] 72-4 (1980).

${ }^{54}$ A. D'Agnano, M. Gargano, C. Malitesta, N. Ravasio and L. Sabbatini, "X-Ray Photoelectron Spectroscopy Insight into the Coordination Modes of Cyanate in Copper(II) Complexes," Journal of Electron Spectroscopy and Related Phenomena, 53 [4] 213-24 (1991).

${ }^{55}$ C. M. Whelan, R. Neubauer, D. Borgmann, R. Denecke and H.-P. Steinruck, "A Fast XRay Photoelectron Spectroscopy Study of the Adsorption and Temperature-Dependent Decomposition of Propene on Ni(100)," Journal of Chemical Physics, 115 [17] 8133-40 (2001).

${ }^{56}$ B. M. Weckhuysen, M. P. Rosynek and J. H. Lunsford, "Characterization of Surface Carbon Formed During the Conversion of Methane to Benzene over Mo/HZSM-5 Catalysts," Catalysis Letters, 52 [1,2] 31-36 (1998).

${ }^{57}$ S.-Y. Jing, C. K. Choi and H.-J. Lee, "A Study on the Formation and Characteristics of the Organic-Inorganic Material with Low Dielectric Constant Deposited by High Density 
Plasma Chemical Vapor Deposition," Journal of the Korean Physical Society, 39 [Suppl. Issue] S302-S05 (2001).

${ }^{58}$ B. Bartlett, J. M. Valdisera and J. N. Russell, Jr., "A Comparison of the Surface Chemistry of Phenyl Cyanate and Phenol on Al(111)," Surface Science, 442 [2] 265-76 (1999).

${ }^{59}$ J. Matienzo, L. I. Yin, S. O. Grim and W. E. Swartz, Jr., "X-Ray Photoelectron Spectroscopy of Nickel Compounds," Inorganic Chemistry, 12 [12] 2762-9 (1973).

${ }^{60} \mathrm{M}$. Bron and R. Holze, "Cyanate and Thiocyanate Adsorption at Copper and Gold Electrodes as Probed by in Situ Infrared and Surface-Enhanced Raman Spectroscopy," Journal of Electroanalytical Chemistry, 385 [1] 105-13 (1995).

${ }^{61} \mathrm{C}$. Le Borgne and M. Chabanel, "Vibrational Study of Ionic Association in Polar Aprotic Solvents. Isocyanate Complexes of Non-Transition-Metal Ions," Journal of Molecular Liquids, 73-74, 171-78 (1997).

${ }^{62}$ G. E. B. Y. Ahlijah and E. F. Mooney, "Attenuated Total Reflection Spectra of Polyatomic Inorganic Anions. II. Nitrogen-Containing Anions," Spectrochimica Acta, Part A: Molecular and Biomolecular Spectroscopy, 25 [3] 619-27 (1969).

${ }^{63}$ D. A. Ben-Efraim, "Detection and Determination of Cyanates, Isocyanates, Isothiocyanates, and Thiocyanates," Chem. Cyanates Their Thio Deriv., 1, 191-236 (1977).

${ }^{64}$ P. V. Kamath, M. Dixit, L. Indira, A. K. Shukla, V. G. Kumar and N. Munichandraiah, "Stabilized $\alpha-\mathrm{Ni}(\mathrm{OH})_{2}$ as Electrode Material for Alkaline Secondary Cells," J. Electrochem. Soc., 141 [11] 2956-9 (1994).

${ }^{65} \mathrm{C}$. Mousty, S. Therias, C. Forano and J.-P. Besse, "Anion-Exchanging Clay-Modified Electrodes: Synthetic Layered Double Hydroxides Intercalated with Electroactive Organic Anions," Journal of Electroanalytical Chemistry, 374 [1-2] 63-69 (1994).

${ }^{66}$ H. K. Roobottom, H. D. B. Jenkins, J. Passmore and L. Glasser, "Thermochemical Radii of Complex Ions," J. Chem. Educ., 76 [11] 1570-73 (1999).

${ }^{67}$ D. R. Hines, G. T. Seidler, M. M. J. Treacy and S. A. Solin, "Random Stacking of a Commensurate Guest Layer in an Ordered Host: Ni/Al Layer-Double-Hydroxides," Solid. State Communications, 101 [11] 835-39 (1997). 


\title{
THREE-COMPONENT LAYER DOUBLE HYDROXIDES BY UREA PRECIPITATION: STRUCTURAL STABILITY AND ELECTROCHEMISTRY
}

A paper to be submitted to Journal of Power Sources

Bora Mavis and Mufit Akinc

\begin{abstract}
Three-component layer double hydroxides (LDHs) with varying compositions were produced by urea precipitation, and tested for their stability and electrochemical performance. Optimum initial metal ion concentrations in the starting solutions were established. Initial $\mathrm{Al}^{3+}$ concentration in the solution needs to be at least $0.015 \mathrm{M}$ for the $\mathrm{LDH}$ formation. From the solutions with initial $\mathrm{Al}^{3+}$ concentration of $0.025 \mathrm{M}$, higher fractions of $\mathrm{Ni}^{2+}$ and $\mathrm{Co}^{2+}$ could be recovered. $\mathrm{Co}^{2+}$ could be incorporated at various levels without disturbing the $\mathrm{LDH}$ structure. $\mathrm{LDH}$ structure proved stable once it formed. Cyanate in the LDHs was dominantly $\mathrm{N}$-bonded which contributed to the stability of the structure. Highest specific discharge capacity delivered by a LDH was $336 \mathrm{mAhr} / \mathrm{g}$, which was about $30 \%$ higher than that by $\beta-\mathrm{Ni}(\mathrm{OH})_{2}$. LDHs reached their stable capacities at a lower rate than either $\beta-\mathrm{Ni}(\mathrm{OH})_{2}$ or the interstratified- $\mathrm{Ni}(\mathrm{OH})_{2}(\alpha+\beta)$. The interstratified sample delivered the highest capacity compared to any of the tested compositions.
\end{abstract}

\section{Introduction}

Nickel hydroxide is used in the positive electrode of the rechargeable alkaline batteries based on nickel, e.g. $\mathrm{Ni} / \mathrm{Cd}, \mathrm{Ni} / \mathrm{Zn}, \mathrm{Ni} / \mathrm{MH}$. It has two polymorphs, namely $\beta$ and $\alpha$, both of which consists of brucite-type layers. Two polymorphs are different in the stacking of these layers. Layers can be well-ordered and closely packed along the c-axis as in the $\beta$-phase (interlayer separation $\approx 4.6 \AA$ ) or could be randomly stacked along the c-axis with water or anionic intercalates residing within the Van der Waals gap as in the $\alpha$-phase. Intercalating species result in a larger interlayer separation ( 7 to $8 \AA$ depending on the size and bonding of 
the intercalating species)..$^{1-4} \alpha$-phase transform to $\beta$-phase upon exposure to the common electrolyte $(6 \mathrm{M} \mathrm{KOH})$ used in this battery system.

In general, it is assumed that there is a hydroxyl deficiency in the basal planes of $\alpha$-phase that would permit the intercalation of negatively charged anions within the interlayer spacing. This could be represented with the formula $\mathrm{Ni}(\mathrm{OH})_{2-\mathrm{x}}\left(\mathrm{A}^{n-}\right)_{x / n} \cdot m \mathrm{H}_{2} \mathrm{O}$, where $\mathrm{A}$ represents the anion. Hydroxyl deficiency can be compensated by the direct insertion of the anion for the hydroxide site. Another alternative mode of intercalation is the intercalation of the free anion between the basal planes. For this alternative to be realized, it is assumed that all hydroxyls are in their crystallographically defined sites and a positively charged layer (i.e. protonated layer, $\left.\left[\mathrm{Ni}(\mathrm{OH})_{2-\mathrm{x}}\left(\mathrm{H}_{2} \mathrm{O}\right)_{\mathrm{x}}\right]^{\mathrm{x}+}\right)$ exists. ${ }^{1,5,6}$ Yet another possibility is the existence of a trivalent cation within the basal planes which would permit both modes of anion intercalation. ${ }^{6}$

Intercalation compounds that are represented by $\left[\mathrm{M}^{2+}{ }_{1-\mathrm{x}} \mathrm{M}^{3+}{ }_{\mathrm{x}}(\mathrm{OH})_{2}\right]^{\mathrm{x+}}\left[\mathrm{A}^{\mathrm{n-}}{ }_{\mathrm{x} / \mathrm{n}}\right]^{\mathrm{x}-} \cdot \mathrm{mH}_{2} \mathrm{O}$ has been investigated under the name Layer Double Hydroxides (LDHs). These compounds have also been referred to as hydrotalcite-like compounds, mixed metal-layered hydroxides or anionic clays. Again stacking of brucite-like octahedral layers forms their crystal structure. Direct substitution of the divalent cation $\left(\mathrm{M}^{2+}\right.$ can be $\mathrm{Mg}^{2+} \mathrm{Mn}^{2+} \mathrm{Fe}^{2+} \mathrm{Co}^{2+} \mathrm{Ni}^{2+} \mathrm{Cu}^{2+} \mathrm{Zn}^{2+}$ or $\mathrm{Ca}^{2+} \ldots$ ) with a trivalent ion $\left(\mathrm{M}^{3+}\right.$ can be $\left.\mathrm{Al}^{3+} \mathrm{Cr}^{3+} \mathrm{Mn}^{3+} \mathrm{Fe}^{3+} \mathrm{Co}^{3+} \mathrm{Ni}^{3+} \ldots\right)$ creates a permanent positive layer charge. This necessitates the intercalation $\left(A^{n-}\right.$ can be selected from a wide range of inorganic anions, organic anions and complexes) between the layers as charge balancing species. ${ }^{7-9}$

$\mathrm{Co}^{2+}$ is known to irreversibly oxidize to $\mathrm{Co}^{3+}$ during charging and claimed to supply such an extra charge to the layers when used in the $\mathrm{Ni}(\mathrm{OH})_{2}$ system. ${ }^{10,11}$ It is possible to use urea precipitation method in order to produce pure $\alpha-\mathrm{Ni}(\mathrm{OH})_{2}{ }^{\prime} \mathrm{s}^{2,12-18}$ or cobalt doped $\alpha$ $\mathrm{Ni}(\mathrm{OH})_{2}$ 's that are more or less stable under electrochemical cycling. ${ }^{19}$

Use of a trivalent cation like $\mathrm{Al}^{3+}$ (i.e. producing a Ni/Al LDH) has proven to be another effective method of increasing the stability of $\alpha$-phase in the electrolyte. ${ }^{20,21}$ Costantino et al. reported the first use of urea precipitation method in producing Ni/Al LDHs. Nevertheless their main focus was to prepare intercalation compounds with alkoxides and they did not study its electrochemical properties. ${ }^{22}$ 
Concurrent to this work, a number of articles have appeared on the electrochemical properties of the Ni/Al based LDHs. ${ }^{23-27}$ Maximum reported capacities were $238 \mathrm{mAhr} / \mathrm{g}$ at $1 \mathrm{C}$ rate ${ }^{27}, 303 \mathrm{mAhr} / \mathrm{g}$ at $0.33 \mathrm{C}$ rate ${ }^{26}$ and $340 \mathrm{mAhr} / \mathrm{g}$ at $0.2 \mathrm{C}$ rate (a battery rated at 1000 $\mathrm{mAh}$, when discharged at $\mathrm{C}$ rate will provide $1000 \mathrm{~mA}$ for 1 hour whereas, at $0.2 \mathrm{C}$ rate same battery would provide $200 \mathrm{~mA}$ for 5 hours). In two most recent studies three-component LDHs (TC-LDHs) were produced and tested: Ni/Al/Zn resulted in $425 \mathrm{mAhr} / \mathrm{g}$ at C-rate ${ }^{28}$ and $\mathrm{Ni} / \mathrm{Al} / \mathrm{Co}$ which could be obtained only as a turbostratic phase delivered $319 \mathrm{mAhr} / \mathrm{g}$ at about $0.2 \mathrm{C}$ rate ${ }^{29}$. Wang and co-workers have recently reported an interesting result from a "nanostructural multiphase" $\mathrm{Ni}(\mathrm{OH})_{2}$ (i.e. interstratified $\alpha$ and $\beta$ phases) produced by doping $\mathrm{Ni}(\mathrm{OH})_{2}$ with various levels of $\mathrm{Co}, \mathrm{Zn}$, and $\mathrm{Mn}^{4}$ At least in one case they were able to obtain a capacity of $375 \mathrm{mAhr} / \mathrm{g}$ at $0.2 \mathrm{C}$.

To our knowledge precipitation of a TC-LDH with urea decomposition has not been reported. Furthermore, in the sole attempt with $\mathrm{Ni} / \mathrm{Al} / \mathrm{Co}$, the $\mathrm{LDH}$ structure was not observed. ${ }^{29}$ We explored the viability of urea precipitation as a method to produce $\mathrm{Ni} / \mathrm{Al} / \mathrm{Co}$ TC-LDHs and tested their stability and electrochemical characteristics, and compared with a commercially available $\beta-\mathrm{Ni}(\mathrm{OH})_{2}$ sample and a sample with interstratified structure which was produced by heterogeneous precipitation.

\section{Experimental Method}

\section{Powder Synthesis and Ageing}

Precipitation of three-component LDHs (TC-LDHs) by urea decomposition was carried out under similar experimental conditions previously described for precipitation of $\alpha$ $\mathrm{Ni}(\mathrm{OH})_{2}$ and $\mathrm{Ni} / \mathrm{Al}$ LDHs. ${ }^{30-32}$ Stock solutions of metal ions $\left(0.8 \mathrm{M}^{\text {in Ni }} \mathrm{Ni}^{2+}\right.$ and $0.5 \mathrm{M}^{2} \mathrm{Co}^{2+}$ and $\mathrm{Al}^{3+}$ ) were prepared from reagent grade $\mathrm{NiCl}_{2} \cdot 6 \mathrm{H}_{2} \mathrm{O}, \mathrm{AlCl}_{3} \cdot 6 \mathrm{H}_{2} \mathrm{O}$ (Fisher Scientific) and $\mathrm{CoCl}_{2} \cdot 6 \mathrm{H}_{2} \mathrm{O}$ (J. T. Baker Chemical Co.). Appropriate volumes of stock solutions were mixed in $1 \mathrm{~L}$ Pyrex Brand media bottles and the balance of $500 \mathrm{~mL}$ was added up with deionized water $(18 \mathrm{M} \Omega-\mathrm{cm})$. This solution was preheated to $90 \pm 1{ }^{\circ} \mathrm{C}$. As a precipitation agent, $90.0900 \mathrm{~g}$ of reagent grade urea (Fisher Scientific) was dissolved in $250 \mathrm{~mL}$ deionized water and added to the preheated $\mathrm{Ni}^{2+} / \mathrm{Co}^{2+} / \mathrm{Al}^{3+}$ solution. Concentrations of cations were adjusted such that they would add up to $0.1 \mathrm{M}$ in the final volume (i.e. $750 \mathrm{~mL}$ ). The solution was 
digested for 2 hours before quenching the reaction in an ice-water bath. Pressure was kept near ambient during digestion, by attaching a balloon to the reaction bottle and the solution was stirred continuously. Precipitates were separated from the mother liquor by centrifugation, washed three times and saved for further analysis after drying at $70{ }^{\circ} \mathrm{C}$. Effects of $\mathrm{Co}^{2+}$ and $\mathrm{Al}^{3+}$ concentrations were investigated by precipitating LDHs with $\mathrm{Ni}^{2+}{ }_{1-}$ $(x+y) / \mathrm{Co}^{2+}{ }_{x} / \mathrm{Al}^{3+}{ }_{y}$, where $\mathrm{x}$ and $\mathrm{y}$ were varied between 0.00 and, 0.25 (refer to Table 1 for sample compositions and identification).

Synthesized powders $(\approx 0.5 \mathrm{~g})$ were aged in $35 \mathrm{~mL}$ of $6 \mathrm{M} \mathrm{KOH}$ for 1 week in order to monitor the effects of electrolyte solution on stability of structures formed.

\section{Characterization}

Yield of reactions were accessed by measuring percent recovery of metal ions from the solution. Supernatant solutions from the centrifuge were stored at $-5{ }^{\circ} \mathrm{C}$ for analysis. For $\left[\mathrm{Ni}^{2+}\right]$ both UV/VIS (procedure described elsewhere ${ }^{31}$ ) and ICP spectroscopies were used and results were averaged, whereas $\left[\mathrm{Co}^{2+}\right]$ and $\left[\mathrm{Al}^{3+}\right]$ were determined only by ICP.

FTIR data was collected in transmission mode with $\mathrm{KBr}$ pellets. Spectra were taken using an air-purged Bomem - Hartmann and Braun - MB 102 unit with $4 \mathrm{~cm}^{-1}$ resolution. $\mathrm{KBr}$ pellets were prepared by mixing $0.70-0.75 \mathrm{wt} \%$ ground powder into $\mathrm{KBr}$ matrix and then pressing to $80 \mathrm{MPa}$ with an evacuable die. Pure $\mathrm{KBr}$ was run as the reference. Certain regions in spectra (especially $\approx 2200 \mathrm{~cm}^{-1}$ where $\mathrm{C}-\mathrm{N}$ of cyanate is located) were analyzed by peak deconvolution details of which are described previously. ${ }^{33}$

Structural characterization was made by powder X-ray diffraction (Scintag X1-365) unit with $\mathrm{Cu}-\mathrm{K} \alpha$ radiation. Crystallite size was determined by $\mathrm{X}$-ray line broadening and using Scherrer expression. Instrumental broadening of the peaks was accounted for by correcting the FWHM (full width at half maximum) values with that of the crystalline silicon

reference. ${ }^{34}$ Specific surface area of powders was measured with 11 -point BET method after outgasing the sample at $100^{\circ} \mathrm{C}$ for 12 hours (Quantachrome Autosorb - 1). Specific surface area values reported are the average of 5 consecutive runs.

All electrochemical studies were performed using a Radiometer - PGP 201 Potentiostat / Galvanostat unit in combination with a three-electrode cell. Chronopotentiometry 
experiments were performed in $6 \mathrm{M} \mathrm{KOH}$ solutions. A Pt wire electrode was used as the auxiliary electrode while the measurements were referenced to a $\mathrm{Hg} / \mathrm{HgO}$ electrode. Working electrodes were produced by pressing ( $85 \mathrm{MPa}$ ) an active material paste between two circular porous nickel foams, one of which was initially attached to a Pt wire (current collector). Paste mixture contained active powder along with carbon (60/40 wt\%, respectively) that was kneaded with appropriate amount of PTFE dispersed in water (8.6 wt\%). Carbon provides a conductive path for electron transfer $\left(\mathrm{Ni}(\mathrm{OH})_{2}\right.$ is a p-type semi-conductor with limited conductance ${ }^{35-37}$ ). PTFE acts as binder for attaching the paste to the foams. The electrodes were encapsulated in a glass rod, which was then sealed from top to prevent the electrolyte wetting the current collector. In the preliminary experiments, electrodes were charged and discharged at $0.2 \mathrm{C}$ rate up to $150 \%$ of the theoretical capacity of $\beta-\mathrm{Ni}(\mathrm{OH})_{2}\left(289 \mathrm{mAh} / \mathrm{g}^{26,37}\right)$ for 12 cycles followed by cycling at 6 different rates and then finally at $C$ rate for 40 cycles. Once the experimental conditions were set, electrodes were cycled at $\mathrm{C}$ rate up to $150 \%$ of the theoretical capacity for 40 cycles. Specific capacities are determined by taking the derivative of voltage versus specific current plots and determining the maximum of the derivative. All charge and discharge cycles were performed between $100 \mathrm{mV}$ and $600 \mathrm{mV}$ against $\mathrm{Hg} / \mathrm{HgO}$ electrode.

In order to compare the electrochemical performance of TC-LDHs produced in this study to commercial $\beta-\mathrm{Ni}(\mathrm{OH})_{2}$ was tested under the same conditions. In addition, an interstratified ( $\alpha$ - $\beta$ phase mixture $) \mathrm{Ni}(\mathrm{OH})_{2}$ sample was produced by titrating a $180 \mathrm{~mL}$ aqueous mixture of $\mathrm{Ni}^{2+}$ and $\mathrm{Co}^{2+}(0.09$ and $0.01 \mathrm{M}$ in the final solution, respectively) with $40 \mathrm{~mL}$ of aqueous mixture of $\mathrm{NaOH}$ and $\mathrm{Na}_{2} \mathrm{CO}_{3}(0.14$ and $0.06 \mathrm{M}$ in the final solution, respectively) in 60 minutes at $90^{\circ} \mathrm{C}$. After 60 minutes of digestion, powders were characterized in the same way as LDH compositions described above.

\section{Results}

\section{Recovery}

Compositions studied and the percentage of cations that could be recovered from those solutions is summarized in Table 1. Generally, higher fractions of cations were recovered as the concentration of trivalent cation $\mathrm{Al}^{3+}$ in the starting solution increases. While all of $\mathrm{Al}^{3+}$ 
was recovered with 0.005 and $0.015 \mathrm{M} \mathrm{All}^{3 \cdot+}$, approximately 84 to $94 \%$ of $\mathrm{Al}^{3+}$ was incorporated in the precipitate when $0.025 \mathrm{M} \mathrm{Al}^{3+}$ was used. However, $\mathrm{Ni}^{2+}$ and $\mathrm{Co}^{2+}$ recoveries were the highest for these cases. With a composition identical to sample A4 (Table 1) UV/VIS spectroscopic analysis showed that practically all of $\mathrm{Ni}^{2+}$ precipitated out in three hours. Nickel recovery was highest with the highest initial $\mathrm{Al}^{3+}$ concentration and in the absence of $\mathrm{CO}^{2+}$ (A4 through D4). It seems that a composition with high $\left[\mathrm{Al}^{3+}\right]_{0}$ and low $\left[\mathrm{Co}^{2+}\right]_{0}$ such as $\mathrm{A} 3$, should be a good starting point for electrochemical experiments.

\section{Structural Stability}

Typical XRD patterns of $\beta$, interstratified $\alpha+\beta, \alpha$, and LDHs are given in Figure 1 . It can be seen that layer separation increases, in the same order. Interstratified structure shows that intercalation in a segment of layers decreases the interlayer separation (i.e. basal spacing) in the adjacent layers (to values even smaller than in $\beta$ due to the 006 of $\alpha$-phase). Asymmetric peak due to (10) for $\alpha$ peak becomes symmetric peak (012) in LDH as layers are aligned in LDH. Results of interlayer separation and crystallite size measurements from all compositions before and after one week of ageing in $6 \mathrm{M} \mathrm{KOH}$ are given in Table 1. An initial $\mathrm{Al}^{3+}$ concentration of $0.005 \mathrm{M}$ (C series) was not enough to trigger the formation of LDH phase while $0.015 \mathrm{M}$ was sufficient. While interlayer separation among $\mathrm{A}$ and $\mathrm{B}$ compositions did not show significant variation, it was notably lower for the $\mathrm{C}$ and $\mathrm{D}$ series, $\mathrm{C}$ being the intermediate. Upon ageing, although $\mathrm{A}$ series showed a slight decrease in the basal spacing, B series remained unchanged. On the other hand, basal spacing seems to expand in $\mathrm{C}$ and $\mathrm{D}$ series with ageing. Considering that $\mathrm{A} / \mathrm{B}$ and $\mathrm{C} / \mathrm{D}$ series give patterns characteristic to $\alpha$-phase and the LDH, respectively, these differences can be attributed to the different ageing mechanisms in these phases. Fact that interlayer separation varies ever so slightly within a series makes reference to the minimal change in the intercalating species coordination chemistry within the series. Except in one composition (A3), crystallite sizes decreased within a series for all series as the $\left[\mathrm{CO}^{2+}\right]_{0}$ decreased. Although there was one overlapping result between $\mathrm{A}$ and $\mathrm{B}$ series, all crystallite sizes measured from $\mathrm{A}$ series was larger than $B$ and both were larger than ones measured from $C$ and $D$ series. The differences between $\mathrm{C}$ and $\mathrm{D}$ series were considerably smaller than the ones among other series. 
Table 1. TC-LDH compositions studied and the percentage of metal ions recovered from the mother liquors as precipitate ${ }^{\mathrm{a}}$. Also given are the calculated interlayer separation and crystallite size along c-axis before and after the one week ageing in $6 \mathrm{M} \mathrm{KOH}$.

\begin{tabular}{|c|c|c|c|c|c|c|c|c|c|c|}
\hline \multirow[b]{2}{*}{ Sample } & \multirow[b]{2}{*}[\mathrm{All}^{3+}]{$_{0}$} & \multirow[b]{2}{*}[\mathrm{Ni}^{2+}]{$_{0} /\left[\mathrm{Co}^{2+}\right]_{\mathrm{o}}$} & \multicolumn{3}{|c|}{$\%$ Recovered $^{\mathrm{b}}$} & \multirow[b]{2}{*}{ Phase $^{\mathrm{d}}$} & \multicolumn{2}{|c|}{$\begin{aligned} & d_{003} \\
\pm & 0.02(\AA)\end{aligned}$} & \multicolumn{2}{|c|}{$\begin{array}{l}\text { Crystallite size } \\
\quad \pm 0.2(\mathrm{~nm})\end{array}$} \\
\hline & & & $\mathrm{Ni}^{2+}$ & $\mathrm{Co}^{2+}$ & $A l^{3+}$ & & Fresh & Aged & Fresh & Aged \\
\hline Al & \multirow{4}{*}{0.025} & $0.050 / 0.025$ & 74 & 52 & 89 & \multirow{4}{*}{ LDH } & 7.71 & 7.70 & 14.0 & 14.6 \\
\hline$A 2$ & & $0.060 / 0.015$ & 75 & 67 & 93 & & 7.72 & 7.70 & 12.1 & 12.7 \\
\hline$A 3$ & & $0.070 / 0.005$ & 87 & 86 & 94 & & 7.78 & 7.71 & 12.2 & 13.2 \\
\hline A4 & & $0.075 / 0.000$ & 78 & - & 84 & & 7.78 & 7.75 & 10.7 & 11.4 \\
\hline$B I$ & \multirow{4}{*}{0.015} & $0.060 / 0.025$ & 73 & 52 & 100 & \multirow{4}{*}{$\mathrm{LDH}$} & 7.69 & 7.70 & 11.2 & 12.5 \\
\hline$B 2$ & & $0.070 / 0.015$ & 69 & 59 & 100 & & 7.69 & 7.69 & 9.9 & 11.5 \\
\hline$B 3$ & & $0.080 / 0.005$ & 64 & 63 & 100 & & 7.70 & 7.70 & 8.8 & 11.0 \\
\hline$B 4$ & & $0.085 / 0.000$ & 79 & - & 100 & & 7.66 & 7.69 & 8.0 & 10.8 \\
\hline $\mathrm{Cl}$ & \multirow{4}{*}{0.005} & $0.070 / 0.025$ & 65 & 58 & 100 & \multirow{4}{*}{$\alpha$} & 7.43 & 7.51 & 6.9 & 7.1 \\
\hline$C 2$ & & $0.080 / 0.015$ & 57 & 51 & 100 & & 7.41 & 7.54 & 6.5 & 7.5 \\
\hline$C 3$ & & $0.090 / 0.005$ & 50 & 36 & 100 & & 7.41 & 7.49 & 6.4 & 6.4 \\
\hline$C 4$ & & $0.095 / 0.000$ & 69 & - & 100 & & 7.40 & N.S. & 6.2 & N.S. \\
\hline$D I$ & \multirow{4}{*}{0} & $0.075 / 0.025$ & 45 & 52 & - & & 7.23 & 7.35 & 7.2 & 6.7 \\
\hline$D 2$ & & $0.085 / 0.015$ & 45 & 59 & - & & 7.21 & 7.21 & 6.7 & 4.8 \\
\hline$D 3$ & & $0.095 / 0.005$ & 52 & 66 & - & & 7.19 & N.S. & 6.6 & N.S. \\
\hline D4 & & $0.100 / 0.000$ & 44 & - & - & & 7.26 & N.S. & 6.1 & N.S. \\
\hline
\end{tabular}

${ }^{a}$ Note that $\mathrm{D} 4$ and $\mathrm{A} 4$ are the compositions that were studied extensively in our previous communication, ${ }^{33 \mathrm{~b}}$ After 2 hours of digestion at $90{ }^{\circ} \mathrm{C},{ }^{\circ}$ Crystallite size along c-axis, ${ }^{\mathrm{d}}$ Decided by the appearance of the asymmetric peak between $30^{\circ}$ to $55^{\circ} 2 \theta$. An asymmetric peak is due to turbostratic $\alpha$ phase, ${ }^{\mathrm{e}}$ N.S. denotes "not stable". 
Ageing consistently increased the crystallite size along the c-axis among the LDHs and showed mixed effect on $\alpha$-phases. With increase in $\left[\mathrm{Co}^{2+}\right]$, stability of $\mathrm{C}$ series $(\alpha$-phase with insufficient $\mathrm{Al}^{3+}$ ) improved while the crystallite size either increased or unaltered. On the other hand, in the absence of $\mathrm{Al}^{3+}$ transformation to $\beta$ took place faster and more $\mathrm{CO}^{2+}$ was required to slow down the transformation. It is interesting to note that ageing decreased the crystallite size of $\mathrm{D}$ series (no $\mathrm{Al}^{3+}$ ). Intuitively, crystal growth with aging was expected. $\mathrm{A}$ decrease in crystallite size might imply partial dissolution of $\alpha$ in favor of $\beta$ phase. Electrochemical tests were limited to compositions forming stable LDHs.

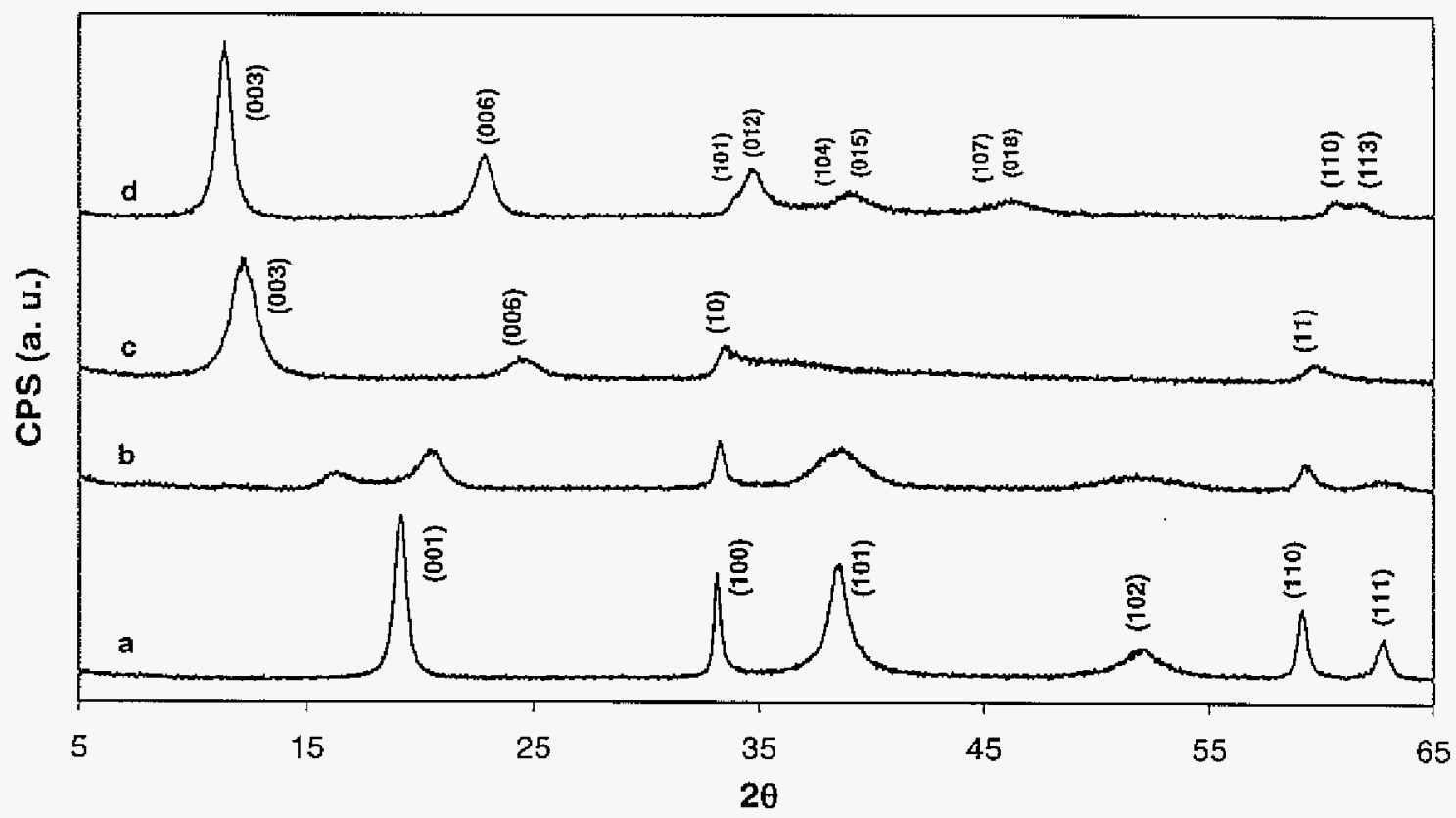

Figure 1. Typical XRD patterns collected from a. $\beta$, b. interstratified $\alpha$ and $\beta$, c. $\alpha$ and d. LDH phases.

\section{Intercalating Species}

$\alpha-\mathrm{Ni}(\mathrm{OH})_{2}$ and LDHs precipitated by urea decomposition show interesting signatures in the FTIR spectra. ${ }^{31,33}$ Features were assigned to hydroxyl stretching in the brucite type layers $\left(3640 \mathrm{~cm}^{-1}\right)$, hydrogen bonding between intercalating species and the layers, and similar alternatives ending with a hydrogen bond formation, $\left(3600-3300 \mathrm{~cm}^{-1}\right), \mathrm{C}-\mathrm{N}$ stretch of cyanate $\left(2200 \mathrm{~cm}^{-1}\right), \mathrm{H}-\mathrm{O}-\mathrm{H}$ bending mode of water $\left(1600-1650 \mathrm{~cm}^{-1}\right)$, carbonaceous species (1300-1500 $\left.\mathrm{cm}^{-1}\right)$, combination of some modes of carbonaceous species and cyanate 
deformation mode $\left(620-720 \mathrm{~cm}^{-1}\right)$ and metal-O stretches combined with in-plane OH deformations $\left(400-550 \mathrm{~cm}^{-1}\right)$. From these features, the peak around $2200 \mathrm{~cm}^{-1}$ was studied in some detail due to crucial role of cyanate in the urea precipitated powders. It showed interesting shoulder features that could be attributed to different modes of intercalation of cyanate within the layers. It was demonstrated that relative population of a certain mode could be qualitatively compared to another by looking at the percent area under the relevant mode. ${ }^{33}$ Analyses revealed that for LDHs, cyanate remains $N$-bonded throughout the digestion, while it switches from $\mathrm{N}$-bonded to O-bonded cyanate in the turbostratic $\alpha$-phase. Similar peak analyses were carried-out for as-prepared powders produced in this study and results are summarized in Table 2 . While the population of $\mathrm{N}$-bonded cyanate gradually decreases, that of O-bonded cyanate increases with decreasing $\left[\mathrm{Al}^{3+}\right]_{0}$ (i.e. in going from $\mathrm{A}$ to $\mathrm{D}$ or from LDH to $\alpha$ structure). Trend is most obvious in absorptions assigned to both modes of cyanates at "atop" sites. These results are in excellent agreement with our previous observations. Similar transient features in other absorption peaks were also observed. As an example, the $1300-1500 \mathrm{~cm}^{-1}$ region (carbonaceous species and water absorptions) of A4/B4/C4/D4 is depicted in Figure 2A. It can be seen that carbonate coordination seems to change from free carbonate ion $\left(\mathrm{D}_{3 \mathrm{~h}}\right.$, a.k.a. tridentate) to unidentate $\left(\mathrm{C}_{\mathrm{s}}\right)$ and bidentate $\left(\mathrm{C}_{2 \mathrm{v}}\right)$ as the structure changes from $\mathrm{LDH}$ to $\alpha$-phase with decreasing $\left[\mathrm{Al}^{3+}\right]_{0}$. Absorptions with all three coordinations seem to appear for the intermediate compositions. It is known that interlamellar carbonate in LDH is surrounded by water molecules. Therefore symmetry of carbonate species in LDH should resemble "free ions" $\left(D_{3 h}\right){ }^{21,38}$ It is then expected that a reduction in hydration level should follow a change in carbonate coordination. On the other hand, an increase in hydration is associated with broadening and elevation of $3300-3600 \mathrm{~cm}^{-1}$ band in FTIR spectra (i.e. extensive hydrogen bond formation). Figure $2 B$ shows the transition in hydration level as the structure changes from LDH to $\alpha$-phase. Variations in the intercalation chemistry of aged samples and samples submitted to electrochemical tests are subject of future research. 


\section{Specific Surface Area}

Results of specific surface area measurements from select samples are given in Table 3 . For the A series, there is no identifiable trend, however both B3 and D4 were slightly higher than all $\mathrm{A}$ compositions. While all compositions tested had notably higher surface areas with respect to $\beta$-phase, sample with the interstratified structure showed an even higher surface area compared to these compositions. Although surface area itself is not indicative or powder's capacity as electrode material, for a given composition and structure, higher the surface area higher the rate, and higher capacity.

Table 2. Deconvolutions results from compositions studied.

\begin{tabular}{|c|c|c|c|c|c|c|}
\hline $\begin{array}{c}\text { Adsorption } \\
\text { Sites }^{\mathrm{a}}\end{array}$ & $\begin{array}{l}\text { Calculated } \\
\left(\mathrm{cm}^{\mathrm{a}}\right)\end{array}$ & Series & $\mathbf{A}$ & B & C & $D^{e}$ \\
\hline \multirow{2}{*}{$\begin{array}{c}\text { Cyanate- } O \\
\text { atop }\end{array}$} & \multirow{2}{*}{2246} & $\omega_{\mathrm{C}-\mathrm{N}}\left(\mathrm{cm}^{-1}\right)^{\mathrm{b}}$ & $2240 \pm 2^{d}$ & $2256 \pm 1$ & $2260 \pm 2$ & $2244 \pm 3$ \\
\hline & & $\%$ Area $^{\mathrm{c}}$ & $10 \pm 2^{d}$ & $15 \pm 4$ & $27 \pm 2$ & $39 \pm 3$ \\
\hline \multirow{2}{*}{$\begin{array}{c}\text { Cyanate- } O \\
\text { bridge }\end{array}$} & \multirow{2}{*}{2228} & $\omega_{\mathrm{C}-\mathrm{N}}\left(\mathrm{cm}^{-1}\right)$ & - & - & - & - \\
\hline & & \%Area & - & - & - & - \\
\hline \multirow{2}{*}{$\begin{array}{c}\text { Cyanate } O \\
\text { 4-fold }\end{array}$} & \multirow{2}{*}{2212} & $\omega_{\mathrm{C}-\mathrm{N}}\left(\mathrm{cm}^{-1}\right)$ & $2205 \pm 1$ & $2214 \pm 1$ & $2219 \pm 1$ & $2205 \pm 0$ \\
\hline & & $\%$ Area & $26 \pm 2$ & $32 \pm 3$ & $28 \pm 4$ & $11 \pm 2$ \\
\hline \multirow{2}{*}{$\begin{array}{c}\text { Isocyanate } N \\
\text { atop }\end{array}$} & \multirow{2}{*}{2182} & $\omega_{\mathrm{C}-\mathrm{N}}\left(\mathrm{cm}^{-1}\right)$ & $2182 \pm 1$ & $2180 \pm 1$ & $2174 \pm 2$ & $2176 \pm 0$ \\
\hline & & \%Area & $62 \pm 3$ & $50 \pm 2$ & $31 \pm 2$ & $19 \pm 3$ \\
\hline \multirow{2}{*}{$\begin{array}{c}\text { Isocyanate- } N \\
\text { bridge }\end{array}$} & \multirow{2}{*}{2163} & $\omega_{\mathrm{C}-\mathrm{N}}\left(\mathrm{cm}^{-1}\right)$ & - & - & - & - \\
\hline & & \%Area & - & - & - & - \\
\hline \multirow{2}{*}{$\begin{array}{c}\text { Isocyanate-N } \\
\text { 4-fold } \\
\end{array}$} & \multirow{2}{*}{2151} & $\omega_{\mathrm{C}-\mathrm{N}}\left(\mathrm{cm}^{-1}\right)$ & - & - & - & $2155 \pm 1$ \\
\hline & & $\%$ Area & - & $=$ & - & $11 \pm 2$ \\
\hline \multirow{2}{*}{$\begin{array}{c}\text { Other } \\
\text { Geometries }\end{array}$} & \multirow{2}{*}{$2057^{f}$} & $\omega_{\mathrm{C}-\mathrm{N}}\left(\mathrm{cm}^{-1}\right)$ & $2120 \pm 1$ & $2119 \pm 1$ & $2115 \pm 1$ & $2118 \pm 3$ \\
\hline & & $\%$ Area & $1 \pm 0$ & $3 \pm 1$ & $10 \pm 1$ & $20 \pm 2^{\mathrm{c}}$ \\
\hline
\end{tabular}

a Calculated positions and assignments are for cyanate adsorbed on $\mathrm{Ni}(100)$ as reported by $\mathrm{Yang}$ and Whitten ${ }^{39}$. A detailed discussion can be found in our previous communication, ${ }^{33 \mathrm{~b}}$ Observed position of $\mathrm{C}$ $\mathrm{N}$ stretch of cyanate in this work, "Balance $(\approx 2 \%)$ is the area under the "artifact" peaks due to $\mathrm{CO}_{2}$ in the measurement system, d Standard deviations were obtained from the 4 different compositions within one series, "Due to the large particle sizes $\mathrm{KBr}$ pellets prepared from these samples were not as homogeneous as in others and $O C N^{-}$peak was associated with a large background on both sides which could hardly be treated. For more accurate representation reader should refer to our previous communication, ${ }^{33}$, "Yang et al. also calculated the energetics of the side-on bonded cyanate and $\mathrm{N}$-bonded cyanate with different tilt angles. It is plausible that this additional mode could be assigned to one of those discussed. ${ }^{39}$ 

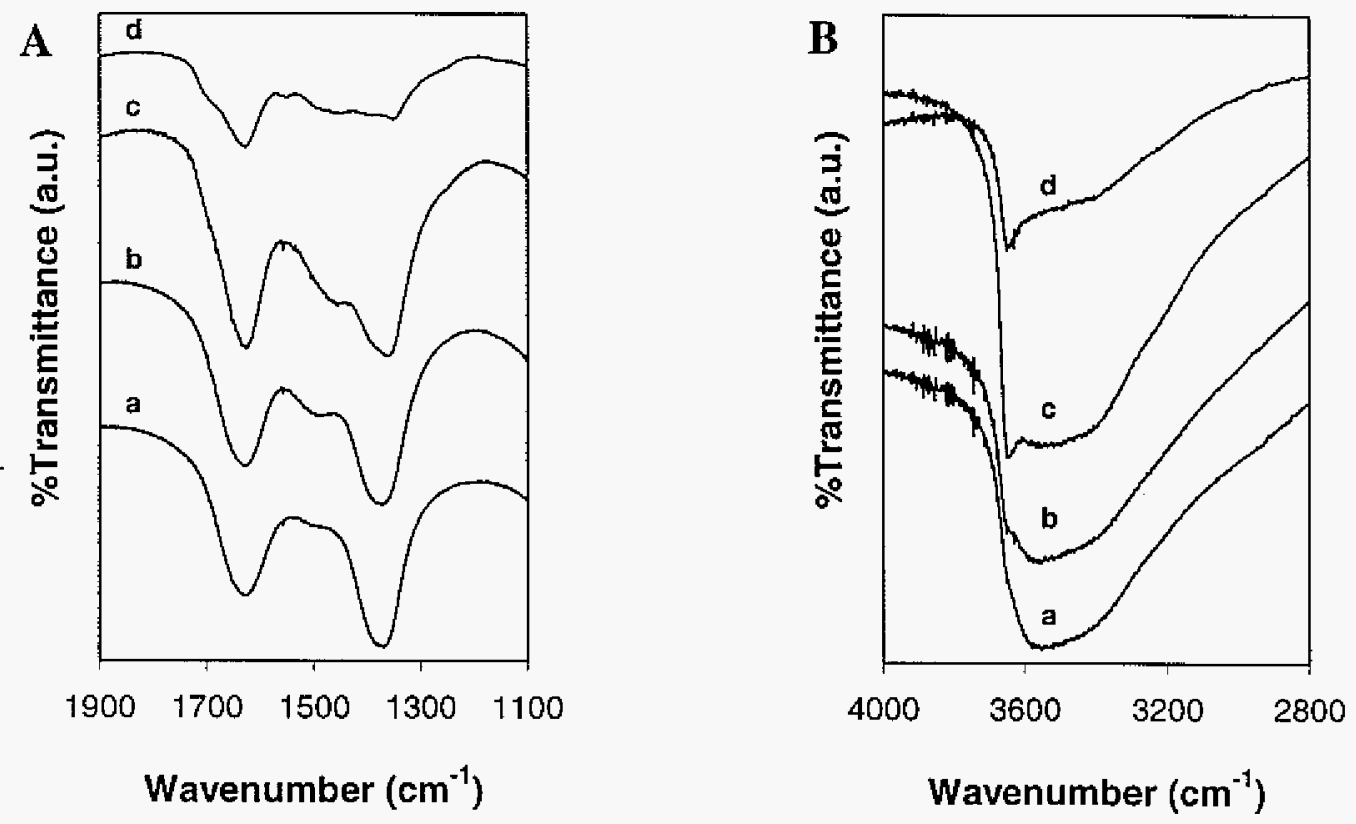

Figure 2. Evolution of FTIR spectra of; $\mathbf{A}$. carbonaceous species and $\mathbf{B}$. water around the $3300-3600 \mathrm{~cm}^{-1}$ region (indicating hydration level) observed in samples a. A4, b. B4, c. C4 and d. D4.

Table 3. Specific surface areas of select samples.

\begin{tabular}{ccc} 
Sample & Surface Area $^{a}$ & $s^{\mathrm{b}}$ \\
\hline$\beta-\mathrm{Ni}(\mathrm{OH})_{2}$ & 14.6 & 0.3 \\
Interstratified $(\alpha+\beta)$ & $111.5^{\mathrm{c}}$ & - \\
\hline$A 1$ & 55.7 & 0.9 \\
$A 2$ & 58.8 & 0.5 \\
$A 3$ & 55.7 & 0.6 \\
$A 4$ & 65.7 & 0.7 \\
\hline$B 3$ & 85.0 & 3.4 \\
\hline$D 4$ & 94.6 & 1.7 \\
\hline
\end{tabular}

${ }^{a}$ Specific surface area measured by 11 -point BET method in $\mathrm{m}^{2} / \mathrm{g},{ }^{b}$ Sample standard deviation from 5 consecutive runs, ${ }^{\mathrm{c}}$ Average of 2 runs.

\section{Capacity Measurements}

Judging by the percentage of metal ions recovered from the solution, sample A3 seemed to provide the optimum synthesis conditions. Therefore, electrochemical tests were carried 
out with this sample. First, the effect of $\mathrm{Al}^{3+}$ was studied by comparing $\mathrm{A} 3\left(\left[\mathrm{~A}^{3+}\right]_{0}=0.025 \mathrm{M}\right)$ with B3 $\left(\left[\mathrm{A}^{3+}\right]_{0}=0.015 \mathrm{M}\right)$, both of which had same $\left[\mathrm{Co}^{2+}\right]_{0}=0.005 \mathrm{M}$. Results of initial 12 cycles with $0.2 \mathrm{C}$ rate are summarized in Figures 3 and 4 . Also depicted is the performance of $\beta$-phase (Aldrich Chemical Company) under identical conditions. Measured values are subject to $5 \%$ error due variations in electrode preparation. Although $\beta$-phase reached its stabilized capacity faster than the LDHs, the latter outperformed the $\beta$-phase after a relatively short number of cycles. It is also important that both LDHs delivered their high capacities at higher and more stable voltages. $\beta$-phase investigated in this work had displayed signatures from intercalated water and carbonate in its FTIR spectra. Although it was determined to be $\mathrm{X}$-Ray phase-pure it is not clear if there is a slight interstratification with $\alpha$-phase or surface adsorption. It was recently noted that interstratified structures could deliver higher specific capacities. ${ }^{4}$ Observation of surprisingly high specific capacity from $\beta$-phase $(\approx 90 \%$ of theoretical capacity) invokes the possibility of a slight interstratification and/or optimized electrode preparation method.

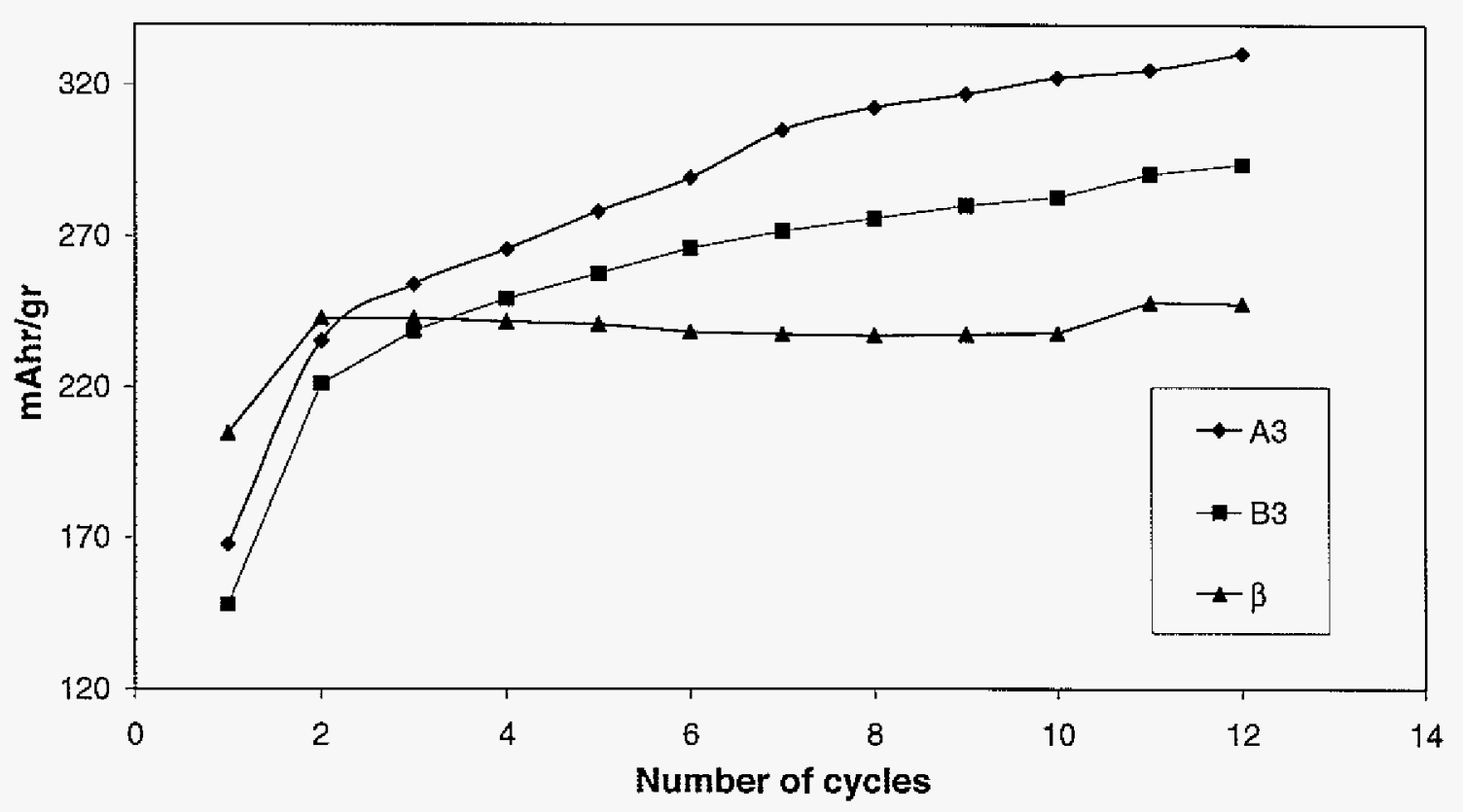

Figure 3. Capacities measured from initial 12 cycles (at $0.2 \mathrm{C}$ rate) for samples $\mathrm{A} 3, \mathrm{~B} 3$ and $\beta$-phase. 


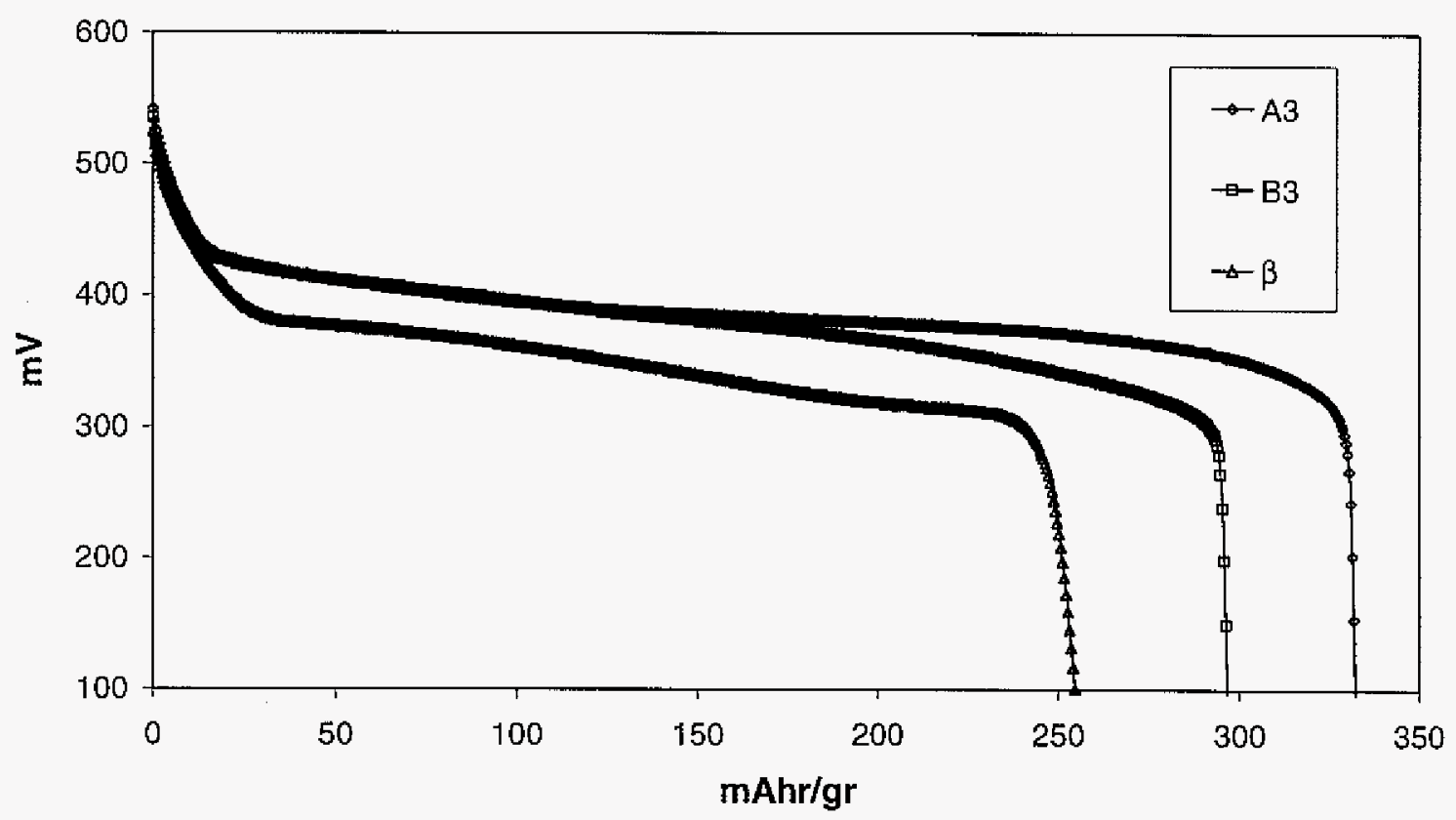

Figure 4. $12^{\text {th }}$ cycles from Figure 3 at $0.2 \mathrm{C}$ rate from samples $\mathrm{A} 3, \mathrm{~B} 3$ and $\beta$-phase.

Percent drop in capacity with increasing discharge rates is a parameter that has significance in practical applications. Figure 5 shows the drop in capacity of the same samples at 6 different rates. At around $\mathrm{C}$ rate the drop was not significant for any of the samples. In addition, the drops observed at relatively higher rates were comparable to what is reported in literature. ${ }^{28}$ It is also noted that at higher discharge rates the capacity drop in $A 3$ was to a smaller extent compared to that in $\mathrm{B} 3$ and the $\beta$-phase.

Long-term electrochemical stability is one of the most important characteristics of electrode material. Figure 6 presents the charge capacity of the three samples for 40 cycles at $\mathrm{C}$ rate. All compositions delivered relatively stable capacities. In addition, A3 continued to exhibit the highest capacity of the three.

As A3 showed the highest capacity and electrochemical stability, the effect of $\mathrm{Co}^{2+}$ content was determined by subjecting the A1/A2/A4 to 40 cycles at $\mathrm{C}$ rate. Results are compared to that from the similarly treated interstratified $(\alpha+\beta)$ sample in Figure 7 . The results indicate that the initial 12 cycles and the cycles at different rates applied to A3, B3 and $\beta$-phase prior to the subsequent 40 cycles bring these samples to the stable capacities. However starting with 40 cycles at $\mathrm{C}$-rate was not sufficient to achieve the stable capacities 
for the samples shown in Figure 7. The increasing trend in capacities was notable, however the difference among $\mathrm{A} 1, \mathrm{~A} 2$ and $\mathrm{A} 3$ was subtle. Considering the effects of processing parameters on the particle morphology and intercalate chemistry ${ }^{33}$, these differences were believed to be within the experimental error. In contrast to A series, the interstratified $(\alpha+\beta)$ sample reached its stable capacity within the first 40 cycles and exhibited the highest specific capacity attained in this study. Highest capacities reached by all samples are summarized in Table 4. Note that although the results from the two sets of schedules cannot be compared directly, it is possible to evaluate interstratified sample and the samples in the first set together. It is also obvious that all compositions performed better than the $\beta$-phase. While the capacity measured from A2 was only $1 \mathrm{mAhr} / \mathrm{g}$ higher than that from $\beta$, we can assume that A2 would deliver higher capacities upon further cycling.

Figure 8 depicts the $40^{\text {th }}$ discharge cycle from sample with interstratified structure and samples $\mathrm{A} 1, \mathrm{~A} 2$ and $\mathrm{A} 4$. It is evident that $\mathrm{Ni} / \mathrm{Al} \mathrm{LDH}$ delivers its capacity at a higher voltage than the others. Three-component LDHs discharge at intermediate voltages while the interstratified structure supply its capacity at a considerably lower voltage compared to all samples in this group.

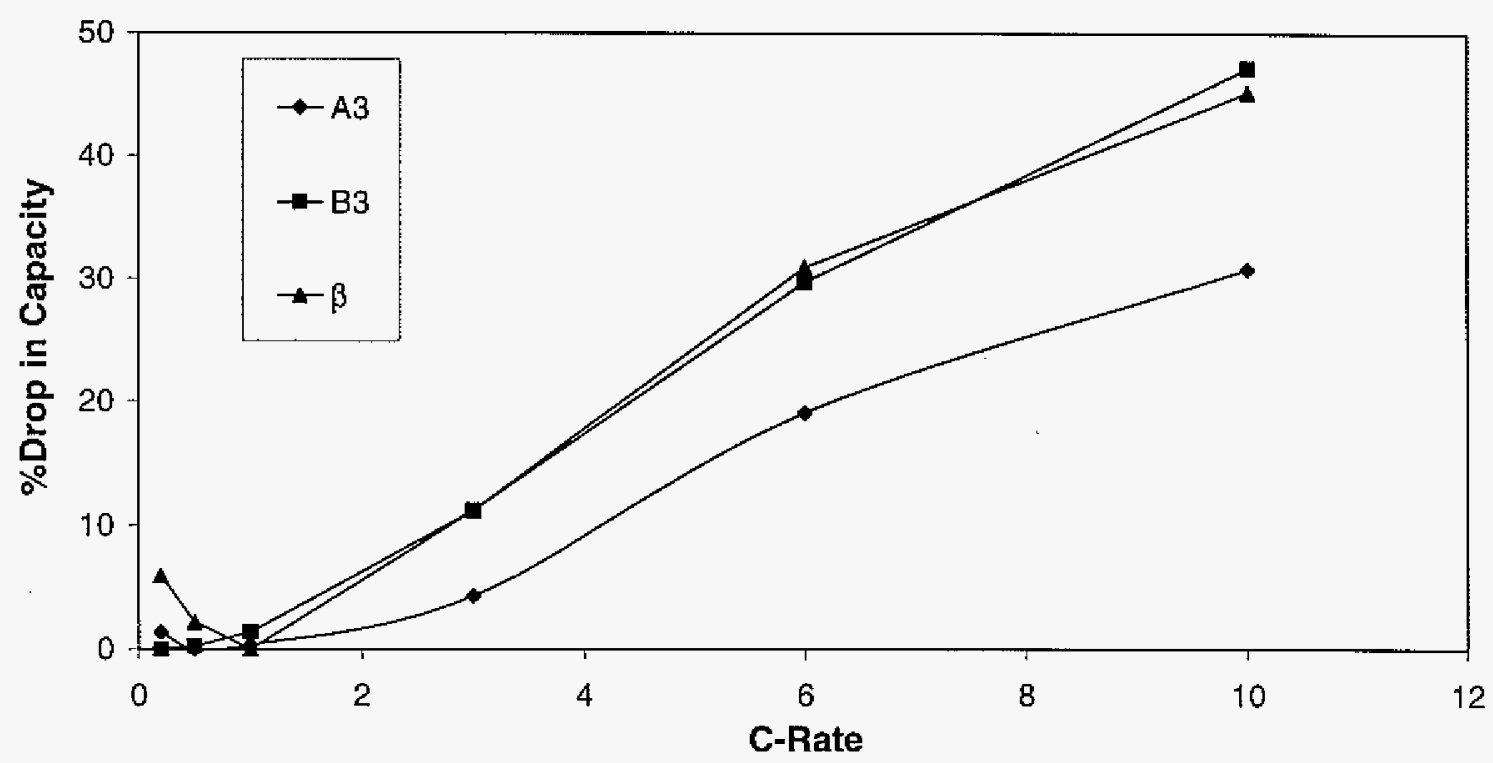

Figure 5. Percent drop in capacity of samples A3, B3 and $\beta$-phase with increasing discharge rates. 


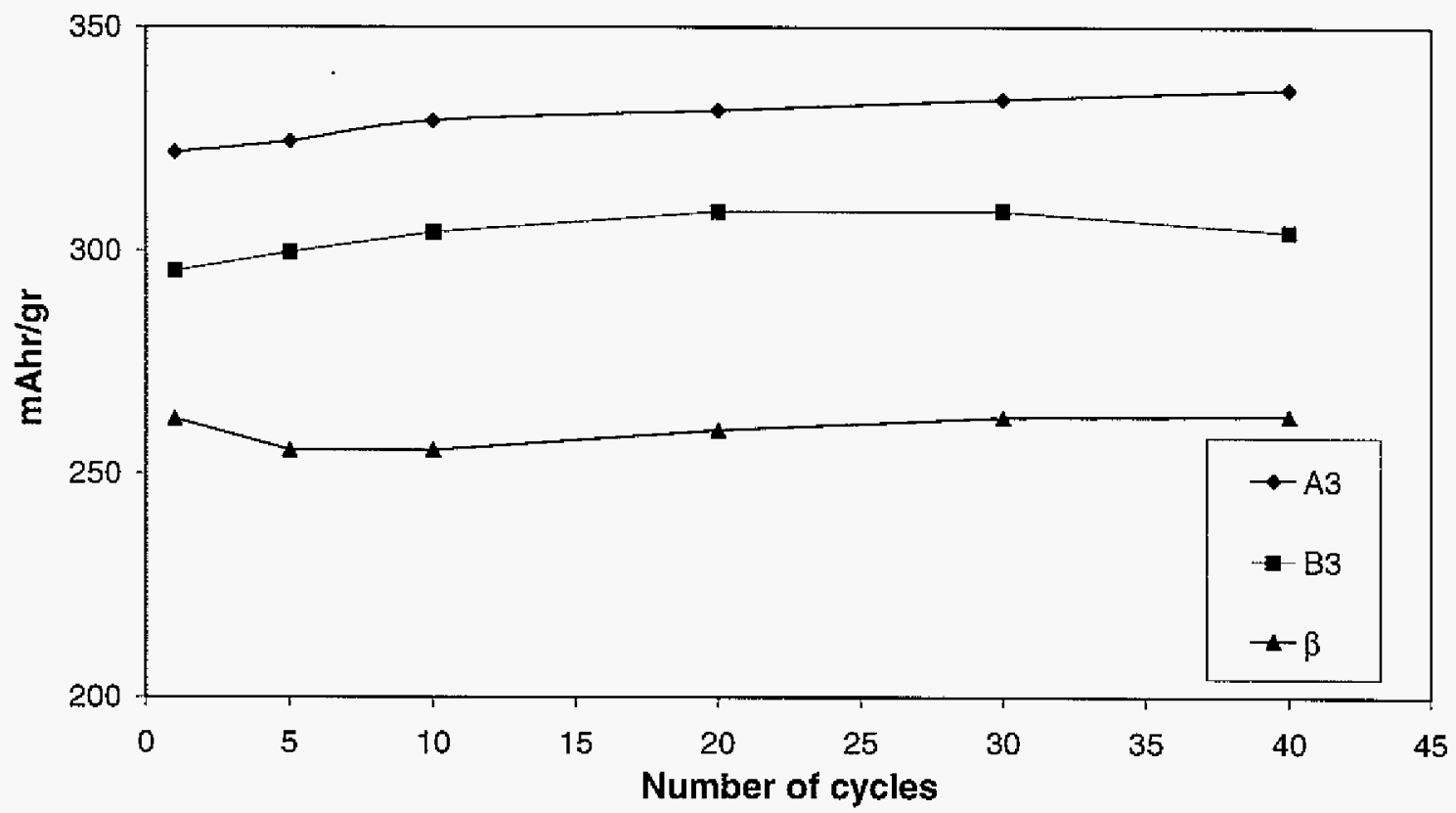

Figure 6. Effect of 40 additional cycles at $C$ rate on capacities of samples $A 3, B 3$ and $\beta$ phase.

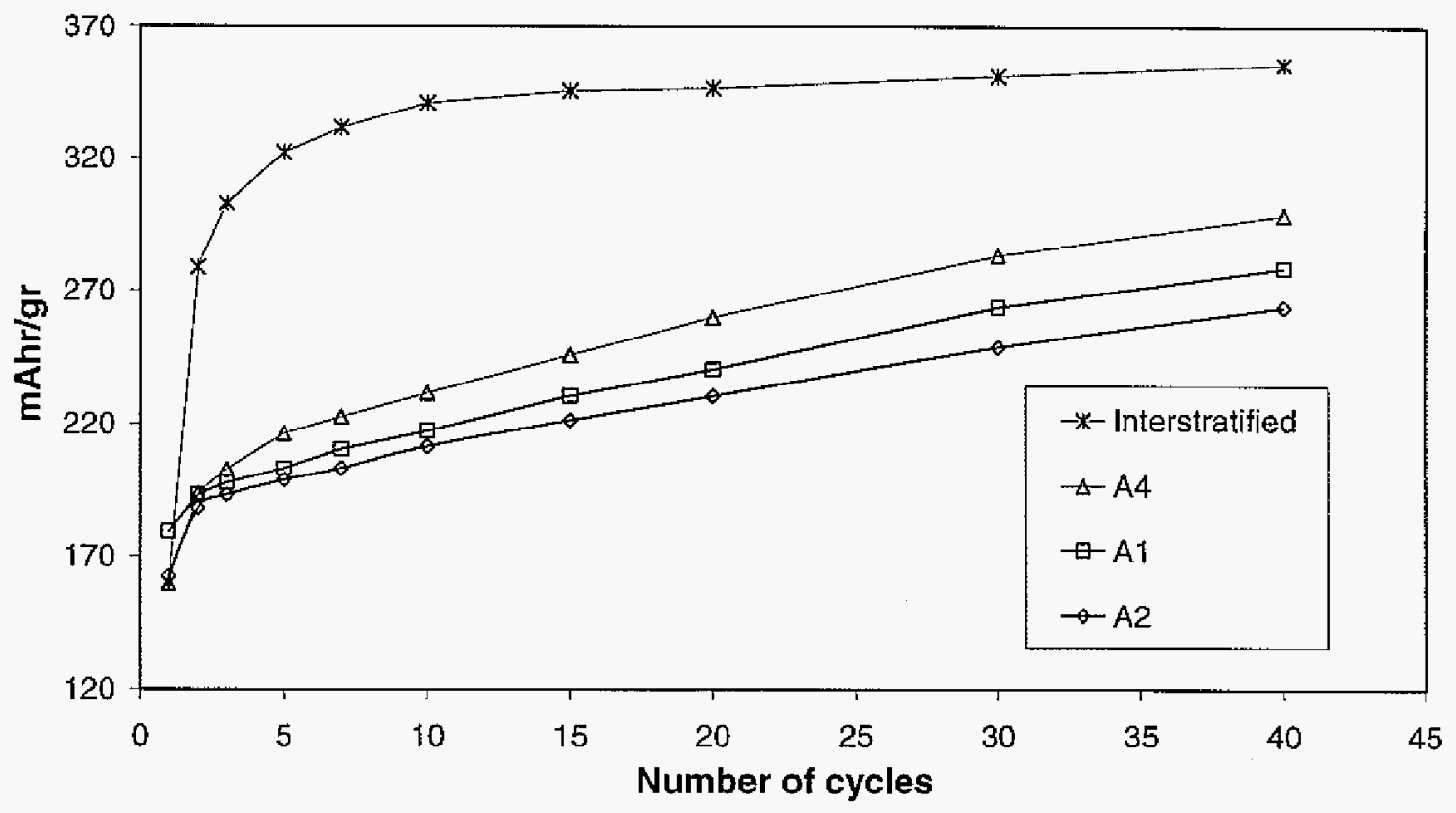

Figure 7. Changes in capacities of samples in series A (A1, A2 and A4) compared with changes in interstratified $(\alpha+\beta)$ phase $(40$ cycles at $C$ rate). 
Table 4. Maximum specific capacity measured for compositions tested with two different cycling schedules.

\begin{tabular}{cc} 
Sample & Specific Capacity \\
\hline$A 3^{\mathrm{b}}$ & 336 \\
$B 3^{\mathrm{b}}$ & 304 \\
$\beta-N i(O H)_{2}^{\mathrm{b}}$ & 263 \\
\hline${\text { Interstratified }(\alpha+\beta)^{\mathrm{b}}}^{\mathrm{b}}$ & 356 \\
$A 4^{\mathrm{c}}$ & 299 \\
$A I^{\mathrm{c}}$ & 279 \\
$A 2^{\mathrm{c}}$ & 264 \\
\hline
\end{tabular}

${ }^{\mathrm{a}}$ In units of mAhr/g, ${ }^{\mathrm{b}}$ Stabilized values, ${ }^{\mathrm{c}}$ Stabilized value was not achieved.

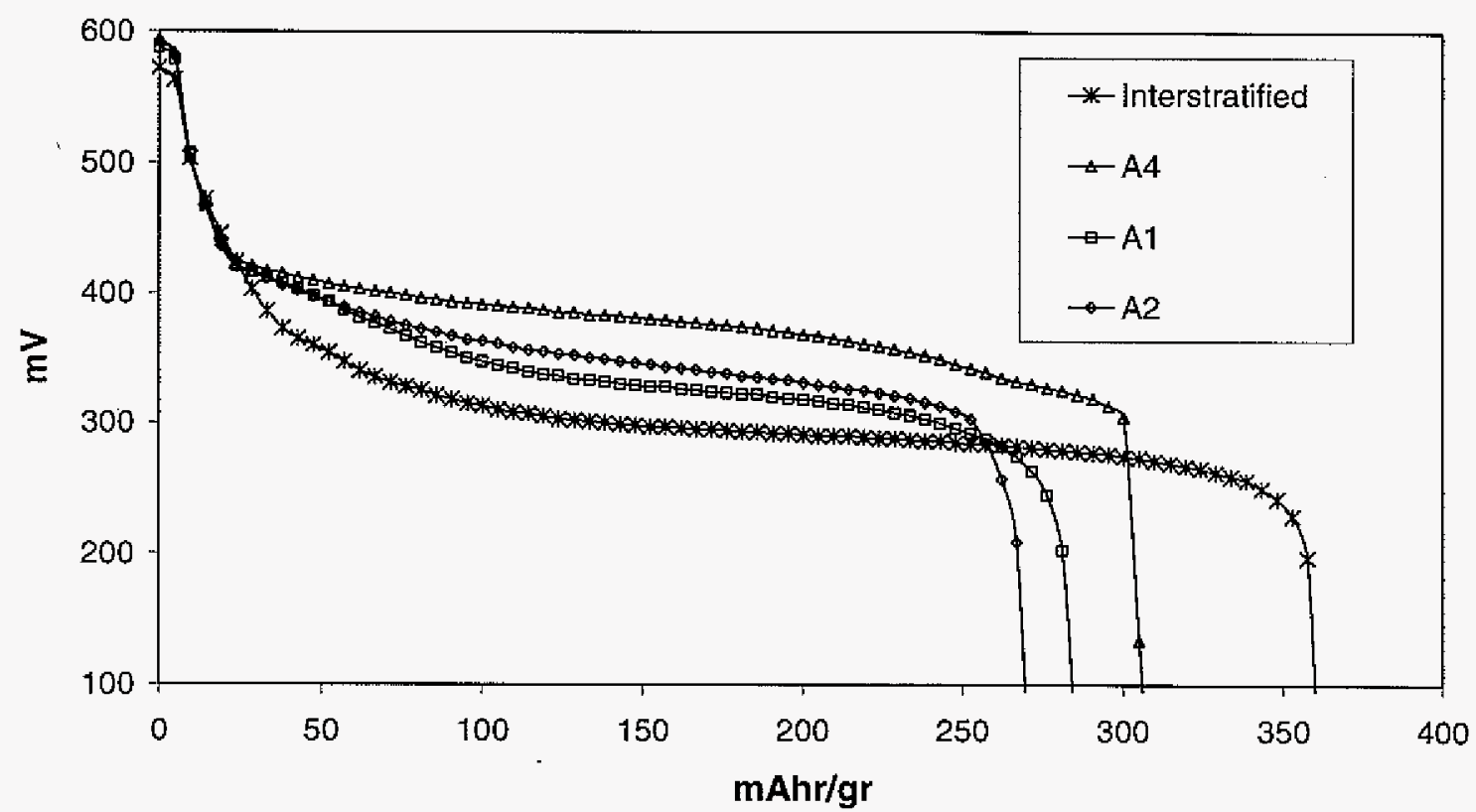

Figure 8. $40^{\text {th }}$ discharge cycle from samples $\mathrm{A} 1, \mathrm{~A} 2$ and $\mathrm{A} 4$ is compared with that of interstratified phase ( 40 cycles at $\mathrm{C}$ rate).

\section{Discussion}

It was shown experimentally that $\mathrm{Ni}-\mathrm{Al}$ LDHs could be precipitated by urea decomposition in aqueous solutions. ${ }^{22,33}$ XRD and FTIR results suggest that urea could also be utilized in precipitating three-component LDHs incorporating $\mathrm{Co}^{2+}$ in addition to $\mathrm{Ni}$-Al. 
A two-hour digestion was sufficient to precipitate $0.015 \mathrm{M}$ aluminum completely but not $0.025 \mathrm{M}$. This suggests that at an intermediate $\left[\mathrm{Al}^{3+}\right]_{0}$ (i.e. $\approx 0.020 \mathrm{M}$ ), all of aluminum along with maximum amount of $\mathrm{Ni}^{2+}$ and $\mathrm{Co}^{2+}$ will be recovered. Similarly, $\mathrm{Ni}^{2+}$ could be precipitated completely in about 3 hours under experimental conditions similar to A4. In addition, incorporation of up to $40 \% \mathrm{Al}^{3+}$ into the basal planes have been reported. ${ }^{40}$ It can be proposed that use of even higher $\left[\mathrm{Al}^{3+}\right]_{0}$ would result in complete recovery of other cations in less than 3 hours. Nevertheless, as the $\mathrm{M}^{3+}$ incorporation increases the amount of $\mathrm{M}^{2+}$ that would available for electrochemical cycling would decrease per mass of material. Intuitively, keeping the $\mathrm{M}^{3+}$ at a minimum while preserving the structural integrity would be desirable in the delivery of highest possible capacity.

For the formation of LDHs an initial $\mathrm{Al}^{3+}$ concentration of $0.015 \mathrm{M}$ was needed. Presence of $\mathrm{Co}^{2+}$ did not impede the formation of LDHs. Basal plane spacing remained similar in LDHs upon aging, but it expanded in $\alpha$-phase. Crystallite sizes decreased or remained unaffected in $\alpha$-phase with ageing, but there was a notable increase in LDHs. This suggests that once the $\mathrm{LDH}$ forms, it is a highly stable structure in the electrolyte. With higher $\left[\mathrm{Al}^{3+}\right]_{0}$ larger crystallites were obtained. This hints a strain-free stacking of layers. With a couple of exceptions, $\mathrm{Co}^{2+}$ seems to trigger a faster crystallite growth in the c-axis. Results presented in this work are insufficient to suggest a self-consistent mechanism.

FTIR results provide evidence for co-intercalation of water, cyanate and carbonaceous species. Most of cyanate seems to be bonded through its nitrogen in LDHs while it stays mostly oxygen bonded in $\alpha$-phase and mixed-mode for the compositions in between. Yang et al. found that $\mathrm{N}$-isocyanate was energetically more stable at all sites on $\mathrm{Ni}(100)$ compared to O-isocyanate. This is in line with the observed stability of LDHs in the electrolyte. ${ }^{39}$

It is proposed that water molecules can be removed reversibly without destroying the LDH structure. ${ }^{41}$ Given the hydration level differences observed in A3 and B3 (similar to A4 and B4 that were depicted in Figure 2B), it is plausible to attribute the capacity difference observed between these samples to the availability of water that could be reversibly exchanged during cycling.

In general all LDH compositions exhibited better electrochemical characteristics than the $\beta$-phase. On the other hand, it was noted that they reached their stable capacities more 
slowly. It was shown by mathematical models on $\mathrm{Ni}(\mathrm{OH})_{2}$ electrodes that response of the electrode in cyclic voltammetry is more sensitive compared to its response in chronopotentiometry to changes in the diffusion constant of the active species. ${ }^{42}$ For that reason, attributing the higher capacities observed in LDHs to the higher diffusivities of the active species can not be claimed without cyclic voltammetry data. Reproducible results obtained in cyclic chronopotentiometry may be attributable to long-term stability of LDHs in the aggressive electrolyte. It is believed that the procedural differences among different research groups make a quantitative comparison of results doubtful if not impossible.

We have not recorded a substantial improvement by the addition of $\mathrm{Co}^{2+}$ in the $\mathrm{Ni}-\mathrm{Al}$ $\mathrm{LDH}$. It could be thought that once the stability is attained and electrode construction is optimized (with Carbon addition) under near-equilibrium testing conditions, there is no added advantage of increasing basal plane conductivity. Absence of pronounced effect of $\mathrm{Co}^{2+}$ on capacity may be attributable to either the fact that process is not controlled via electron transport and the electrode construction provides an unobstructed pathway for electron flow (i.e. $\mathrm{Co}^{2+}$ is not needed), or benefit provided by $\mathrm{Co}^{2+}$ is compromised by the decreased amount of active $\mathrm{Ni}^{2+}$ ions that are available for cycling (i.e. $\mathrm{Co}^{2+}$ irreversibly oxidizes to $\mathrm{Co}^{3+}$ and does not participate in the redox process).

Sample with the interstratified structure showed an exceptionally high capacity compared to all other samples. Besides, although it delivered this capacity at a lower voltage it was the fastest to stabilize. These observations are in agreement with what Wang et al. has recently reported, ${ }^{4}$ It is not known with what mechanism capacities of this magnitude can be achieved in such structures. It is entirely possible that the high specific surface area obtained for this sample may have contributed to the observed superior capacity. This hypothesis needs to be checked rigorously.

\section{Conclusions}

Precipitation of TC-LDH with $\mathrm{Ni} / \mathrm{Al} / \mathrm{Co}$ is proven conceptually by the urea precipitation method. A minimum initial $\mathrm{Al}^{3+}$ concentration of $0.015 \mathrm{M}$ is necessary for the formation of LDH structure when total metal ion concentration is set to $0.1 \mathrm{M}$. All compositions leading to LDH formation proved to be stable in the electrolyte solution for at least one week and showed no signs of transformation to $\beta$-phase. Previous findings on the role of $\mathrm{OCN}^{-}$ 
coordination in precipitation of $\mathrm{Ni}(\mathrm{OH})_{2}$ by urea were supported with the detailed FTIR studies performed on TC-LDH studied here. $\mathrm{N}$-bonded cyanates were found to dominate any other cyanate species in the LDHs. Addition of $\mathrm{Co}^{2+}$ does not impede the LDH formation and stability of the structure. On the other hand, added basal plane conductivity with the incorporation of $\mathrm{Co}^{2+}$ does not seem to enhance the capacity of the powders. While capacities obtained from all LDH compositions were higher than that from $\beta$-phase, interstratified phase produced by heterogeneous precipitation showed the highest capacity attained in this study. Additional work is necessary to understand the mechanism leading to the observation of capacities of this magnitude.

\section{Acknowledgements}

This manuscript has been authored by Iowa State University of Science and Technology under Contract No. W-7405-ENG-82 with the U.S. Department of Energy. The United States Government retains and the publisher, by accepting the article for publication, acknowledges that the United States Government retains a non-exclusive, paid-up, irrevocable, world-wide license to publish or reproduce the published form of this manuscript, or allow others to do so, for United States Government purposes. Authors thank Drs. Andy Thom and Matt Kramer for valuable discussions and Brian Carlson for his help in precipitation experiments. B. M. furthermore acknowledges the financial support from Catron Fellowship.

\section{References}

${ }^{\mathrm{I}}$ M. Rajamathi, P. V. Kamath and R. Seshadri, "Polymorphism in Nickel Hydroxide: Role of Interstratification," J. Mater. Chem., 10 [2] 503-06 (2000).

${ }^{2}$ G. J. d. A. A. Soler-Illia, M. Jobbagy, A. E. Regazzoni and M. A. Blesa, "Synthesis of Nickel Hydroxide by Homogeneous Alkalinization. Precipitation Mechanism," Chem. Mater, 11 [11] 3140-46 (1999).

${ }^{3}$ Q. Song, Z. Tang, H. Guo and S. L. I. Chan, "Structural Characteristics of Nickel Hydroxide Synthesized by a Chemical Precipitation Route under Different pH Values," Journal of Power Sources, 112 [2] 428-34 (2002). 
${ }^{4}$ X. Wang, H. Luo, P. V. Parkhutik, A.-C. Millan and E. Matveeva, "Studies of the Performance of Nanostructural Multiphase Nickel Hydroxide," Journal of Power Sources, 115 [1] 153-60 (2003).

${ }^{5}$ R. S. Jayashree and P. Vishnu Kamath, "Layered Double Hydroxides of Ni with $\mathrm{Cr}$ and Mn as Candidate Electrode Materials for Alkaline Secondary Cells," Journal of Power Sources, 107 [1] 120-24 (2002).

${ }^{6}$ M. Rajamathi and P. V. Kamath, "Urea Hydrolysis of Cobalt(II) Nitrate Melts: Synthesis of Novel Hydroxides and Hydroxynitrates," International Journal of Inorganic Materials, 3 [7] 901-06 (2001).

${ }^{7}$ J. Wang, A. G. Kalinichev, R. J. Kirkpatrick and X. Hou, "Molecular Modeling of the Structure and Energetics of Hydrotalcite Hydration," Chemistry of Materials, 13 [1] 145-50 (2001).

${ }^{8}$ V. R. L. Constantino and T. J. Pinnavaia, "Basic Properties of $\mathrm{Mg}^{2+}{ }_{1-x} \mathrm{Al}^{3+}{ }_{x}$ Layered Double Hydroxides Intercalated by Carbonate, Hydroxide, Chloride, and Sulfate Anions," Inorganic Chemistry, 1995, 34 (1995).

${ }^{9} \mathrm{X}$. Hou and R. J. Kirkpatrick, "Solid-State 77Se NMR and XRD Study of the Structure and Dynamics of Seleno-Oxyanions in Hydrotalcite-Like Compounds," Chem. Mater., 12 [7] 1890-97 (2000).

${ }^{10} \mathrm{C}$. Faure, C. Delmas and P. Willmann, "Preparation and Characterization of CobaltSubstituted $\alpha$-Nickel Hydroxide Stable in Potassium Hydroxide Medium. Part II. $\alpha$ Hydroxide with a Turbostratic Structure," J. Power Sources, 35 [3] 263-77 (1991).

${ }^{11} \mathrm{C}$. Faure, C. Delmas, M. Fouassier and P. Willmann, "Preparation and Characterization of Cobalt-Substituted $\alpha$-Nickel Hydroxides Stable in Potassium Hydroxide Medium. Part I. $\alpha$-Hydroxide with an Ordered Packing," J. Power Sources, 35 [3] 249-61 (1991).

${ }^{12}$ B. S. Maruthiprasad, M. N. Sastri, S. Rajagopal, K. Seshan, K. R. Krishnamurthy and T. S. R. P. Rao, "A Novel Nickel Trihydroxy Isocyanate - Preparation and Characterization," Proc. - Indian Acad. Sci., Chem. Sci., 100 [6] 459-62 (1988).

${ }^{13}$ M. J. Avena, M. V. Vazquez, R. E. Carbonio, C. P. De Pauli and V. A. Macagno, "A Simple and Novel Method for Preparing $\mathrm{Ni}(\mathrm{OH})_{2}$. Part I: Structural Studies and Voltammetric Response," J. Appl. Electrochem., 24 [3] 256-60 (1994). 
${ }^{14}$ M. Dixit, G. N. Subbanna and P. V. Kamath, "Homogeneous Precipitation from Solution by Urea Hydrolysis: A Novel Chemical Route to the $\alpha$-Hydroxides of Nickel and Cobalt," J. Mater. Chem., 6 [8] 1429-32 (1996).

${ }^{15}$ A. Widjaja, "Synthesis and Characterization of Nickel Hydroxide Powders for Battery Applications," M.Sc. Thesis. Iowa State University, Ames, 1997.

${ }^{16} \mathrm{M}$. Akinc, N. Jongen, J. Lemaitre and H. Hofmann, "Synthesis of Nickel Hydroxide Powders by Urea Decomposition," Journal of the European Ceramic Society, 18 [11] 155964 (1998).

${ }^{17}$ R. Acharya, T. Subbaiah, S. Anand and R. P. Das, "Effect of Precipitating Agents on the Physicochemical and Electrolytic Characteristics of Nickel Hydroxide," Materials Letters, 57 [20] 3089-95 (2003).

${ }^{18}$ R. Acharya, T. Subbaiah, S. Anand and R. P. Das, "Effect of Preparation Parameters on Electrolytic Behavior of Turbostratic Nickel Hydroxide," Materials Chemistry and Physics, 81 [1] 45-49 (2003).

${ }^{19}$ I. Yazdi, "Synthesis and Electrochemical Studies of Cobalt Substituted Nickel Hydroxide for Battery Applications," M.Sc. Thesis. Iowa State University, Ames, 1999.

${ }^{20}$ P. V. Kamath, M. Dixit, L. Indira, A. K. Shukla, V. G. Kumar and N. Munichandraiah, "Stabilized $\alpha-\mathrm{Ni}(\mathrm{OH})_{2}$ as Electrode Material for Alkaline Secondary Cells," J. Electrochem. Soc., 141 [11] 2956-9 (1994).

${ }^{21}$ K. T. Ehlsissen, A. Delahaye-Vidal, P. Genin, M. Figlarz and P. Willmann, "Preparation and Characterization of Turbostratic Nickel/Aluminum Layered Double Hydroxides for Nickel Hydroxide Electrode Applications," J. Mater. Chem., 3 [8] 883-8 (1993).

${ }^{22}$ U. Costantino, F. Marmottini, M. Nocchetti and R. Vivani, "New Synthetic Routes to Hydrotalcite-Like Compounds. Characterization and Properties of the Obtained Materials," Eur. J. Inorg. Chem., [10], 1439-46 (1998).

${ }^{23}$ B. Liu, X. Y. Wang, H. T. Yuan, Y. S. Zhang, D. Y. Song and Z. X. Zhou, "Physical and Electrochemical Characteristics of Aluminum-Substituted Nickel Hydroxide," Journal of Applied Electrochemistry, 29 [7] 855-60 (1999). 
${ }^{24}$ R. Roto and G. Villemure, "Electrochemical Impedance Spectroscopy of Electrodes Modified with Thin Films of Ni-Al-Cl Layered Double Hydroxides," Journal of Electroanalytical Chemistry, 527 [1-2] 123-30 (2002).

${ }^{25}$ C. Y. Wang, S. Zhong, K. Konstantinov, G. Walter and H. K. Liu, "Structural Study of Al-Substituted Nickel Hydroxide," Solid State lonics, 148 [3,4] 503-08 (2002).

${ }^{26}$ Z. Hengbin, L. Hansan, C. Xuejing, L. Shujia and S. Chiachung, "Preparation and Properties of the Aluminum-Substituted $\alpha-\mathrm{Ni}(\mathrm{OH})_{2}, "$ Materials Chemistry and Physics, 79 [1] 37-42 (2003).

${ }^{27}$ T. Pan, J. M. Wang, Y. L. Zhao, H. Chen, H. M. Xiao and J. Q. Zhang, "Al-Stabilized $\alpha$-Nickel Hydroxide Prepared by Electrochemical Impregnation," Materials Chemistry and Physics, 78 [3] 711-18 (2003).

${ }^{28}$ H. Chen, J. M. Wang, T. Pan, H. M. Xiao, J. Q. Zhang and C. N. Cao, "Effects of Coprecipitated Zinc on the Structure and Electrochemical Performance of Ni/Al-Layered Double Hydroxide," International Journal of Hydrogen Energy, 27 [5] 489-96 (2002).

${ }^{29} \mathrm{C}$. Y. Wang, S. Zhong, D. H. Bradhurst, H. K. Liu and S. X. Dou, "Ni/Al/CoSubstituted $\alpha-\mathrm{Ni}(\mathrm{OH})_{2}$ as Electrode Materials in the Nickel Metal Hydride Cell," Joumal of Alloys and Compounds, 330-332, 802-05 (2002).

${ }^{30} \mathrm{~B}$. Mavis and M. Akinc, "Homogeneous Precipitation of Layer Double Hydroxides," to be published in the Key Engineering Materials, [European Ceramic Society VIII ${ }^{\text {th }}$ Biannual Meeting Proceedings], (2003).

${ }^{31}$ B. Mavis and M. Akinc, "Kinetics of Urea Decomposition in the Presence of Transition Metal Ions: $\mathrm{Ni}^{2+}, "$ submitted to Journal of American Ceramic Society, (2003).

${ }^{32} \mathrm{~B}$. Mavis and M. Akinc, "Details of Urea Decomposition in the Presence of Transition Metal Ions," to be published in the American Ceramic Society (ACerS) Ceramic Engineering and Science Proceedings (CESP), 24 [3 \& 4] (2003).

${ }^{33} \mathrm{~B}$. Mavis and M. Akinc, "Intercalating Species in the Homogeneous Precipitation of Nickel Hydroxides," to be submitted to Materials Chemistry and Physics, (2003).

${ }^{34}$ F. Boulc'h, M.-C. Schouler, P. Donnadieu, J.-M. Chaix and E. Djurado, "Domain Size Distribution of Y-TZP Nanoparticles Using XRD and HRTEM," Image Analysis \& Stereology, 20 [3] 157-61 (2001). 
${ }^{35}$ P. M. Gomadam, J. W. Weidner, R. A. Dougal and R. E. White, "Mathematical Modeling of Lithium-Ion and Nickel Battery Systems," Journal of Power Sources, 110 [2] 267-84 (2002).

${ }^{36}$ V. Srinivasan, J. W. Weidner and R. E. White, "Mathematical Models of the Nickel Hydroxide Active Material," Journal of Solid State Electrochemistry, 4 [7] 367-82 (2000).

${ }^{37}$ A. B. Yuan and N. X. Xu, "Electrochemical Studies of the Nickel Electrode with Cobalt Modification," Journal of Applied Electrochemistry, 31 [2] 245-50 (2001).

${ }^{38}$ A. S. Prakash, P. V. Kamath and M. S. Hegde, "Synthesis and Characterization of the Layered Double Hydroxides of Mg with Cr," Materials Research Bulletin, 35 [13] 2189-97 (2000).

${ }^{39} \mathrm{H}$. Yang and J. L. Whitten, "Chemisorption of OCN on Ni(100) - an Ab Initio Study," Surface Science, 401 [3] 312-21 (1998).

${ }^{40}$ D. R. Hines, G. T. Seidler, M. M. J. Treacy and S. A. Solin, "Random Stacking of a Commensurate Guest Layer in an Ordered Host: Ni/Al Layer-Double-Hydroxides," Solid State Communications, 101 [11] 835-39 (1997).

${ }^{41}$ V. R. Allmann, "Doppelschichtstrukturen Mit Brucitahnlichen Schichtionen [Me(II) 1 $\left.{ }_{x} \mathrm{Me}(\mathrm{III})_{\mathrm{x}}(\mathrm{OH})_{2}\right]^{\mathrm{x}+}$, " Chimia, 24 [Marz] 99-108 (1970).

${ }^{42}$ K. P. Ta and J. Newman, "Mass Transfer and Kinetic Phenomena at the Nickel Hydroxide Electrode," Journal of the Electrochemical Society, 145 [11] 3860-74 (1998). 


\section{GENERAL CONCLUSIONS}

Precipitation and characterization of nickel hydroxide powders were investigated. A comprehensive precipitation model incorporating the metal ion hydrolysis, complexation and precipitation reactions was developed for the production of the powders with urea precipitation method. Model predictions on $\mathrm{Ni}^{2+}$ precipitation rate were confirmed with precipitation experiments carried out at $90^{\circ} \mathrm{C}$. Experimental data and model predictions were in remarkable agreement. Uncertainty in the solubility product data of nickel hydroxides was found to be the largest contributor to the error. There were demonstrable compositional variation across the particle cross-sections and the growth mechanism was determined to be the aggregation of primary crystallites. This implied that there is a change in the intercalate chemistry of the primary crystallites with digestion time. Predicted changes in the concentrations of simple and complex ions in the solution support the proposed mechanism.

The comprehensive set of hydrolysis reactions used in the model described above allows the investigation of other systems provided that accurate reaction constants are available. The fact that transition metal ions like $\mathrm{Ni}^{2+}$ form strong complexes with ammonia presents a challenge in the full recovery of the $\mathrm{Ni}^{2+}$. On the other hand, presence of $\mathrm{Al}^{3+}$ facilitates the complete precipitation of $\mathrm{Ni}^{2+}$ in about 3 hours of digestion. A challenge in our predictive modeling studies had been the fact that simultaneous incorporation of more than one metal ion necessitates a different approach than just using the equilibrium constants of hydrolysis, complexation and precipitation reactions. Another limitation of using equilibrium constants is that the nucleation stage of digestion, which is controlled mainly by kinetics, is not fully justified. A new program released by IBM Almaden Research Center (Chemical Kinetics Simulator ${ }^{\mathrm{TM}}$, Version 1.01) ${ }^{\mathrm{I}}$ lets the user change the order of kinetic components of a reaction which was set to "stoichiometric constant with which the species appear in the reaction" in KINSIM ${ }^{2}$ by default. For instance, in the case of LDH precipitation, the new program allows to change the order of species in the reactions associated with $\mathrm{Al}^{3+}$ and let the $\mathrm{Ni}^{2+}$ reactions take over. This could be carried on iteratively until a good fit between the experimental data and the predictions were observed. However for such studies availability of accurate equilibrium constants (especially for the solubility products for the solid phase) is a prerequisite. 
It was shown by analysis of FTIR data combined with XPS results that not only the population of intercalates (i.e. cyanate and carbonaceous species) show variance with digestion time, but their bonding modes are also altered. In $\alpha-\mathrm{Ni}(\mathrm{OH})_{2}$, cyanate coordination swayed from $\mathrm{N}$-bonded to O-bonded end-on geometries with time, highest level of change being within the first couple of hours of digestion. $\mathrm{N}$-isocyanate was the dominant species observed in Ni/Al-LDHs. XPS results complimented FTIR results that confirms existence of the $\mathrm{N}$-isocyanate species in the powder structure. Work with alkyl-substituted ureas and heterogeneous precipitation reactions lend additional support on the conclusions driven above. Analysis of aged and partially aged samples showed that isocyanate- $\mathrm{N}$ is more stable than cyanate-O and is more likely to remain intercalated. This observation is in agreement with the energetics calculated for these modes. ${ }^{3}$ XPS data confirmed that indeed the particle composition varies across the particle cross-section.

Results indicate that intermediate (i.e. cyanate) and end products (i.e. carbonaceous species and ammonia) of urea decomposition have a critical role in determining the metal ion recovery and composition, structure and morphology of the particles synthesized.

TC-LDHs with varying $\mathrm{Ni} / \mathrm{Al} / \mathrm{Co}$ contents were produced by the urea precipitation method. When the initial $\mathrm{Al}^{3+}$ concentration in the solution was set to at least $0.015 \mathrm{M}$ (total metal ion concentration remaining constant at $0.1 \mathrm{M}$ ), LDH structure was observed to form consistently at all $\left[\mathrm{Co}^{2+}\right]_{0}$ studied. Compositions resulting in LDH formation also proved stable in the electrolyte solution $(6 \mathrm{M} \mathrm{KOH})$ for at least one week and showed no signs of transformation to $\beta$-phase. Detailed FTIR studies performed on TC-LDHs supported the previously discussed findings on cyanate coordination in urea precipitated $\mathrm{Ni}(\mathrm{OH})_{2}$ 's. Incorporation of $\mathrm{Co}^{2+}$ does not seem to enhance the charge capacity of the synthesized powders. One can argue that the reduction in the redox-active cation concentration (by irreversible oxidation of $\mathrm{Co}^{2+}$ to $\mathrm{Co}^{3+}$ ) is a possible cause for slightly lower than anticipated charge capacity. Nevertheless, charge capacities of all LDH compositions were higher than that of $\beta$-phase. It was noted however that interstratified phase produced by heterogeneous precipitation showed the highest capacity attained in this study. A similar observation was also reported by Wang et al. recently. ${ }^{4}$ 
Carbonaceous species concentration in the solution seems to change with the pressure and possibly affects the aggregation behavior of primary crystallites. It would be helpful to isolate variables like mixing level, pressure and counter anion to see if this prediction could be supported furthermore.

We believe that our knowledge on intercalate chemistry of $\alpha$-phase and LDH structures formed by urea precipitation has progressed considerably. However it is still not clear which modes of cyanates could be indicative of surface adsorbed and which are of grafted or hydrogen bonded to the layers. Use of a lower initial metal ion concentration (likely to cause less aggregation) or surfactants could help in a more accurate description.

Although capacities obtained from the TC-LDHs were comparable to literature and as anticipated, the fact that the interstratified structure delivered a high capacity is intriguing. It is believed that it might have a bearing on future developments in the nickel hydroxide battery systems as long as it could be proved that capacity of this magnitude could be sustained for over 500 cycles. $^{5}$

\section{References}

${ }^{1}$ W. Hinsberg, F. Houle and F. Allen, "Chemical Kinetics Simulator - Designed for the Bench Scientist, v. 1.01" International Business Machines Corporation, 1996.

${ }^{2}$ B. A. Barshop, R. F. Wrenn and C. Frieden, "Analysis of Numerical Methods for Computer Simulation of Kinetic Processes: Development of KINSIM - a Flexible, Portable System," Analytical Biochemistry, 130, 134-45 (1983).

${ }^{3} \mathrm{H}$. Yang and J. L. Whitten, "Reaction and Adsorption Energetics of $\mathrm{CN}+\mathrm{O} \rightarrow \mathrm{OCN}$ on Nickel," Theochem, 458 [1-2] 131-42 (1999).

${ }^{4}$ X. Wang, H. Luo, P. V. Parkhutik, A.-C. Millan and E. Matveeva, "Studies of the Performance of Nanostructural Multiphase Nickel Hydroxide," Journal of Power Sources, 115 [1] 153-60 (2003).

${ }^{5}$ H. Chen, J. M. Wang, T. Pan, H. M. Xiao, J. Q. Zhang and C. N. Cao, "Effects of Coprecipitated Zinc on the Structure and Electrochemical Performance of Ni/Al-Layered Double Hydroxide," International Journal of Hydrogen Energy, 27 [5] 489-96 (2002). 


\section{ACKNOWLEDGEMENTS}

I would like to thank the many people who contributed to this dissertation. Without their help, I would most certainly not have been able to complete this work.

First and foremost I wish to express my deepest appreciation to Dr. Mufit Akinc, who mentored me as my major professor, shared his expertise, optimism and enthusiasm as an avid colleague and dealt with my personal problems like a parent would throughout my Ph.D. studies.

I am indebted to Drs. Dennis Johnson, Jim Espenson, Matt Kramer and Andy Thom for their helpful discussions and James W. Anderegg for collecting and interpreting XPS data. I would like to mention the support given by my research group members in Ames Laboratory, especially Chuanping $\mathrm{Li}$ and also by Henry Kang with whom I shared my office. Furthermore I acknowledge the financial support from Catron Fellowship in 2001-2002. A special thank goes to Dr. Soler-llia for providing a hard copy of his Ph.D. thesis.

I thank my beloved wife, Elif and my parents, Hatice and Avni Maviş for their love and constant support, which sustained me through the many hard times when my confidence and enthusiasm had waned.

Finally, and definitely not least I wish to acknowledge all of my friends back in Turkey and in Ames, for nothing in particular but everything in general.

This work was performed at Ames Laboratory under Contract No. W-7405-Eng-82 with the U.S. Department of Energy. The United States government has assigned the DEO Report number IS-T 2111 to this thesis. 


\title{
APPENDIX A. DETAILS OF UREA DECOMPOSITION IN THE PRESENCE OF TRANSITION METAL IONS
}

A proceedings paper to be published in the American Ceramic Society (ACerS) Ceramic Engineering and Science Proceedings (CESP) 24 [3 \& 4];27 $7^{\text {th }}$ Annual Conference on Composites, Advanced Ceramics, Materials and Structures: A \& B (ECD-FS4-37-2003).

Bora Mavis and Mufit Akinc lowa State University Materials Science and Engineering Department 3053 Gilman Hall Ames, Iowa, 50011

\begin{abstract}
Literature on kinetics of urea decomposition in aqueous solutions was reviewed for 333$373 \mathrm{~K}$ range, After identifying possible reactions in the targeted $\mathrm{pH}$ range, kinetic simulations were performed. Significant accumulation of the cyanate intermediate was observed in the pH-digestion time-temperature range that was studied. Effects of hydrolysis of metal ions and complexes forming between cations and the decomposition products were considered by incorporation of the pertinent equilibria into the simulations. Predictions on the rate of retrieval of cations from the solutions were compared against the experimental data from chemical analyses and UV/VIS.

\section{Introduction}

Homogeneous precipitation with urea has been widely used in preparing metal oxide precursor powders. ${ }^{1-3}$ Powders prepared with $\mathrm{Ni}^{2+}$ cation, resulted in $\alpha-\mathrm{Ni}(\mathrm{OH})_{2}$ structure at digestion temperatures between 60 and $100^{\circ} \mathrm{C}{ }^{4}$ Urea $\left(\mathrm{OC}\left(\mathrm{NH}_{2}\right)_{2}\right)$ has been assumed to yield carbonate and hydroxyl anions upon its decomposition. This simplistic approach was not adequate to explain the results obtained in the presence of $\mathrm{Ni}^{2+}$ cations. ${ }^{5,6}$ Characterization of the intercalating species with FTR revealed the presence of cyanate $\left(\mathrm{OCN}^{-}\right)$ions within the layers along with water and carbonate. It is known that urea decomposes in two steps and cyanate is the intermediate. In a system where a strong interaction between the metal cation and the intermediate exists, effect of the second step has to be taken into account.

Soler-Illia and co-workers were first to incorporate the intermediate step of urea decomposition into an approximate numerical solution to predict the concentrations of the species during the hydrolysis of urea. ${ }^{5,7,8}$
\end{abstract}




$$
\begin{aligned}
& \mathrm{OC}\left(\mathrm{NH}_{2}\right)_{2} \stackrel{\mathrm{k}_{1}}{\mathrm{k}_{-1}} \mathrm{OCN}^{-}+\mathrm{NH}_{4}{ }^{+} \\
& \mathrm{OCN}^{-}+\mathrm{H}^{+}+2 \mathrm{H}_{2} \mathrm{O} \stackrel{\mathrm{k}_{2}}{\longrightarrow} \mathrm{HCO}_{3}{ }^{-}+\mathrm{NH}_{4}{ }^{+} \\
& \mathrm{K}_{2}=\left(\mathrm{k}_{2}{ }^{\circ}+\mathrm{k}_{2}{ }^{\mathrm{a}}\left[\mathrm{H}^{+}\right]\right)
\end{aligned}
$$

Accumulation of $\mathrm{OCN}^{-}$intermediate during the initial stages of hydrolysis was observed. However, second step of hydrolysis was oversimplified and the reaction constants were only approximate. Similar approximations were also used in the high temperature equilibrium constants of the acid/base couples forming in the system. Furthermore numerical solutions were not extended to include metal ions.

After critical review of the available kinetic data on the decomposition of urea in aqueous media, six independent reactions related to urea decomposition and hydrolysis with associated rate constants were identified. Concentrations of all neutral and charged species $\left(\mathrm{OH}^{-}, \mathrm{OCN}^{-}, \mathrm{CO}_{3}{ }^{=}\right.$and $\mathrm{NH}_{3}$ ) as a function of time were calculated using KINSIM (kinetic simulation program $)^{9}$ to predict reaction progress in metal-ion-free solutions. In the next step, reactions involving $\mathrm{Ni}^{2+}$ ion and its compounds with respect to precipitation $\left(\mathrm{Ni}(\mathrm{OH})_{2}(\mathrm{~s})\right.$ and $\mathrm{NiCO}_{3}(\mathrm{~s})$ ), hydrolysis $\left(\mathrm{Ni}_{\mathrm{m}}(\mathrm{OH})_{\mathrm{n}}{ }^{2 \mathrm{~m}-\mathrm{n}}\right)$, and complexation $\left(\mathrm{Ni}\left(\mathrm{NH}_{3}\right)_{\mathrm{n}}{ }^{2+}\right.$ (n=1 to 4 for temperatures above $\left.\approx 80^{\circ} \mathrm{C}\right)$ and $\mathrm{Ni}(\mathrm{NCO})_{n}{ }^{2-n}(\mathrm{n}=1$ to 4$)$ ) were incorporated in the simulation to accurately model the evolution of species. A detailed article covering the constants and computational method used in this work will be published. ${ }^{6}$ In this communication, model predictions will be presented and compared to experimental results.

\section{Experimental Procedure}

\section{Powder Synthesis}

Precipitation of nickel hydroxide by urea decomposition was carried out in $250 \mathrm{~mL}$ Pyrex Brand media bottles placed in a thermostatic water bath that was maintained at $90 \pm 1{ }^{\circ} \mathrm{C}$. Pressure was kept near ambient. $5.9428 \mathrm{~g}$ of reagent grade $\mathrm{NiCl}_{2} \cdot 6 \mathrm{H}_{2} \mathrm{O}$ (Fisher Scientific) was dissolved in $190 \mathrm{~mL}$ deionized water and preheated to $90^{\circ} \mathrm{C} .30 .0300 \mathrm{~g}$ of reagent grade urea (Fisher Scientific) was dissolved in $60 \mathrm{~mL}$ deionized water and added to the preheated $\mathrm{Ni}^{2+}$ solution. Final $\mathrm{Ni}^{2+}$ and urea concentrations in the solution correspond to $0.1 \mathrm{M}$ and 2.0M, respectively. During digestion, the solution was stirred continuously and the sample aliquots were withdrawn from the middle of the solution. Precipitates were separated from the mother liquor by an in-line filter and washed three times. Powders were dried at $70^{\circ} \mathrm{C}$ for at least 12 hours. Solution $\mathrm{pH}$ was monitored (within \pm 0.02 units) continuously in an identical bottle.

\section{Characterization}

Concentration of free $\mathrm{Ni}^{2+}$ ion was measured by a Shimadzu UV-2401PC UV/VIS spectrophotometer unit equipped with a water-jacketed sample and reference cell holder. Calibration curves at 25 and $90{ }^{\circ} \mathrm{C}$ were used to find the molar absorption coefficient (MAC) 
of $\mathrm{Ni}^{2+}$ at those temperatures $\left(5.15\right.$ and $5.48 \mathrm{~L} \mathrm{~mole}^{-1} \mathrm{~cm}^{-1}$ at 25 and $90{ }^{\circ} \mathrm{C}$, respectively). Peak maximum between 300 and $500 \mathrm{~nm}$ was used to determine the $\mathrm{Ni}^{2+}$ concentration in uncomplexed solutions. Presence of cyanate and urea in the standard solutions increased the MAC by 15 and $4 \%$, respectively, necessitating a correction in the measured values. In the complexed solutions (i.e. when $\mathrm{Ni}\left(\mathrm{NH}_{3}\right)_{\mathrm{n}}{ }^{2+}$ starts forming) the characteristic $\mathrm{Ni}^{2+}$ absorption peaks showed a blue-shift and MAC was not same as in the uncomplexed solution.

Carbon, Nitrogen and Hydrogen contents of the precipitated powders were determined using a Perkin Elmer Series II CHNS/O 2400 analyzer. Nickel content was measured by atomic absorption spectrometer (AAS) of the acid $\left(\mathrm{HNO}_{3}\right)$ digested powders. Balance was assigned to oxygen content.

Structural characterization was made by powder X-ray diffraction (Scintag X1-365) unit with $\mathrm{Cu}-\mathrm{K} \alpha$ radiation. In crystallite size determinations, instrumental broadening of the peaks was accounted for by correcting the FWHM (full width at half maximum) values with that of the crystalline silicon reference. ${ }^{10}$

\section{Results and Discussion}

Calculated distribution of species during the hydrolysis of urea predicted the accumulation of $\mathrm{OCN}^{-}$during the first few hours as presented in Figure 1A. In the presence of $\mathrm{Ni}^{2+}$, the $\mathrm{NiNCO}^{+}$complex dominates the same period (Figure 1B) pointing out its importance in the nucleation of particles, which normally takes place within the first hour.
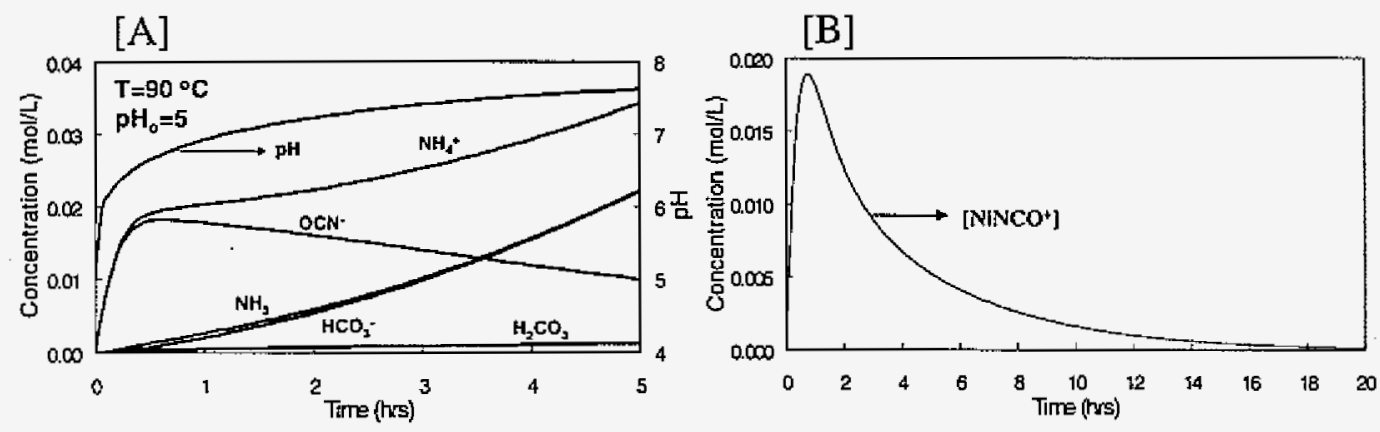

Figure 1. [A] Simulation of distribution of species (only the significant ones are plotted) during the decomposition of $2 \mathrm{M}$ urea at $90^{\circ} \mathrm{C}$ with an initial $\mathrm{pH}$ of 5 (typical value in the presence of $\mathrm{Ni}^{2+}$ ions). Important to note are the accumulation of $\mathrm{OCN}^{-}$and the upper limit of $\mathrm{pH}$ (less than 8) [B] Predicted changes in concentration of $\mathrm{NiNCO}^{+}$complex with increasing digestion time $\left(90^{\circ} \mathrm{C} ;\left[\mathrm{Ni}^{2+}\right]_{0}=0.1 \mathrm{M} ; \mathrm{pH}_{0}=5 ; \mathrm{I}=0\right)$. Plot represents the prediction with $\mathrm{pK}_{\mathrm{sp}}$ of 15.5 .

Review of literature indicates that the processing route can lead to significant variation on the observed solubility products of nickel hydroxides. "Active" powders can have $\mathrm{pK}_{\mathrm{sp}}$ values as low as 14.7 , while $\mathrm{pK}_{\mathrm{sp}}$ for "aged" powders could be as high as 17.95 at $25^{\circ} \mathrm{C}$ and zero ionic strength. Spread of the "prediction envelope" for the concentration of free $\mathrm{Ni}^{2+}$ ion in simulations performed with different $\mathrm{pK}_{\mathrm{sp}}$ values, calls upon the fact that uncertainty in the solubility product constant is the largest error contributor to the whole simulation process. 
Simulations with an intermediate $\mathrm{pK}_{\mathrm{sp}}$ value of 15.5 established the best fit to the experimental data. Thereafter, the simulations were performed with this value. Comparison of experimental and simulated free $\mathrm{Ni}^{2+}$ ion concentrations for two cases where initial $\mathrm{Ni}^{2+}$ ion concentrations were 0.1 and $0.075 \mathrm{M}$ are given in Figure 2.

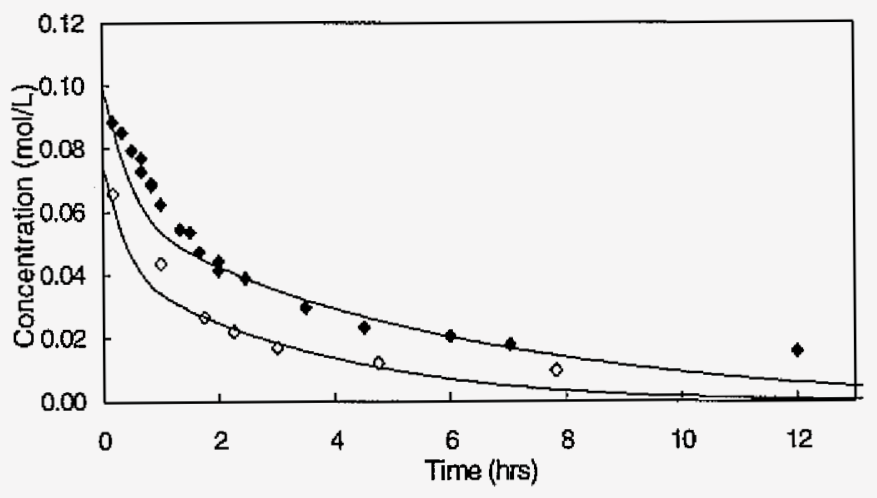

Figure 2. Comparison of simulated $(-)$ and experimental free $\mathrm{Ni}^{2+}$ ion concentrations in solutions with $\left[\mathrm{Ni}^{2+}\right]_{0} ;[\bullet] 0.1 \mathrm{M}$ and $[\diamond] 0.075 \mathrm{M}$.

Apart from the slight discrepancy in the initial stages of the process, the agreement between experimental result and model predictions was excellent. Divergence at longer digestion times was attributed to formation of $\mathrm{Ni}\left(\mathrm{NH}_{3}\right)_{n}{ }^{2+}$ complexes.

Since $\mathrm{Ni}^{2+}$ related reactions were represented as equilibrium reactions in the simulations, the fit between the experimental and predicted $\mathrm{pH}$ data was not satisfactory for the initial stages where the supersaturation needed for the solid phase formation keeps the experimental $\mathrm{pH}$ higher than predicted. Predicted trends in $\mathrm{pH}$ after the nucleation event is in agreement with experimental data within an order of magnitude (level of disagreement is on the order of $\left.10^{-4} \mathrm{M}\right)$.

XRD patterns of precipitates sampled at different digestion times are given in Figure 3. Crystallite size calculations revealed that the crystallites grow up to only $8 \mathrm{~nm}$ along the caxis even after 36 hours. This observation helps in explaining the growth mechanism of the precipitated particles. Although the particle sizes can grow up to several microns, the fact that primary crystallites remain nano-sized, call upon an agglomerative growth mechanism. This mechanism is in line with the recent literature and offers an alternative to LaMer's "burst-nucleation/diffusional growth" mechanism for the precipitation of monodispersed colloids, which may be valid only for particles with well-developed habits.

Previous FTIR analyses ${ }^{5,6}$ points out that nitrogen found in elemental analyses of the precipitates is in the form of cyanate. Change in Nitrogen weight percent in precipitates with increasing digestion time is shown in Figure 4. Results indicated a systematic compositional variation. That is, the crystallites forming in the initial couple of hours are significantly different in composition (i.e. different distribution of intercalated species) compared to the ones form later. Since the solutions were stirred constantly during the entire digestion, the variation in composition can not be attributed to inhomogeneity in solution composition. 


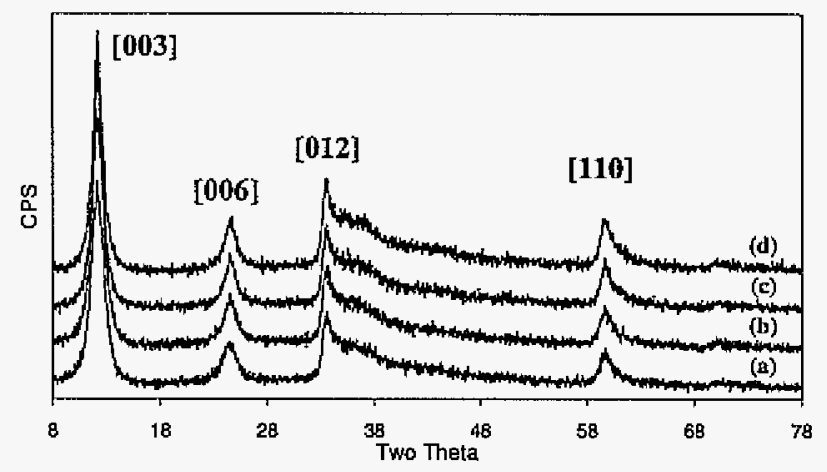

Figure 3. XRD patterns of precipitates sampled at different digestion times: (a) 50 mins, (b) 2 hrs, (c) 24 hrs and (d) 36 hrs.

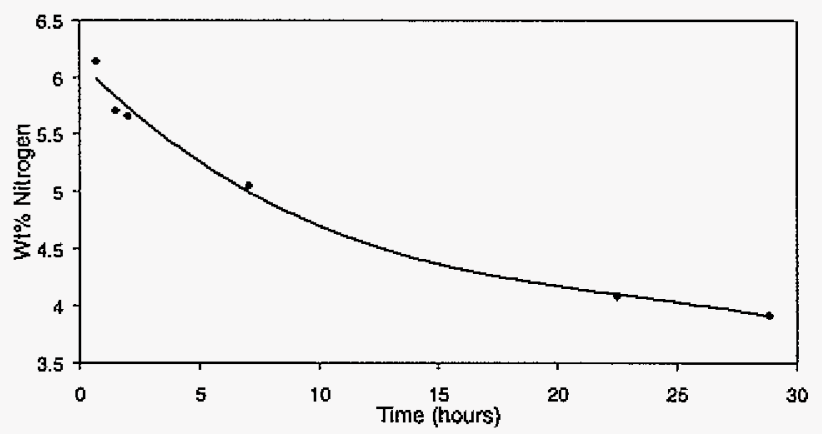

Figure 4. Change in the weight percent of Nitrogen with digestion time.

Based on the agglomerative growth mechanism offered above, one can assume that the crystallites, which agglomerate to form the larger particles, exhibit different interlayer chemistries. This was furthermore supported by the fact that predicted concentrations of $\mathrm{Ni}(\mathrm{NCO})_{n}$ complexes were significantly high and dominating in the first 2-3 hours of digestion.

\section{Conclusion}

A predictive model for urea precipitation of a transition metal ion, $\mathrm{Ni}^{2+}$ was developed. Prediction of $\mathrm{Ni}^{2+}$ precipitation rate was confirmed with the experimental studies. The agreement between experimental data and model predictions was remarkable considering the sources of errors in both. Growth mechanism was determined to be the aggregation of nano-sized primary crystallites. Primary crystallites forming at different stages of the process exhibit compositional differences that cause variations through the cross-section of the particles. 


\section{Acknowledgement}

Notice: This manusctipt has been authored by Iowa State University of Science and Technology under Contract No. W-7405-ENG-82 with the U.S. Department of Energy. The United States Government retains and the publisher, by accepting the article for publication, acknowledges that the United States Government retains a non-exclusive, paid-up, irrevocable, world-wide license to publish or reproduce the published form of this manuscript, or allow others to do so, for United States Government purposes. Authors thank Dr. Soler-Illia for providing a hard copy of his $\mathrm{PhD}$ thesis, and Drs. Jim Espenson, Andy Thom and Matt Kramer for valuable discussions. B. M. furthermore acknowledges the financial support from Catron Fellowship.

\section{References}

${ }^{\mathrm{I}}$ M. Akinc and D. Sordelet, "Preparation of Yttrium, Lanthanum, Cerium, and Neodymium Basic Carbonate Particles by Homogeneous Precipitation," Advanced Ceramic Materials, 2 [3A] 232-8 (1987).

${ }^{2}$ R.J. Candal, A.E. Regazzoni and M.A. Blesa, "Precipitation of Copper(II) Hydrous Oxides and Copper(II) Basic Salts," Journal of Materials Chemistry, 2 [6] 657-61 (1992).

${ }^{3}$ L. Wang, I. Sondi and E. Matijevic, "Preparation of Uniform Needle-Like Aragonite Particles by Homogeneous Precipitation," Journal of Colloid and Interface Science, 218 [2] 545-53 (1999).

${ }^{4} \mathrm{M}$. Akinc, N. Jongen, J. Lemaitre and H. Hofmann, "Synthesis of Nickel Hydroxide Powders by Urea Decomposition," Journal of the European Ceramic Society, 18 [11] 155964 (1998).

${ }^{5}$ G.J. de A.A. Soler-Illia, M. Jobbagy, A.E. Regazzoni and M.A. Blesa, "Synthesis of Nickel Hydroxide by Homogeneous Alkalinization. Precipitation Mechanism," Chemistry of Materials, 11 [11] 3140-46 (1999).

${ }^{6} \mathrm{~B}$. Mavis and M. Akinc, submitted to the Journal of American Ceramic Society, (2003).

${ }^{7}$ G.J. de A.A. Soler-Illia, M. Jobbagy, R.J. CandaI, A.E. Regazzoni and M.A. Blesa, "Synthesis of Metal Oxide Particles from Aqueous Media: The Homogeneous Alkalinization Method," Journal of Dispersion Science and Technology, 19 [2 \& 3] 207-28 (1998).

${ }^{8}$ G.J. de A.A. Soler-Illia, "A Study of Cu-Ni and $\mathrm{Cu}-\mathrm{Zn}$ Mixed Oxide Precursors Synthesis by Homogeneous Alkalinization Methods," PhD Thesis Universidad de Buenos Aires, Buenos Aires, 1998.

${ }^{9}$ B.A. Barshop, R.F. Wrenn and C. Frieden, "Analysis of Numerical Methods for Computer Simulation of Kinetic Processes: Development of KINSIM - a Flexible, Portable System," Analytical Biochemistry, 130, 134-45 (1983).

${ }^{10}$ F. Boulc'h, M.-C. Schouler, P. Donnadieu, J.-M. Chaix and E. Djurado, "Domain Size Distribution of Y-TZP Nanoparticles Using XRD and HRTEM," Image Analysis \& Stereology, 20 [3] 157-61 (2001). 


\title{
APPENDIX B. HOMOGENEOUS PRECIPITATION OF LAYER DOUBLE HYDROXIDES
}

A proceedings paper to be published in the Key Engineering Materials [European Ceramic Society VII ${ }^{\text {th }}$ Biannual Meeting Proceedings].

\author{
Bora Maviş and Mufit Akinc \\ Ames Laboratory and Materials Science and Engineering Department \\ 3053 Gilman Hall, Iowa State University \\ Ames, IA 50011, USA
}

Kevwords: Urea decomposition; Nickel hydroxide; Reaction kinetics simulation; Layer Double Hydroxides

\begin{abstract}
Structure of nickel precipitate from decomposition of urea was found to be $\alpha-$ $\mathrm{Ni}(\mathrm{OH})_{2}$. FTIR analysis revealed the intercalation of cyanate $\left(\mathrm{OCN}^{-}\right)$, which is an intermediate product of urea decomposition. This observation implied that the assumption of single step decomposition of urea to carbon dioxide and ammonia was over simplified. For quantitative analysis on the effects of critical system parameters like initial $\mathrm{pH}$ and metal ion concentration, a detailed analysis of the possible reactions in urea system was carried out. Numerical solutions to reaction pathways predicted significant accumulation of the intermediate cyanate in the time-temperature range investigated. Further elaboration was possible by considering the effects of hydrolysis products of $\mathrm{Ni}^{2+}$ and $\mathrm{Ni}$-amine, $\mathrm{Ni}$-cyanate, and $\mathrm{Ni}$-carbonate complexes in the numerical simulations. Chemical analysis of the precipitate showed a decrease in nitrogen content with increasing reaction times. This was consistent with the predicted decrease in concentration of Ni-cyanate complexes with time. At extended digestion times, formation of $\mathrm{Ni}$-amine complexes limits the complete recovery of the $\mathrm{Ni}^{2+}$.
\end{abstract}

From the two phases of $\mathrm{Ni}(\mathrm{OH})_{2}, \alpha$-phase, with its larger interlayer spacing, offers enhanced electrochemical properties but it transform into thermodynamically stable $\beta$-phase. Stabilizing $\alpha$-phase with $\mathrm{Co}^{2+}$ substitution which oxidizes irreversibly to $\mathrm{Co}^{3+}$ with electrochemical cycling along with forming layer double hydroxides (LDH's: $\left[\mathrm{M}^{2+}{ }_{1-}\right.$ $\left.\left.{ }_{x} \mathrm{M}^{3+}{ }_{x}(\mathrm{OH})_{2}\right]^{x+}\left[\mathrm{A}^{\mathrm{n}-}{ }_{x / \mathrm{n}}\right]^{\mathrm{x}-} \cdot \mathrm{mH}_{2} \mathrm{O}\right)$ were studied. Various compositions of LDH's containing $\mathrm{Ni}^{2+} / \mathrm{Co}^{2+}$ and $\mathrm{Al}^{3+}$ ions were produced by urea and tested with chronopotentiometry to assess their potential utility as rechargeable electrode materials.

\section{Introduction}

Homogeneous precipitation in aqueous solutions has been widely used to prepare various metal-oxide precursor powders [1-5]. Urea decomposition in the presence of transition metal ion, $\mathrm{Ni}^{2+}$ yields $\alpha-\mathrm{Ni}(\mathrm{OH})_{2}$ as the precipitate [6]. Same system was also investigated in detail 
by Soler Illia et al. [7]. Results from their work indicated that the second step of urea decomposition becomes important in cases where the interaction between cyanate (OCN'; product of first step) and the transition metal ion is strong. It is known that $\mathrm{Ni}^{2+}$ ions can form tetrahedral complexes with cyanate $[8,9]$. FTIR results from our group and others confirmed these findings $[10,11]$. A thorough analysis of the literature on urea decomposition in aqueous solutions indicated that second step (cyanate hydrolysis) could be represented with five reactions (Fig. 1B). Depending on the $\mathrm{pH}$ range and the metal ion employed, a few will dominate. A comprehensive numerical solution to the hydrolysis process was possible through the use of a reaction kinetics program, KINSIM [12]. Furthermore, effects of hydrolysis products of $\mathrm{Ni}^{2+}$ and possible $\mathrm{Ni}$-amine, $\mathrm{Ni}$-cyanate, and $\mathrm{Ni}$-carbonate complexes were also incorporated using equilibrium constant and by assuming a fast reverse reaction rate constant. This led to finding the forward rate by,

$$
\mathrm{k}_{\text {forward }}=\mathrm{k}_{\text {reverse }} \times \mathrm{K}_{\text {equilibrium. }} \text {. }
$$

[A]

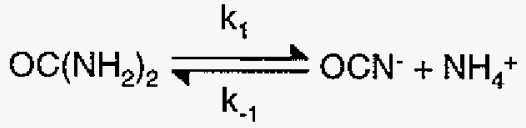

$$
\begin{aligned}
& \mathrm{OCN}^{-}+\mathrm{H}^{+}+2 \mathrm{H}_{2} \mathrm{O} \stackrel{\mathrm{k}_{2}}{\longrightarrow} \mathrm{HCO}_{3}^{-}+\mathrm{NH}_{4}^{+} \\
& k_{2}=\left(k_{2}^{o}+k_{2}^{a}\left[H^{+}\right]\right)
\end{aligned}
$$

Fig. 1. [A] A simple representation of the urea hydrolysis adopted by Soler-Illia [13] [B] Reaction scheme used in this study. Note that second step (cyanate hydrolysis) is represented with five reactions.
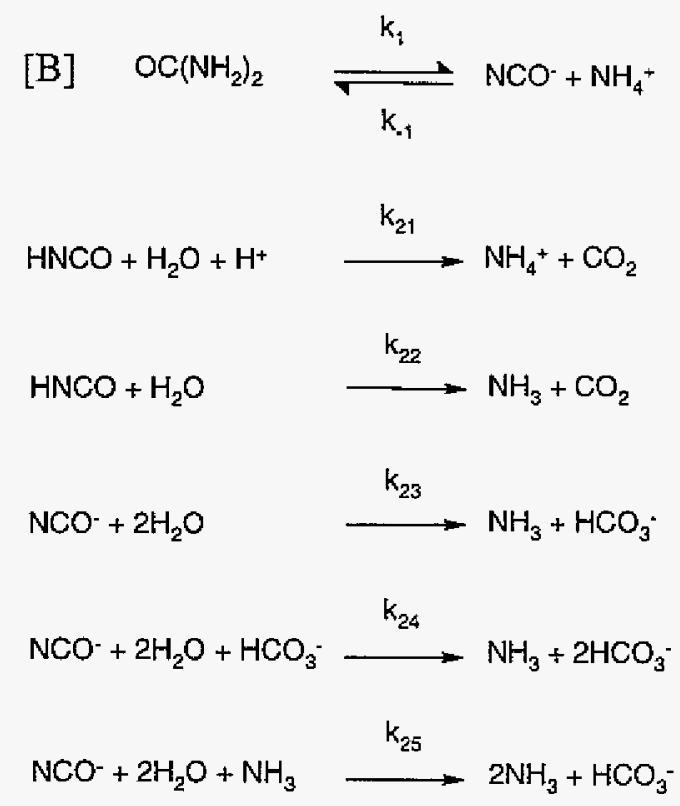

To check the reliability of the model, predicted concentrations of free $\mathrm{Ni}^{2+}$ and $\mathrm{H}^{+}$ions with respect to digestion time were compared to experimental results.

$\alpha-\mathrm{Ni}(\mathrm{OH})_{2}$ suffers from stability against transformation into $\beta$-phase in long term cycling and in alkaline medium. Among the viable solutions, doping of $\mathrm{Co}^{2+}$ was observed to help solve this problem. Irreversible oxidation of $\mathrm{Co}^{2+}$ to $\mathrm{Co}^{3+}$ was offered as the mechanism providing the stability [14]. An additional benefit of Cobalt doping is the increased conductivity within the basal planes. Similarly, layer double hydroxides (LDH's) in which a trivalent cation like $\mathrm{Al}^{3+}$ facilitates the better crystallization during the precipitation from solution were considered for improved stability. A number of $\mathrm{LDH}^{\prime} \mathrm{s}$ with $\mathrm{Ni}^{2+}$ and $\mathrm{Al}^{3+}$ were produced by urea precipitation. Effect of $\mathrm{Co}^{2+}$ was investigated by producing an additional 
group of LDH's with $\mathrm{Ni}^{2+}{ }_{1-(\mathrm{y}+\mathrm{x})} / \mathrm{Co}^{2+}{ }_{\mathrm{y}}$ and $\mathrm{Al}^{3+}{ }_{\mathrm{x}}$ (y and $\mathrm{x}$ were varied between 0.00 and, $0.25)$.

\section{Experimental Procedure}

Powder Synthesis. Precipitation of nickel hydroxide by urea decomposition was carried out as previously described [15]. In precipitation of LDH's total metal ion concentration in the final solution was adjusted to $0.1 \mathrm{M}$. During digestion, the solution was stirred continuously under ambient pressure and the reaction was stopped after $2 \mathrm{hrs}$. Precipitates were washed three times with water and dried at $70^{\circ} \mathrm{C}$ for 12 hours.

Characterization. Concentration of free $\mathrm{Ni}^{2+}$ ion was measured by a UV/VIS spectrophotometer unit with analysis capability at $90{ }^{\circ} \mathrm{C}$. Peak maximum between 300 and $500 \mathrm{~nm}$ was used to determine the $\mathrm{Ni}^{2+}$ concentration. In the later stages of the digestion $\mathrm{Ni}^{2+}$ absorption peaks showed a blue-shift due to $\mathrm{Ni}\left(\mathrm{NH}_{3}\right)_{\mathrm{n}}{ }^{2+}$ complex formation. Structural characterization of the precipitates was made by powder X-ray diffraction. Chronopotentiometry experiments were performed in $6 \mathrm{M}$ KOH solutions. Measurements were referenced to a $\mathrm{Hg} / \mathrm{HgO}$ electrode. Working electrodes were produced by pressing an active material paste between two circular porous Nickel foams. Paste mixture contained active powder mixed with carbon $(60 / 40 \mathrm{wt} \%$, respectively) that was kneaded with appropriate amount of PTFE dispersed in water.

\section{Results and Discussions}

In Fig. 2A distribution of species during the hydrolysis of urea is presented. Accumulation of $\mathrm{OCN}^{-}$during the first few hours is evident. Simulations carried out in the presence of $\mathrm{Ni}^{2+}$, showed that $\mathrm{NiNCO}^{+}$complex formation could have prominent affects on species distribution and nucleation (Fig. 2B). Literature indicates that observed solubility products of nickel hydroxides can be as high as $10^{-14.7}$ for "active" powders, while it can be as low as $10^{-}$ ${ }_{17.95}$ for "aged" powders. Simulations performed with different $\mathrm{pK}_{\mathrm{sp}}$ values presents a broad prediction envelope. This indicates that uncertainty in the solubility product constant is the largest error contributor. Best fit to the experimental data was obtained with a $\mathrm{pK}_{\mathrm{sp}}$ value of 15.5. Comparison of experimental and simulated free $\mathrm{Ni}^{2+}$ ion concentrations for initial $\mathrm{Ni}^{+2}$ concentrations of 0.1 and $0.075 \mathrm{M}$ is given in Fig. 3 .

Discrepancy in the later stages of the process was due to the formation of $\mathrm{Ni}\left(\mathrm{NH}_{3}\right)_{\mathrm{n}}{ }^{2+}$ complexes. Predicted trends in $\mathrm{pH}$ after the nucleation event are in agreement with experimental data (level of disagreement is on the order of $10^{-4} \mathrm{M}$ ). The fact that particles can grow up to several microns, while the primary crystallite size remain less than $10 \mathrm{~nm}$ even after 36 hours, calls upon an agglomerative growth mechanism.

Fig. 4A presents the stabilization effect obtained by the addition of a trivalent cation like $\mathrm{Al}^{3+}$. After 1 week of ageing in $6 \mathrm{M} \mathrm{KOH} \alpha$-phase was preserved in LDH's, while same period causes transformation to $\beta$-phase in powders with no substitutions. 
Result of a chronopotentiometry experiment on a selected LDH is compared to commercially available $\beta$-phase powders' response in Fig. 4B. Calculated specific capacities were 240 and $330 \mathrm{mAhr} / \mathrm{gr}$ for $\beta$-phase and the $\mathrm{LDH}$, respectively.

[A]

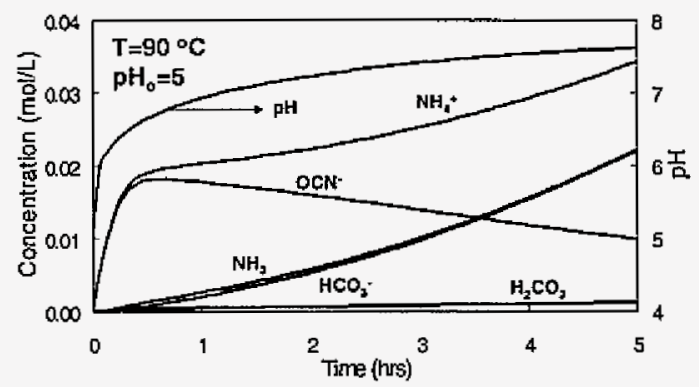

[B]

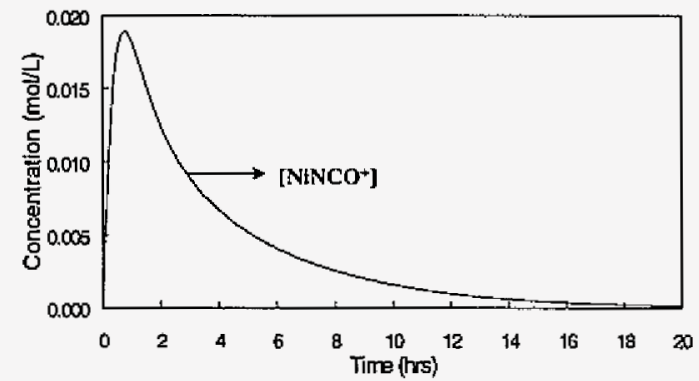

Fig. 2. [A] Simulation of distribution of species during the decomposition of $2 \mathrm{M}$ urea [B] Predicted changes in concentration of $\mathrm{NiNCO}^{+}$. Plot represents the prediction with $\mathrm{pK}_{\mathrm{sp}}$ of 15.5 .

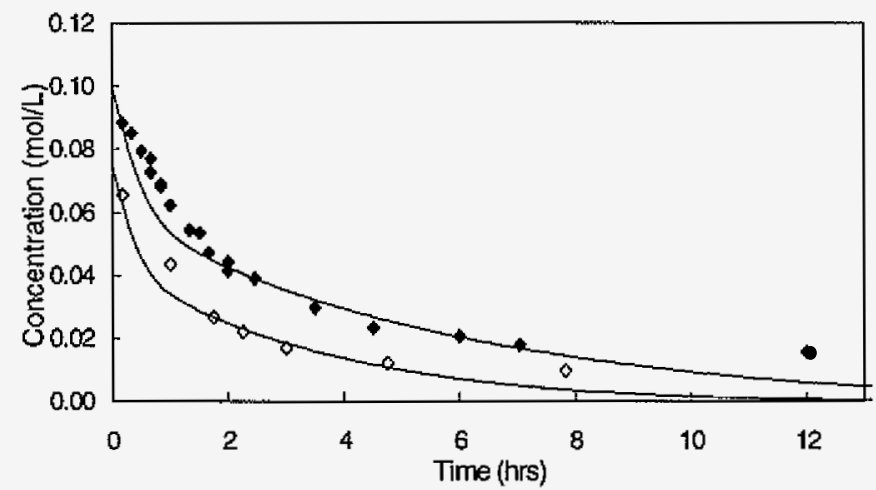

Fig. 3. Comparison of simulated $\left(\rightarrow\right.$ and experimental free $\mathrm{Ni}^{2+}$ ion concentrations in solutions with $\left[\mathrm{Ni}^{2+}\right]_{0} ;[\bullet] 0.1 \mathrm{M}$ and $[\diamond] 0.075 \mathrm{M}$.
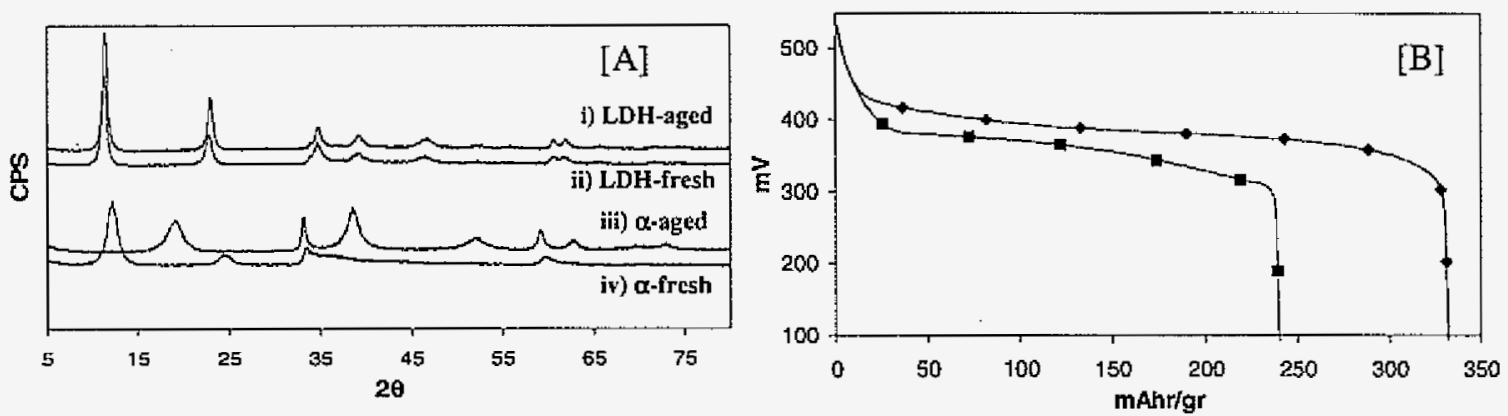

Fig. 4. XRD patterns of [A] a layer double hydroxide (initial cation concentrations are $\mathrm{Ni} / \mathrm{Co} / \mathrm{Al}: 0.070 / 0.005 / 0.025$ ) after (i) and before (ii) ageing show the stability obtained; whereas $\alpha-\beta$ transformation is visible in patterns acquired from $\alpha-\mathrm{Ni}(\mathrm{OH})_{2}(\mathrm{Ni} / \mathrm{Co} / \mathrm{Al}$; 
0.1/0/0) after (iii) and before (iv) ageing. [B] Capacity enhancement in the same LDH (with respect to the commercially available $\beta$-phase (-n-) at $0.2 \mathrm{C}$ charge-discharge rate.

\section{Conclusions}

A robust predictive model for urea precipitation of a transition metal ion, $\mathrm{Ni}^{2+}$ was developed. Agreement between experimental data and model predictions was significant considering the possible sources of error. Predictions with $\mathrm{pK}_{\mathrm{sp}}$ of 15.5 provided the best fit. Complete recovery of $\mathrm{Ni}^{2+}$ was not possible due to Nickel-amine complex formation. Doping with a trivalent cation stabilized the $\alpha$-structure for extended periods. Optimum initial $\mathrm{Al}^{3+}$ concentration was between 0.015 and $0.025 \mathrm{M}$. Cobalt doping did not interfere with the stability of LDH's up to the tested level of $0.025 \mathrm{M}$ in the initial solution. Under similar experimental conditions a stable LDH $\left(\left[\mathrm{Ni}^{2+} / \mathrm{Co}^{2+} / \mathrm{Al}^{3+}\right]_{0}: 0.07 / 0.005 / 0.025 \mathrm{M}\right)$ outperformed $\beta$-phase by about 40 percent in terms of capacity.

\section{Acknowledgement}

Notice: This manuscript has been authored by Iowa State University of Science and Technology under Contract No. W-7405-ENG-82 with the U.S. Department of Energy. The United States Government retains and the publisher, by accepting the article for publication, acknowledges that the United States Government retains a non-exclusive, paid-up, irrevocable, world-wide license to publish or reproduce the published form of this manuscript, or allow others to do so, for United States Government purposes. Authors thank Dr. Soler-Illia for providing a hard copy of his PhD thesis, and Drs. Jim Espenson, Andy Thom and Matt Kramer for valuable discussions. B. M. furthermore acknowledges the financial support from Catron Fellowship.

\section{References}

[1] M. L. Panchula; M. Akinc: Journal of the European Ceramic Society Vol. 16 (1996), p. $833-841$.

[2] J. Grau; M. Akinc: J. Am. Ceram. Soc. Vol. 79 (1996), p. 1073-1082.

[3] D. J. Sordelet; M. Akinc; M. L. Panchula; Y. Han; M. H. Han: J. Eur. Ceram. Soc. Vol. 14 (1994), p. 123-130.

[4] A. Celikkaya; M. Akinc: J. Am. Ceram. Soc. Vol. 73 (1990), p. 245-250.

[5] D. Sordelet; M. Akinc: J. Colloid Interface Sci. Vol. 122 (1988), p. 47-59.

[6] M. Akinc; N. Jongen; J. Lemaitre; H. Hofmann: Journal of the European Ceramic Society Vol. 18 (1998), p. 1559-1564.

[7] G. J. d. A. A. Soler-Illia; M. Jobbagy; R. J. Candal; A. E. Regazzoni; M. A. Blesa: J. Dispersion Sci. Technol. Vol. 19 (1998), p. 207-228.

[8] D. Forster; D. M. L. Goodgame: J. Chem. Soc. Vol. (1965), p. 262-267.

[9] J. P. Fackler, Jr.; G. E. Dolbear; D. Coucouvanis: J. Inorg. Nucl. Chem. Vol. 26 (1964), p. 2035-2037.

[10] B. S. Maruthiprasad; M. N. Sastri; S. Rajagopal; K. Seshan; K. R. Krishnamurthy; T. S. R. P. Rao: Proc. - Indian Acad. Sci., Chem. Sci. Vol. 100 (1988), p. 459-462. 
[11] G. J. d. A. A. Soler-Illia; M. Jobbagy; A. E. Regazzoni; M. A. Blesa: Chem. Mater. Vol. 11 (1999), p. 3140-3146.

[12] B. A. Barshop; R. F. Wrenn; C. Frieden: Analytical Biochemistry Vol. 130 (1983), p. 134-145.

[13] G. J. d. A. A. Soler-nlia PhD Thesis, Universidad de Buenos Aires, Buenos Aires, 1998.

[14] C. Delmas; Y. Borthomieu; C. Faure; A. Delahaye; M. Figlarz: Solid State Ionics Vol. 32-33 (1989), p. 104-111.

[15] B. Mavis; M. Akinc: submitted to Journal of American Ceramic Society (2003). 